\title{
DEVELOPMENT OF BARLEY INTROGRESSION LINES CARRYING THE LEAF RUST RESISTANCE GENES Rph1 TO Rph15
}

\author{
A THESIS \\ SUBMITTED TO THE FACULTY OF THE GRADUATE SCHOOL \\ OF THE UNIVERSITY OF MINNESOTA \\ BY
}

MATTHEW JAMES MARTIN

IN PARTIAL FULFILLMENT OF THE REQUIREMENTS FOR THE DEGREE OF MASTER OF SCIENCE

Adviser: Brian J. Steffenson

July, 2018 
Matthew Martin copyright 2018 


\section{Acknowledgements}

I would like to extend thanks to Dr. Brian Steffenson and Dr. Jerry Franckowiak for providing me the opportunity to bring to fruition this long-term project. Their insight and motivation improved the quality of the research. I would also like to express gratitude to my other committee members, Dr. Kevin Smith and Dr. Melania Figueroa for their critical reviews of the thesis and general support during my program. I would like to acknowledge work done by Dr. Jerry Franckowiak, Dr. Brian Steffenson, Dr. Oswaldo Chicaiza, and Juan Caffarel in the years before my involvement with this research. Their extensive technical work spent collecting, backcrossing, and screening sources of leaf rust resistance in barley made it possible for me to carry this project to a logical end. Additionally, I would like to thank Dr. Arnis Druka and Dr. Dragan Perovic (Julius Kuehn Institute in Gatersleben, Germany) for providing the genotyping data on the barley germplasm used in this research. During my time in Dr. Steffenson's lab, I have worked with many incredible people who I owe thanks to for challenging, assisting, teaching, and letting loose with me. My utmost thanks

goes out to Tamas Szinyei for being a master technician and amazing friend, Oadi Matny for being a great co-worker and father figure around the lab, Ryan Johnson for being a constant beacon of hope and energy, Austin Case for his friendship, knowledge, and comedic relief, and Matthew Haas for his comradery and witty banter. I also offer thanks to the other graduate and undergraduate students who have come through our project as I have had the pleasure to befriend, teach, and learn from each of them. I have also had the opportunity to learn from many of the faculty in the Department of Plant Pathology and would like to thank them for their dedication to the student body and the mission of the department. I give a shoutout to the department administrators for being always willing to help in any way they can. Thanks are also in order to the Minnesota Agricultural Experiment Station (MAES) and the College of Food Agriculture and Natural Resource Sciences (CFANS) for providing excellent workspaces. 


\section{Dedication}

This thesis is dedicated to my wife, Annie Martin, for always being there and believing in me. A very special sincere thanks to all of my family and friends outside the lab for their relentless encouragement and support. 


\section{Table of Contents}

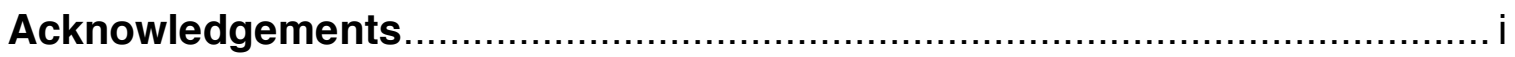

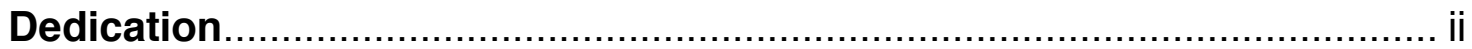

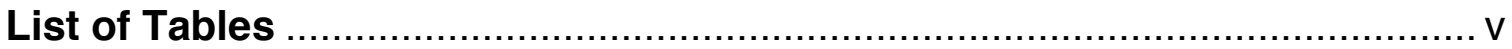

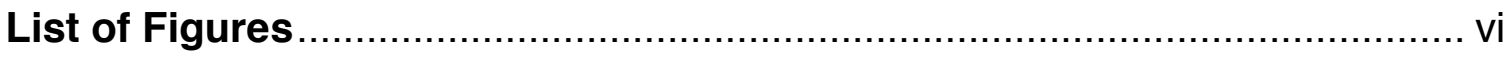

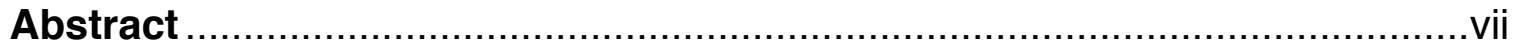

Chapter One: General Introduction and Literature Review ........................ 1

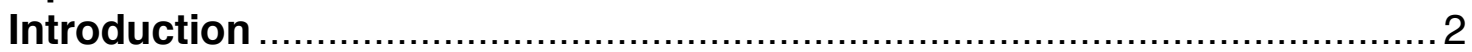

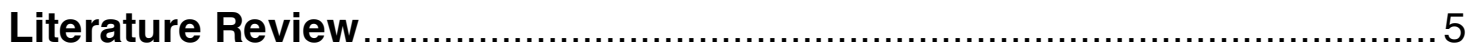

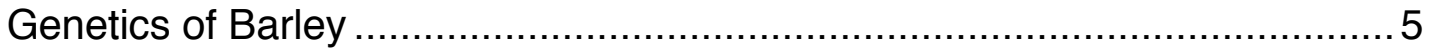

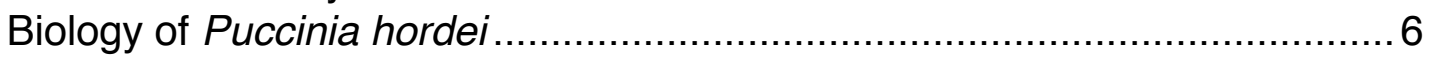

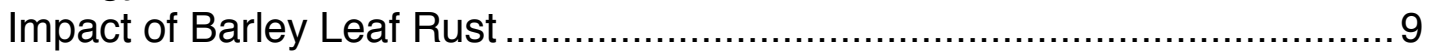

Resistance of Barley to Leaf Rust .......................................................... 13

Genetics of Leaf Rust Resistance in Barley .......................................... 16

Bowman Introgression Lines for Leaf Rust Resistance..............................26

Chapter Two: Phenotypic and Genotypic Characterization of Barley Introgression Lines Carrying the Leaf Rust Resistance Genes Rph1 to

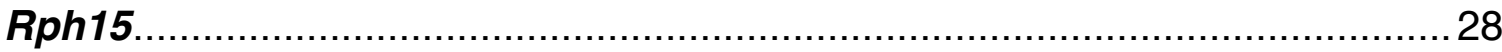

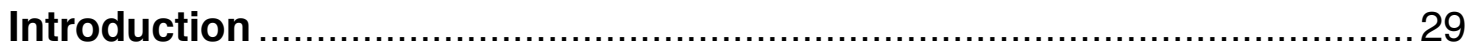

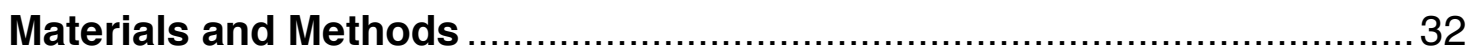

Plant Materials and Development of Introgression Lines .......................... 32

Pathogen Isolates and Race Nomenclature ….........................................3

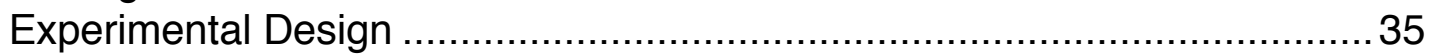

Inoculation and Disease Phenotyping Protocols ....................................... 35

Genotyping the Bowman Introgression Lines and Resistance Donors .......38

Selection of Bowman Introgression Lines for the Leaf Rust Differential Set 40

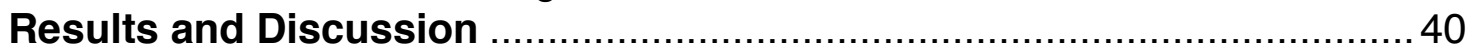

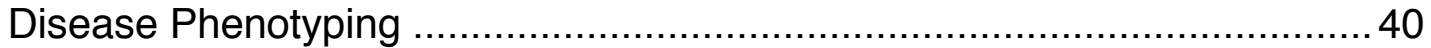

Genotyping Resistant Donor Sources and their Derived Introgression Lines

Phenotypic and Genotypic Characterization of Introgression Lines

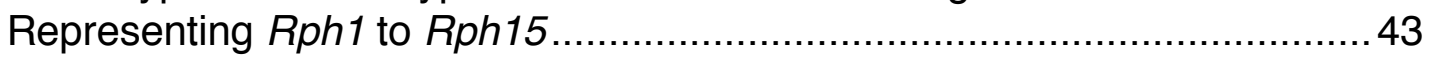

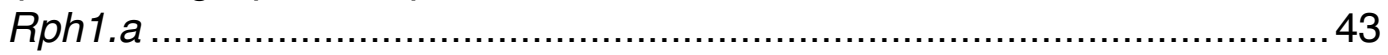

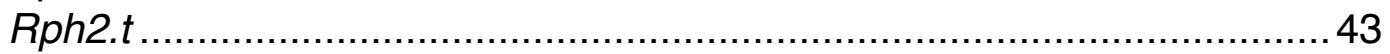

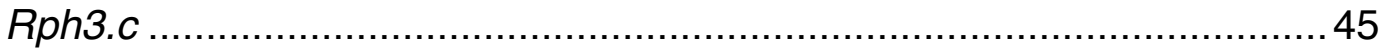

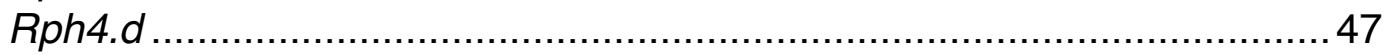

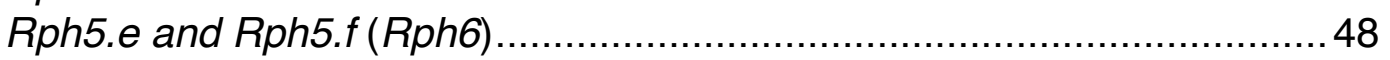

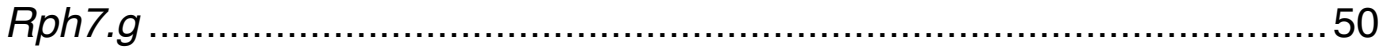

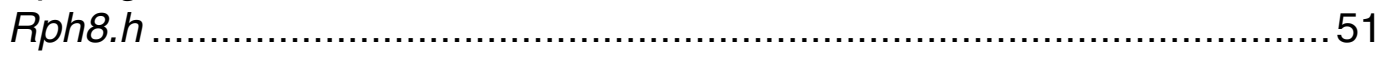

Rph9.i and Rph9.z (Rph12) …................................................... 51 


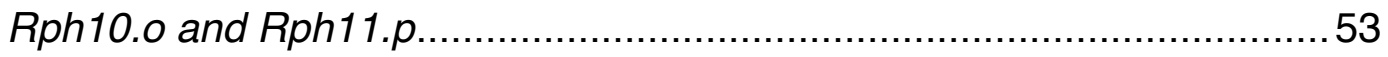

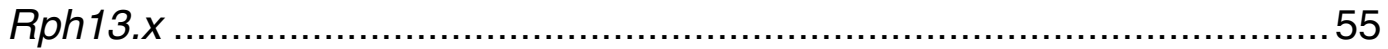

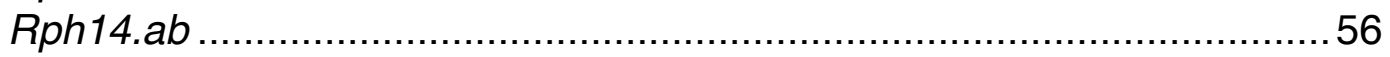

Rph15.ad ....................................................................... 56

Other Leaf Rust Resistance Genes .................................................58

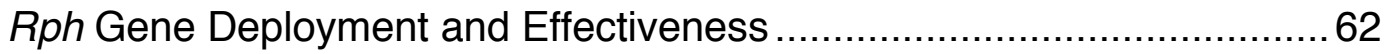

Candidate Leaf Rust Resistance Genes.........................................6 66

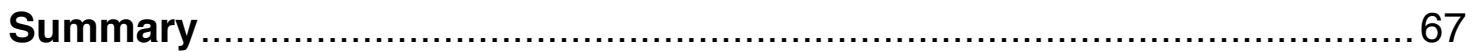

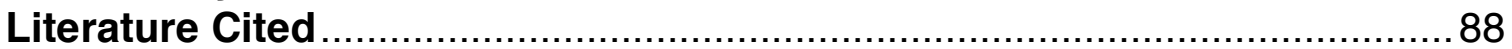




\section{List of Tables}

Table 1: Accession details for Bowman and the 15 selected parental donors of leaf rust resistance

Table 2: Pedigree details for the Rph1-15 introgression lines selected for the barley leaf rust differential set ................................................................. 71

Table 3: Race nomenclature of Puccinia hordei isolates used to select for leaf rust resistance genes Rph1-15 in Bowman introgression lines.

Table 4: Median infection types and general reactions of barley differential lines carrying leaf rust resistance genes Rph1-24 to 12 global isolates of $P$. hordei... 73 Table 5: Median infection types and general reactions of the resistant donor parents for Rph1-15 and their derived Bowman introgression lines selected for the barley leaf rust differential set.

Table 6: Infection type mode and range for the selected Bowman introgression lines carrying the leaf rust resistance genes Rph1-15 against 12 isolates of Puccinia hordei....

Table 7: Annotated genes involved in disease resistance and residing in the same contigs as BOPA SNP markers within Bowman introgression lines carrying nine of the 15 leaf rust resistance alleles used in this study....

Appendix Table 1: Accession details for the 24 barley leaf rust differential lines used in this study

Appendix Table 2: Accession details for the barley cultivar Bowman and the 95 donors of leaf rust resistance used in this study 101 Appendix Table 3: Pedigrees and recognized Rph genes in the 95 Bowman introgression lines used in this study 106 Appendix Table 4: Details for the 12 Puccinia hordei isolates used to characterize 95 leaf rust resistant introgression lines in Bowman 111 Appendix Table 5: Raw infection types of Bowman introgression lines postulated to carry Rph2, Rph3, Rph4, Rph5, Rph9, or unknown resistance gene(s) .......112 Appendix Table 6: Raw infection types of 50 Bowman introgression lines postulated to carry Rph15 116 Appendix Table 7: Raw infection types for barley cultivar Bowman and the 95 leaf rust resistance gene donors across three experiments 120 Appendix Table 8: Raw infection types of barley differential lines carrying the leaf rust resistance genes Rph1-24 in this and a previous study 128 Appendix Table 9: Annotated genes in the same contig as SNP markers residing in Rph-carrying introgressions 135 


\section{List of Figures}

Figure 1: Examples of leaf rust infection types (ITs) observed on Bowman introgression lines................................................................................ 79

Figure 2: Graphical genotypes for Bowman introgression lines carrying leaf rust resistance genes $R p h 1-15$ selected for the barley leaf rust differential set .........80 


\begin{abstract}
Barley (Hordeum vulgare) is the fourth most planted and harvested grain crop in the world. In many production areas, barley is attacked by the leaf rust pathogen (Puccinia hordel), a basidiomycetous fungus that reduces both its yield and quality. Many leaf rust resistance genes, known as reaction to $\underline{P}$. hordei $(R p h)$ genes, have been described in barley. Resistance deployed in cultivars has often been transient due to the pertinacious nature of single gene virulence mutations in $P$. hodei populations. To differentiate genetic variants for virulence in $P$. hordei populations, plant pathologists use barley accessions with different resistance genes, referred to as a differential set. The barley leaf rust differential set evolved through time as more Rph genes were described. The sources of Rph1-15 were derived from barleys with diverse geographic origins and agromorphological traits. Ideal differential sets include lines where single resistance genes are backcrossed into the genetic background of an adapted susceptible cultivar. Sources for Rph1-15, along with many other Rph gene donors were backcrossed to the susceptible cultivar Bowman. Overall, 95 Bowman introgression lines for leaf rust resistance were developed, and a single line was recommended for use as the new backcrossed differential host line for each individual Rph1-15 gene. Genomic positions and gene candidates for Rph1-15 were characterized and the existence of possible new resistance genes was postulated. The new Bowman Rph1-15 differential lines will facilitate the efficient virulence phenotyping of $P$. hordei and serve as valuable genetic stocks for $R p h$ gene stacking and cloning in barley.
\end{abstract}


CHAPTER 1

General Introduction and Literature Review 


\section{INTRODUCTION}

Barley (Hordeum vulgare L.) is the fourth most planted and harvested cereal grain crop in terms of global production behind wheat, corn, and rice (USDA, 2017). It is an important feedstuff for animals and essential raw ingredient for the brewing industry. Barley is desirable as a cultivated crop due to its shorter maturation period and ability to yield well under stressful environments such as extreme elevation, cold, and saline soils where other cereal grains cannot produce (Ullrich, 2011). Despite these advantages, barley is subject to the biotic stresses from both herbivores and pathogens capable of targeting all types of tissue. Leaf rust, a disease caused by the fungal plant pathogen Puccinia hordei Otth, is very common throughout the barley production regions of the world. Although leaf rust rarely destroys entire crops, it does cause enough damage to regularly challenge the economic sustainability of barley production and therefore merits the need for control (Newton et al., 1945; King \& Polley, 1976; Johnson \& Wilcoxson, 1979; Whelan et al., 1997; González et al., 2013). Deploying cultivars with genetic resistance to leaf rust is the most economically and environmentally sound means of managing the disease.

Over the past century, barley accessions from around the world have been reported to carry resistance to $P$. hordei. Currently, 26 major-effect leaf rust resistance genes (referred to as reaction to $\underline{P}$. hordei (Rph) genes), have been described in Hordeum (Franckowiak et al., 1997; Park et al., 2015; Kavanagh et al., 2017; Ziems et al., 2017, Yu et al., In Press). Among these described genes, Rph3, Rph7, Rph9, and Rph12 have been commonly used in breeding programs because they confer a high level of resistance, are broadly effective against different pathotypes of $P$. hordei, and exist in agronomically suitable genetic backgrounds. The use of these resistance genes in widely grown barley cultivars provided decades of effective leaf rust control in North America, Europe, and 
Australia until virulence finally evolved in populations of $P$. hordei (Cotterill et al., 1992b; Steffenson et al., 1993; Dreiseitl and Steffenson, 2000; Park, 2003; Sandhu et al., 2016). The repeated episodes of resistance genes being overcome have increased the economic pressure of the disease on barley, warranting investment of more resources for control. By understanding the virulence diversity of regional $P$. hordei populations, pathologists can make informed decisions as to which combinations of Rph genes might provide more long-lasting leaf rust resistance. To this end, encouraging resistance gene stewardship could improve the economic and environmental sustainability of barley cropping systems.

Puccinia hordei is classified into different pathotypes (a.k.a. races) based on its infection type reactions or (ITs) across a panel of diverse barley lines that carry different resistance genes. Of the 26 described Rph genes, 17 were identified in barley cultivars or landraces of diverse origins, five from the barley progenitor $H$. vulgare subsp. spontaneum, and four from the secondary gene pool species Hordeum bulbosum L. Characterization of the original genetic stocks carrying Rph1-25 embodied an immense amount of research, and this germplasm remains a useful resource for studying pathogen virulence. To characterize virulence diversity in pathogen populations, many pathologists have established sets of differential host lines, each presumed to carry a different resistance gene (Stakman et al., 1962; Person, 1976; Clifford, 1977). While such selected host lines have adequately served the purpose of typing virulence in the pathogen, they do have some limitations. First, because the lines have not always been genetically characterized for their resistance, some may actually carry more than one resistance gene. In such cases, avirulence genes in the pathogen will remain cryptic if their corresponding resistance gene is not present alone in a differential line. Moreover, epistasis within the host lines may confound the phenotypic expression of some resistance genes. The development of single 
gene introgression lines in a uniform genetic background was a major advance for the efficient typing of pathogen virulence. With such a set of host lines, avirulence genes in the pathogen can be efficiently characterized without the problem of cryptic genes or genetic background effects. The use of an agronomically advanced recurrent parent for the differential set will facilitate experiments in the field because the lines will grow well and have uniform traits such as height and heading date. Introgression lines each possessing a single resistance gene in a uniform genetic background have been developed in a number of pathosystems including wheat leaf rust, wheat stripe rust, barley powdery mildew, and barley loose smut (Tapke, 1945; Clifford, 1977; Roelfs and Martens, 1988; Afanasenko et al., 2009).

Many researchers have investigated the genetics of leaf rust resistance in barley (Roane \& Starling, 1967; Tan, 1978; Jin et al., 1993; Park \& Karakousis, 2002). Mapping resistance gene loci can clarify intergenic relationships and enables the identification of morphological traits and/or molecular markers that are linked to the Rph genes. The advent of molecular marker technologies (Amplified Fragment Length Polymorphisms [AFLP], Restriction Fragment Length Polymorphisms [RFLP], isozyme, Single Nucleotide Polymorphisms [SNP], and Diversity Array Technologies [DArT], Weerasena, 2003; Ivandic et al., 1998; Druka et al., 2011; Golegaonkar et al., 2009) greatly facilitated the efficient mapping of Rph genes in barley. Moreover, the identification of mapping positions and molecular markers for Rph genes can facilitate the selection and transfer of resistance genes more efficiently than standard rust phenotyping in breeding programs. To develop a set of differential host lines for typing virulence in P. hordei, Chicaiza (1996) and Caffarel (2005) backcrossed the donor sources of Rph1-15 into the susceptible two-rowed feed barley cultivar Bowman (PI 483237) (Franckowiak et al., 1985). The Bowman introgression lines were created to provide barley pathologists with a refined set of single gene host lines 
for efficiently characterizing the virulence diversity of $P$. hordei. The introgression lines can also serve barley breeders as advanced genetic stocks for transferring the Rph genes into breeding germplasm with minimal linkage drag. (Franckowiak et al., 1985).

The objectives of this study were: 1) Use multi-pathotype testing to postulate the resistance gene identities of leaf rust resistance donors and introgression lines, 2) Use genotypic data to position the Rph gene-containing introgressions in the genome, and 3) Define a final differential set comprised of Bowman introgression lines for the barley leaf rust resistance genes Rph1-15.

\section{LITERATURE REVIEW}

\section{Genetics of Barley}

Barley is closely related to bread wheat (Triticum aestivum), rye (Secale cereale), oats (Avena sativa), and stiff brome (Brachypodium distachyon), all of which are members of the Triticeae tribe of the subfamily Pooidae in the grass family Poaceae. Other common cereals like rice (Oryza sativa) and corn (Zea mays) belong to other distantly related subfamilies. The global importance of these crops is driving research into their genetic sequences and genomic structures. This information allows for the interpretation of biological gene functions, interspecies relatedness, and evolutionary history.

The barley genome sequence is now assembled and physically sorted (Mayer et al., 2012; Mascher et al., 2017). It is comprised of 5,100 million base pairs $(\mathrm{Mb})$ spread across seven haploid chromosomes $(2 n=2 x=14)$. Like other plants, more than $80 \%$ of the barley genome consists of repetitive non-coding retrotransposon sequences (Ullrich, 2011). Less than $20 \%$ of the remaining 
nucleotides hold an estimated 26,159 gene sequences that are unevenly distributed among the seven barley chromosomes, designated $1 \mathrm{H}$ to $7 \mathrm{H}$ (Mayer et al., 2012). Barley's diploid genome is larger and more diverse than rice (430 $\mathrm{Mb}$ ) or corn (2,400 Mb), but smaller and simpler than bread wheat, which is an allohexaploid (17,000 Mb) (Gale and Devos, 1998). Genetic sequences from simpler model species can be applicable to more complex species. For example, an annotated homologous sequence in rice was used to hypothesize the function of a gene from a leaf rust resistant barley (Chen et al., 2010). Understanding homologous sequences between different species better informs how each species-specific gene has evolved and functions. In this regard, the discovery of disease resistance genes is of particular interest to pathologists and crop producers because of their use in agriculture.

\section{Biology of Puccinia hordei}

Puccinia hordei is the causal organism of barley leaf rust. It is one of 7,000 species described in the genus Puccinia. This genus is one of 100 genera in the basidiomycete family Pucciniaceae, the third largest family of fungi (Maier 2003). Other Latin binomials such as, Uromyces hordei P. Nielsen (1875), Puccinia anomala Rostr. (1878), and Puccinia simplex Erikss. \& E. Henn. (1894), have been used in the past for this organism, but Puccinia hordei Otth (1871) has been accepted as the proper binomial for this organism (Stevenson and Johnson, 1946). Other common disease names such as brown rust or dwarf rust were frequently used in the older research works. According to a survey of the journal community for Molecular Plant Pathology, the Pucciniaceae are collectively considered the third most important fungal plant pathogens behind Magnaporthe oryzae (rice blast) and Botrytis cinerea (gray mold) (Dean et al., 2012). 
Like many other Puccinia species attacking cereal crops, $P$. hordei is a heteroecious and macrocyclic rust pathogen. It is a highly specialized biotrophic pathogen that infects less than 20 plant species within a few genera. This host range is extremely small compared to a generalist plant pathogen like $B$. cinerea that can infect more than 200 plant species (Mains \& Jackson 1924; D'Oliveira, 1949; Williamson et al., 2007). Puccinia hordei is heterothallic and therefore requires individuals of different mating types to fuse before undergoing sexual recombination. Due to its heteroecious nature, $P$. hordei requires two different genera of hosts (Hordeum and Ornithogalum species) in order to complete its life cycle. Urediniospores, teliospores, and basidiospores form on the Hordeum hosts, whereas pycniospores and aeciospores form on the Ornithogalum hosts. The optimal temperature for $P$. hordei growth ranges from 15 to $25^{\circ} \mathrm{C}$. Like other cereal rust pathogens, $P$. hordei requires free moisture or high humidity to induce urediniospores germination and subsequent infection through leaf stomata (Clifford, 1985).

The life cycle of this pathogen begins with the gametophytic phase as teliospores germinate to produce spore-bearing basidia. The emergent haploid basidiospores are disseminated by wind, water, or insects to cause primary infection on the common Star-of-Bethlehem lily, (O. umbellatum L.) and other species of Ornithogalum such as $O$. pyrenaicum L., $O$. narbonense L., or $O$. brachystachys C. Koch (Mains and Jackson, 1924; D'Oliveira, 1961; Anikster \& Wahl, 1979). The resulting spermagonia produce haploid pycniospores in pustules on the adaxial leaf surface. This spore is usually spread by insects and can only cause secondary re-infection on Ornithogalum. When pycnia of one mating type within a pustule are paired with pycnia of a different mating type from another pustule, their hyphae may fuse and produce the dikaryotic phase $(\mathrm{N}+\mathrm{N})$ of the fungus. Though this is considered a fertilization event, the two haploid nuclei do not recombine inside the hyphae, but rather remain as two distinct 
haploid nuclei in a dikaryotic state. The newly formed dikaryotic hyphae proceed to grow downward through the mesophyll cells of the leaf and sporulate on the abaxial leaf margin to produce aeciospores. These aeciospores are wind-borne and do not re-infect Ornithogalum, but instead cause primary infections on cultivated $(H$. vulgare) and wild barley, $H$. vulgare subsp. spontaneum (Mains \& Jackson, 1924; D’Oliveira, 1949). A few other species (H. murinum L., $H$. chilense Roem. \& Schult., H. bulbosum L., and Triticum aestivum L.) can be infected by $P$. hordei, but are generally considered as non-hosts or near nonhosts (Mains, 1930; Straib, 1937; Rubiales \& Niks, 1992). Infection of the grass hosts by aeciospores is the beginning of the sporophytic phase and results in the eruption of pustules bearing dikaryotic urediniospores on both adaxial and abaxial surfaces of the leaf. This phase of the life cycle is most prolific in terms of spore production because multiple generations of urediniospores can re-infect the barley host causing economic damage.

A urediniospore in contact with a susceptible host can germinate within ten hours when the environment is conducive $\left(15\right.$ to $25^{\circ} \mathrm{C}$ and $80 \%$ or more humidity). A germ tube emerges from the urediniospore and grows across the leaf surface in search of stomata. If a stomate is found, the fungus forms an appresorium above the pore. The fungus enters the plant via a penetration peg and the resulting hypha forms a substomatal vesicle. Within 24 hours, most substomatal vesicles produce at least one haustorium, a specialized cell that penetrates the plant cell wall and interfaces with the plant cell membrane. Successful infection sites are often comprised of at least eight haustoria that secrete effector molecules into plant cells to facilitate parasitization. Using these acquired nutrients, infective hyphae grow and ramify to neighboring plant cells and begin the formation of uredinia bearing urediniospores (Niks, 1983; Chen et al., 2010). As mentioned above, urediniospores can re-infect barley multiple times during the growing season. However, as the crop approaches maturity, the 
fungus begins to produce teliospores within the uredinia. This marks the full life cycle rotation for the fungus.

\section{Impact of Barley Leaf Rust}

Barley leaf rust rarely results in total crop loss, but infections can regularly reduce yields by $30 \%$ in moderate epidemics and by more than $60 \%$ in severe epidemics (Newton et al., 1945; Melville \& Griffin, 1976; Johnson \& Wilcoxson, 1979; Cotterill et al., 1992a; Griffey et al., 1994; Whelan et al., 1997; Woldeab et al., 2007). Besides yield loss, other negative impacts of the disease include reduced tillering, green leaf area, root volume, straw integrity, and most importantly reductions in grain quality (Newton et al., 1945; Whelan et al., 1997; González et al., 2013). Even in cases where yield loss is minimal, leaf rust can reduce grain quality from malting to feed grade, nullifying the premium paid to producers by the malting industry. Frequent dockage of barley from malting to feed grade may discourage future plantings of the crop by producers. Although fungicide use can protect the crop from leaf rust infection, the number of applications needed is generally not economical in many production systems. Leaf rust continues to challenge the sustainability of barley farming and merits research to quantify its impact and develop effective control measures.

The cosmopolitan nature of leaf rust has become more apparent as barley plantings have increased worldwide through the twentieth century. In the Western Hemisphere from Canada to Argentina, barley is subject to leaf rust infection. In Canada, Newton et al. (1944) found that barley not protected by sulfur dust suffered $24 \%$ yield loss from leaf rust infection, and the main component for loss was reduced kernel weight. Buchannon and Wallace (1962) recorded leaf rust severities as high as $32-53 \%$ on the barley cultivar Parkland in Canada. They considered leaf rust to be economically important in their experiments even 
though other foliar diseases were more common at the time. In field experiments in the United States, Johnson and Wilcoxson (1979) reported back-to-back yield losses of $35 \%$ in 1976 and $42 \%$ in 1977. Soon after, Andres et al. (1983) discovered that the severe leaf rust epidemics of 1979 and 1981 in the Upper Midwest US were coincident with an evolutionary shift for greater virulence in the pathogen population. Griffey et al. (1994) investigated the effects of leaf rust on winter barleys in Virginia after another virulence shift in the $P$. hordei population. They recorded a maximum yield loss of $32 \%$ and estimated that for every incremental percent increase in leaf rust severity, yield was reduced by $0.42 \%$. Griffey et al. (2004) also commented that the price paid for feed barley made applying fungicides for leaf rust control uneconomical. In another study in Virginia, Das et al. (2007) reported yield losses up to 33\% due to leaf rust. They also found that in most cases, a single application of a triazol fungicide (Triadimefon) could adequately protect the crop from the disease. In Mexico, leaf rust has become an increasingly important factor limiting barley production. For example, Gonzalez et al. (2013) reported losses up to $30 \%$ in the cultivar Esmeralda, and the harvested grain could not be marketed as premium malting barley. They also noted that a single application of a triazole-based fungicide can control the disease, but this management strategy became uneconomical if more than one application was ever required. Pereyra and Ackerman (2007) observed leaf rust yield losses up to $25 \%$ in Uruguay. Although the fungicides used in this study were effective in controlling the disease, even a single treatment was not economical. As summarized above, yield losses due to leaf rust in North and South America were comparable ranging from $24-33 \%$ and in only a few cases was fungicide use considered economical. 
Barley leaf rust is just as pervasive and damaging throughout the Eastern Hemisphere as it is in the Western Hemisphere. According to King (1972), England's barley plantings increased from 0.86 to 2.14 million hectares from 1957 to 1967, a time concurrent with widespread and high leaf rust infection, reaching an average severity of $12 \%$ on the flag leaf. From this foliar disease survey, King (1972) calculated that for every $1 \%$ severity of flag leaf infection, the yield was reduced by $0.66 \%$ and for every $1 \%$ severity on the penultimate leaves, the yield was reduced by $0.5 \%$. These estimates are higher than the $0.42 \%$ incremental loss of yield for each $1 \%$ severity on the upper two leaves calculated by Griffey et al. (1994) in the US. In England, King and Polley (1976) corroborated these values and found that, for every $1 \%$ rust severity on the flag leaf, yield was lowered by $0.6 \%$, equal to 27.6 kilograms/hectare. Melville and Griffin (1976) reported that leaf rust infections on barley in England reached epidemic levels in 1971, and that for every $1 \%$ increase in rust severity on the penultimate leaves caused a yield reduction of $0.77 \%$. In their study, an excessive fungicide regimen of eight applications increased yield 17 to $31 \%$ compared to untreated plots with the increase being mostly due to higher grain weight.

Leaf rust also impacts barley producers in Eurasia and Africa. Although reports of outbreaks are common, specific estimates regarding yield losses are rare (Wilten, 1953; Martínez et al., 2001; van Niekerk et al., 2001; Woldeab et al., 2006; Sadravi et al., 2007). Rubiales et al. (1992) noted a leaf rust epidemic in Spain in 1989; Sadravi et al. (2007) reported a 1 million metric ton (MMT) yield loss in Iran in 1993; van Niekerk et al. (2001) noted an epidemic in South Africa in 1999; and Woldeab et al. (2006) estimated a $28 \%$ yield loss in Ethiopia in 2003. Although no yield loss studies were conducted recently in Germany or the former USSR, literature on this pathosystem is voluminous, indicating the importance of the disease (Straib, 1937; D'Oliveira, 1961; Grunewaldt-Stocker, 
1983; Khokhlova, 1982; Nover \& Lehmann, 1974; Shelko, 1974; Tan, 1977). In contrast to the above reports, Wilten (1953) stated that, at that time, leaf rust was not of economic concern in the Netherlands, which could perhaps be attributed to the effective disease resistance of their local barley cultivars at that time.

Compared to other regions in the world, it appears that barley in New Zealand and Australia is most impacted by leaf rust (Arnst et al., 1979; Lim \& Gaunt, 1986 Cotterill et al., 1992a; Whelan et al., 1997; Murray \& Brennan, 2010). In New Zealand, Arnst et al. (1979) observed widespread incidence of the disease and reported that frequent epidemics raised concerns about its economic impact in this region. After studying the pathogen population and its effect on the crop, he estimated that up to $21 \%$ yield loss was incurred, mainly due to lower grain weight. Also in New Zealand, Lim and Gaunt (1986) evaluated the effects of leaf rust and powdery mildew co-infections on the popular susceptible cultivar Zephyr. They found that late infection of leaf rust reduced yield by $10 \%$, early infection of leaf rust reduced yield by $32 \%$, and a late co-infection of both leaf rust and powdery mildew reduced yield as much as 52\%. Whelan et al. (1997) also investigated yield loss in barley due to leaf rust in New Zealand and found the highest percent loss (63\%) ever recorded in 1987 with a lower but still significant loss of $38 \%$ during the following year. Early leaf rust infections reduce yield more and do so by reducing tiller numbers, while later infections reduce yield less markedly by lowering the total number of grains and grain weight (Whelan et al., 1997). Similar to the findings in New Zealand, Cotterill et al. (1992a) in Australia recorded yield losses as high as $62 \%$ in the barley cultivar Gus during a moderate to severe leaf rust epidemic in 1990. Murray and Brennan (2010) organized coordinated disease surveys across the four major barley-producing regions in Australia to determine the value of disease control. From this work, leaf rust was ranked as the fourth most economically important disease of barley, causing an average yield loss worth 21 million Australian dollars. This average 
dollar loss estimate was based on just a $2 \%$ yield reduction nationwide. Deployment of resistant cultivars saved an average of 47 million Australian dollars per annum for producers, providing a solid case for the importance of resistance breeding over the use of fungicides.

The economic importance of barley leaf rust worldwide is evident. Reductions in grain quality are often more devastating to producers than losses in grain yield. If long-lasting (durable) resistant cultivars can be developed, the need for expensive fungicides could be decreased, and producers could reap higher returns on their barley crops. While there are some cases of cultivars remaining resistant to leaf rust for decades, many varieties carrying single resistance genes have been rendered susceptible in just a few short years by genetic changes in $P$. hordei populations.

\section{Resistance of Barley to Leaf Rust}

Barley, wheat, and oat all diverged from a common ancestor 7 - 9 million years ago (mya) (Middleton et al., 2014). Puccinia species were probably among the first biotrophic fungal species to infect them as fossil evidence dates basidiomycete evolution to around 300 mya (Tiffney and Barghoorn, 1974, Krings et al., 2011). This lineage of fungal pathogens appears far more ancient than the cereal hosts and many other plants they infect today. Different types of rust can infect plants from relatively ancient to recently derived lineages. For each of the many thousand species of Puccinia to successfully co-evolve with all of these plants, a co-evolution model predicts that as more plant species emerged, the first rusts able to infect them were plurivorous, able to infect all individuals of that species. As the barley lineage flourished, diversifying selection for leaf rust resistance would encourage the evolution of many plants with different resistance factors. This has been predicted in the co-evolution model and also observed in 
barley germplasm, as the catalog of known leaf rust resistance genes is much larger than genes for stem or stripe rust resistance (Anikster, 1989; Heath, 1991; Tosa, 1992). The host-parasite gene-for-gene concept first described in the flax rust pathosystem by $\mathrm{H}$. H. Flor (1942) explains the genetic basis for plantpathogen interactions, declaring that a gene product in the host plant can detect a gene product in the pathogen. Jones and Dangl (2006) later reviewed and summarized gene-for-gene concepts into a more advanced model of multifaceted plant immunity mechanisms. A plant's ability to mitigate microbial invasion encourages microbes to evolve ways to avoid detection by the plant. A theory about general plant-pathogen coevolution exists and is called the "arm's race theory". As plants evolve ways to recognize and respond to pathogens, in turn, pathogens evolve ways to down regulate plant defense responses and avoid recognition.

Against biotrophic pathogens like the rusts, there are two general classifications of host resistance: race-specific and non-race-specific, each thought to be controlled by different groups of genes. Both types of resistance can be expressed at either the seedling stage, the adult plant stage, or both stages (Berloo et al., 2001; Qi et al., 1998). Non-race-specific disease resistance is also referred to as partial resistance or quantitative minor effect resistance and often comprised of many coordinated genes each with their own small effect on general disease level. This type of resistance, conferred by quantitative trait loci (QTL), often restricts many pathogen races by reducing infection frequency, slowing the growth rate of infection, and decreasing spore productivity (Neervoort and Parlevliet, 1978). QTL for partial leaf rust resistance in barley have been thought to co-localize with genes encoding receptor-like kinases, wheat-inducedresistance (WIR1) homologues, and other genes like peroxidases, superoxide dismutase, and thaumatin, all of which have antimicrobial properties (Chen et al., 2010; Marcel et al., 2007). Some minor effect QTL have even been precisely 
mapped close to annotated genes for defense response. Chen et al. (2010) hypothesized that a minor effect QTL for leaf rust resistance was modulating the expression of a defense response gene. Subedi (2017) recently discovered that this same minor effect QTL could be a kinase gene potentially involved in disease response signaling. Results from Chapter 2 also revealed the potential role of similarly annotated genes in leaf rust resistance.

Race-specific disease resistance genes exhibit a qualitative type of resistance against only specific races of the pathogen. These genes allow the plant to genetically recognize protein products of an avirulence gene secreted by the pathogen's haustoria (Ellis et al., 2014). Oftentimes, resistance is achieved after the plant molecularly senses the pathogen and signals a defense response. The role of a pathogen's effector molecule is to silence a plant's ability to signal the defense response (Dodds and Rathjen, 2010). If the plant's defense is mounted successfully, disease severity is reduced most commonly by the hypersensitive (HR) cell death response, which engulfs biotrophic pathogens like the rusts, choking their access to living host tissue. To achieve the HR response, different race-specific resistance factors can collaborate to detect microbial activity, bind pathogen avirulence molecules, and/or initiate signal transduction pathways that result in localized cell death (Jones and Dangl, 2006; Dodds and Rathjen, 2010; Ellis et al., 2014). A study by Bernardo et al. (2012) compared the disease resistance proteomes between Bowman and the Rph15 Bowman introgression line (BW719) used in this study (Chapter 2). They discovered a group of 18 genes that were significantly differentially expressed upon infection by $P$. hordei, and the coordinated functions of these genes upregulated a defense response and diverted energy metabolism towards mounting this defense response. 
In total, 26 barley leaf rust resistance loci have been identified across the barley genome (Park et al., 2015; Kavanagh et al., 2017; Ziems et al., 2017, Yu et al., In Press). Initially referred to as Puccinia anomola ( $\mathrm{Pa}$ ) genes, these leaf rust resistance genes are now designated as reaction to $\underline{P} u c c i n i a$ hordei (Rph) genes, reflecting the change in the accepted nomenclature for the pathogen (Franckowiak et al., 1997). Each unique Rph gene in the plant may interact with a unique avirulence gene in the pathogen. In any barley-producing region, the genetic diversity of the local pathogen dictates the effectiveness of an Rph gene. A group of barley accessions each carrying a different $R p h$ gene is referred to as a differential set and is used to study virulence diversity in $P$. hordei populations.

\section{Genetics of Leaf Rust Resistance in Barley}

Inspired by previous genetic work in other cereal rust pathosystems, Waterhouse (1927) in Australia initiated the first study on the genetics of leaf rust resistance in barley. Through his investigations with several barley crosses, Waterhouse observed Mendelian inheritance of single completely dominant resistance genes. In the United States, Mains (1930) screened barley cultivars and various species of Hordeum to two different isolates of $P$. hordei and postulated that different resistance genes may exist in the germplasm and that diversity in the pathogen may be useful in detecting these genes. Researchers in other countries such as Canada, Germany, Argentina, and England investigated the resistance of hundreds of different barley accessions to local isolates of $P$. hordei and reported similar results with respect to diversity for resistance in the host and for virulence in the pathogen (Brown, 1931; Hey, 1931; Mains and Martini, 1932; Hirschhorn, 1933; Ronsdorf, 1935; D’Oliveira, 1939). 
Continuing the research of Waterhouse (1927), Watson and Butler (1947) described the first two leaf rust resistance genes (i.e. Pa genes for Puccinia anomala, the old taxonomic epithet for $P$. hordei) from barley: Pa1 from Minn. II 21.15 (Smooth Awn x Manchuria) and Pa2 from No. 22 (Weider, Clho 1021). Henderson (1945) also studied the genetics of leaf rust resistance in Weider and reported a single incompletely dominant gene, which he assigned as $\mathrm{Pa}$, inconsistent with Watson and Butler's previous designation for the gene in Weider. Henderson also found a different gene present in the cultivar Estate (Clho 3410; PI 57700) and designated it as $P_{1}$. In Canada, Zloten (1952) developed genetic populations with Rph2-carrying lines (Kwan, Ricardo, and $\mathrm{Cl}$ 4219) reported to be resistant to Minnesotan $P$. hordei isolates in Henderson's work. He discovered evidence for single gene factors in Kwan and Ricardo, plus evidence for multiple resistance factors being present in $\mathrm{Cl} 4219$.

Stakman and his co-workers commented that the different genotypes used in various countries to study $P$. hordei diversity made it practically impossible to compare results (Stakman et al., 1933). This led to a study by Levine and Cherewick (1952) to determine which barley accessions, out of all previously reported ones used to study pathogen diversity around the world, were essential for separating North American isolates of $P$. hordei into different races. They found that nine selected barley lines differentiated the maximum number of $P$. hordei races. Those lines were Speciale (Clho 7536), Sudan (Clho 6489), Oderbrucker (Clho 1272), Reka I (Clho 5051), Gold (Clho 1145), Lechtaler (Clho 6488), Quinn (Clho 1024, PI 39401), Bolivia (Clho 1257, PI 36360), and Egypt 4 (Clho 6481). The efficiency of these nine genotypes in differentiating North American isolates of the pathogen led Roane (1962) to presume the existence of additional leaf rust resistance loci in barley than those few already described. Moreover, inconsistencies in the naming of resistance loci among several research groups (Waterhouse, 1927, Watson and Butler, 1947, and Henderson, 
1945) also prompted Roane (1962) to study the genetics of the nine differential barley accessions selected by Levine and Cherewick (1952). Roane (1962) investigated the genetics of leaf rust resistance in the nine differential barleys by crossing them all to the susceptible cultivar Moore (Clho 7251). He also intercrossed all of the differential lines for tests of allelism. From this work, Roane (1962) detected six leaf rust resistance loci. Subsequently, Roane and Starling (1967) conducted genetic studies on other leaf rust resistant lines described by Henderson (1945) and Watson and Butler (1947) to provide comprehensive information on the identity of the six Pa genes they suspected to reside in the germplasm. According to their results, $P a_{1}$ was present in Oderbrucker, an accession carrying the same allele as Minn. II 21.15, Especiale, and Sudan; $\mathrm{Pa}_{2}$ was present in Weider, Reka I, Quinn, and Bolivia; $\mathrm{Pa}_{3}$ was present in Estate; $P a_{4}$ was present in Gold and Lechtaler; $P a_{5}$ was present in Quinn; and another gene, tentatively designated $P a_{x}$, was present in Bolivia, but had not yet been distinguished from $P a_{5}$, the gene in Quinn. These accessions became the first genetic standards for future research on leaf rust resistance genes in barley.

As the discovery of new leaf rust resistance genes continued, distinguishing among them became more challenging. After the characterization of the first six genes by Roane and Starling (1967), a new gene, PaY was postulated to be present in Cebada Capa (Clho 6193, PI 539113) and other accessions based on their much broader resistance spectrum against various races of $P$. hordei (Johnson, 1968; Dillard and Brown, 1969). Roane and Starling (1970) performed allelism tests between Cebada Capa and the previously described sources of Pa genes. After observing a lack of susceptible progeny in the $\mathrm{F}_{2}$ generation of a Cebada Capa $\times$ Quinn cross, they concluded that Pay was not a unique locus, but rather an allele at the $\mathrm{Pa}_{5}$ locus. They also mentioned the possibility that $P a_{y}$ and $P a_{5}$ could actually comprise two very tightly linked loci, but the number of progeny needed to resolve this in an allelism test would be 
much higher. Furthermore, after observing segregation for leaf rust resistance in a cross between Cebada Capa and Bolivia, they designated $P a_{x}$ as a new gene, $P a_{6}$. If $P a_{Y}$ had initially been described as a unique gene, it would have been $P a_{6}$, and then the $P a_{6}$ gene named by Roane and Starling (1970) would likely have been considered an allele of $P a_{5}$. Besides the linkage between $P a_{5}, P a_{x}$, and $P a_{Y}$, Roane and Starling (1970) also reported a possible linkage between $\mathrm{Pa}_{3}$ and $P a_{5}$. Although they clarified the genetic identities of $P a_{1-5}$, their conclusions about $P a_{X}$ and $P a_{Y}$ were soon challenged.

More robust genetic approaches became necessary to resolve, with more confidence, the newly described leaf rust resistance genes. Around the same time as the genetic investigations by Roane and Starling (1970) in the United States, Frecha (1970) in Argentina published the discovery of a new gene he designated as $P a y$, but it was from a different barley line called Forrajera Klein. In contrast to the results of Roane and Starling (1970), the cross between Forrajera Klein and Quinn yielded segregation in the $F_{2}$ generation, indicative of tight linkage between $\mathrm{Pa}_{Y}$ and $\mathrm{Pa}_{5}$ (Frecha, 1970). Based on these results, Nover and Lehman (1974) first designated the gene in Forrajera Klein as $P a_{7}$. Parlevliet (1976) then determined that $\mathrm{Pa}_{7}$ was also present in Cebada Capa after performing an allelism test between these two lines. Tan (1978) used crosses between trisomic lines and both Cebada Capa and Estate in order to position $\mathrm{Pa}_{7}$ to chromosome $3 \mathrm{H}$ and determine that $\mathrm{Pa}_{3}$ from Estate was not linked on this same chromosome. After the identity of Pa7 was clarified, Zhong et al. (2003) developed backcross lines derived from Bolivia $\left(\mathrm{Pa}_{2+6}\right)$ that were postulated to carry singly either $P a_{2}$ or $P a_{6}$. The derived line carrying $P a_{6}$ only was used in an allelism test with Magnif 102 , which carries $P a_{5}$. Strong evidence that $P a_{5}$ and $P a_{6}$ are actually alleles of the same gene was provided when no susceptible progeny were found from more than 2,000 $\mathrm{F}_{2}$ plants evaluated. The additional genetic analysis involving trisomic lines and monogenic backcross lines provided 
important data to resolve the relationships among the genes $P a_{3}, P a_{5}, P a_{6}$, and $\mathrm{Pa}$.

The genetics of the next provisionally accepted leaf rust resistance gene remains poorly understood. Clifford (1977) cited a personal communication with B. $\mathrm{H}$. Tan that a single gene reported in Egypt 4 should be named $P a_{8}$. Unlike the other described lines carrying different $\mathrm{Pa}$ genes, this accession has a narrow spectrum of resistance to $P$. hordei (Clifford, 1977). The resistance gene in Egypt 4 went undetected in studies by Roane (1962) and Roane and Starling (1967), presumably because no $P$. hordei isolate with avirulence for Egypt 4 could be found. Although $\mathrm{Pa}_{8}$ is accepted as a unique gene, its chromosomal position and allelic relationship with other genes have not been reported. The genomic locus associated with this gene is described in Chapter 2.

Another case of unresolved allelism for leaf rust resistance genes arose between the Ethiopian landrace Abyssinian (Clho1243, HOR2596) and the German cultivar Trumpf (PI 548762, HOR 4967). Both accessions were thought to carry the same gene, one that displayed a wider spectrum of resistance than previously seen in other barley accessions (Clifford and Udeogalanya, 1976). Crosses between Abyssinian and the other widely resistant sources of Estate $\left(\mathrm{Pa}_{3}\right)$ and Cebada Capa $\left(\mathrm{Pa}_{7}\right)$ yielded evidence that a new gene, $P a_{9}$, must be present in Abyssinian (Tan, 1977). In Germany, the leaf rust resistance in cultivar Trumpf was overcome by virulent $P$. hordei isolates, spurring investigations into its genetic ancestry. The resistance in Trumpf may have been derived from the Ethiopian line HOR 2596 (Abyssinian or $\mathrm{Cl}$ 1243), which was previously described as carrying $\mathrm{Pa}_{9}$. Data from $\mathrm{F}_{2}$ populations of reciprocal allelism crosses failed to reject a model predicting multiple incompletely dominant genes, indicating that HOR 2596 and Trumpf carry the same resistance gene (Walther, 1987). Other pathotype screening data indicated that Trumpf reacted differently 
than Abyssinian (Jones and Clifford, 1980). Corroborating allelism and pathotype testing by Jin et al. (1993) led to the designation of a new leaf rust resistance gene (Rph12) in Trumpf, using the modern gene epithet, which will be used throughout this chapter. In a subsequent study, Borovkova et al. (1998) evaluated a large $F_{2}$ population of nearly 4,000 individuals from a cross between Abyssinian and Triumph (Clho 12307, PI 290195), the American imported source of Trumpf grown in the United States, and found no susceptible segregants. They concluded that Rph9 and Rph12 must be alleles of each other at the same locus. They also found that both genes were linked to the sequence-tagged site (STS) molecular marker $A B C 155$ on chromosome $5 \mathrm{HL}$. The two genes were within 3 $\mathrm{cM}$ of each other. A third possible allele at this locus was described in the cultivar Cantala. This contention was based on the fact that no segregating $F_{3}$ families were observed from a cross between Cantala and Triumph (Dracatos et al., 2014). It remains unclear whether these genes are truly alleles at the same locus or are distinct but closely linked loci.

The gene in Trumpf was named Rph12 because two new genes from wild barley had previously been described by Feuerstein et al. (1990). In the work by Feuerstein et al. (1990), 56 different Hordeum vulgare ssp. spontaneum accessions from Israel were backcrossed to the susceptible cultivar Clipper and two broadly resistant $\mathrm{BC}_{3} \mathrm{~F}_{2}$ families were chosen for genetic analysis. A partially dominant gene was identified in the backcross line BC-8 (GSHO 1588) and was linked with the isozyme locus Est2 on chromosome $3 \mathrm{H}$. This gene was designated as Rph10 without performing allelism tests with other genes positioned on the same chromosome. A different partially dominant resistance gene in another backcross line BC-67 (GSHO 1589) was linked with the isozyme loci Acp3 and Dip2 on chromosome 6H and designated as Rph11 since no other leaf rust resistance genes had been described on this chromosome. This 
pioneering work with wild barley was followed by other investigations mining disease resistance genes in other wild Hordeum germplasm.

The next several leaf rust resistance genes were discovered after evaluation of a diverse collection of wild and cultivated barley accessions (Jin and Steffenson, 1994). Using a panel of $P$. hordei isolates with virulence for genes Rph1-Rph12, these workers reported that wild barleys are typically more resistant than cultivated barleys and often carry multiple genes with dominant or recessive gene action. A later publication based on this initial work led to the discovery of barley accessions with resistance to widely virulent $P$. hordei isolates and the designation of two new leaf rust resistance genes (Jin et al., 1996). The wild barley-derived accession PI 531849 (BS 99-2-1) segregated for a single dominant gene when crossed with the susceptible cultivar Bowman, and its uniqueness was revealed in allelism tests with Rph1-Rph12. The gene in PI 531849 was designated as $R p h 13$ and was reported as possibly linked with $R p h 9$ on chromosome $5 \mathrm{HL}$ after a deficiency of susceptible $\mathrm{F}_{2}$ progeny was observed in the cross PI $531849 \times$ HOR 2596. PI 584760 (PI 531901-1, NDBLR01) segregated for a single incompletely dominant gene when crossed with Bowman. Higher infection types in some $F_{2}$ progeny classified as resistant from this cross suggested the incompletely dominant nature of this gene. Allelism tests with the donors of Rph1-Rph13 confirmed a novel gene in PI 584760, which was designated as Rph14. The incompletely dominant nature of this gene was confirmed and complete co-segregation between this gene and the Diversity Arrays Technology (DArT) marker bPb-1664 on chromosome 2HS was observed (Golegaonkar et al., 2009). In addition to Rph13 and Rph14, another resistance gene from wild barley was reported in accession PI 355447 (Chicaiza, 1996). This accession, along with several others, exhibited a high level of resistance to a wide array of $P$. hordei isolates. After backcrossing the resistance gene into Bowman and also performing allelism tests with the sources of Rph1-14, this new 
single dominant resistance gene was named Rph15. Crossing PI 355447 with morphological marker stocks provided the initial genetic evidence that Rph15 lies on chromosome $2 \mathrm{HL}$ between the six-rowed spike 1 (vrs1) locus and the ribbon grass (white streak 7, wst7) locus (Chicaiza, 1996). However, this placement of Rph 15 on the long arm of chromosome $2 \mathrm{H}$ would later be corrected.

The discovery of two other widely resistant $H$. vulgare ssp. spontaneum accessions led to the identification of another leaf rust resistance allele of Rph15 by Ivandic et al. (1998). They found two wild barley accessions (HSO78 and HS084) resistant to $P$. hordei isolates with virulence for $R p h 7$ and developed a doubled haploid population for each with the susceptible line, L94. After construction of Restriction Fragment Length Polymorphism (RFLP) marker maps, Ivandic et al. (1998) positioned the resistance loci of both HSO78 and HSO84 in the short arm of chromosome $2 \mathrm{H}$ via linkage with RFLP markers MWG784 and MWG2133. They concluded the gene was novel and named it as Rph16 (Ivandic et al., 1998). A later investigation by Weerasena et al. (2004) concluded that Rph15 and Rph16 are likely alleles of each other. Additionally, Amplified Fragment Length Polymorphism (AFLP) markers on the short arm of chromosome $2 \mathrm{H}$, not the long arm, were found linked to Rph15. Moreover, there was no evidence of segregation observed in $1,027 F_{2}$ individuals from the cross Bowman-Rph15 (the backcross line from Chicaiza) x HS084 (one of Ivandic's parental wild barleys). One AFLP marker was long enough to be converted to a Cleaved Amplified Polymorphic Sequence (CAPS) marker, P13M40, making it amenable for marker-assisted selection in breeding (Weerasena et al., 2004). Another allele at the Rph15/16 locus was described in a different wild barley accession, Hordeum spontaneum 677 (Kopahnke et al., 2004). Without the appropriate allelism tests or fine-mapping data, it is uncertain whether these genes lie at separate linked loci or are alleles at the same locus. 
Other barley leaf rust resistance genes were identified in the secondary gene pool species, Hordeum bulbosum. In New Zealand, Pickering (1995, 1997, and 2000) successfully introgressed large segments of chromatin from different $H$. bulbosum accessions into two $H$. vulgare cultivars bred for high levels of horizontal leaf rust resistance. The first introgression line was produced as an $F_{3}$ recombinant inbred line between $H$. bulbosum accession $81882 \times H$. vulgare cultivar Vada (PI 243182). The introgression was mapped to the short arm of chromosome $2 \mathrm{H}$ and the resistance gene was designated as Rph17. The next introgression line was produced as a $\mathrm{BC}_{2} \mathrm{~F}_{2}$ line derived from $\mathrm{H}$. bulbosum accession $2032 \times \mathrm{H}$. vulgare cultivar Emir (Clho 11790). This introgression was mapped to the long arm of chromosome $2 \mathrm{H}$ and the resistance gene was designated as Rph18. Within these large segments of introgressed chromatin, it is possible that more than one resistance gene might be present. Johnston et al. (2013) created another introgression line 182Q20 between $H$. bulbosum accession A17-1 x H. vulgare cultivar Golden Promise (PI 342079). Many recombination events were assayed in a large population of $F_{2}$ progeny to map this resistance gene (Rph22) to the long arm of chromosome $2 \mathrm{H}$ (Johnston et al., 2013). Of the two H. bulbosum-derived genes of Rph18 and Rph22 positioned in chromosome $2 \mathrm{HL}$, flanking polymerase chain reaction (PCR) markers of WEB114/WEB113 and WEB115/WEB114 were identified, respectively. These genes are considered to have a qualitative effect on resistance even though their observed modes of action and potential gene transcripts are generally considered horizontal quantitative resistance mechanisms (Pickering et al., 2000; Pickering et al., 1995; Pickering et al., 1998).

Two recently characterized seedling resistance genes were identified from two older cultivars Reka I and Ricardo (PI 328933, HOR 2471). Originally used as a differential host line by Levine and Cherewick (1952), Reka I was likely derived from the Australian cultivar Prior released in 1905. Reka I is also known 
to carry Rph2 and an uncharacterized gene, named RphP (Cotterill et al., 1995). Park and Karakousis (2002) mapped RphP to the long arm of chromosome $7 \mathrm{H}$ in a doubled haploid population between Chebec $x$ Harrington. They then performed an allelism test between Estate and Prior that provided evidence of repulsion-phase linkage between $R p h 3$ and $R p h P$ around $28 \mathrm{cM}$ on $7 \mathrm{HL}$, allowing them to designate RphP as Rph19. Since 1945, the cultivar Ricardo has also been known to carry two resistance genes, Rph2 and one additional gene. Using bulked segregant analysis and single sequence repeat (SSR) genotyping on an $F_{3}$ population, the uncharacterized gene from Ricardo was mapped on chromosome 4H (Sandhu et al., 2012). Since this was the only leaf rust resistance gene mapped to this chromosome, it was declared unique and given the gene designation of Rph21.

The remaining barley leaf rust resistance genes were first described as quantitative trait loci (QTL). Rph20 is an adult plant resistance (APR) gene that was identified from the Australian cultivar Flagship (Hickey et al., 2011). In a doubled haploid population between Flagship x ND24260, the QTL qRphFlag, contributed by Flagship, accounted for $64-85 \%$ of the phenotypic variation in the field and was associated with the DArT marker $b P b-0837$ in the short arm of chromosome $5 \mathrm{H}$. Also from this population, ND24260 donated a weaker effect resistance QTL, designated as $q R p h N D$, that was detected in chromosome $6 \mathrm{H}$ and only accounted for $2-5 \%$ of disease variation. The origin of Rph20 traces back to Hordeum laevigatum, which contributed the major effect nonhypersensitive APR in other cultivars such as Vada and Emir. Another APR gene, Rph23, was described in a different Australian cultivar Yerong (Derevnina et al., 2013; Singh et al., 2015). The largest effect resistance QTL from Yerong (qRphYer-7H) accounted for $18-20 \%$ of the phenotypic variation and was very closely linked to the co-dominant SSR marker Ebmac0603 in the short arm of chromosome 7H. The QTL from ND24260 reported by Hickey et al. (2011) was 
later characterized as Rph24 (Ziems et al., 2017). Barleys carrying a combination of Rph20 with Rph23, Rph24, or other small effect resistance QTL displayed enhanced levels of APR compared to barleys carrying a single QTL. Rph25 was first identified as the QTL, RphFT, in the Chinese cultivar Fong Tien during an investigation of diverse barley germplasm for seedling resistance (Kavanagh et al., 2017). Using DArT marker analysis in a doubled haploid population, Rph25 was positioned to chromosome $5 \mathrm{HL}$ near the Rph9/Rph12 locus. Although $R p h 25$ only provides resistance to a single Australian $P$. hordei isolate and was not considered to be of much value for breeding programs, it could still be useful in combination with other resistance genes. The most recently described leaf rust resistance gene is Rph26, derived from a cross between the Hordeum bulbosum accession $\mathrm{A} 17$ and the cultivar Emir ( $\mathrm{Yu}$ et al., in press). The resultant line 200A12 contains this novel $H$. bulbosum resistance introgression in chromosome 1HL. A group of five separate QTLs within this introgression was collectively designated as Rph26. They were inherited in an incompletely dominant fashion and were reported to be less effective in heterozygous individuals. Leaf rust resistance genes with quantitative resistance mechanisms can have qualitative effects on disease severity.

\section{Bowman Introgression Lines for Leaf Rust Resistance}

The current collection of barley accessions used as leaf rust differentials by various research groups is genetically diverse. Agronomic and genetic differences among these lines can make them difficult to study and use in breeding programs. Also, some of these lines even carry combinations of resistance genes that effectively encrypt the actions of single genes. Isolating individual Rph genes into a common susceptible cultivar is ideal both for normalizing the agronomic characteristics of the differential set and for revealing 
the true resistance spectrum of single resistance genes (Person, 1959; Clifford, 1977).

In recognition of these research limitations, the barley leaf rust resistance genes Rph1-15 were backcrossed to the susceptible cultivar Bowman to develop a set of near-isogenic differential host lines (Chicaiza, 1996; Caffarel, 2005). Between 1-10 backcrosses were used to develop 95 Bowman introgression lines representing these leaf rust resistance genes, their potential allelic variants, and perhaps yet undescribed genes for resistance. In this study, 12 diverse pathotypes of $P$. hordei were used to compare the phenotypic reaction patterns between the introgression lines and their respective donor lines. Altogether this effort was intended to develop a new barley leaf rust differential set consisting of single-gene introgression lines in a uniform genetic background.

As part of a large, comprehensive genetic study of barley, Druka et al. (2011) genotyped barley mutants backcrossed to Bowman to investigate morphological gene mutants as single gene lines. The germplasm included the 95 leaf rust introgression lines, but these genotype data have not been published. More recently, Genotyping-by-Sequencing (GBS) Single Nucleotide Polymorphism (SNP) data were generated for these 95 lines to better define the introgressions carrying the resistance genes. In Chapter 2 of this thesis, a comprehensive phenotypic and genotypic analysis of these 95 introgression lines was completed with the goal of selecting a refined set of single gene host lines for characterizing the virulence diversity of $P$. hordei. 
CHAPTER 2

PHENOTYPIC AND GENOTYPIC CHARACTERIZATION OF BARLEY INTROGRESSION LINES CARRYING THE LEAF RUST RESISTANCE GENES Rph1 TO Rph15 


\section{Introduction}

Barley (Hordeum vulgare L.) ranks fourth among cereal crops in the world with an average annual production from 2014-2017 of 145 million metric tons (MMT) from 50 million planted hectares (MHa) (USDA, 2017). Puccinia hordei Otth, the causal agent of barley leaf rust, is one of the most ubiquitous pathogens challenging the sustainability of the crop across the world. Under moderate epidemics, yield losses around $30 \%$ are common in barley, but can reach up to 63\% during severe epidemics (Levine and Cherewick, 1952; King and Polley, 1976; Cotterill et al., 1992a; Griffey et al., 1994). Breeding cultivars with resistance is the preferred method of controlling barley leaf rust because fungicide applications, while effective, are rarely economical and can contaminate the environment. To date, 26 major effect resistance genes, referred to as Reaction to Puccinia hordei (Rph) genes, have been identified and mapped to unique positions across the barley genome (Park et al., 2015; Kavanagh et al., 2017; Ziems et al., 2017; Yu et al., in press). While many of these resistance genes have been rendered ineffective in deployed cultivars due to the appearance of new virulent pathotypes of $P$. hordei, they still provide a means to characterize virulence phenotypes in pathogen populations.

To differentiate virulence phenotypes within pathogen populations, researchers compile sets of host genotypes that are postulated to carry unique resistance genes. These collections of resistant host lines are referred to as differential sets. Stakman and Levine (1922) developed one of the first differential sets in their pioneering research to characterize the virulence diversity of the wheat stem rust pathogen, Puccinia graminis f. sp. tritici. From the evaluation of many wheat lines, they selected 12 that were thought to carry distinct resistance genes. This wheat stem rust differential set became an international standard for characterizing races of $P$. graminis f. sp. tritici. After the initial research by 
Stakman and Levine (1922), differential host lines were established for many other pathosystems such as flax rust, wheat stripe rust, wheat stem rust, and oat crown rust (Flor, 1942; Zimmer et al., 1963; Roelfs and Martens, 1988; and Chen et al., 2014). With barley, a number of differential sets have been developed to type virulence to such diverse pathogens as Cochliobolus sativus (spot blotch pathogen), Pyrenophora teres f. sp. teres (net form net blotch pathogen), Blumeria graminis f. sp. hordei (powdery mildew pathogen), Puccinia striiformis $\mathrm{f}$. sp. hordei (stripe rust pathogen), and Puccinia hordei (leaf rust pathogen) (Levine and Cherewick, 1952; Kolster, 1986; Valjavec-Gratian and Steffenson, 1997; Afanasenko et al., 2009; Wan and Chen, 2014; Park et al., 2015).

Levine and Cherewick (1952) proposed the first barley leaf rust differential set, highlighting the difficulties of comparing virulence data derived from different sets of host lines used by workers around the world. This original set of nine lines was used internationally for 25 years (Moseman and Roane, 1959; Nover and Lehmann, 1974; Shelko, 1974), until genetic studies by Roane and Starling (1970) identified redundancies within this first set. Soon afterwards, a proposal for an international barley leaf rust differential set was forwarded by Clifford (1977) and comprised of eight lines, each with a different recognized resistance gene. As new resistance genes were characterized, this set was expanded and has been regularly used by various international research groups (Yahyaoui et al., 1988; Steffenson and Jin 1992; Brodny and Rivadeneira, 1996; van Niekerk et al., 2001; Park, 2003; Germán et al., 2005; Jones, 2005; Woldeab et al., 2006; Czembor et al., 2007). The current barley leaf rust differential set is comprised of cultivars, landraces, and wild barley introgression lines originating from around the world. Although this differential set is comprised of accessions that, in most cases, are known to carry only a single Rph gene, their diverse genetic backgrounds can sometimes affect the expression of resistance. For example, $R p h 3$ confers a strong hypersensitive reaction to many $P$. hordei isolates when 
present in the barley cultivar Ribari, but gives incomplete resistance when transferred into the susceptible line L94 (Niks et al., 2011). Also, epistasis can occur in differential lines carrying more than one Rph gene, thereby confounding the true reaction types of the genes present. Finally, due to the diverse agronomic phenotypes of these lines, comparisons for leaf rust resistance can be difficult in the field due to differences in heading date, plant height, and leaf morphology. The current barley leaf rust differential set has been successfully used to characterize the virulence of $P$. hordei isolates in many studies; however, its utility can be improved.

An ideal and efficient differential set for characterizing pathogen virulence is one comprised of lines that each carry a single resistance gene backcrossed into the uniform genetic background of a single susceptible genotype (Person, 1959). With successive backcrossing, differential sets comprised of near-isogenic lines have been developed for the wheat leaf rust, wheat stripe rust, barley leaf scald, and barley powdery mildew pathogens (Kolster et al., 1987; Patil et al., 2002; Dyck, 2011; Chen et al., 2014). A future intent to develop backcrossed differential lines for the wheat stem rust, barley net form net blotch, and the barley leaf rust pathosystems have been communicated in the literature (Clifford, 1977; Roelfs and Martens, 1988; Steffenson and Jin, 1992; Afanasenko et al., 2009). With respect to this effort in the barley leaf rust pathosystem, the donor lines for the resistance genes Rph1-15 were first crossed to the susceptible feed barley cultivar Bowman (PI 483237) as part of a large effort to develop backcross lines for major morphological markers in barley (Chicaiza, 1996; Caffarel, 2005; Druka et al., 2011). Multiple sources for many of these Rph genes were backcrossed to Bowman to compare the reactions between alleles of the same gene. The cultivar Bowman was selected as the recurrent parent based on its superior agronomic traits, adaptation across diverse environments, and broad susceptibility to isolates of the leaf rust pathogen (Franckowiak et al., 1985). 
Chicaiza (1996) initiated development of 95 Bowman introgression lines carrying different $R p h$ alleles. Fifteen of these lines were initially recommended to represent Rph1-15 by Caffarel (2005). As part of a large, comprehensive genetic study of barley, Druka et al. (2011) utilized Barley Oligonucleotide Pooled Assay (BOPA) SNP markers to genotype hundreds of Bowman introgression lines with mutations for altered morphological traits. This germplasm also included Bowman lines with introgressions from 95 leaf rust resistant donors, but these genotyping data were not previously published. Genotyping-by-sequencing (GBS) SNP data were recently collected for these 95 Bowman introgression lines, plus their respective original donors. The main objective of this investigation was to characterize the phenotypic and genotypic polymorphisms of barley introgression lines carrying leaf rust resistance genes. This was done by evaluating the 95 introgression lines for their infection types (ITs) to 12 global isolates of the leaf rust pathogen and genotyping with SNP markers. These data were used to describe the phenotypic differences among alleles at the same loci, the precise physical positions for the leaf rust resistance gene introgressions across the barley genome, and the existence of putative new resistance genes in the germplasm. In turn, these data were used to select an improved set of differential host lines each carrying a single Rph gene (from Rph1 to Rph15) for typing virulence in $P$. hordei.

\section{Materials and Methods}

Plant Materials and Development of Introgression Lines

The donors for Rph1-24 were obtained from the original investigators or the United States Department of Agriculture-Agricultural Research Service (USDA-ARS) National Small Grains Collection (NSGC) in Aberdeen, Idaho. Data on the line names, accession numbers, recognized Rph genes, country of origin, 
and donors for these resistance sources are given in Appendix Table 1. When the program to introgress leaf rust resistance genes into Bowman (PI 483237) was first initiated, only Rph1 to Rph15 were described (Chicaiza, 1996) (Table 1). Thus, only these 15 leaf rust resistance genes are included in the final differential set of Bowman introgression lines (Table 2). The main focus of this investigation was on the 15 introgression lines (Rph1-15) selected for use as differential host lines. However, we also characterized the other 80 leaf rust resistant donors used as parents in the larger resistance introgression effort. To develop the introgression lines, a single $F_{1}$ progeny from each cross between Bowman and the Rph donor parent was backcrossed to Bowman. From each resulting $\mathrm{BC}_{1} \mathrm{~F}_{2}$ population, a single progeny that closely resembled the respective donor parent's ITs to a selected pathotype of $P$. hordei was transplanted and used in backcrossing. Details regarding the accession number, origin, improvement status, pedigrees, and derived BW lines for Bowman and the 95 donor parents given in Appendix Table 2. Appendix Table 3 details the respective donor parents, numbers of backcross generations, pedigrees, and postulated gene identities for each of the 95 introgression lines.

\section{Pathogen Isolates and Race Nomenclature}

From a global collection of more than 350 isolates of $P$. hordei, Chicaiza (1996) and Caffarel (2005) selected 12 diverse ones for use in the introgression project. These isolates had unique virulence combinations capable of differentiating each leaf rust resistance gene under study. Together, the panel of isolates provided redundant avirulence and virulence phenotypes for all Rph genes, except Rph15 for which no virulent isolate was available. The panel was assembled to provide avirulence to each gene in at least two of the 12 isolates. Redundancies for virulence and avirulence in an isolate panel help validate that each resistance gene is functioning independently. 
In this study, four of the same isolates from Chicaiza (1996) and Caffarel (2005) were used, but eight alternative isolates were selected from the global collection (Fetch et al., 1998). Together, this modified panel of $12 P$. hordei isolates improved the balance between avirulence and virulence redundancies for Rph1 to Rph14 and also added virulence for Rph15, the widely effective resistance gene first described by Chicaiza (1996). Complete details for the avirulence/virulence (Avr/Vir) formulae (Clifford, 1985), coded triplet octal notations (Gilmour, 1972), and North American rust race codes (Roelfs and Martens, 1988) for the $12 P$. hordei isolates are listed in Table 3. Donors of these P. hordei isolates and their origins of collection are detailed in Appendix Table 4.

These different race nomenclatural systems have been used to represent the virulence phenotypes of $P$. hordei in order to simplify comparisons among isolates. In the Avr/Vir system, the Rph genes for which the isolate is avirulent are listed first followed by a slash and then the Rph genes for which the isolate is virulent. In the coded triplet octal notation system, each resistance gene of the differential set is aligned chronologically from right to left. Across all of the Avr Vir reactions, reaction types of three resistance genes (genes 1-3, or 4-6, or 7-9) are used together as a triple-digit value to encode a single numeral from 1 to 7 that abbreviates the virulence combinations (Gilmour, 1973; Limpert and Müller, 1994). Isolates with different virulence combinations will have different numerical codes. In this scheme, higher numbers indicate wider virulence. Instead of using numerals to name pathotypes of the pathogen, under the North American system, rust isolates are named according to an alphabetical letter code (Roelfs and Martens, 1988; Wan and Chen, 2014). The Avr/Vir reactions of the differential lines are grouped sequentially in groups of four and the different possible four-digit reaction patterns are converted into alphabetical letters from " $B$ " to " $S$ ". In this race code system, letters furthest from the beginning of the alphabet imply wider virulence. 


\section{Experimental Design}

Leaf rust evaluations of resistance donors and derived introgression lines were performed in a greenhouse $(\mathrm{GH})$ on the Saint Paul campus of the University of Minnesota. These evaluations were conducted in three separate experiments, each with two replicates, in the fall/spring GH season of 2016-17 and the spring GH season of 2017-18. Also included in the experiment were several replications of the recurrent parent Bowman and the differential host lines for Rph1-24. The medium used for growing the plants was a 50:50 mixture of steam-sterilized soil and a commercial potting mix (SS \#8 F2 mix; Sun Gro Horticulture brand, Agawam, MA). Plastic cells measuring $3.8 \mathrm{~cm}$ wide and $21 \mathrm{~cm}$ deep (RL98 tray with SC10 Super cells; Ray Leach Cone-tainer ${ }^{\mathrm{TM}}$ brand, Stuewe and Sons Inc, Tangen, OR) were filled with the growth medium into which three seeds of each line were sown. After sowing, a slow release fertilizer was applied according to the manufacturer's instructions (Osmocote 14-14-14; Scotts brand, Marysville, $\mathrm{OH})$.

Inoculation and Disease Phenotyping Protocols

Inoculum for each isolate was produced in an isolated greenhouse on seedlings of the susceptible barley cultivar Moore (Clho 7251). Prior to inoculation, plants were grown in a rust-free GH with a day/night temperature of $24 / 20^{\circ} \mathrm{C}$ and 16 -hour photoperiod supplemented by 1000-watt high-pressure sodium (HPS) bulbs emitting 350-400 $\mu \mathrm{mol} \cdot \mathrm{m}^{-2} \cdot \mathrm{s}^{-1}$. Seedlings were grown in peat pots (Dioni trays containing $7 \times 9 \mathrm{~cm}$ peat pots; FertilUSA, Slatington, PA) filled with the same growing mix detailed above. For ease of handling, the peat pots were set into 16-count plastic trays. When coleoptiles first emerged from the soil, the plants were treated with a maleic acid hydrazide solution $\left(380 \cdot \mathrm{mg} \cdot \mathrm{L}^{-1}\right)$ to retard their growth, making the collection of urediniospores more convenient. The 
12 stock isolates of $P$. hordei were stored as urediniospores in a $-80^{\circ} \mathrm{C}$ freezer. To prepare the inoculum for inoculation, each sample was individually heat shocked for 15 minutes in a $45^{\circ} \mathrm{C}$ water bath. Then, the urediniospores were rehydrated in a chamber at $80 \%$ relative humidity for a minimum of 3 hours. Rehydrated spores were suspended in a light mineral oil (Soltrol 170, Chevron Phillips Chemical Company LP, The Woodlands, TX) at a concentration of $10 \cdot \mathrm{mg} \cdot \mathrm{ml}^{-1}$. Suspended urediniospores were aerosolized using a custom spore inoculator (GRA-301, Tallgrass Solutions, Manhattan, KS) pressured by a pump (DOA-P704-AA, GAST, Benton Harbor, MI) set to $34.5 \mathrm{kPa}$. Fully emerged primary leaves of cultivar Moore seedlings were inoculated at a rate of approximately $24 \mu \mathrm{g}$ per plant. Urediniospores of individual isolates were collected on separate days 12-14 days post inoculation using a large cyclone spore collector (GRA-101; Tallgrass Solutions) attached to a shop vacuum (WS0250VA; Workshop Wet/Dry Vacs, Saint Louis, MI). Urediniospores were desiccated over silica crystals for 3-7 days and then placed inside size "00" gelatin capsules (Fagron, Saint Paul, MN). These capsules were then placed inside of cryovials (T311-2; Simport, Beloeil QC, Canada) for long term storage at $-80^{\circ} \mathrm{C}$.

For the phenotyping experiments, the fully expanded primary leaves (8-9 days old) of accessions were inoculated with the same inoculum concentration as detailed above. To reduce the risk of phytotoxicity, the Soltrol 170 oil carrier was volatilized from the leaf surfaces by 2 hours of gentle fanning from an oscillating fan under 400-watt HPS lamps. For the infection period, inoculated seedlings were placed in mist chambers at $22^{\circ} \mathrm{C}$ and $\sim 100 \%$ relative humidity in the dark. The mist was generated by household ultrasonic humidifiers (V5100NS; Vicks, Cincinnati, $\mathrm{OH}$ ) run for ten minutes at the outset and thereafter for two continuous minutes at 15-minute intervals. After the infection period, plants were allowed to dry off slowly before being incubated in a GH with a day/night temperature of 
$20 / 15^{\circ} \mathrm{C}$ and 16 -hour photoperiod supplemented by 1000 -watt HPS bulbs emitting $350-400 \mu \mathrm{mol} \cdot \mathrm{m}^{-2} \cdot \mathrm{s}^{-1}$. Once returned to the $\mathrm{GH}$, each full cone-rack $(\mathrm{N}=98)$ was fertilized with $10 \cdot \mathrm{g} \cdot \mathrm{L}^{-1}$ of a water-soluble fertilizer (20-10-20; N-P-K; J.R. Peter's, Inc.; Allentown, PA). Then, the cones were spaced out at half density to allow for full light penetration on the leaves.

Leaf rust infection types (ITs) were assessed on the barley germplasm at 10 and 12 days post inoculation (dpi). ITs were scored using the original 0-4 rating scale developed by Mains (1930) with the additional notations of "+" and "." to indicate larger or smaller size variations of classically described uredinia (Levine and Cherewick, 1952) and "c" and " $\mathrm{n}$ " to indicate the presence of chlorotic or necrotic reactions (Moseman and Roane, 1959), respectively. Complex ITs were recorded when more than one IT was observed on a single leaf. For example, an IT of 213- indicates that all three pustule types were present on the same leaf, and that the " 2 " type pustules were the most common, followed by the "1" type, with " 3 -" type pustules being the least common. ITs from " 0 " to "23-c" were considered resistant $(R)$, and ITs from "23-" to "4" were considered susceptible (S) (Steffenson et al. 1993). The presence of chlorosis in a "23-c" reaction indicates some level of incompatibility and is therefore not considered susceptible like the "23-" reaction lacking a chlorotic response. Among the ITs classified into the general category of $\mathrm{R}$, two phenotypic classes were either highly resistant (ITs "0" to "0;12") or moderate (M) reactions (ITs "12" to "23-c"). Figure 1 displays the range of infection types grouped within each of the three reaction classifications. 
Genotyping the Bowman Introgression Lines and Resistance Donors

As part of a large comprehensive study to genetically characterize the introgression of various morphological traits into Bowman barley, Druka et al. (2011) utilized the BOPA_1 and BOPA_2 SNP marker sets to genotype more than 800 Bowman introgression lines for 3,072 SNP loci. As part of this study, Druka et al. (2011) also SNP genotyped the 95 leaf rust introgression lines, but these data were not included in the publication. Full details on the SNP genotyping methods used are described in Druka et al. (2011). SNP sequences were obtained from The Triticeae Toolbox (https://triticeaetoolbox.org/barley/) and queried through the BARLey genome EXplorer (Barlex; https://apex.ipkgatersleben.de/apex/f? $p=284: 10$ ) in order to obtain updated POPulation SEQuencing (POPSEQ) positions (in CentiMorgans [CM]) according to Mascher et al. (2013). An unpublished consensus map combining eight barley linkage and consensus maps was designed as part of a meta-analysis study by Ahmad Sallam (personal communication) and used to update the cM positions for any SNP lacking information in Barlex. Estimated physical positions for the BOPA SNPs were obtained from an unpublished dataset provided by Shiaoman Chao (USDA-ARS, Fargo, ND).

In addition to the BOPA SNP genotyping, cooperators at the Julius-Küehn Institute (Quedlinburg, Germany), under the direction of Dragan Perovic, performed Genotyping-by-Sequencing (GBS) for Bowman, the 95 resistance donors, and the 95 introgression lines. DNA was extracted from seedlings at the two-leaf stage according to the methodology of Stein et al. (2001). Then, the genomic DNA was cleaved, repaired, and quantified according to Wendler et al. (2014). With 96-well plates, three separate genotyping runs were made on a MiSeq instrument (Illumina, Inc., San Diego, CA) using the Illumina Kit V3 and 150 total paired-end cycles. Starting libraries consisted of genomic fragments 
with an average length of 453 base pairs (bp) at an average concentration of 39.5 nanomolar $(\mathrm{nM})$. Working libraries were diluted to an average DNA concentration of $0.64 \mathrm{ng} \cdot \mathrm{\mu l}^{-1}$ according to Qubit quantification. The average library concentration used for the MiSeq runs was 8.7 picomols (pM), and the average 96 -well cluster density was $1201.7 \mathrm{~K} \cdot \mathrm{mm}^{2}$. Across the three MiSeq runs, $87.5 \%$ of the clusters passed quality filtration, representing a matrix of multisequence alignment across 3,952.7 megabases $(\mathrm{Mb})$ of the $5,100 \mathrm{Mb}$ genome. Trim Galore software from Babraham Bioinformatics was utilized to trim the first $13 \mathrm{bp}$ of the adaptor sequence from the amplified genomic sequences. SNP reads were aligned against the reference barley genome sequence "150831 barley pseudomolecules.fasta" (Mascher et al., 2017) using the BWA-MEM algorithm (Li and Durbin, 2009). Missing marker data was imputed using Beagle (Browning and Browning, 2016). SAMtools Mpileup software was used to call SNPs (Li, 2011). Execution of the GBS pipeline was done through the open online Galaxy platform (https://galaxyproject.org/). A total of 41,460 SNP markers were included in a vcf data format before performing quality assessment. Unmapped markers and those that were either monomorphic or had more than $20 \%$ heterozygosity among the parental lines were removed. In total, 19,593 SNP markers were retained and used in the final analyses. The GBS marker profiles for all of the lines were converted into a Microsoft Xcel spreadsheet in order to compare the genotypes between the donors and their respective introgression lines. Non-Bowman type markers within the introgression lines represent regions where donor sequences were retained. Graphical genotypes for the introgression lines selected to represent Rph1-15 are displayed in Figure 2 and were drawn using MapChart software (Voorrips 2002). 
Selection of Bowman Introgression Lines for the Leaf Rust Differential Set

Within a group of introgression lines presumed to carry the same Rph gene, only one was selected to represent that gene in the final barley leaf rust differential set. The selection of introgression lines to best represent the Rph1-15 alleles in a Bowman background was based on several criteria. The first criterion was based on parentage. Preference was placed on introgression lines derived from the most commonly used historical differentials. The second criterion was whether the introgression line exhibited the same or similar reaction pattern to its original donor parent in response to the $12 P$. hordei isolates. The third criterion was whether the introgression line retained donor chromatin at a position matching the previously described genomic location of the respective Rph gene, if known. The final criterion was based on size of the transferred chromosomal segment(s) in the introgression lines according to both the BOPA and GBS SNP datasets. Introgression lines with the greatest number of backcrosses and the smallest introgression(s) were given the priority in the final selection process.

\section{Results and Discussion}

\section{Disease Phenotyping}

The median ITs of the 24 Rph donors to the 12 isolates of $P$. hordei are presented in Table 4. These median ITs were based on three independent experimental replications and represent the central IT tendencies for each interaction. In each experiment, the $12 P$. hordei isolates produced clear differential reaction patterns for each $R p h$ gene, except for the reaction patterns between Rph5 versus Rph6, Rph9 versus Rph12, and Rph10 versus Rph11. Two of these three gene pairs are likely alleles of the same gene (Borovkova et al., 1998; Zhong et al., 2003), but Rph10 and Rph11 have always been 
considered unique genes and not alleles. Multiple different reaction patterns among the other Rph genes were observed in both the the donor parents and their respective introgression lines. Out of the 95 introgression lines, only a single line carries Rph1, Rph7, Rph8, Rph10, Rph11, Rph13, or Rph14. Three introgression lines carry Rph4, six introgression lines carry Rph2, Rph3, Rph5/6, or Rph9/12, and 50 introgression lines carry Rph15. The remaining 11 introgression lines potentially carry other genes for leaf rust resistance. Phenotypic comparisons among groups of introgression lines considered to carry the same genes are detailed in Appendix Table 5 (for Rph2, 3, 4, 5, and 9) and Appendix Table 6 (for Rph15 and Rph15+). The phenotypes for all of the parental lines (i.e. Bowman and the Rph donors) are detailed in Appendix Table 7. Additional IT data for the 24 leaf rust resistance sources from earlier seed increase generations and from an earlier investigation (Fetch et al. 1998) are given in Appendix Table 8.

The median ITs and general reactions (GRs) of Rph1-15 introgression lines selected for the differential set and their respective donor parents to the 12 $P$. hordei isolates are given in Table 5 . The GRs display whether the IT is classified as resistant $(R)$, moderate $(M)$, or susceptible $(S)$. The mode and range of ITs for the selected introgression lines are presented in Table 6. The mode displays the most commonly observed IT across the three experiments, while the range conveys an inference of the variation observed (i.e. lowest and highest ITs). No GR differences were observed between the donor lines and respective introgression lines for Rph1, Rph7, and Rph15 (Table 5). The introgression lines selected for Rph3, Rph5, Rph10, Rph11, Rph12, and Rph14 had higher ITs (i.e. more compatible GRs) than their respective donor parents for one to three of the isolates, and those selected for Rph2, Rph4, Rph6, Rph9, and Rph13 had higher ITs (i.e. more compatible GRs) than their respective donor parents for four or more of the isolates. In other cases, introgression lines selected for Rph5, Rph6, 
Rph8, Rph10, Rph11, and Rph14 had lower ITs (i.e. less compatible GRs) than their respective donor parents to one or a few isolates.

Genotyping Resistant Donor Sources and their Derived Introgression Lines

Initially, a total of 981 polymorphic BOPA SNP markers were used to analyze the genomes of Bowman and the 95 introgression lines (Druka et al., 2011). Increasing the marker density by 20 -fold, the GBS dataset comprised 19,593 polymorphic markers that were used to genotype not just Bowman and the 95 introgression lines, but also their respective Rph donor parents. In both SNP datasets, chromosomal regions containing blocks of "non-Bowman" type markers were considered introgressions from the Rph donor parents. Introgressions for Rph1-15 were detected with both the BOPA and GBS SNP datasets, the exceptions being with Rph4 and Rph14, which were only observed with the GBS dataset. For each Rph-associated introgression, the physical positions from the GBS dataset coincided with the physical distances of the SNP markers (data not shown). Graphical genotypes of the $15 R p h$ introgression lines selected for the leaf rust differential set were constructed from the GBS SNP dataset (Figure 2). Annotated defense genes on the same contigs as BOPA SNP markers within the Rph gene-containing donor chromatin of these selected 15 introgression lines are listed in Table 7. Every annotated gene found on the same contig as a BOPA SNP marker within Rph gene-containing introgressions are listed in Appendix Table 9. 
Phenotypic and Genotypic Characterization of Introgression Lines representing Rph1 to Rph15

Rph1.a

Rph1 was originally described in the experimental line Minn. II 21.15, which was derived from the cultivar Manchuria (Clho 2330). The gene was subsequently reported in the Portuguese cultivar Sudan and several other accessions (Watson and Butler, 1947; Roane and Starling, 1967). Based on trisomic analysis with another Rph1 donor source (Speciale, Clho 7536), Tuleen and McDaniel (1971) positioned the gene in chromosome $2 \mathrm{H}$. Sudan was the only source of Rph1 used in this study. Its derived introgression line, BW682, exhibited an identical general reaction pattern (Table 2). In BW682, BOPA SNP markers were detected between 2.2 and $7.4 \mathrm{cM}$ in chromosome 2HS, confirming the original chromosome assignment of Tuleen and McDaniel (1971). GBS SNP markers placed this $\sim 16.3$ megabase $(\mathrm{Mb})$ introgression from 6.8 to $23.1 \mathrm{Mb}$ in chromosome 2HS (Figure 2). No other introgressions were detected in this introgression line. BW682 was selected as the Rph1 source for the differential host set. Although it was the only introgression line carrying this gene, it has the desirable attributes of being phenotypically similar to its Rph1 donor source against $P$. hordei and carries just one small introgression.

Rph2.t

Many lines of different origin are presumed to carry Rph2 (Franckowiak et al., 1997). Although the current barley leaf rust differential set employs the South American landrace Peruvian to represent Rph2, the gene was originally described in the Australian line Weider and subsequently identified in the Australian cultivar Reka I, in combination with Rph19 (Watson and Butler, 1947; 
Roane and Starling, 1967; Park and Karakousis, 2002). In another study, crosses between the barley line Q21861 (PI 584766) and different sources of Rph2 (Peruvian, PI 531840, PI 531841, and Bolivia) indicated that this gene is linked with various markers in chromosome 5HS near the centromere (Borovkova et al., 1997). In this study, six different donors of Rph2 (Peruvian, Bolivia, Reka I, BS78-3-4, Juliaca, and MSI3351) were used to develop six introgression lines (BW737, BW742, BW743, BW744, BW739, and BW732, respectively) in Bowman. The general reactions to $P$. hordei among these six Rph2-introgression lines were mostly similar (Appendix Table 5). Only minor general reaction differences from highly resistant to moderate or from moderate to susceptible were detected to several $P$. hordei isolates. Line BW739, with the gene derived from Juliaca (PI 39151), was highly resistant to isolate AUS 220, while most of the other introgression lines carrying Rph2 were susceptible. This suggests that BW739 may carry an allele of Rph2 that is different from the other sources or that it possibly carries an additional resistance gene within its chromosome $1 \mathrm{HS}$ or $3 \mathrm{HL}$ introgressions. Considering the moderately sized $5 \mathrm{HS}$ introgressions and slight phenotypic differences observed among these six lines, it was not possible to determine whether or not they carry identical alleles at the Rph2 locus or perhaps other linked genes that together confer a similar reaction pattern. As discussed by Jin and Steffenson (1996), allelism tests should be made among these six Rph2-introgression lines to resolve this genetic question.

All of the six introgression lines that putatively carry Rph2 have a common donor segment $(>300 \mathrm{Mb})$ in chromosome $5 \mathrm{HS}$, thus corroborating the initial mapping position of the gene reported by Borovkova et al. (1997). Although other introgressions were detected in these six lines, they occurred in positions that were unique to each member of the group. The best representative among them is BW743. This introgression line exhibits a phenotype very similar to its donor parent, Reka I, was developed with six backcrosses, and also matches the 
reaction pattern of the other Rph2 donors. BOPA SNP markers detected three introgressions $(1 \mathrm{H}, 5 \mathrm{H}$, and $6 \mathrm{H})$ within $B W 743$, and the introgression carrying Rph2 was initially positioned from 60 to $121 \mathrm{cM}$ in chromosome 5HS. The GBS SNP markers confirmed that BW743 carries the smallest chromosome 5HS introgression (38.6 to $349.8 \mathrm{Mb}$; Figure 2) within the Rph2 group (Appendix Table 5). Despite having two other small introgressions in chromosomes $1 \mathrm{H}$ and $6 \mathrm{H}$, BW743 was the best candidate for the Rph2 source in the leaf rust differential set.

Rph3.c

Originally discovered in the Egyptian cultivar Aim (PI 57650), Rph3 is also present in Estate (PI 57700), a landrace also from Egypt (Henderson, 1945; Roane and Starling, 1967). These two accessions have been widely used as the sources for Rph3 in differential sets (Levine and Cherewick, 1952; Moseman and Greeley, 1965; Nover and Lehman, 1974; Khokhlova, 1982). Tan (1978) crossed Estate to the susceptible cultivar Moore and first hypothesized the location of Rph3 in either chromosome $7 \mathrm{H}$ or $2 \mathrm{H}$. Jin et al. (1993) confirmed the chromosome $7 \mathrm{HL}$ position of Rph3 in Estate through its linkage to the morphological marker Xnt1 (Xantha seedling 1). In this study, infection types between Estate and its derived introgression line, BW746, were nearly identical in response to the $12 P$. hordei isolates (Table 5). Definitive evidence for the chromosome $7 \mathrm{HL}$ position of $R p h 3$ was revealed through molecular marker data. In BW746, BOPA SNP markers were detected between 119.8 and $126.1 \mathrm{cM}$ in chromosome 7HL. GBS SNP markers placed this $\sim 8.5 \mathrm{Mb}$ introgression at 628.4 to $636.9 \mathrm{Mb}$ in $7 \mathrm{HL}$ (Figure 2). Five other alleles of Rph3 were hypothesized to exist in the introgression lines BW675, BW687, BW740, BW745, and BW747 derived from Gija/Tanekase, PI 531901-2, Q21861, PC249, and PI 466324, respectively (Appendix Table 5). BW746 was selected as the Rph3 source for 
the final differential set because it exhibits a phenotype to $P$. hordei that is very similar to its donor source, carries only a single introgression, was developed using more backcrosses than other Rph3-introgression lines, and was derived from the Rph3 donor that has been most widely used in the past.

In this study, both phenotype and genotype data strongly suggested that Rph3 was present in Q21861. The reaction patterns of Q21861 and BW740 were more similar to donor and introgression lines containing Rph3 than to those carrying Rph2. If Q21861 and BW740 did not carry Rph3, they would be susceptible to isolates Ger 7, 98-20, and 94-8 (Appendix Table 5). At the $\mathrm{BC}_{1}$ generation, there are at least 13 introgressions in BW740. There is an introgression in chromosome $7 \mathrm{HL}$ near the Rph3 locus and no introgression in chromosome $5 \mathrm{H}$ near the Rph2 locus. Previously, using bulked segregant analysis, Poulsen et al. (1995) revealed that Q21861 carries an allele of Rph2, but the presence of Rph3 was not detected. In the investigation of Borovkova et al. (1997), a P. hordei isolate avirulent for both Rph2 and Rph3 was used during their genetic investigation of Q21861 and Rph3 was not detected in their study either, adding further evidence that these two genes do not co-exist in this line. Hypothetically, if Q21861 carries both Rph2 and Rph3, then Rph2 could have been separated from Rph3 in the segregating populations studied by Borovkova et al. (1997), explaining why their observed resistance segregation fit a singlegene model. Either Q21861 carries multiple genes for leaf rust resistance and its copy of Rph2 was not captured in the introgression line BW740, or the source of Q21861 used in this or the previous studies was incorrect. 
Rph4.d

First described in the cultivar Gold (Clho 1145), Rph4 was also found to exist in Lechtaler (Clho 6488), Franger (PI 180669), and in this study, the cultivar Batna (Clho 3391), also reported to carry Rph2 (Roane and Starling, 1967 \& 1970; Jin and Steffenson, 1996). Previously, the resistance genes in Gold and Lechtaler were designated as the same allele (Rph4.d) at the Rph4 locus. Using trisomic analysis, Tan (1978) mapped Rph4 in chromosome $1 \mathrm{H}$. In this study, the three Rph4 sources of Gold, Lechtaler, and Batna were used to develop the introgression lines of BW752, BW753, and BW738, respectively. The general reactions between Gold and BW752 were more similar than those between Lechtaler and BW753 (Appendix Tables 5 and 7). Both BW752 and BW753 contained a BOPA SNP marker at the telomere of chromosome 1HS. GBS analysis detected overlapping introgressions (from 52 to 290 kilobases [Kb]) near the telomere of chromosome $1 \mathrm{HS}$ in both lines, confirming the original $1 \mathrm{HS}$ chromosomal assignment for Rph4 by Tan (1978). BW752 was selected as the Rph4 source for the final differential set because, despite having three other introgressions in addition to chromosome $1 \mathrm{HS}$, it has a phenotype very similar to its donor source (Figure 2). Moreover, this introgression line was derived from Gold, the Rph4 donor most widely used as a differential line in the past.

In two previous studies, Batna was reported to carry Rph2 based on its reaction to a suite of different $P$. hordei isolates (Chicaiza 1996; Jin and Steffenson 1996). In this study, phenotypic and genotypic analysis of Batna and its derived introgression line BW738 revealed the possible presence of Rph4. Batna and BW738 exhibited general reactions that were very similar to each other and also to the other Rph4-carrying donor and introgression lines (Gold, Lechtaler, BW752, and BW753) (Appendix Table 5). In contrast, some of their general reactions were distinct from the Rph2 donors and their derived 
introgression lines. GBS SNP markers revealed a single donor segment in BW738 that overlapped with the 1HS telomeric introgression of the Rph4carrying lines of BW752 and BW753. Again, if the seed source used in this study is correct, then based on these data, it appears that Batna and BW738 likely carry an allele of Rph4 and not Rph2 as previously hypothesized. Another new leaf rust resistance gene that is more broadly effective than Rph4 was discovered in chromosome $1 \mathrm{HS}$ near the Rph4 locus (Konig et al., 2012). This gene was derived from the Yugoslavian landrace MBR1012 and was given the temporary designation of RphMBR1012. This new gene segregated from Rph4 in an allelism test and will likely be designated as a new Rph gene (D. Perovic, M. Martin, and B. Steffenson, unpublished).

Rph5.e and Rph5.f (Rph6)

Rph5 was originally described as one of two Rph genes in the Australian landrace Quinn (PI 39401) and was bred into the Argentinian cultivar Magnif 102 (PI 337140) (Roane and Starling, 1967). In a trisomic study, Tan (1978) positioned Rph5 from Quinn in chromosome $3 \mathrm{H}$ and described its tight linkage with Rph7 from Cebada Capa. Roane and Starling (1970) first described Rph6 as one of two Rph genes (with Rph2) in the Bolivian landrace eponymously named Bolivia (PI 36360). Using progeny testing and $P$. hordei isolates with differential virulence patterns, Zhong et al. (2003) developed a line (Bolivia-Rph6) carrying only the putative Rph6 gene. Molecular mapping and bulked segregant analysis positioned the putative Rph6 gene in chromosome $3 \mathrm{H}$, near Rph5 and also Rph7 (Zhong et al., 2003), corroborating the previous results of Tan (1978). Allelism tests between Bolivia-Rph6 and Magnif 102 (Rph5) and Cebada Capa (Rph7) revealed that $R p h 6$ was allelic with $R p h 5$ and closely linked with $R p h 7$. Although isolates of $P$. hordei (e.g. Ger 11, Mex 930001, 99-26) are capable of differentiating reaction types between the original donor lines of Magnif 102 and 
Bolivia-Rph6 (Fetch et al., 1998), it is still unknown whether these two genes are really alleles of the same gene or are different tightly linked genes at the 3HS locus.

None of the $P$. hordei isolates used in this study were capable of differentiating Rph5 from Rph6 in either the donor or introgression lines. Both BW755 and BW756 had overlapping introgressions in chromosome 3HS. For Rph5 in BW755, only a single BOPA SNP marker from the donor was detected and that was near the $3 \mathrm{HS}$ telomere at $1 \mathrm{cM}$. GBS SNP markers revealed a single $2.6 \mathrm{Mb}$ introgression from $586 \mathrm{~Kb}$ to $7.2 \mathrm{Mb}$ in chromosome $3 \mathrm{HS}$ of BW755 (Figure 2). For Rph6 in BW756, BOPA SNP markers from the donor were detected between 0 and $8.4 \mathrm{cM}$, while GBS SNP markers placed this $\sim 10.4 \mathrm{Mb}$ introgression from 1.1 to $11.5 \mathrm{Mb}$ also in chromosome $3 \mathrm{HS}$ (Figure 2). A second $5.4 \mathrm{cM}$ introgression in chromosome $2 \mathrm{HS}$ of BW756 was detected by BOPA SNP markers, but not by GBS SNP markers. Since Rph5 and Rph6 are presumed to be allelic, we concur with the Rph6.f to Rph5.f epithet change as suggested by Franckowiak (1997) in the Barley Genetics Stock (BGS) 575 description. Based on both phenotypic and genotypic results, other alleles of $R p h 5$ were postulated in the introgression lines derived from PI 531990 (BW676) (Jin and Steffenson, 1994) and the three landraces from Tunisia (Yahyaoui 1986): namely Tunisia 17 (BW757), Tunisia 25 (BW748), and Tunisia 29 (BW750). BW755 and BW756 were selected as the introgression lines representing Rph5.e and Rph5.f for the final differential set because their phenotypes were very similar to their donor sources, they had fewer introgressions, and their respective donors (Magnif 102 and Bolivia-Rph6) were most widely used in the differential set in the past. 
Rph7.g

Rph7 was first described in the Argentinian cultivar Cebada Capa and subsequently in Forrajera Klein and other cultivars (Frecha, 1970, Nover and Lehman, 1974). This gene was first positioned in chromosome 3HS by Tan (1978) through trisomic analysis and later corroborated with molecular mapping by Brunner et al. (2000) and Graner et al. (2000). In this study, the general reaction patterns of Cebada Capa and BW758 were identical. Genotype analysis of BW758 identified BOPA SNP markers from the donor between $0 \mathrm{cM}$ and 8.5 $\mathrm{cM}$ in the telomeric region of chromosome 3HS, while GBS SNP markers placed this $\sim 12.4 \mathrm{Mb}$ introgression between $438 \mathrm{~Kb}$ and $12.8 \mathrm{Mb}$ (Figure 2). This introgression overlaps with those found for Rph5.e and Rph5.f in BW755 and BW756, respectively, corroborating previously reported evidence of close linkage between the Rph5/6 and Rph7 loci (Johnson, 1968; Roane and Starling, 1970; Frecha, 1970; Parlevliet, 1975; and Tan; 1978). Since the telomeric introgression for $R p h 7$ is longer than that for $R p h 5 / 6$ (Zhong et al., 2003), the Rph7 locus likely exists proximal from the Rph5/6 locus between 7.2 and $12.8 \mathrm{Mb}$ in chromosome 3HS (Figure 2). Only a single introgression was detected in BW758, and no other introgression lines were hypothesized to carry Rph7. BW758 was selected as the $R p h 7$ source for the final differential set because it carries a single introgression and is the only source of this gene introgressed into Bowman. 
Rph8.h

In some earlier investigations, Egypt 4 was used as a universal susceptible in the differential set (Levine and Cherewick 1952; Roane and Starling 1967). Tan (1977a) first described Rph8 in Egypt 4 after observing its leaf rust resistance during a seedling screening experiment. It is the only reported source of Rph8 and was used to develop the introgression line BW759 in this study. No studies have been done to assign Rph8 to a chromosome. The general reactions of BW759 were similar to Egypt 4 in most cases; however, BW759 exhibited moderate reactions to a few $P$. hordei isolates (ARG231, 98-20, and 94-8) for which Egypt 4 was susceptible. This result was likely due to transferring Rph8 into the Bowman genetic background. Genotypic analysis of BW759 detected BOPA SNP markers from the donor between 24.7 and $38.2 \mathrm{cM}$ in chromosome 2HS. Additionally, GBS SNP markers placed this $25.8 \mathrm{Mb}$ introgression between 32.7 and $58.5 \mathrm{Mb}$ in the same chromosome (Figure 2). BW759 was selected as the source of Rph8 for the differential set because no other introgressions exist in BW759, and no other introgression lines were postulated to carry this gene.

Rph9.i and Rph9.z (Rph12)

Based on their broad resistance to a panel of $P$. hordei isolates virulent for Rph1-8, the Ethiopian landrace Hor 2596 and German cultivar Trumpf were both thought to carry a new resistance gene (Clifford and Udeogalanya 1976). Tan (1977a) named the gene Rph9 after observing segregation in $F_{2}$ populations made between landraces considered to carry Rph9 and the donors of Rph1-8. The leaf rust resistance gene carried by Trumpf was investigated after it was rendered susceptible in the field by a virulence shift in the leaf rust pathogen. Walther (1987) noted Hor 2596 may be in the pedigree for Trumpf; however, data 
from an allelism test did not unequivocally demonstrate that both lines share the same gene. In a later study, the gene in Trumpf was designated as Rph12 after Jin et al. (1993) observed not only different reaction types between Hor 2596 and Trumpf to races of $P$. hordei, but also segregation in an allelism test between the two accessions. They also reported the first chromosomal assignment of this gene after linkage between Rph12 and the semi-smooth awn ( $r$ locus) in chromosome 5HL was observed. Borovkova et al. (1998) evaluated a much larger population (3,800 $\mathrm{F}_{2}$ progeny) between Hor 2596 and Trumpf and found no susceptible segregants. Based on this result, they concluded that the gene in Trumpf is an allele of Rph9, and designated it as Rph9.z. Another allele at this locus was recently described in the Australian cultivar Cantala and mapped to 5HL (Dracatos et al., 2014). Introgression lines BW760 and BW761 were developed from the donor sources of Hor 2596 and Trumpf, respectively. The general reactions between Hor 2596 and Triumph were nearly identical with only isolate Neth 28 differentiating the two (Table 5). This result, plus the definitive allelism test conducted by Borovkova et al. (1998), supports the contention that the originally assigned genes of $R p h 9$ and $R p h 12$ are indeed different alleles at the same locus. The chromosome 5H location for Rph9.z (and therefore Rph9.i by lieu of linkage), originally postulated by Jin et al. (1993), was confirmed by genotyping in this study as both BW760 and BW761 had overlapping introgressions (from 605 to $614 \mathrm{Mb}$ ) in chromosome 5HL. In BW760, BOPA SNP markers from the donors were detected between 114 to $135.1 \mathrm{cM}$ and in BW761, between 119 to $155.8 \mathrm{cM}$. GBS SNP markers revealed $\sim 36.4$ and $\sim 77.7 \mathrm{Mb}$ introgressions from 578.3 to $614.7 \mathrm{Mb}$ and from 577.5 to $655.3 \mathrm{Mb}$ in BW760 and BW761, respectively (Figure 2). No other introgressions were detected in either of these introgression lines. Since the current genetic evidence indicates that $R p h 9$ and Rph12 are alleles, we concur with the recommended allele designation of Rph9.i for the gene in Hor 2596 and Rph9.z for the gene in Trumpf as suggested by Franckowiak (1997) in the BGS 333 description. Although four 
other introgression lines were hypothesized to carry the same gene, BW760 and BW761 were selected as the sources for Rph9.i and Rph9.z because they were derived from the original differential sources of these genes, developed with more generations of backcrossing, and their general reactions were the most similar to their donor parents (Appendix Table 5).

Rph10.o and Rph11.p

Rph10 and Rph11 were originally derived from two wild barley (Hordeum vulgare subsp. spontaneum) accessions, Bar Giyyora 30 and Maalot 17, respectively (Feuerstein et al., 1990). Backcross selections made from crosses between the Australian cultivar Clipper and Bar Giyyora 30 (Clipper BC8) and Maalot 17 (Clipper BC67) became the donor sources of Rph10 and Rph11, respectively, in the barley leaf rust differential set. Currently, these selections are the only known sources for these genes. Rph10 and Rph11 were positioned in $3 \mathrm{HL}$ and $6 \mathrm{HL}$, respectively, using isozyme markers (Feuerstein et al., 1990). Bowman introgression line BW683 was derived from Clipper BC8, whereas BW684 was derived from Clipper BC67. Although reported as being broadly resistant to leaf rust in Australia, neither Clipper BC8 nor Clipper BC67 exhibited highly resistant reactions to the panel of $12 P$. hordei isolates used in this study. Both the donor lines and their respective introgression lines produced a similar pattern of general reactions to the leaf rust pathogen, with moderate ITs predominating (Table 5). In BW683, BOPA SNP markers identified an introgression from 52.8 to $68.2 \mathrm{cM}$ in chromosome $3 \mathrm{HL}$, supporting the original chromosome assignment for Rph10 established by Feuerstein et al. (1990). GBS SNP markers placed this $\sim 79.7 \mathrm{Mb}$ introgression from 490.3 to $570 \mathrm{Mb}$ in $3 \mathrm{HL}$ (Figure 2). In BW684, one BOPA SNP marker from the donor was identified at $117.6 \mathrm{cM}$ in chromosome 6HL. The GBS SNP markers placed this $\sim 10.9 \mathrm{Mb}$ introgression from 561.9 to $572.8 \mathrm{Mb}$ in the same chromosome. No other 
introgressions were detected in BW684 (Figure 2). These data confirm the original chromosome 6HL assignment for Rph11 by Feuerstein et al. (1990).

In BW683, although the BOPA SNP marker data highlighted two additional introgressions in chromosome $3 \mathrm{HS}$ and $7 \mathrm{HL}$, the GBS SNP data indicated a third introgression of $\sim 5.9 \mathrm{Mb}$ within the same region as the $6 \mathrm{HL}$ introgression containing Rph11 in BW684. The $6 \mathrm{HL}$ introgression in BW683 is not entirely comprised of non-Bowman type alleles and is perhaps an example of a data quality issue with the detection of this introgression. In previous studies by Feuerstein et al. (1990) and Druka et al. (2011), it is possible that the 6HL introgression in BW683 was not detected due to a paucity of markers. Few scattered markers (mostly isozymes and morphological) were available in the study by Feuerstein et al. (1990). Although a larger number of BOPA SNP markers $(3,072)$ were available in the study by Druka et al. (2011), it is still possible that their distribution failed to detect the smaller $6 \mathrm{HL}$ introgression in BW683. The potential presence of overlapping $6 \mathrm{HL}$ introgressions in both BW683 and BW684 raises a question about whether Rph10 exists as a unique gene in chromosome $3 \mathrm{HL}$ or is an allele of the resistance gene at the Rph11 locus in chromosome 6HL. Rph10 and Rph11 exhibited very similar general reactions to $P$. hordei in this study, a common hallmark of resistance alleles (Table 5). Additional research should be done to resolve the mapping position of Rph10 and whether it could be allelic to Rph11, whose mapping position was well established. Without stronger evidence, Rph10 is still assumed to exist in $3 \mathrm{HL}$ and Rph11 in 6HL. BW683 and BW684 were selected as the Rph10 and Rph11 sources, respectively, for the final differential set because no other donor sources of these genes are known. 
Rph13.x

PI 531849 is an experimental barley line from the United Kingdom and was originally derived from a wild barley accession. It exhibited a high level of resistance to a panel of isolates virulent for Rph1-12 and segregated for a single resistance gene when crossed to Bowman (Jin and Steffenson, 1994). Subsequent allelism tests with the Rph1-12 donors produced two-gene and three-gene (i.e. the cross with Bolivia having both Rph2 and Rph6) segregation ratios, indicating that the leaf rust resistance gene in PI 531849 was unique. Jin et al. (1996) designated the gene as Rph13. BW685, the introgression line derived from $\mathrm{PI} 531849$, had a general reaction pattern similar to its donor, but showed a lower level of resistance to four of the P. hordei isolates (ARG231, Race 4, 94-8, and 90-3) tested in this study (Table 5). Jin et al. (1996) observed a deficiency of susceptible $F_{2}$ progeny in a cross between PI 531849 and Hor 2596 suggesting that this locus was possibly linked with the Rph9 locus in chromosome 5HL. However, BOPA SNP data for BW685 revealed only one introgression between 103.7 and $154.9 \mathrm{cM}$ in chromosome 3HL. The GBS SNP markers identified two introgressions in $3 \mathrm{HL}$, one of $\sim 30.6 \mathrm{Mb}$ from 640.3 to $670.9 \mathrm{Mb}$ and the second nearly $14 \mathrm{Mb}$ from 684.6 to $698.5 \mathrm{Mb}$ (Figure 2). BW685 was selected as the Rph13 source for the differential set because PI 531849 is the only known source of this gene, its general reaction pattern matched its donor parent, and no other introgressions were detected in BW685 by either BOPA or GBS SNP data. 
Rph14.ab

Rph14 was identified in the Egyptian line PI 584760, which was originally selected from PI 531901-1 (NDBLR01) (Jin et al., 1996). Crosses between PI 584760 and Bowman revealed a single incompletely dominant gene. Allelism tests between this line and the sources of Rph1-13 confirmed this gene as novel and hence it was designated Rph14. Using Diversity Arrays Technology (DArT) markers, Golegaonkar et al. (2009) mapped Rph14 to chromosome 2HS. The general reactions between PI 584760 and its introgression line BW686 were similar (Table 5). The $P$. hordei isolates Race 4, WGCC, and Neth 28 produced more compatible infections on BW686, while one isolate, ARG231, was more compatible on the parent (Table 5). In BW686, BOPA SNP markers revealed an introgression around $42 \mathrm{cM}$ in $2 \mathrm{HS}$, confirming the initial gene mapping results of Golegaonkar et al. (2009). GBS SNP markers placed this $11.6 \mathrm{Mb}$ introgression from 45.7 to $57.3 \mathrm{Mb}$ in chromosome 2HS (Figure 2). Two other introgressions were detected in BW686, one in chromosome $1 \mathrm{HL}$ and another in chromosome 6HL. BW686 was selected as the Rph14 source for the differential set because no other donor sources of this gene are known, its general reaction pattern was similar to its parent, and no other introgressions were detected.

Rph15.ad

Rph15 was identified in a wild barley accession (PI 355447) from Israel by Chicaiza (1996). It has a wider resistance spectrum than any of the Rph1-14 genes to diverse P. hordei isolates (Table 4). Crosses made between PI 355447 and morphological marker stocks suggested a possible chromosome $2 \mathrm{HL}$ position for the gene based on linkage to the six-rowed spike 1 (vrs1) locus and the ribbon grass (white streak 7, wst7) locus. Soon after Rph15 was described, Ivandic et al. (1998) identified another new leaf rust resistance gene (designated 
Rph16) in a different accession of wild barley. This gene was mapped in chromosome 2HS using restriction fragment length polymorphism (RFLP) markers. Weeraseena et al. (2004) conducted an allelism test between Rph15 and Rph16 and concluded that these genes were likely alleles at the same locus. They also mapped Rph15 to the same locus as Rph16 using amplified fragment length polymorphism (AFLP) markers. Kopahnke et al. (2004) investigated another widely effective leaf rust resistance gene from a different wild barley accession ( $H$. spontaneum 677). Based on a doubled haploid population genotyped with AFLP markers, they positioned this gene at or very near the Rph15/Rph16 locus.

In this study, 50 different wild barley accessions with a wide resistance spectrum similar to the Rph15 donor (PI 355447) were used to develop introgression lines in cultivar Bowman (Appendix Table 6). Subsequent phenotypic and genotypic analysis revealed that all of these introgression lines had broad spectrum resistance and carried an introgression at the same location. Of these 50 introgression lines, just five carry a single introgression at the Rph15/Rph16 locus. In BW719, BOPA SNP markers from the donor were detected between 39.7 and $44 \mathrm{cM}$ in chromosome 2HS, and GBS SNP markers placed this $\sim 12.4 \mathrm{Mb}$ introgression from 44.8 to $57.3 \mathrm{Mb}$ (Figure 2). BW719 was selected to represent Rph15 in the differential set because it was derived from the wild barley accession PI 355447, has a single introgression at the Rph15/Rph16 locus, and retained the least amount of donor chromatin.

The introgression for Rph15 overlaps with the introgressions for Rph14 and Rph8. The introgression for Rph8 begins more than $10 \mathrm{Mb}$ distal from the Rph14 and Rph15 introgressions and ends about $1.2 \mathrm{Mb}$ proximal from their ending positions. This indicates that Rph8 may lie in 2HS somewhere either in the distal region between 32.7 and $44.8 \mathrm{Mb}$ or in the proximal region between 
57.3 and $58.5 \mathrm{Mb}$. The introgression for Rph14 begins about $900 \mathrm{~Kb}$ proximal from the starting position for Rph15, and both of these introgressions end at the same position. This suggests that either Rph15 lies somewhere in the $900 \mathrm{~Kb}$ region between 44.8 and $45.7 \mathrm{Mb}$ or both of these genes are tightly linked within the $11.6 \mathrm{Mb}$ region from 45.7 to $57.3 \mathrm{Mb}$. Additionally, the chromosome $2 \mathrm{HS}$ introgression carrying Rph15 in three introgression lines (BW723, BW724, and BW725) was translocated into chromosome 4HS (Franckowiak, personal communication).

\section{Other Leaf Rust Resistance Genes}

BW731, BW677, BW741, and BW754 were all derived from leaf rust resistance donors not previously thought to carry Rph9 (PI 466247, PI 531853, and Quinn) and had introgressions spanning the same physical positions as the Rph9-carrying introgressions from BW760 and BW761. BW731, derived from wild barley accession PI 466247, exhibited enhanced levels of resistance to several $P$. hordei isolates compared to other introgression lines carrying $R p h 9$ alleles (Appendix Table 5). This result could be due to a single Rph9 allele providing a wider resistance spectrum or possibly an additional seedling resistance QTL in BW731. In comparison to other Rph9-carrying introgression lines, the 5HL Rph9-introgression in BW731 begins at a position more proximal, overlapping with the reported positions of two seedling QTLs (Rphq7 and Rphq17) at $\sim 155.6 \mathrm{cM}$ (Schnaithmann et al., 2014). Additionally, it also carries introgressions in chromosomes $3 \mathrm{H}$ and $7 \mathrm{H}$. The introgression in $3 \mathrm{HS}$ overlaps with the Rph5 locus, and the one in chromosome $7 \mathrm{H}$ coincides with two other previously reported seedling resistance QTL, Rphq1 and Rphq8 (Marcel et al. 2007, Schnaithmann et al. 2014). It is unlikely that BW731 carries an allele of $R p h 5$ based on the differential reactions it exhibits to specific $P$. hordei isolates. A more likely possibility is that the enhanced resistance is due to one or more 
seedling QTL present in the line. Derived from another wild barley accession (PI 531853), BW677 is a different introgression line that expressed enhanced resistance to some $P$. hordei isolates compared to other Rph9-carrying lines (Appendix Table 5). BW677 has an additional introgression in $2 \mathrm{HL}$ that coincides with the previously reported location of another seedling resistance QTL, Rphq11 (Marcel et al. 2007). The last two introgression lines with phenotypes similar to Rph9 lines were BW741 and BW754, both derived from Quinn and sharing identical general reactions with each other. Both BW741 and BW754 have an introgression in $5 \mathrm{HL}$ coinciding with the Rph9 locus and their general reaction patterns are most similar to other Rph9-carrying introgression lines. The donor parent Quinn is known to carry both Rph2 and Rph5, and was not previously postulated to carry an allele at the Rph9 locus. An allelism test between BW741 or BW754 and either Hor 2596 or Triumph is necessary in order to resolve the identity of the other Rph gene in Quinn.

Of the 50 introgression lines postulated to carry Rph15 from wild barley, three (BW697, BW691, and BW709) displayed enhanced levels of resistance to one or two of the P. hordei isolates (Appendix Table 6). BW697, derived from PI 391121 , showed a highly resistant reaction to isolate Neth 28 , unseen in other lines thought to solely carry Rph15. The BOPA and GBS SNP marker data revealed $\mathrm{a} \sim 13.1 \mathrm{Mb}$ introgression in chromosome $3 \mathrm{HS}$ that overlaps with both the $R p h 5 / 6$ and $R p h 7$ loci. Neither Rph5/6 nor Rph7 confers resistance to isolate Neth 28, indicating that either this line has an Rph15 translocation at this locus or a potentially new gene exists in this region with a resistance spectrum similar to Rph15 alleles. BW691, derived from PI 391045, was moderate in its reaction to isolate 90-3 and highly resistant to Neth 28 . It has introgressions in every chromosome except for chromosome $1 \mathrm{H}$, some of which co-locate to previously reported QTL for leaf rust resistance at the seedling stage. While the presence of any of these QTL has not been confirmed in BW691, it should be noted that 
introgressions coincident with seedling resistance QTL exist, such as one unnamed QTL in chromosome $3 \mathrm{HL}$ reported by Jafary (2006), Rphq10 in 4HS, Rphq20 in 4HL, Rphq4 in 5HS, and Rphq7 or Rphq16 in 5HL (Marcel et al., 2007; Marcel et al., 2008; Schnaithmann et al., 2014). BW709, derived from PI 405399, exhibited a moderate level of resistance to isolates 90-3 and Neth 28 (Appendix Table 6). While BOPA SNP markers revealed introgressions only in chromosomes $2 \mathrm{HS}$ and $4 \mathrm{HL}$, GBS SNP markers indicated that additional introgressions exist in chromosomes $1 \mathrm{HL}$ and $2 \mathrm{HL}$. In addition to likely carrying Rph15, BW709 could also contain the chromosome 2H QTL of Rphq6 and/or Rphq18 or the chromosome 4H QTL of Rphq5 and/or Rphq20 (Marcel et al., 2007; Schnaithmann et al., 2014).

Eleven introgression lines had a reaction pattern unlike that of Rph1-15. Some of these lines contain other major resistance genes beyond these 15 genes and others contain introgressions that coincide with several previously reported seedling leaf rust resistance QTL. Two members of this group, BW735 and BW736, were respectively derived from the Hordeum bulbosum introgression lines 81882 (Vada/H. bulbosum), which carries Rph17, and 38P18/9/4 (Emir/H. bulbosum), which carries Rph18. BW735 has an introgression in chromosome $2 \mathrm{H}$ that overlaps with the Rph17 region previously reported by Pickering (1997), but also several other introgressions as well. BW736 has an introgression in $2 \mathrm{H}$ that overlaps with the Rph18 region previously reported by Pickering (1999), but again carries several other introgressions. Both BW735 and BW736 exhibited reaction patterns very similar to their respective parents (Appendix Tables 5 and 7, respectively), indicating the successful transfer and expression of the respective resistance genes in a Bowman background. BW726, an $F_{3}$ inbred line derived from the wild barley accession, HS584, exhibited highly resistant reactions to all $12 P$. hordei isolates used in this study and carries a total of 16 distinct introgressions that span all arms of the seven chromosomes except $6 \mathrm{HL}$. 
Unless a new gene for resistance exists in one of the many introgressions of BW726, the only known Rph genes that could result in this phenotype would be a combination of Rph13 and Rph15. BW672, derived from another wild barley accession (PI 466373), has an introgression overlapping the position of Rph8 in chromosome $2 \mathrm{H}$, but its reaction pattern is different to some $P$. hordei isolates in comparison to the reactions for Rph8. $h$ in BW759 (Table 5). Other introgressions that may be affecting the reaction spectrum of BW672 overlap with the reported positions of the seedling resistance QTL, Rphq10 in chromosome 4HS and Rph11 in chromosome 6HL (Marcel et al., 2007).

The seven remaining introgression lines exhibited partially or fully incompatible reactions to a few of the $P$. hordei isolates, indicating that they carry at least one effective resistance gene. The three most resistant members of this group (BW727, BW728, and BW749) each have an introgression that overlaps with the reported region of Rphq21 in chromosome 1HS near the centromere (Marcel et al., 2008). While BW728 and BW749 carry only one introgression that possibly contains Rphq21, BW727 carries several other introgressions that overlap with the positions of other reported QTL for leaf rust resistance. This may explain why, out of these remaining seven introgression lines, BW727 is the least compatible with isolates of $P$. hordei. It is also possible that BW749 carries an allele of Rph19 in chromosome 7HL because it has a coincident introgression in this region and also a reaction pattern similar to this gene derived from the cultivar Prior.

The remaining four introgression lines were generally susceptible, but exhibited an incompatible reaction to at least one isolate of $P$. hordei (Appendix Table 5). Based on their introgression positions, each of these four lines may contain different combinations of $R p h$ genes and/or previously reported seedling resistance QTL. BW668 expressed a moderate reaction to four of the P. hordei 
isolates and may carry Rphq9 in chromosome 7H (Qi et al., 1998, Marcel et al., 2007). BW698 expressed a moderate reaction to three $P$. hordei isolates and may contain Rphq6 in chromosome $2 \mathrm{H}$, Rphq8 in chromosome $7 \mathrm{H}$, and/or Rphq19 in chromosome $4 \mathrm{H}$. BW701 only occasionally exhibited a moderate response against a few $P$. hordei isolates in just one of three experiments. Although it contains an introgression in chromosome $6 \mathrm{H}$ coincident with the purported location of $R p h q 3$, without a more consistent resistant reaction across replications, it is unlikely BW701 contains this QTL (Marcel et al., 2007, Schnaithmann et al., 2014). Finally, BW751 does not appear to carry any introgressions. It gave a moderate reaction in only one experiment against a single $P$. hordei isolate, which is likely due to environmental differences between the experimental replications.

\section{Rph Gene Deployment and Effectiveness}

Many Rph genes have been deployed in barley cultivars grown across diverse production regions of the world. Despite the long track record of failure, most of these deployed cultivars were bred with only a single leaf rust resistance gene. Except for Rph2 and Rph7, nearly all other Rph genes deployed in cultivars have failed to provide lasting resistance in any of the production regions where they have been grown. Rph1 was first released in the Minnesota cultivar Manchuria in 1918 and was found to be susceptible to an isolate in 1925 (Mains, 1930). Unlike Rph1, Rph2 was first deployed in the South American landrace Peruvian in the early $20^{\text {th }}$ century and did not succumb to a virulent $P$. hordei race until 1960 in Argentina (D'Oliveira, 1961). Henderson (1945) first described Rph3 in the Egyptian line Aim, but the donor source more widely used in breeding is the Egyptian landrace Estate. Rph3 has been deployed in Europe, Oceania, and North America. In the Czech Republic, the cultivar Karat with Rph3 was released in 1981 and by 1988 a virulent race had rendered this gene 
completely ineffective (Dreiseitl and Steffenson, 2000). Before the release of Rph3-containing barley varieties, fifty years of virulence surveys did not detect virulence for Rph3 in the nation's $P$. hordei population. Several Australian barley varieties (Fitzroy, Yarra, Starmalt, and others) with Rph3 were released in the early 2000's and the resistance conferred by this gene was rendered ineffective as early as 2008 (Park, 2013). In the southeastern United States, Rph3 was deployed in the cultivar Doyce in 2003 and was rendered susceptible by mutations in the pathogen in 2010 (Rouse et al., 2013). Virulence for Rph4 is very common around the world. Cultivars carrying Rph4 often possess other genes for leaf rust resistance in production regions where this virulence abounds, such as with the Australian cultivar Tallon, known to carry both Rph4 and Rph12 (Christopher et al., 2007). Rph5 and Rph6 have been deployed in Australia and the Americas. Rph5 is present in the Australian cultivar Quinn and was incorporated into the Argentinian cultivar Magnif 102. Rph6 is carried by the South American landrace Bolivia. Reports of these cultivars succumbing to virulent $P$. hordei isolates are not well documented, but virulence for both of these genes is common around the world (Rintelen, 1974; Khokhlova, 1982; Andres et al., 1983; Yahyaoui et al., 1988; Manisterski, 1989; Cotterill et al., 1995). One of the most durable leaf rust resistance genes used in agriculture is $R p h 7$, a gene widely used in the United States and derived from the cultivar Cebada Capa. Varieties carrying Rph7 were released in the Mid-Atlantic region of the United States starting in 1968 with the cultivar Hanover. A virulent isolate was not identified until 22 years later in 1990 (Steffenson et al., 1993). Rph8 has apparently never been deployed in a widely grown cultivar to our knowledge. Rph9 has been largely utilized in Australia and was first deployed in 1989. By 1991, a virulent isolate was collected on the cultivar Tallon in Tasmania and hypothesized to have been introduced to Australia from New Zealand (Cotterill et al., 1992b). Rph12 was incorporated into European and Australian cultivars and rendered ineffective by shifts in pathogen virulence within a very short time. In 
Germany, the cultivar Trumpf with Rph12 was released in 1973, and virulent pathotypes of $P$. hordei were observed as early as 1977. In Australia, cultivar Franklin with Rph12 was released in 1989 and rendered susceptible by Rph12virulent isolates in 1993 (Dreiseitl and Steffenson, 2000; Park, 2003). Rph10 and Rph11 were both backcrossed into the cultivar Clipper, but have not been deployed in agriculture. Neither Rph13, Rph14, nor Rph15 have been deployed in cultivars at this time.

In a study by Fetch et al. (1998), more than 350 isolates of $P$. hordei from around the world were examined on a differential set consisting of the original donors of genes Rph1-15. The frequencies of virulence to each of these genes were reported by region. On a global scale, Rph14 and Rph15 were the most widely effective genes being resistant to $98 \%$ and $>99 \%$ of the isolates, respectively. The next most widely effective genes were $R p h 3, R p h 7, R p h 9$, and Rph12, which were all resistant to $95 \%$ of the isolates. Rph2, Rph10, Rph11, and Rph13 were resistant against 30 to $50 \%$ of the evaluated isolates, while Rph5 and Rph6 were resistant to about $20 \%$ of the isolates. Rph1, Rph4, and Rph8 were the least effective genes, conferring resistance to $<10 \%$ of the isolates.

Strong regional differences for $P$. hordei virulence have been reported. In North America, no virulence has been detected for Rph12, Rph14, or Rph15 and less than $1 \%$ of the isolates were virulent on Rph3 and Rph7 (Fetch et al., 1998). In the last four years (2014-2017) of United States P. hordei surveys, virulence for genes Rph1-14 has been detected while Rph15 resistance has remained intact (M. Rouse, personal communication). The genes Rph7, Rph9, Rph12, Rph13, and Rph15 were all effective against a South American collection of the pathogen. However, an isolate with virulence for Rph9 and Rph12 was recently detected in Uruguay (Hickey et al., 2011). Rph15 was effective against all $P$. hordei isolates from Africa, while Rph3, Rph13, and Rph14 were effective against 
$89 \%$. Rph3 and Rph7 were reported to be effective against all isolates in Morocco, Tunisia, Egypt, and Ethiopia (Yahyaoui et al., 1988; Woldeab et al., 2006). In Israel, Jordan, and Syria, only Rph3 and Rph7 have remained effective against the pathogen, while a few reports have listed $R p h 7$ and $R p h 9$ virulence as very rare (Yahyaoui et al., 1988; Brodny and Rivadeneira, 1996). In Europe, no virulence has been detected for Rph15, while Rph14 virulence remains rare. $R p h 7$ has only been overcome by $8 \%$ of the European P. hordei isolates. It appears that Rph7 is still effective in the United Kingdom and Spain as no virulence for the gene has been reported. No recent reports of $P$. hordei virulence from Spain have been published since the work of Shtaya et al. (2006). The same is true for the United Kingdom since the elimination of barley leaf rust from the UK Cereal Pathogen Surveys (Jones, 2005; Shtaya et al., 2006). In Australia, only $R p h 7$ remains effective as a singly deployed resistance gene. No virulence has been detected for the non-deployed genes of Rph11, Rph14, or Rph15 in Australia (Park, 2003; Park et al., 2015).

According to Fetch et al. (1998), it is advisable to combine multiple major effect resistance genes with minor effect resistance genes in order to provide durable leaf rust resistance. In barley production regions today, the most effective genes for combining are Rph7, Rph9, and Rph12-15. In Africa, Rph5 and Rph6 may also be worth including because they have not previously been deployed in cultivars. Although virulence for these genes in North and East African P. hordei populations has been detected, those isolates with virulence are not the predominantly isolated pathotypes (Yahyaoui and Sharp, 1987; Woldeab et al., 2006). Aside from Rph1-15, Rph20 has shown broad effectiveness at the seedling and adult plant stage against the 12 isolates tested in this study. Other resistance genes such as Rph21, and Rph23-25 may also be useful for gene pyramiding. Until the large linkage blocks containing the $H$. bulbosum-derived genes of Rph17, Rph18, and Rph22 can be reduced to minimize linkage drag, 
these genes may be difficult to utilize in elite breeding programs. Towards this effort, Pickering et al. (2000) dissected the genomic region where Rph18 was introgressed into cultivated barley from $H$. bulbosum. Their work will help elucidate the causal gene for Rph18 and make available a better genetic resource for this gene. In addition to the major effect Rph genes, minor effect QTLs should also be targeted for gene stacking. Derived from the broadly resistant cultivar Vada, Rphq2 and Rphq11 both significantly reduce disease severity at the seedling stage, while Rphq3 and Rphq4 are both effective at the adult plant stage (Qi et al., 1998; Spaner et al., 1998; Marcel et al., 2007).

\section{Candidate Leaf Rust Resistance Genes}

Within the 15 introgression lines selected for the final barley leaf rust differential set, we explored whether annotated genes on the same contigs as the BOPA SNPs might be present by performing BLAST searches against the barley reference sequence of the cultivar Morex (Mascher et al., 2017). The entire list for the annotated gene constructs are compiled in Appendix Table 9. From this list, only genes implicated in disease resistance functions were collated into Table 7. In total, 41 genes with some putative disease resistance function were found on the same contigs as BOPA SNP markers from within these Rph-gene containing introgressions. Six of these genes have leucine rich repeat receptorlike kinase domains that are most commonly associated with disease resistance against biotrophic pathogens (Ellis et al., 2014). These were found in the introgressions for Rph2.t, Rph9.i, Rph10.o, Rph9.z, and Rph13.x. Several other genes implicated in disease resistance were also identified. Peroxidases within a plant's apoplast are involved in signaling the presence of pathogens by creating bursts of reactive oxygen species (Chen et al., 2010). Ubiquitinases catalyze the attachment of ubiquitin that signals potentially invasive proteins for degradation (Zhou et al., 2017). Cysteine proteases have recently been found to signal 
downstream defense responses such as hypersensitive cell death (Misas-Villamil et al., 2017). Pectin lyases may be involved in transducing signals downstream of the initial recognition event (Cao, 2012). Finally, reticulon-like proteins are involved in trafficking and activating certain immune receptors (Lee et al., 2011). These types of genes, along with various kinds of transcription factors were found within the introgressions for Rph1.a, Rph2.t, Rph3.c, Rph7.g, Rph9.i, Rph10.o, Rph9.z, Rph13.x, and Rph15.ad (Table 7).

\section{Summary}

The development of introgression lines each possessing a single Rph gene in the genetic background of the susceptible cultivar Bowman is an ideal genetic resource for characterizing the virulence diversity of $P$. hordei. By developing these introgression lines through repeated backcrossing, the effect of individual Rph genes can be assessed without influence from other possible epistatic resistance or various agro-morphological traits. Moreover, since Bowman is an agronomically advanced and widely adapted cultivar, the differential set developed and characterized in this study can be grown in many different environments to assess the virulence of naturally occurring $P$. hordei isolates and also the effect of individual $R p h$ genes in conferring resistance. In this study, we characterized the resistance spectra and chromosomal positions of $95 \mathrm{Rph}$ introgression lines in a Bowman background using 12 global isolates of $P$. hordei and SNP genotyping. The results validated the successful transfer of genes Rph1-15 and provided important new data on their chromosomal positions based on the physical map of barley.

Fifteen introgression lines were selected to represent Rph1-15 in a proposed new barley leaf rust differential set. Eleven of these 15 lines carry a single introgression that agrees with previously described mapping positions for 
the respective Rph genes. The other four differential lines carried multiple introgressions, with one at the putative location of the gene. Highly similar phenotypes and overlapping introgressions were found between Rph5 and Rph6, Rph9 and Rph12, and Rph10 and Rph11; thus, it was not possible to determine whether these pairs represent different tightly linked genes or alleles of the same gene. In the future, an allelism test between BW683 and BW684 should be performed to determine whether Rph10 and Rph11 are unique genes or alleles of the same gene. Allelism tests have already been used to study the relationships of Rph5/Rph6 and Rph9/Rph12, and these two pairs of genes appear to be alleles of each other. In these cases, seed stocks for the respective introgression lines could be mutated to knockout the causal gene(s). Tight genetic linkage was observed among Rph5, Rph6, and Rph7 in chromosome $3 \mathrm{H}$ and also among Rph8, Rph14, and Rph15 in chromosome 2H. For introgressions of different genes that overlap in the same chromosome segment, identifying the physical positions of the causal genes would clarify their exact physical positions.

Eleven of the 95 introgression lines exhibited reaction patterns distinct from those exhibited by Rph1-15. Many of these lines contained introgressions that coincided with several previously reported seedling leaf rust resistance QTL. Whether or not QTLs exist in any of these lines was not confirmed. One highly resistant backcross line (BW697) may contain either an Rph15 translocation, a novel allele at the Rph5 or Rph7 locus, or a closely linked gene that has not yet been described. Allelism tests should be performed between lines containing Rph5, Rph6, Rph7, and BW697.

Currently, the major effect leaf rust resistance genes of Rph3, Rph7, Rph9, Rph12, Rph14 and Rph15 are the most broadly effective in barley. The respective introgression lines for these genes, BW746, BW758, BW760, BW761, BW686, and BW719, could be the preferred resource for the stacking or cloning 
of these resistance genes. For the 15 introgression lines selected for the final leaf rust differential set, annotated gene constructs within their Rph gene-containing introgressions were recorded. Many genes with disease resistance functions were found and six genes with leucine rich repeat receptor-like kinase descriptions may represent the candidate genes for Rph2.t, Rph9.i, Rph9.z, and Rph13.x. A mutant gene knockout approach could be applied to seed stocks of these introgression lines to determine which particular candidate gene(s) may be responsible for the disease resistance effect. 
Table 1. Accession details for Bowman and the 15 selected parental donors of leaf rust resistance.

\begin{tabular}{|c|c|c|c|c|c|}
\hline Accession Name & Accession Number ${ }^{1}$ & Origin & Improvement Status ${ }^{2}$ & Gene(s) & Allele(s) $)^{3}$ \\
\hline Bowman & PI 483237 & North Dakota, USA & Cultivar & NA & NA \\
\hline Sudan & Clho 6489 & Lisbon, Portugal & Unknown & Rph1 & Rph1.a \\
\hline Reka I & Clho 5051 & New South Wales, Australia & Cultivar & Rph2+19 & Rph2.t+19.ah \\
\hline Estate & PI 57700 & Sharqiya, Egypt & Landrace & Rph3 & Rph3.c \\
\hline Gold & Clho 1145 & Malmöhus, Sweden & Cultivar & Rph4 & Rph4.d \\
\hline Magnif 102 & PI 337140 & Buenos Aires, Argentina & Cultivar & Rph5 & Rph5.e \\
\hline Bolivia & PI 36360 & Oruro, Bolivia & Landrace & Rph6 & Rph2.r+Rph5.f \\
\hline Cebada Capa & PI 539113 & Argentina & Cultivar & Rph7 & Rph7.g \\
\hline Egypt 4 & Clho 6481 & Germany & Unknown & Rph8 & Rph8.h \\
\hline Hor2596 & Clho 1243 & Ethiopia & Landrace & Rph9 & Rph9.i \\
\hline Clipper BC8 & GSHO 1588 & Australia & H.v.s. backcross line & Rph10 & Rph10.o \\
\hline Clipper BC67 & GSHO 1589 & Australia & H.v.s. backcross line & Rph11 & Rph11.p \\
\hline Triumph & PI 290195 & German & Cultivar & Rph12 & Rph9.z \\
\hline BS 99-2-1 & PI 531849 & England & Breeding line & Rph13 & Rph13.x \\
\hline NDBLR01 & PI 584760 & Egypt & Unknown & Rph14 & Rph14.ab \\
\hline 703 & PI 355447 & Israel & H.v.s. accession & Rph15 & Rph15.ad \\
\hline
\end{tabular}

1. Accession numbers are a combination of an abbreviation and a numerical identifier. PI stands for Plant Introduction, Clho stands for Cereal Investigation in Hordeum, and GSHO stands for Genetic Stock of Hordeum.

2. Improvement status indicates the level of domestication for each of the differential lines. Hordeum vulgare subsp. spontaneum and Hordeum bulbosum are respectively abbreviated as H.v.s. and H.b.

3. Rph allele symbols were assigned according to Franckowiak et al. (1997). 
Table 2. Pedigree details for the Rph1-15 introgression lines selected for the barley leaf rust differential set.

\begin{tabular}{clccl} 
BW Line $^{1}$ & Donor Parent & Generation & Rph Allele & Pedigree $^{3}$ \\
\hline BW682 & Sudan & $\mathrm{BC}_{5} \mathrm{~F}_{3}$ & Rph1.a & Bowman*6/Sudan \\
\hline BW743 & Reka I & $\mathrm{BC}_{7} \mathrm{~F}_{3}$ & Rph2.t & Bowman*8/Reka I \\
\hline BW746 & Estate & $\mathrm{BC}_{10} \mathrm{~F}_{3}$ & Rph3.c & Bowman*11//Estate/3.2 uz als MM \\
\hline BW752 & Gold & $\mathrm{BC}_{5} \mathrm{~F}_{3}$ & Rph4.d & Gold/6*Bowman \\
\hline BW755 & Magnif 102 & $\mathrm{BC}_{7} \mathrm{~F}_{3}$ & Rph5.e & Magnif 102/8*Bowman \\
\hline BW756 & Bolivia & $\mathrm{BC}_{7} \mathrm{~F}_{3}$ & Rph5.f & Bowman*8/Bolivia \\
\hline BW758 & Cebada Capa & $\mathrm{BC}_{7} \mathrm{~F}_{3}$ & Rph7.g & Bowman*8/4/ND7771//Cebada Capa/MT81195 \\
\hline BW759 & Egypt 4 & $\mathrm{BC}_{5} \mathrm{~F}_{3}$ & Rph8.h & Bowman*6/Egypt 4 \\
\hline BW760 & Hor2596 & $\mathrm{BC}_{7} \mathrm{~F}_{3}$ & Rph9.i & Bowman*8/Hor 2596 \\
\hline BW683 & Clipper BC8 & $\mathrm{BC}_{5} \mathrm{~F}_{3}$ & Rph10.o & Clipper BC8/6*Bowman \\
\hline BW684 & Clipper BC67 & $\mathrm{BC}_{5} \mathrm{~F}_{3}$ & Rph11.p & Bowman*6/Clipper BC67 \\
\hline BW761 & Triumph & $\mathrm{BC}_{8} \mathrm{~F}_{3}$ & Rph9.z & Bowman*9/Triumph \\
\hline BW685 & PI 531841 & $\mathrm{BC}_{6} \mathrm{~F}_{3}$ & Rph13.x & Bowman*7/PI 531849 \\
\hline BW686 & PI 584760 & $\mathrm{BC}_{4} \mathrm{~F}_{3}$ & Rph14.ab & Bowman*5/PI 584760 \\
\hline BW719 & PI 355447 & $\mathrm{BC}_{7} \mathrm{~F}_{3}$ & Rph15.ad & Pl 355447/8*Bowman
\end{tabular}

1. Bowman leaf rust resistance introgression lines are abbreviated as "BW" followed by a number.

2. Rph allele symbols were assigned according to Franckowiak et al. (1997).

3. The pedigree used to develop each Bowman introgression line. 
Table 3. Race nomenclature ${ }^{1}$ of Puccinia hordei isolates ${ }^{2}$ used to select for leaf rust resistance genes Rph1-15 in Bowman introgression lines.

\begin{tabular}{ccccc} 
Isolate & Octal Notation & Race Code & Avr/Vir & Rph Vir \\
\hline BR (Octal 11) & 00011 & MBBC & $1,2,3,4,5,6,7,8,9,10,11,12,13,14,15,16,17,18,19,20,21,22,23 / 24$ & 1 \\
\hline ARG231 & 00041 & LGBC & $1,2,3,4,5,6,7,9,10,11,12,13,14,15,16,17,18,19,20,21,23 / 8,22,24$ & 3 \\
\hline Aus220 & 00060 & BQBC & $1,2,3,4,7,8,9,10,11,12,13,14,15,16,17,18,20,21,22,23 / 5,6,19,24$ & 4 \\
\hline Race 4 & 21200 & BCGH & $1,2,3,5,6,7,8,9,11,12,13,14,15,16,17,18,19,20,21,22 / 4,10,23,24$ & 4 \\
\hline Ger 7 & 00012 & HBBC & $1,2,3,4,5,6,7,9,11,12,13,15,16,17,18,19,20,21,22,23 / 8,10,14,24$ & 4 \\
\hline WGCC & 00060 & BQBC & $1,2,3,4,7,8,9,10,11,12,13,14,15,16,17,18,20,21,23 / 5,6,19,22,24$ \\
\hline $98-20$ & 11113 & RDGM & $3,5,6,9,10,11,12,14,15,17,18,19,20,21,22 / 1,2,4,7,8,13,16,23,24$ \\
\hline $94-8$ & 14413 & RBMM & $2,3,5,6,7,10,11,13,14,15,17,18,20,21 / 1,4,8,9,12,16,19,22,23,24$ \\
\hline BRS 76-12 & 00275 & PRBC & $2,5,6,7,9,11,12,13,14,15,17,18,20,21 / 1,3,4,8,10,16,19,22,23,24$ \\
\hline $90-3$ & 67673 & RRTK & $3,4,9,13,14,15,17,18,20 / 1,2,5,6,7,8,10,11,12,16,19,21,22,23,24$ & 15 \\
\hline Neth 28 & 24767 & STMH & $3,5,7,10,11,1,17,18 / 1,2,4,6,8,9,12,14,15,16,19,20,21,22,23,24$ & 16 \\
\hline $92-7$ & 24777 & TTMH & $11,13,14,15,17,18,20 / 1,2,3,4,5,6,7,8,9,10,12,16,19,21,22,23,24$ & 17 \\
\hline
\end{tabular}

1. Octal notation, North American rust code, and avirulence/virulence formulae race nomenclature systems were as described by Gilmour (1973; Limpert and Müller, 1994), Roelfs and Martens (1988), and Clifford (1985), respectively.

2. Isolate names were given according to the original epithet provided by the collector.

3. Rph Vir indicates the number of Rph genes for which an isolate has virulence. 
Table 4. Median infection types ${ }^{1}$ and general reactions ${ }^{2}$ of barley differential lines carrying leaf rust resistance genes Rph1-24 to 12 isolates of Puccinia hordei.

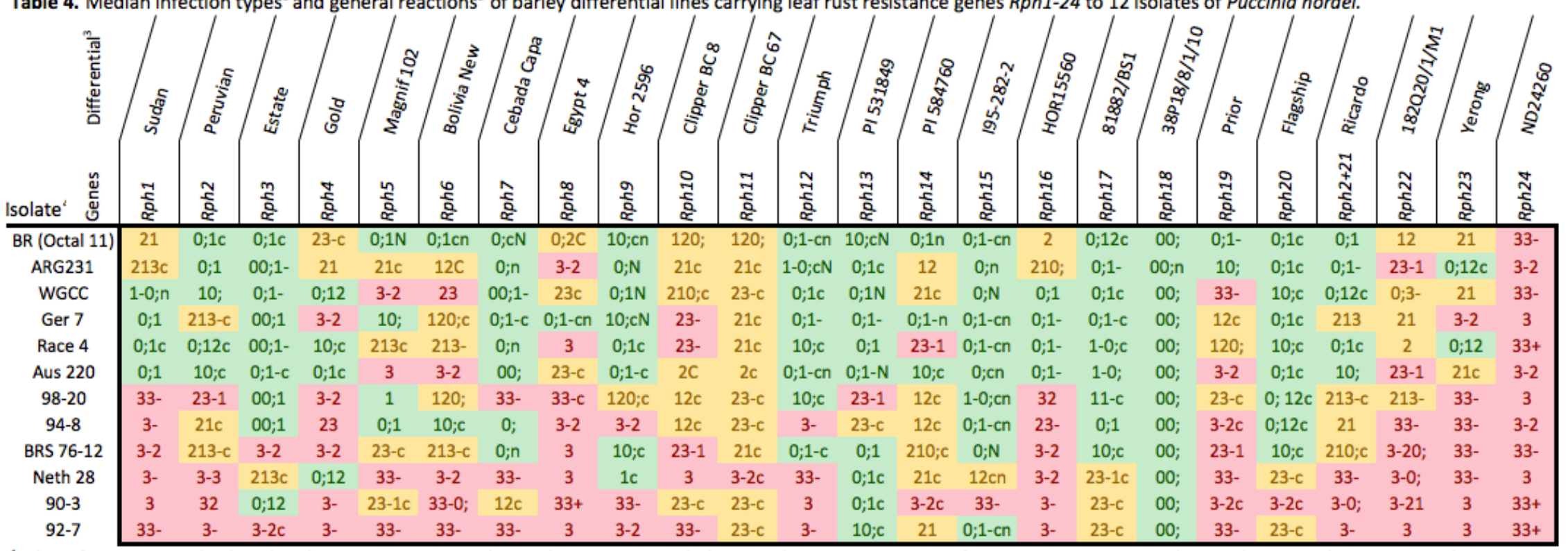

The infection types displayed in the matrix represent the median score recorded across three experiments. Infection types were scored using the original 0-4 rating scale

developed by Mains (1930) with the additional notations of " + " and "-" to indicate larger or smaller size variations of classically described uredinia (Levine and Cherewick, 1952) and " $\mathrm{c}$ " and " $\mathrm{n}$ " to indicate the presence of chlorotic or necrotic reactions (Moseman and Roane, 1959), respectively. Complex ITs were recorded when more than one IT was observed on a single leaf. For example, an IT of 213- indicates that all three pustule types exist on the same leaf and that the " 2 " type pustules were the most common, followed by the " 1 " type, with " $3-$ " type pustules being the least common.

'General reactions are different classes of infection types. Infection types from "0;" to "0;12" are classified as highly resistant ("R", green cells), infections types from "12" to "23-c" are classified as moderately resistant ("M", yellow cells), and infection types from "23-" to "33+" are classified as susceptible ("S", red cells) (Steffenson et al., 1993).

3. The differential lines representing Rph1-24 were selected from the most commonly used sources of these genes (Roane, 1962; Steffenson and Jin, 1992; Park et al., 2015; Ziems et al., 2017). Seed stocks of Rph1-15 were provided by Brian J. Steffenson; Robert Park provided stocks of Rph16-21, and Rph23; Rph22 was obtained from the Norgen genebank; and Rph24 was provided by Jerome D. Franckowiak.

4. Isolates used in this study were selected from a global collection of over 350 isolates of $P$. hordei (Fetch et al., 1998). Four of the isolates in this panel were also used to develop the Bowman leaf rust introgression lines (Chicaiza, 1996; Caffarel, 2005). The remaining isolates were chosen to balance redundancies for virulence and avirulence across Rph1-15. 
Table 5. Median infection types ${ }^{1}$ and general reactions ${ }^{2}$ of the resistant donor parents ${ }^{3}$ for Rphl-15 and their derived Bowman introgression lines ${ }^{4}$ selected for the barley leaf rust differential set.

\begin{tabular}{|c|c|c|c|c|c|c|c|c|c|c|c|c|c|c|c|c|c|c|c|c|c|c|c|c|}
\hline \multirow[b]{3}{*}{ Host line Allele } & \multicolumn{24}{|c|}{ P. hordei Isolates } \\
\hline & \multicolumn{2}{|c|}{ BR (Octal 11) } & \multicolumn{2}{|c|}{ ARG231 } & \multicolumn{2}{|c|}{ Aus 220} & \multicolumn{2}{|c|}{ Race 4} & \multicolumn{2}{|c|}{ Ger 7} & \multicolumn{2}{|c|}{ WGCC } & \multicolumn{2}{|c|}{$98-20$} & \multicolumn{2}{|c|}{$94-8$} & \multicolumn{2}{|c|}{ BRS 76-12 } & \multicolumn{2}{|c|}{$90-3$} & \multicolumn{2}{|c|}{ Neth 28} & \multicolumn{2}{|c|}{$92-7$} \\
\hline & IT & GR & IT & GR & IT & GR & IT & GR & IT & GR & IT & GR & IT & GR & IT & GR & IT & GR & IT & GR & IT & GR & IT & GR \\
\hline Sudan Rphl.a & $3-2 c$ & $\mathrm{~S}$ & $3-0$ & $\mathrm{~S}$ & $0 ; 1$ & $\mathrm{R}$ & $0 ; 1-$ & $\mathrm{R}$ & $0 ; 1-$ & $\mathrm{R}$ & $0 ; 12$ & $\mathrm{R}$ & 33- & $\mathrm{S}$ & 33- & $\mathrm{S}$ & 33- & $\mathrm{S}$ & 3 & $\mathrm{~S}$ & 33- & $\mathrm{S}$ & 3- & $\mathrm{S}$ \\
\hline BW682 Rphl.a & $3-2 \mathrm{c}$ & $\mathrm{s}$ & $3-0 ; \mathrm{c}$ & $\mathrm{S}$ & $0 ; 1-$ & $\mathrm{R}$ & $0 ; 1-$ & $\mathrm{R}$ & $0 ; 1-$ & $\mathrm{R}$ & $0 ; 12$ & $\mathrm{R}$ & 3 & $\mathrm{~S}$ & 33- & $\mathrm{S}$ & $33+$ & $\mathrm{s}$ & $33+$ & s & 3 & $\mathrm{~S}$ & 3 & $\mathrm{~S}$ \\
\hline Reka I Rph2.t+Rph19.ah & $0 ; \mathrm{n}$ & $\bar{R}$ & 120 & $\bar{M}$ & $0 ; 1-$ & $R$ & $0 ; 1$ & $R$ & $0 ; 1-$ & $\bar{R}$ & $0 ; 12$ & $\bar{R}$ & $3-2$ & $\bar{S}$ & $23-1$ & $\bar{S}$ & $3-2$ & $S$ & 33- & $\bar{S}$ & 33- & $\bar{S}$ & 3 & $\bar{S}$ \\
\hline BW743 Rph2.t & $120 ; \mathrm{c}$ & $M$ & 120 & $\mathrm{M}$ & $23-\mathrm{c}$ & $M$ & $213-\mathrm{c}$ & $M$ & $3-2$ & $S$ & 120 & $M$ & 3 & $\mathrm{~s}$ & $3-2$ & $\mathrm{~s}$ & $213-\mathrm{c}$ & $M$ & $33-$ & $\mathrm{S}$ & $3-$ & $\mathrm{S}$ & 3- & $\mathrm{S}$ \\
\hline Estate $R p h 3 . c$ & $0 ; 1-\mathrm{c}$ & $\bar{R}$ & $00 ; 1$ & $\mathrm{R}$ & $0 ; 1-\mathrm{c}$ & $\mathrm{R}$ & $00 ; 1=$ & $\bar{R}$ & $00 ; 2$ & $\mathrm{R}$ & $00 ; 2$ & $\bar{R}$ & $00 ; 1 \mathrm{c}$ & $\mathrm{R}$ & $00 ; 1$ & $\overline{\mathrm{R}}$ & $3-$ & $\mathrm{S}$ & $0 ; 12 \mathrm{c}$ & $R$ & $213-c$ & $\bar{M}$ & $3-2 \mathrm{c}$ & $\bar{S}$ \\
\hline BW746 Rph3.c & $0 ; 1 \mathrm{c}$ & $\mathrm{R}$ & $0 ; 1-\mathrm{c}$ & $\mathrm{R}$ & $0 ; 1-\mathrm{c}$ & $\mathrm{R}$ & $0 ; 1 \mathrm{c}$ & $\mathrm{R}$ & $00 ; 1$ & $\mathrm{R}$ & $0 ; 1 \mathrm{c}$ & $\mathrm{R}$ & $0 ; \mathrm{cn}$ & $\mathrm{R}$ & 0 & $\mathrm{R}$ & $3-2 \mathrm{c}$ & $\mathrm{s}$ & $21 \mathrm{c}$ & $M$ & $23-$ & $S$ & $3-$ & $\mathrm{S}$ \\
\hline Gold Rph4.d & $23-\mathrm{c}$ & $M$ & $23-\mathrm{c}$ & $\mathrm{M}$ & $0 ; 1$ & $R$ & 10 & $R$ & 3-2 & $\mathrm{S}$ & $0 ; 12$ & $R$ & $3-2$ & $\mathrm{~S}$ & $3-2 c$ & $\mathrm{~S}$ & $3-2$ & $\mathrm{~S}$ & 33- & $\mathrm{S}$ & $0 ; 12$ & $R$ & 33- & $\mathrm{S}$ \\
\hline BW752 Rph4.d & $3-2$ & $S$ & 21 & M & 120 & $M$ & $120 ; \mathrm{c}$ & $M$ & 3 & $\mathrm{~S}$ & $120 ; \mathrm{c}$ & $M$ & 3 & $\mathrm{~S}$ & $3-2$ & $\mathrm{~S}$ & $3-2$ & $\mathrm{~S}$ & 33- & S & $120 ; \mathrm{c}$ & $M$ & 3 & $\mathrm{~S}$ \\
\hline Magnif 102 Rph5.e & $0 ; 1-\mathrm{n}$ & $\mathrm{R}$ & $11-\mathrm{cN}$ & $\bar{R}$ & $3-2 \mathrm{c}$ & $\mathrm{S}$ & 213- & $\overline{\mathrm{M}}$ & $120 ; \mathrm{c}$ & $\mathrm{M}$ & $3-2$ & $\mathrm{~S}$ & 120 & $\bar{M}$ & $0 ; 1$ & $\bar{R}$ & $23-\mathrm{c}$ & $\bar{M}$ & $3-2 c$ & $\mathrm{~S}$ & $33-$ & $\mathrm{S}$ & 33- & $\mathrm{S}$ \\
\hline BW755 Rph5.e & $0 ; 1$ & $\mathrm{R}$ & $23-\mathrm{c}$ & $M$ & 3 & $\mathrm{~S}$ & $213-\mathrm{c}$ & $\mathrm{M}$ & $120 ; \mathrm{c}$ & $\mathrm{M}$ & 3 & S & $10 ; \mathrm{c}$ & $R$ & $10 ; \mathrm{c}$ & $\mathrm{R}$ & $3-2 \mathrm{c}$ & $S$ & 33- & S & 3- & S & 33- & S \\
\hline Bolivia $R p h 2 . r+R p h 5 . f$ & $0 ; 1-$ & $\mathrm{R}$ & $0 ; 1-\mathrm{n}$ & $R$ & $0 ; 1$ & $R$ & 0 & $R$ & $0 ; 1$ & $R$ & $0 ; 1$ & $R$ & $23-0$ & $S$ & $23-0$ & $S$ & 210 & $M$ & 3 & $\mathrm{~S}$ & 33- & $\mathrm{S}$ & 3 & $\mathrm{~S}$ \\
\hline BW756 Rph5.f & $0 ; 1$ & $\mathrm{R}$ & $3-2$ & $S$ & 3 & $S$ & $213-\mathrm{c}$ & $M$ & $21 \mathrm{c}$ & $M$ & 3 & $S$ & $120 ; \mathrm{c}$ & $M$ & $10 ; \mathrm{c}$ & $R$ & $3-2 \mathrm{c}$ & $S$ & 3-3 & $\mathrm{S}$ & 3- & $\mathrm{S}$ & 3- & S \\
\hline Cebada Capa Rph7.g & $00 ; \mathrm{n}$ & $\overline{\mathrm{R}}$ & $0 ; 1-\mathrm{cn}$ & $\overline{\mathrm{R}}$ & 00 & $\overline{\mathrm{R}}$ & $0 ; 1-\mathrm{c}$ & $\mathrm{R}$ & $0 ; 1-\mathrm{c}$ & $\mathrm{R}$ & 00 & $\overline{\mathrm{R}}$ & $3-20$ & $\mathrm{~S}$ & $0 ; 1-\mathrm{cn}$ & $\overline{\mathrm{R}}$ & $0 ; \mathrm{n}$ & $\overline{\mathrm{R}}$ & $213-c$ & $\bar{M}$ & $33-\mathrm{c}$ & $\bar{S}$ & 33- & $\bar{S}$ \\
\hline BW758 Rph7.g & $0 ; 1-\mathrm{cn}$ & $\mathrm{R}$ & $0 ; 1-\mathrm{cn}$ & $\mathrm{R}$ & $00 ; \mathrm{n}$ & $\mathrm{R}$ & $0 ; 1-\mathrm{cn}$ & $\mathrm{R}$ & $0 ; 1-\mathrm{c}$ & $\mathrm{R}$ & $0 ; \mathrm{n}$ & $\mathrm{R}$ & $3-2$ & $\mathrm{~S}$ & $0 ; 1-\mathrm{cn}$ & $\mathrm{R}$ & $0 ; 1-\mathrm{cn}$ & $\mathrm{R}$ & $21 \mathrm{c}$ & $\mathrm{M}$ & 33- & $\mathrm{S}$ & 33- & $\mathrm{S}$ \\
\hline Egypt 4 Rph $8 . h$ & $0 ; 1 \mathrm{n}$ & $\mathrm{R}$ & $3-2$ & $S$ & $23-\mathrm{c}$ & $\bar{M}$ & 3 & $\mathrm{~S}$ & $0 ; 1-\mathrm{c}$ & $\bar{R}$ & $23-\mathrm{c}$ & $\bar{M}$ & $3-\mathrm{c}$ & $S$ & $3-2 c$ & $S$ & $3-2$ & $\mathrm{~S}$ & 3 & $\mathrm{~S}$ & 33- & $\mathrm{S}$ & 3 & $\mathrm{~S}$ \\
\hline BW759 Rph8.h & $0 ; 1-\mathrm{cn}$ & $\mathrm{R}$ & $23-\mathrm{c}$ & $M$ & $21 \mathrm{c}$ & $\mathrm{M}$ & 3 & $\mathrm{~S}$ & $0 ; 1-\mathrm{c}$ & $\mathrm{R}$ & $23-\mathrm{c}$ & $\mathrm{M}$ & 213- & $M$ & $23-\mathrm{c}$ & $M$ & $3-2 \mathrm{c}$ & $\mathrm{s}$ & 3 & $\mathrm{~S}$ & 3- & $\mathrm{S}$ & 3- & $\mathrm{s}$ \\
\hline Hor 2596 Rph9.i & $0 ; 1 \mathrm{~N}$ & $\mathrm{R}$ & $0 ; \mathrm{n}$ & $R$ & $0 ; 1-\mathrm{cn}$ & $R$ & $0 ; 1-\mathrm{c}$ & $R$ & $1-0 ; \mathrm{cn}$ & $\mathrm{R}$ & $0 ; 1-\mathrm{c}$ & $R$ & $10 ; \mathrm{c}$ & $R$ & $3-2 \mathrm{c}$ & $\mathrm{S}$ & $10 ; \mathrm{c}$ & $R$ & 3 & $\mathrm{~S}$ & $120 ; \mathrm{c}$ & $M$ & 23- & $\mathrm{S}$ \\
\hline BW760 Rph9.i & $11-\mathrm{c}$ & $\mathrm{R}$ & $21 \mathrm{c}$ & $M$ & $213-\mathrm{c}$ & $M$ & 213- & $M$ & $0 ; 1 \mathrm{c}$ & $\mathrm{R}$ & $213-\mathrm{c}$ & $M$ & $23-\mathrm{c}$ & $M$ & $3-2$ & S & $12 \mathrm{c}$ & $M$ & 3 & $\mathrm{~S}$ & 3-2 & $S$ & 3 & $\mathrm{~S}$ \\
\hline Clipper BC8 Rph10.o & 120 & $\mathrm{M}$ & $12 \mathrm{c}$ & $\mathrm{M}$ & $10 ; \mathrm{c}$ & $R$ & $23-$ & $\mathrm{S}$ & $23-$ & $S$ & $12 \mathrm{c}$ & $\mathrm{M}$ & $120 ; \mathrm{c}$ & $\bar{M}$ & 10 & $R$ & $23-1 \mathrm{c}$ & $\bar{M}$ & $23-\mathrm{c}$ & $M$ & 3 & $S$ & 33- & $S$ \\
\hline BW683 Rph10.o & $21 \mathrm{c}$ & $\mathrm{M}$ & 12 & $\mathrm{M}$ & $12 \mathrm{c}$ & $M$ & $3-2 \mathrm{c}$ & $\mathrm{S}$ & $23-\mathrm{c}$ & $M$ & $21 \mathrm{c}$ & $\mathrm{M}$ & $3-2 \mathrm{c}$ & $S$ & $23-\mathrm{c}$ & $M$ & $23-\mathrm{c}$ & $\mathrm{M}$ & 33- & $S$ & $23-\mathrm{c}$ & $M$ & $23-\mathrm{c}$ & $M$ \\
\hline Clipper BC67 Rph11.p & 21 & $\mathrm{M}$ & $21 \mathrm{c}$ & $\mathrm{M}$ & $23-\mathrm{c}$ & $\mathrm{M}$ & $21 \mathrm{c}$ & $\mathrm{M}$ & $21 \mathrm{c}$ & $\mathrm{M}$ & $23-\mathrm{c}$ & $\mathrm{M}$ & $23-\mathrm{c}$ & $\mathrm{M}$ & $23-\mathrm{c}$ & $\mathrm{M}$ & $21 \mathrm{c}$ & $\mathrm{M}$ & $23-\mathrm{c}$ & $M$ & $3-2 \mathrm{c}$ & $S$ & $23-\mathrm{c}$ & $\mathrm{M}$ \\
\hline BW684 Rph11.p & $2 \mathrm{c}$ & $\mathrm{M}$ & $213-c$ & $\mathrm{M}$ & $21 \mathrm{c}$ & M & $213-\mathrm{c}$ & $\mathrm{M}$ & $23-\mathrm{c}$ & $\mathrm{M}$ & $21 \mathrm{c}$ & M & $23-\mathrm{c}$ & $\mathrm{M}$ & $23-\mathrm{c}$ & $\mathrm{M}$ & $23-1 \mathrm{c}$ & $\mathrm{M}$ & 33- & $S$ & $23-1 c$ & $M$ & $23-\mathrm{c}$ & M \\
\hline Triumph $R p h 9 . z$ & $0 ; 1-$ & $\bar{R}$ & $0 ; 1$ & $\bar{R}$ & $0 ; 1-\mathrm{c}$ & $R$ & $10 ; \mathrm{c}$ & $\bar{R}$ & $0 ; 1-\mathrm{c}$ & $\bar{R}$ & $0 ; 1-\mathrm{c}$ & $\mathrm{R}$ & $10 ; \mathrm{c}$ & $\mathrm{R}$ & 3- & $\mathrm{S}$ & $0 ; 1-\mathrm{c}$ & $\bar{R}$ & 3 & $\bar{S}$ & 3 & $\mathrm{~S}$ & 3 & $\mathrm{~S}$ \\
\hline BW761 Rph9.z & $0 ; 1$ & $\mathrm{R}$ & $0 ; 12 \mathrm{c}$ & $\mathrm{R}$ & 120 & $M$ & $0 ; 12 \mathrm{c}$ & $\mathrm{R}$ & $0 ; 1 \mathrm{c}$ & $\mathrm{R}$ & $10 ; \mathrm{c}$ & $\mathrm{R}$ & $10 ; \mathrm{c}$ & $\mathrm{R}$ & 3-3 & $\mathrm{S}$ & $10 ; \mathrm{c}$ & $\mathrm{R}$ & 3 & $\mathrm{~S}$ & $3-2$ & $\mathrm{~S}$ & 33- & $\mathrm{S}$ \\
\hline PI $531849 \operatorname{Rph} 13 . x$ & $0 ; 1-$ & $\mathrm{R}$ & $0 ; 1 \mathrm{c}$ & $R$ & $00 ; 1-$ & $\mathrm{R}$ & $0 ; 1$ & $R$ & $0 ; 1-$ & $\mathrm{R}$ & $0 ; 1-$ & $\mathrm{R}$ & $23-1$ & $\mathrm{~S}$ & $23-\mathrm{c}$ & $\bar{M}$ & $0 ; 1$ & $\mathrm{R}$ & $0 ; 1 \mathrm{c}$ & $R$ & $0 ; 1 \mathrm{c}$ & $\mathrm{R}$ & $0 ; 1$ & $\mathrm{R}$ \\
\hline BW685 Rph13.x & $0 ; 1$ & $\mathrm{R}$ & 210 & $M$ & $0 ; 1-\mathrm{c}$ & $\mathrm{R}$ & 21 & $M$ & $10 ; \mathrm{c}$ & $\mathrm{R}$ & $0 ; 1$ & $\mathrm{R}$ & $3-2$ & $\mathrm{~S}$ & $33-$ & $S$ & $10 ; \mathrm{c}$ & $\mathrm{R}$ & $12 \mathrm{c}$ & $M$ & $10 ; \mathrm{c}$ & $\mathrm{R}$ & 10 & $\mathrm{R}$ \\
\hline PI 531901-1 Rph14.ab & $0 ; 1 \mathrm{n}$ & $\mathrm{R}$ & $23-$ & $S$ & $21 \mathrm{c}$ & $\mathrm{M}$ & 213- & $M$ & $0 ; \mathrm{cn}$ & $\mathrm{R}$ & $10 ; \mathrm{c}$ & $R$ & $210 ; \mathrm{c}$ & $\bar{M}$ & $210 ; \mathrm{c}$ & $\bar{M}$ & $21 \mathrm{c}$ & $\bar{M}$ & 3- & $\mathrm{S}$ & $23-\mathrm{c}$ & $M$ & $3-2$ & $\mathrm{~S}$ \\
\hline BW686 Rph14.ab & $00 ; 1 \mathrm{c}$ & $\mathrm{R}$ & 21 & $M$ & $12 \mathrm{c}$ & $\mathrm{M}$ & 33- & $S$ & $0 ; 1-\mathrm{cn}$ & $\mathrm{R}$ & $21 \mathrm{c}$ & $M$ & $210 ; \mathrm{c}$ & $\mathrm{M}$ & $21 \mathrm{c}$ & $\mathrm{M}$ & $213-\mathrm{c}$ & $\mathrm{M}$ & 33- & $\mathrm{S}$ & $3-2$ & $S$ & $3-$ & S \\
\hline PI 355447 Rph15.ad & $0 ; 1-\mathrm{cn}$ & $\mathrm{R}$ & $0 ; 1-$ & $\mathrm{R}$ & $0 ; \mathrm{cn}$ & $\mathrm{R}$ & $0 ; 1-\mathrm{cn}$ & $\bar{R}$ & $0 ; \mathrm{cn}$ & $\mathrm{R}$ & $0 ; \mathrm{cn}$ & $\mathrm{R}$ & $0 ; 1-\mathrm{cn}$ & $\mathrm{R}$ & $0 ; 1-\mathrm{cn}$ & $\mathrm{R}$ & $0 ; \mathrm{cn}$ & $\mathrm{R}$ & 3- & $\mathrm{S}$ & $23-\mathrm{cn}$ & $\mathrm{M}$ & $0 ; 1 \mathrm{cn}$ & $\bar{R}$ \\
\hline BW719 Rphl5.ad & $0 ; 1-\mathrm{cn}$ & $\mathrm{R}$ & $0 ; \mathrm{cn}$ & $\mathrm{R}$ & $0 ; \mathrm{cn}$ & $\mathrm{R}$ & $1-0 ; \mathrm{cn}$ & $\mathrm{R}$ & $0 ; 1-\mathrm{cn}$ & $\mathrm{R}$ & $0 ; \mathrm{cn}$ & $\mathrm{R}$ & $10 ; \mathrm{cn}$ & $\mathrm{R}$ & $1-0 ; \mathrm{cn}$ & $\mathrm{R}$ & $0 ; \mathrm{cn}$ & $\mathrm{R}$ & 3-3 & $\mathrm{s}$ & $21 \mathrm{cn}$ & $\mathrm{M}$ & $0 ; 1-\mathrm{cn}$ & $\mathrm{R}$ \\
\hline
\end{tabular}

$D$ 


\section{Table 5 Footnotes.}

1. The infection types displayed in the matrix represent the median score recorded across three experiments. Infection types were scored using the original 0-4 rating scale developed by Mains (1930) with the additional notations of " + " and " " to indicate larger or smaller size variations of classically described uredinia (Levine and Cherewick, 1952) and " $c$ " and " $n$ " to indicate the presence of chlorotic or necrotic reactions (Moseman and Roane, 1959), respectively. Complex ITs were recorded when more than one IT was observed on a single leaf. For example, an IT of 213-indicates that all three pustule types exist on the same leaf and that the " 2 " type pustules were most common, followed by the "1" type, with "3-" type pustules being the least common.

2. General reactions are different classes of infection types. Infection types from "0;" to "0;12" are classified as highly resistant ("R", green cells), infections types from "12" to "23-c" are classified as moderately resistant ("M", yellow cells), and infection types from "23-" to "33+" are classified as susceptible ("S", red cells) (Steffenson et al., 1993). GRs in italics denote cases where different reactions occurred between the donor parent and its introgression line.

3. The host lines are listed sequentially from Rph1-15 with the original donor parent above each respective introgression line.

4. The Bowman introgression lines are abbreviated using the letters BW and a three digit number identifier. 
Table 6. Infection type mode ${ }^{1}$ and range ${ }^{2}$ for the selected Bowman introgression lines carrying the leaf rust resistance genes Rph1-15 against 12 isolates of Puccinia hordei.

\begin{tabular}{|c|c|c|c|c|c|c|c|c|c|c|c|c|c|c|c|c|c|c|c|c|c|c|c|c|c|}
\hline \multirow[b]{3}{*}{ Line } & \multirow[b]{3}{*}{ Allele $^{3}$} & \multicolumn{24}{|c|}{ Isolates of $P$. hordei } \\
\hline & & \multicolumn{2}{|c|}{$\overline{\text { BR (Octal 11) }}$} & \multicolumn{2}{|c|}{ ARG231 } & \multicolumn{2}{|c|}{ Aus 220} & \multicolumn{2}{|c|}{ Race 4} & \multicolumn{2}{|c|}{ Ger 7} & \multicolumn{2}{|c|}{ WGCC } & \multicolumn{2}{|c|}{$98-20$} & \multicolumn{2}{|r|}{ 94-8 } & \multicolumn{2}{|c|}{ BRS 76-12 } & \multicolumn{2}{|r|}{$90-3$} & \multicolumn{2}{|c|}{ Neth 28} & \multicolumn{2}{|r|}{$92-7$} \\
\hline & & $\mathbf{M}$ & $\mathbf{R}$ & M & $\mathbf{R}$ & $\mathbf{M}$ & $\mathbf{R}$ & $\mathbf{M}$ & $\mathbf{R}$ & M & $\mathbf{R}$ & $\mathbf{M}$ & $\mathbf{R}$ & $\mathbf{M}$ & $\mathbf{R}$ & $\mathbf{M}$ & $\mathbf{R}$ & $\mathbf{M}$ & $\mathbf{R}$ & $\mathbf{M}$ & $\mathbf{R}$ & $\mathbf{M}$ & $\mathbf{R}$ & $\mathbf{M}$ & $\mathbf{R}$ \\
\hline BW682 & Rph1.a & $3-$ & 2 to $3-$ & $3-$ & 0 ; to 3- & 0 & 0 ; to 2 & 0 & 0 ; to 1 & 0 & 0 ; to $1-$ & 0 & 0 ; to 2 & 3 & 3- to $3+$ & 3 & 3- to $3+$ & 3 & 1 to $3+$ & 3 & 3 to $3+$ & 3 & 3 - to 3 & 3 & 2 to $3+$ \\
\hline BW743 & Rph2.t & 1 & $0 ;$ to 2 & 1 & 0 ; to 3- & 2 & 1 to $3-$ & 2 & 0 ; to 3- & $3-$ & 2 to $3-$ & 2 & 0 ; to 3- & 3 & 2 to $3+$ & $3-$ & $0 ;$ to 3 & $3-$ & 1 to $3-$ & $3-$ & $3-$ to 3 & $3-$ & 2 to $2-$ & $3-$ & 2 to $3-$ \\
\hline BW746 & Rph3.c & 0 & $0 ;$ to 1 & 0 & 0 ; to $1-$ & 0 & $0 ;$ to 1 & 0 & 0 ; to 2 & 0 & 0 to 2 & 0 & 0 ; to 1 & 0 & $0 ;$ to 1 & 0 & 0 ; to $1-$ & $3-$ & 2 to 3 & 2 & 0 ; to 3- & 3- & 2 to $3-$ & 3- & 2 to $3-$ \\
\hline BW752 & Rph4.d & $3-$ & 1 to $3-$ & 2 & 0 ; to 3- & 1 & 0 ; to 2 & 1 & 0 ; to 2 & 3 & 2 to 3 & 1 & 0 ; to 3- & 3 & 1 to 3 & 3 & 1 to $3+$ & 3- & 2 to 3 & 3 & 2 to 3 & 1 & 0 ; to 2 & 3 & 3 \\
\hline BW755 & Rph5.e & 1 & 0 ; to 1 & 2 & 1 to $3-$ & 3 & 2 to 3 & 2 & 0 ; to 3- & 1 & 0 ; to 2 & 3 & 2 to 3 & 1 & 0 ; to 2 & 1 & 0 ; to 1 & 3- & 0 ; to 3 & 3- & 3- to 3 & 3- & 2 to $3-$ & 3- & 3 - to 3 \\
\hline BW756 & Rph5.f & 1 & $0 ;$ to 1 & & 2 to $3-$ & 3 & 3 - to 3 & 2 & 1 to $3-$ & 2 & 1 to $3-$ & 3 & 2 to 3 & 1 & $0 ;$ to 2 & 1 & $0 ;$ to 1 & $3-$ & $0 ;$ to 3 & 3- & 2 to 3 & 3- & 2 to 3 & 3- & 2 to 3 \\
\hline BW758 & Rph7.g & 0 ; & 0 ; to $1-$ & 0 ; & 0 ; to $1-$ & 0 & 0 to 0 ; & 0 & 0 ; to $1-$ & 0 ; & 0 ; to 1 & 0 & 0 ; to $1-$ & 3- & 2 to $3+$ & 0 ; & 0 ; to 1 & 0 ; & 0 ; to 1 & 2 & 1 to $3-$ & 3- & 2 to 3 & 3- & 3 - to 3 \\
\hline BW759 & Rph8.h & 0 & 0 ; to $1-$ & 2 & 1 to $3-$ & 2 & 1 to $3-$ & 3 & 3 to $3+$ & 0 & 0 ; to 1 & 2 & 1 to $3-$ & 2 & 1 to $3-$ & 2 & 1 to $3-$ & 3- & 2 to $3-$ & 3 & 2 to 3 & 3- & 2 to 3 & 3- & 3- to 3 \\
\hline BW760 & Rph9.i & 1 & 0 ; to 2 & 2 & 0 ; to 2 & 2 & 1 to $3-$ & 1 & 0 ; to 3- & 1 & 0 ; to 2 & 2 & 0 ; to 3- & 2 & 1 to $3-$ & 3- & 1 to $3-$ & 1 & 0 ; to 2 & 3 & 3 - to 3 & 3- & 2 to 3 & 3 & $3-$ to 3 \\
\hline BW683 & Rph10.o & 2 & 1 to $3-$ & 1 & 0 ; to 2 & 1 & 0 ; to 2 & 2 & 0 ; to 3- & 2 & 1 to $3-$ & 2 & 0 ; to 3- & 3- & 1 to $3-$ & 2 & 0 ; to 3- & 2 & 1 to $3-$ & 3 & 3 - to 3 & 2 & 1 to $3-$ & 2 & 1 to $3-$ \\
\hline BW684 & Rph11.p & 2 & 1 to $3-$ & 2 & 1 to $3-$ & 2 & 1 to $3-$ & 2 & 1 to $3-$ & 2 & 1 to $3-$ & 2 & 0 ; to 3- & 2 & 2 to $3-$ & 2 & 1 to $3-$ & 2 & 0 ; to 3- & 3 & 3- to $3+$ & 2 & 1 to $3-$ & 2 & 1 to $3-$ \\
\hline BW761 & Rph9.z & 1 & 0 ; to 1 & 1 & 0 ; to 2 & 1 & 0 ; to 2 & 1 & 0 ; to 2 & 0 & 0 ; to 1 & 1 & 0 ; to 1 & 1 & 0 ; to 2 & 3 & 1 to $3+$ & 1 & 0 ; to 2 & 3 & 3- to 3 & 3- & 2 to 3 & 3- & 2 to 3 \\
\hline BW685 & Rph13.x & 0 & 0 ; to 2 & 1 & 0 ; to 2 & 0 & 0 ; to 1 & 2 & 1 to $3-$ & 0 & 0 ; to 2 & 0 & $0 ;$ to 1 & 3- & 2 to $3-$ & 3 & 3- to $3+$ & 1 & 0 ; to 2 & 1 & 0 ; to 3- & 1 & 0 ; to 2 & 1 & 0 ; to 2 \\
\hline BW686 & Rph14.ab & 0 & 0 to 1 & 2 & 0 ; to 3- & 1 & 0 ; to 2 & 3 & 2 to 3 & 0 & 0 ; to $1-$ & 2 & 1 to $3-$ & 2 & 0 ; to 2 & 2 & $0 ;$ to 2 & 2 & 1 to $3-$ & 3- & 2 to 3 & 3- & 2 to $3-$ & & 2 to 3 \\
\hline BW719 & Rph15.ad & $1-$ & 0 ; to $1-$ & & 0 ; to $1-$ & 0 & 0 & & 0 ; to $1-$ & 0 & 0 ; to $1-$ & 0 & 0 ; to $1-$ & 1 & 0 ; to 1 & 1- & 0 ; to 1 & & 0 & 3- & 3- to 3 & & 1 to $3-$ & & 0 ; to 1 \\
\hline
\end{tabular}

${ }^{1} \mathrm{M}=$ Infection type mode: the most common single infection type (IT) observed across three experiments.

${ }^{2} \mathrm{R}=$ Range of observed ITs: the lowest and highest ITs observed across three experiments.

${ }^{3 .}$ Rph allele symbols were designated according to Franckowiak et al. (1997). 
Table 7. Annotated genes involved in disease resistance and residing in the same contigs as BOPA SNP markers within Bowman introgression lines carrying nine ${ }^{1}$ of the 15 leaf rust resistance alleles used in this study.

\begin{tabular}{|c|c|c|c|c|}
\hline BW Line ${ }^{2}$ & Rph introgression ${ }^{3}$ & BOPA_SNP ${ }^{4}$ & Genes on contig $^{5}$ & Annotation $^{6}$ \\
\hline BW682 & Rph1.a & 2_1377 & AK361947 & Zinc finger (Ran-binding) family protein \\
\hline BW743 & Rph2.t & 2_1253 & MLOC_54218.3 & Protein kinase superfamily protein LENGTH=390 \\
\hline BW743 & Rph2.t & 1_1432 & MLOC_73036.2 & Leucine Rich Repeat family protein \\
\hline BW743 & Rph2.t & 2_0697 & MLOC_64255.1 & Transmembrane protein \\
\hline BW743 & Rph2.t & 1_0240 & MLOC_54831.1 & Thioredoxin $\mathrm{m}$ \\
\hline BW743 & Rph2.t & 2_0332 & AK248962.1 & Ubiquitin activating enzyme 2 \\
\hline BW743 & Rph2.t & 2_0461 & AK251412.1 & Peroxidase superfamily protein \\
\hline BW743 & Rph2.t & 2_0372 & MLOC_6055.1 & Ubiquitin-conjugating enzyme variant \\
\hline BW743 & Rph2.t & 2_1200 & MLOC_52504.2 & WRKY transcription factor \\
\hline BW743 & Rph2.t & 2_0265 & AK365065 & Trehalose-6-phosphate phosphatase \\
\hline BW743 & Rph2.t & 1_1281 & MLOC_11773.1 & Trehalose-6-phosphate synthase \\
\hline BW743 & Rph2.t & 2_1121 & MLOC_34809.1 & Cathepsin L-like cysteine proteinase \\
\hline BW746 & Rph3.c & 1_0797 & MLOC_50091.1 & Senescence-associated protein $\mathrm{DH}$ \\
\hline BW746 & Rph3.c & 2_1160 & MLOC_60881.1 & WD-repeat protein 57 \\
\hline BW758 & Rph7.g & 1_0112 & AK249901.1 & Bowman-Birk type trypsin inhibitor \\
\hline BW758 & Rph7.g & 2_0595 & MLOC_36532.1 & Ubiquitin-conjugating enzyme 22 \\
\hline BW760 & Rph9.i & 2_0653 & MLOC_53949.2 & Leucine-rich repeat receptor-like protein kinase \\
\hline BW760 & Rph9.i & $2 \_1247$ & MLOC_4611.1 & Protein kinase \\
\hline BW760 & Rph9.i & 1_1090 & AK373628 & Transcription factor \\
\hline BW760 & Rph9.i & 1_1080 & AK364080 & Cysteine proteinase \\
\hline BW760 & Rph9.i & 1_0292 & AK371585 & Succinate dehydrogenase subunit $A$ \\
\hline BW760 & Rph9.i & 2_0731 & MLOC_6875.2 & Reticulon-like protein B8 \\
\hline BW683 & Rph10.o & 1_0728 & AK358661 & Chitinase \\
\hline BW683 & Rph10.o & 1_0335 & MLOC_11772.1 & RING finger and $\mathrm{CHY}$ zinc finger domain-containing protein 1 \\
\hline BW683 & Rph10.o & 2_1305 & MLOC_50950.1 & NBS-LRR-like protein \\
\hline BW683 & Rph10.o & 2_0931 & MLOC_63920.1 & WD-40 repeat family protein \\
\hline
\end{tabular}


Table 7. Annotated genes involved in disease resistance and residing in the same contigs as BOPA SNP markers within Bowman introgression lines carrying nine ${ }^{1}$ of the 15 leaf rust resistance alleles used in this study.

BW Line ${ }^{2}$ Rph introgression ${ }^{3}$ BOPA_SNP ${ }^{4}$ Genes on contig Annotation $^{6}$

\begin{tabular}{|c|c|c|c|c|}
\hline BW761 & Rph9.z & 2_0653 & MLOC_53949.2 & Leucine-rich repeat receptor-like protein kinase \\
\hline BW761 & Rph9.z & 2_1247 & MLOC_4611.1 & Protein kinase \\
\hline BW761 & Rph9.z & 1_1090 & AK373628 & Transcription factor \\
\hline BW761 & Rph9.z & 2_1241 & MLOC_57253.1 & Receptor-like protein kinase 2 \\
\hline BW761 & Rph9.z & 1_1080 & AK364080 & Cysteine proteinase \\
\hline BW761 & Rph9.z & 1_0292 & AK371585 & Succinate dehydrogenase subunit A \\
\hline BW761 & Rph9.z & 2_0731 & MLOC_6875.2 & Reticulon-like protein B8 \\
\hline BW761 & Rph9.z & 2_0876 & AK367513 & Remorin \\
\hline BW761 & Rph9.z & 2_0686 & AK364134 & Kinase family protein \\
\hline BW761 & Rph9.z & $2 \_0536$ & MLOC_13213.1 & Pectin lyase-like superfamily protein \\
\hline BW685 & Rph13.x & 2_0612 & MLOC_37645.1 & Zinc finger $\mathrm{CCCH}$ domain-containing protein \\
\hline BW685 & Rph13.x & 1_0842 & MLOC_17018.1 & Peptidyl-prolyl cis-trans isomerase \\
\hline BW685 & Rph13.x & 2_1427 & AK369539 & NBS-LRR disease resistance protein homologue \\
\hline BW719 & Rph15.ad & 2_1153 & MLOC_44144.1 & CW-type Zinc Finger family protein \\
\hline
\end{tabular}

1. No genes for defense were found in the Rph-allele containing introgressions for Rph4.d, Rph5.e, Rph5.f, Rph8.h, Rph11.p, or Rph14.ab.

2. BW lines are the Bowman leaf rust resistance introgression lines whose introgressions carry annotated genes for defense.

3. $R$ ph gene residing in an introgression of the corresponding $\mathrm{BW}$ line.

4. BOPA SNP markers residing on the same genetic contig as annotated defense genes.

5. Annotated genes for defense residing on the same contig as Barley Oligonucleotide Polymorphic Assay (BOPA) SNP markers.

6. The listed gene annotation from the barley genome explorer provided by the Leibniz-Institut für Pflanzengenetik und Kulturpflanzenforschung (IPK, Gatersleben, Germany). 


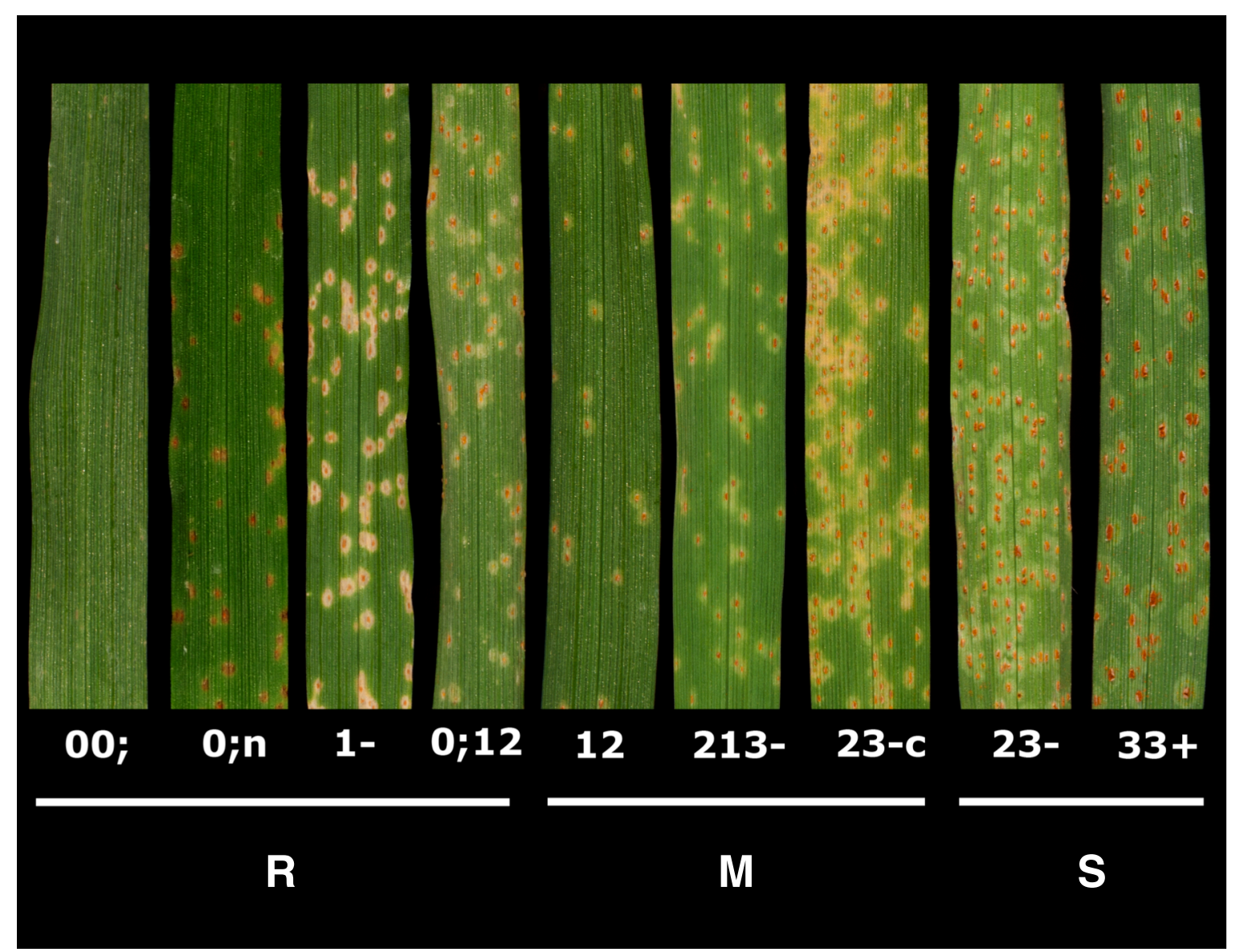

Figure 1. Examples of leaf rust infection types (ITs) observed on Bowman introgression lines. Infection types were scored using the original 0-4 rating scale developed by Mains (1930) with the additional notations of "+" and "-" to indicate larger or smaller size variations of classically described uredinia (Levine and Cherewick, 1952) and "c" and " $n$ " to indicate the presence of chlorotic or necrotic reactions (Moseman and Roane, 1959), respectively. Complex ITs were recorded when more than one IT was observed on a single leaf. For example, an IT of 213indicates that all three pustule types exist on the same leaf and that the "2" type pustules were the most common, followed by the "1" type, with "3-" type pustules being the least common. General reactions are different classes of infection types. Infection types from "0;" to "0;12" are infection tvpes from "23-" to "33+" are classified as susceptible ("S". red cells) (Steffenson et al.. 1993). 


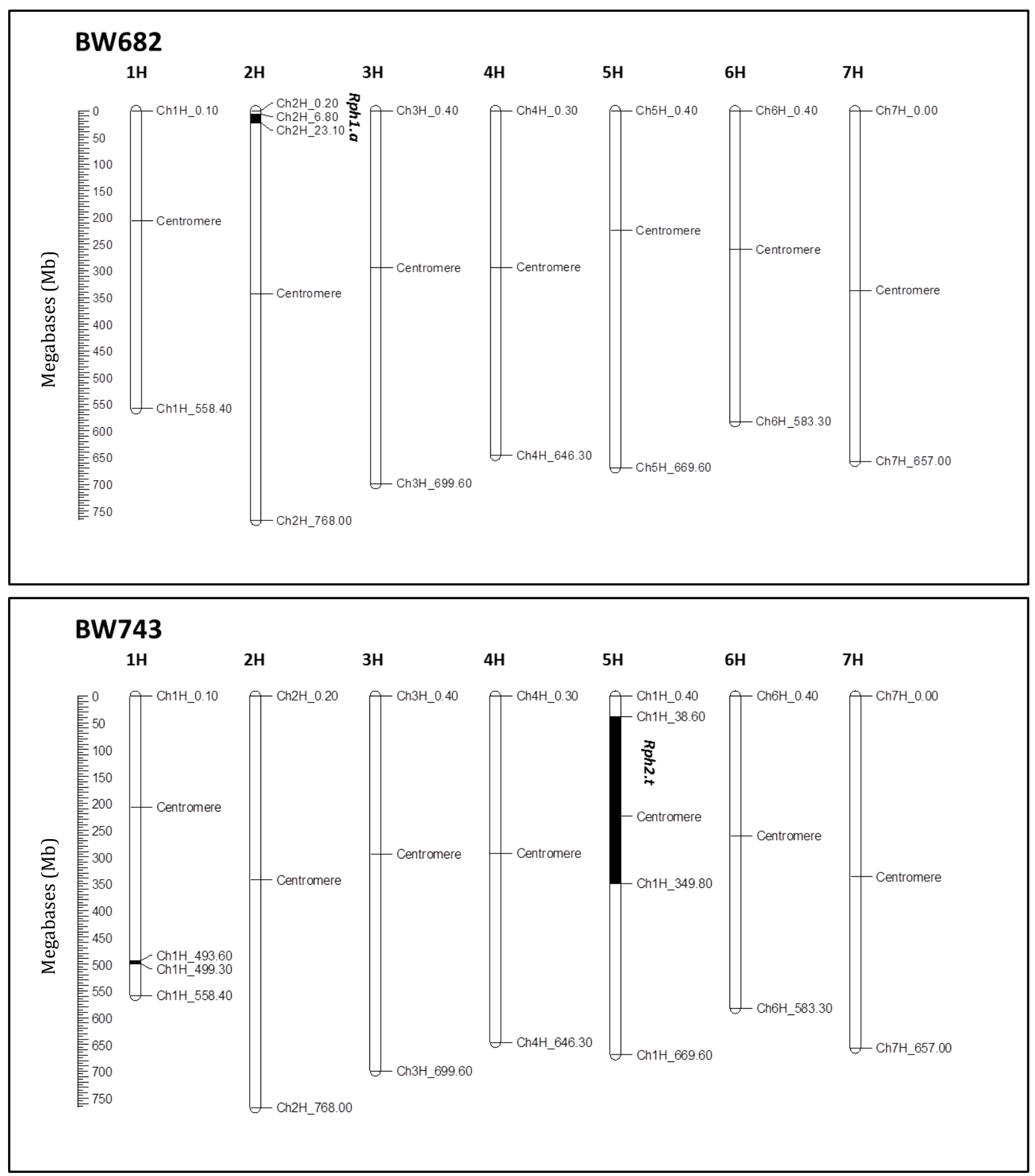

Figure 2. Graphical genotypes for Bowman introgression lines carrying leaf rust resistance genes Rph1-15 selected for the barley leaf rust differential set. Physical distances along the genome are represented in centimorgans (cM). Bold sections within a chromosome are the regions of retained donor chromatin. 


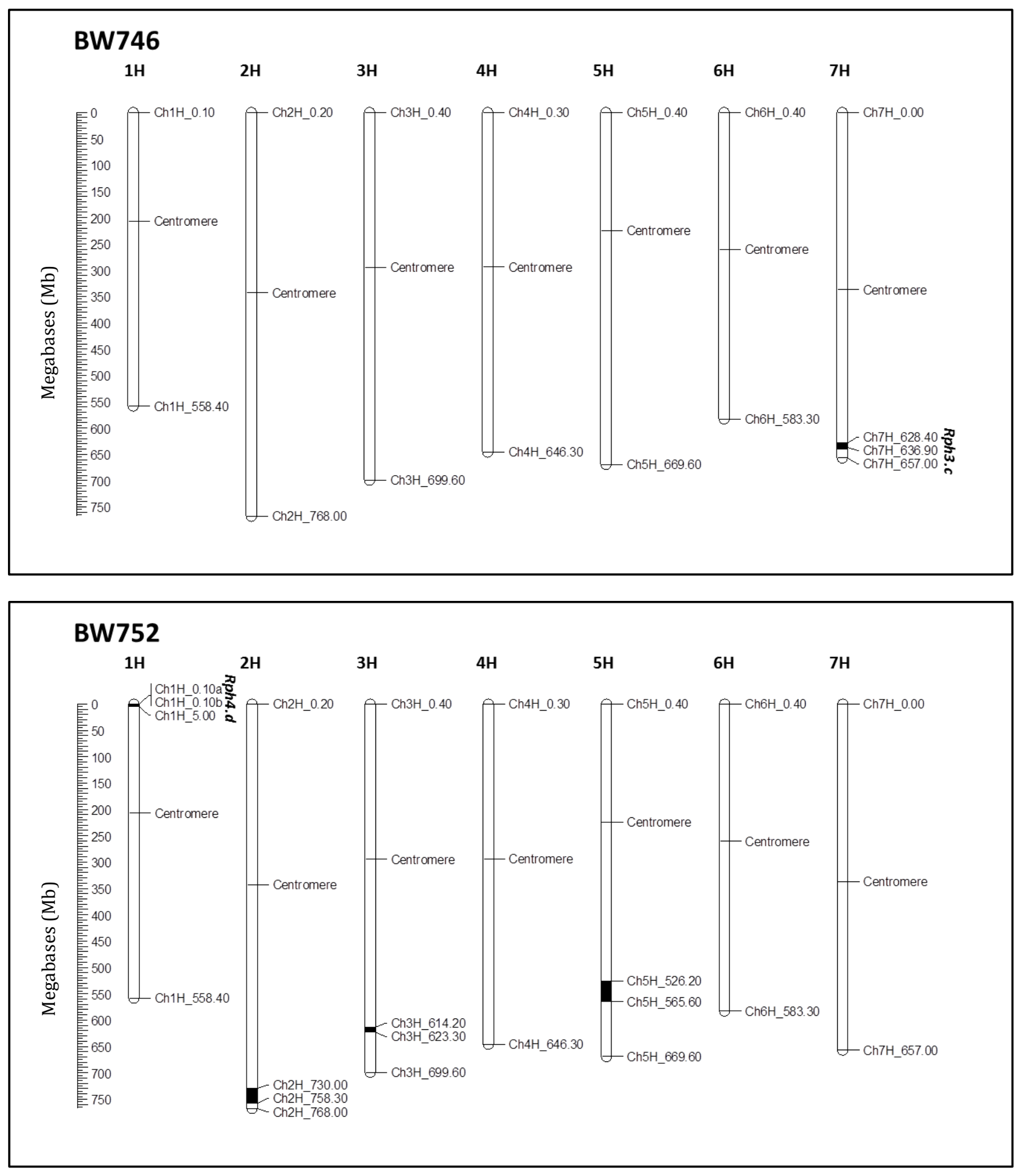

Figure 2 continued. Graphical genotypes for Bowman introgression lines carrying leaf rust resistance genes $R p h 1-15$ selected for the barley leaf rust differential set. 

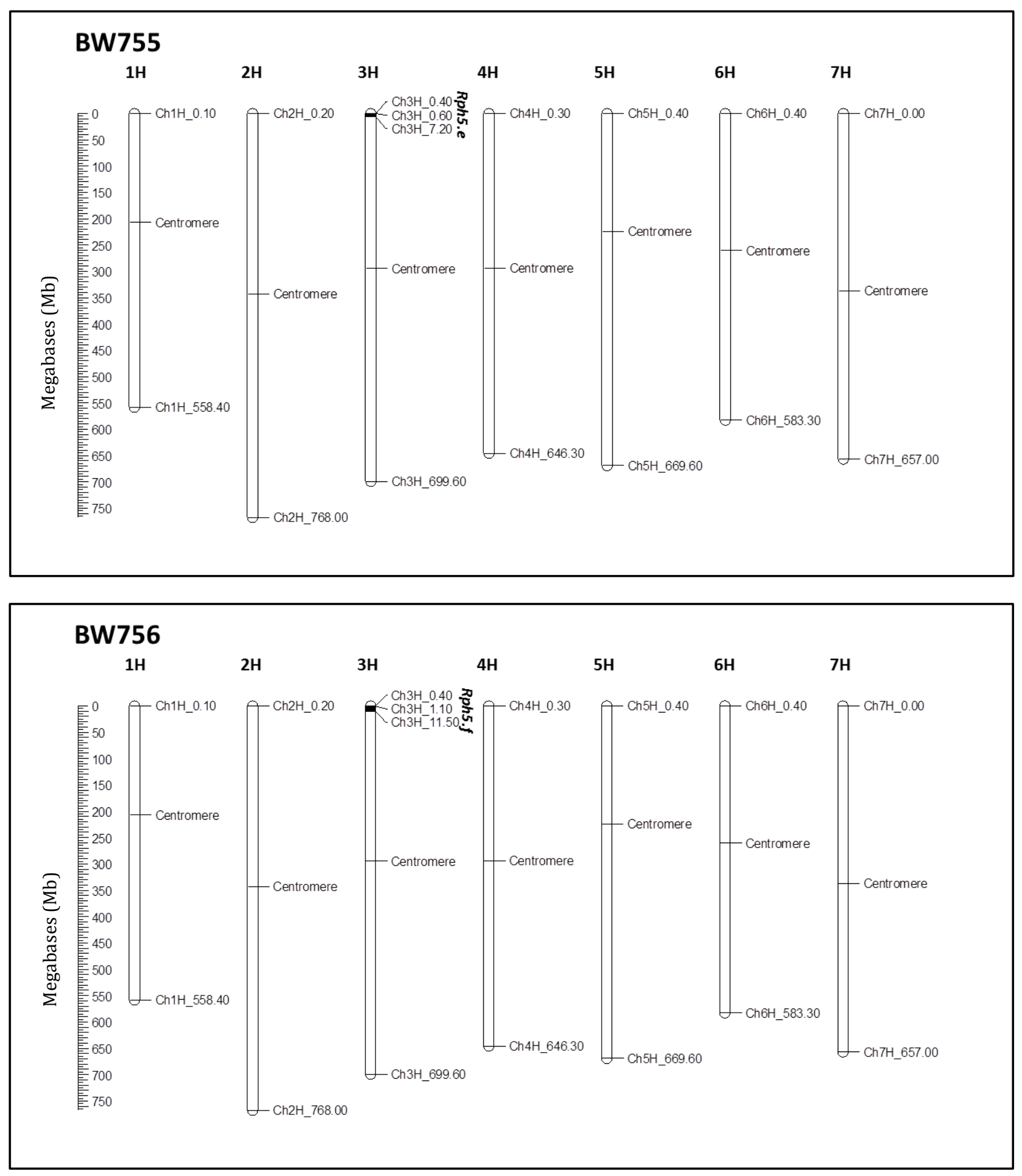

Figure 2 continued. Graphical genotypes for Bowman introgression lines carrying leaf rust resistance genes Rph1-15 selected for the barley leaf rust differential set. 


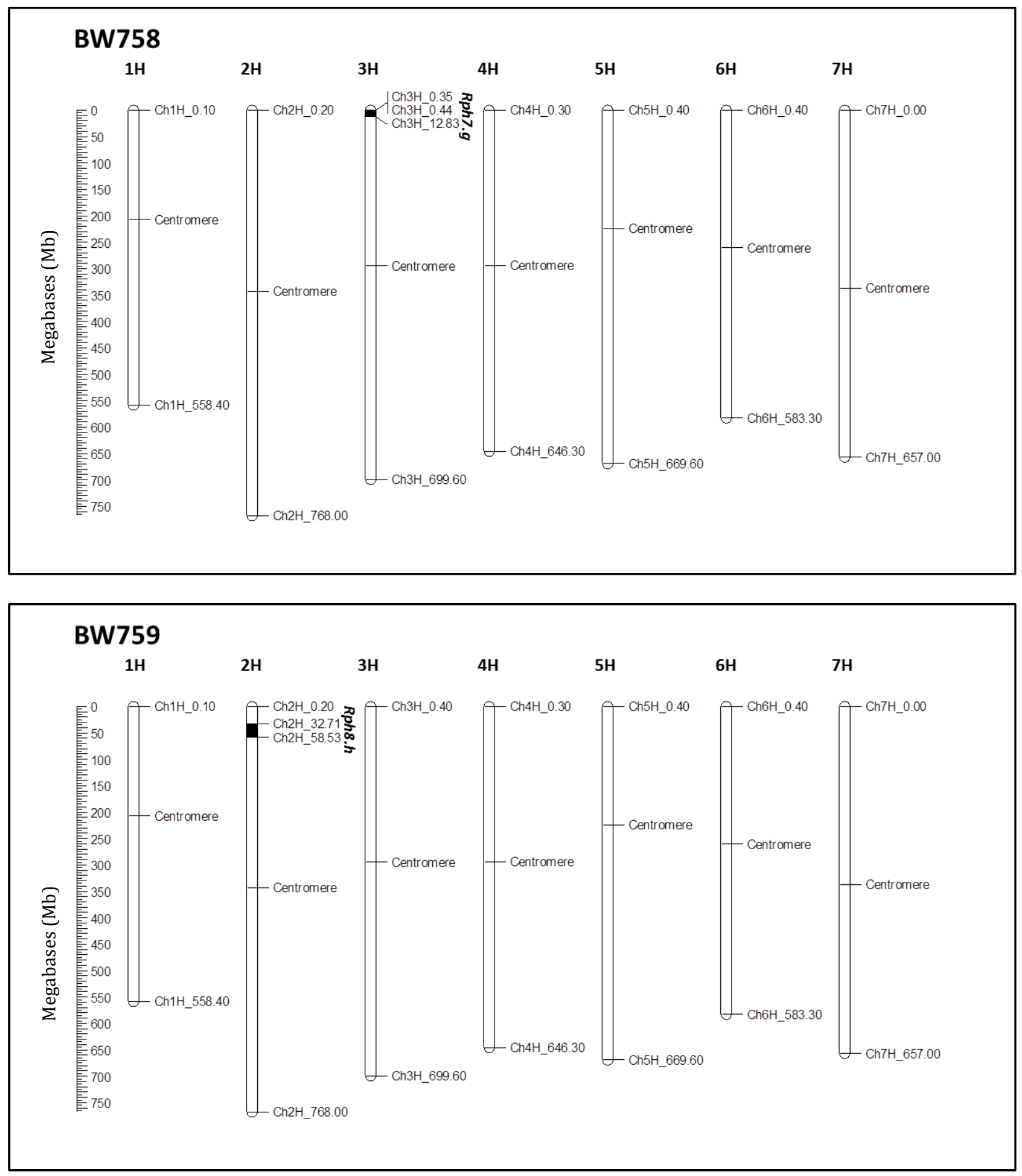

Figure 2 continued. Graphical genotypes for Bowman introgression lines carrying leaf rust resistance genes Rph1-15 selected for the barley leaf rust differential set. 


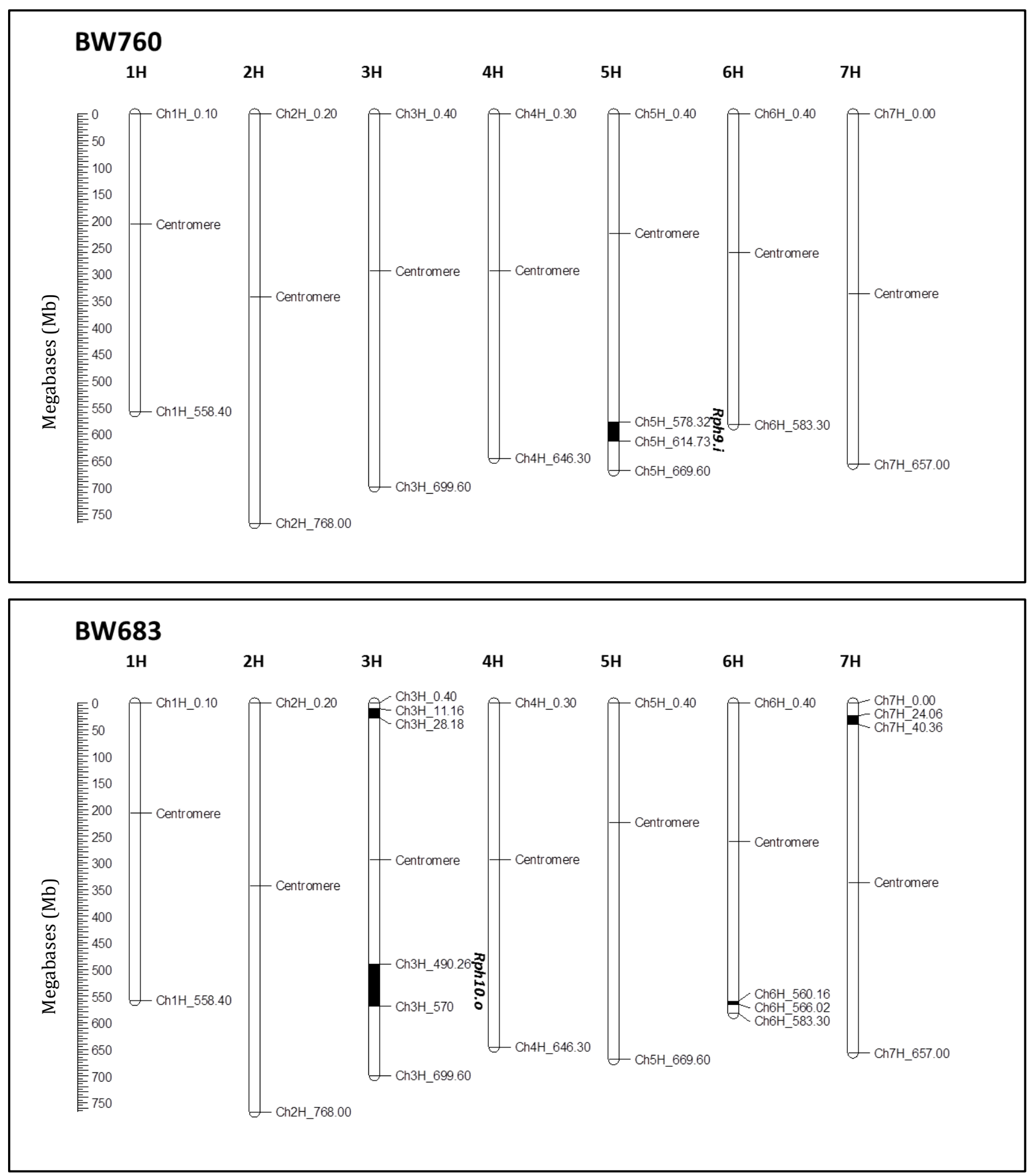

Figure 2 continued. Graphical genotypes for Bowman introgression lines carrying leaf rust resistance genes Rph1-15 selected for the barley leaf rust differential set. 


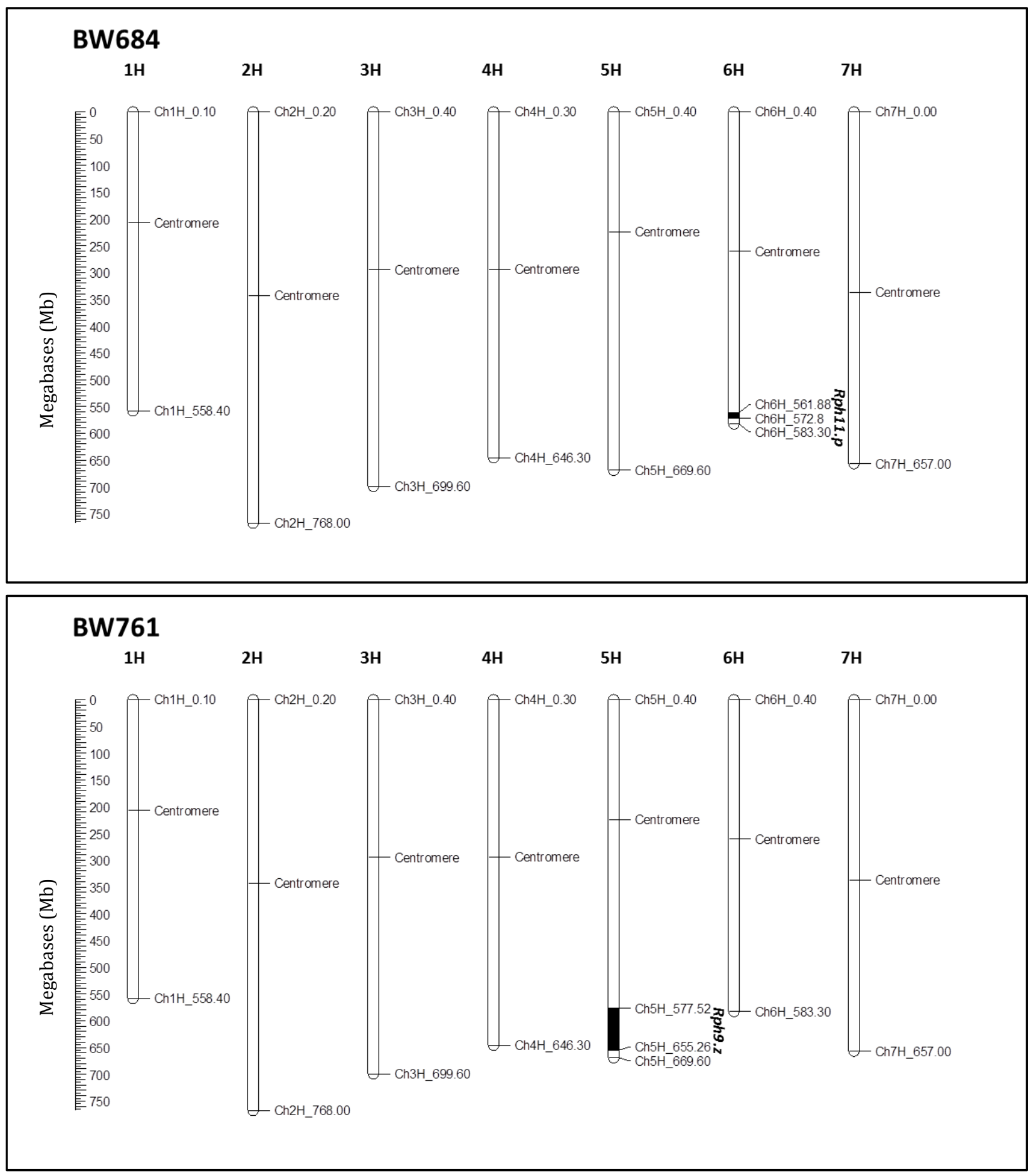

Figure 2 continued. Graphical genotypes for Bowman introgression lines carrying leaf rust resistance genes $R p h 1-15$ selected for the barley leaf rust differential set. 


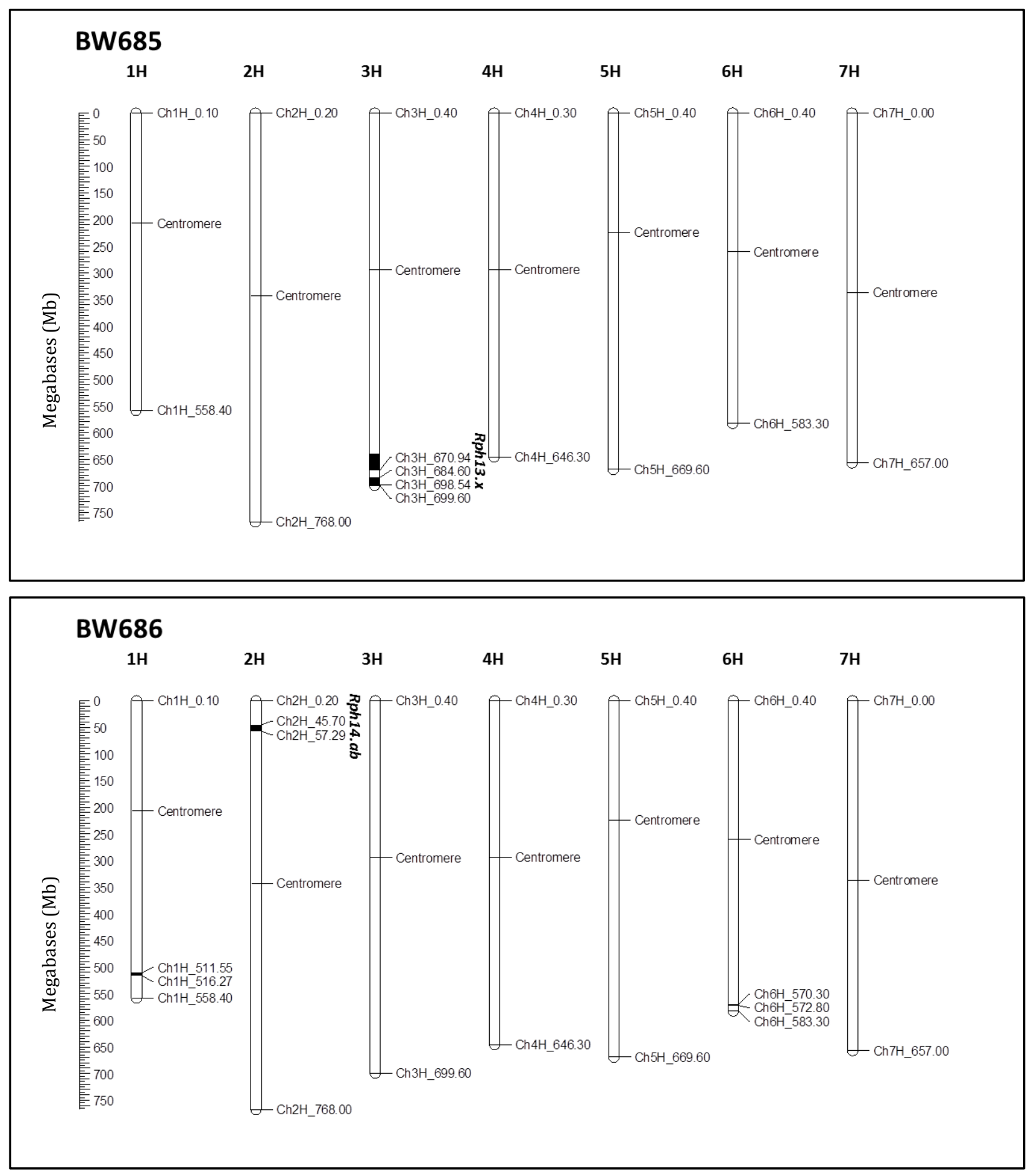

Figure 2 continued. Graphical genotypes for Bowman introgression lines carrying leaf rust resistance genes Rph1-15 selected for the barley leaf rust differential set. 


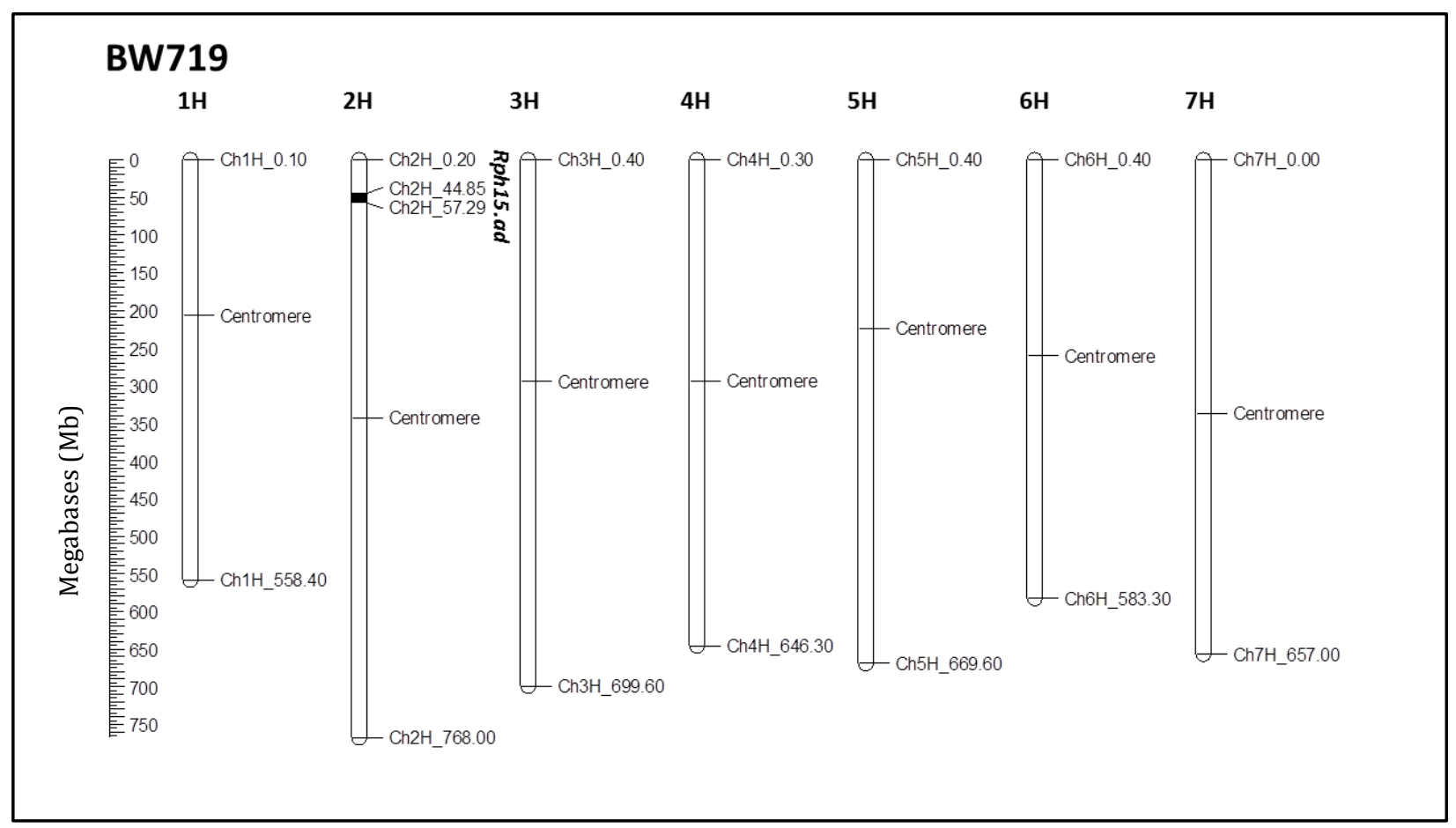

Figure 2 continued. Graphical genotypes for Bowman introgression lines carrying leaf rust resistance genes Rph1-15 selected for the barley leaf rust differential set. 


\section{Literature Cited}

Afanasenko, O.S., M. Jalli, H.O. Pinnschmidt, O. Filatova, and G.J. Platz. 2009. Development of an international standard set of barley differential genotypes for Pyrenophora teres f. sp. teres. Plant Pathol. 58:665-676.

Andres, M.W., R.D. Wilcoxson, A.P. Roelfs, and Z.A. Pretorius. 1983. Races of Puccinia hordei in the United States from 1979-1982. Plant Dis. 67:13361337.

Anikster, Y. 1989. Host specificity versus plurivority in barley leaf rusts and their microcyclic relatives. Mycol. Res. 93:175-181.

Anikster, Y., and I. Wahl. 1979. Coevolution of the rust fungi on Gramineae and Liliaceae and their hosts. Annu. Rev. Phytopathol. 17:367-403.

Arnst, B.J., J.W. Martens, G.M. Wright, P.A. Burnett, and F.R. Sanderson. 1979. Incidence, importance and virulence of Puccinia hordei on barley in New Zealand. Annu. Appl. Biol. 92:185-190.

Babraham Bioinformatics. 2012. Trim Galore script. Cambridge, England. "http://www.bioinformatics.babraham.ac.uk/projects/trim_galore/".

Berloo, R. v, H. Aalbers, A. Werkman, and R.E. Niks. 2001. Resistance QTL confirmed through development of QTL-NILs for barley leaf rust resistance. Mol. Breed. 8:187-195.

Bernardo, L., B. Prinsi, A.S. Negri, L. Cattivelli, L. Espen, and G. Valè. 2012. Proteomic characterization of the Rph15 barley resistance gene-mediated defence responses to leaf rust. BMC Genomics 13(1).

Borovkova, I.G., B.J. Steffenson, Y. Jin, A. Kilian, A. Kleinhofs, and T.K. Blake. 1997. Identification and mapping of a leaf rust resistance gene in barley line Q21861. Genome 40:236-241.

Borovkova, I.G., Y. Jin, and B.J. Steffenson. 1998. Chromosomal location and genetic-relationship of leaf rust resistance genes Rph9 and Rph12 in barley. Phytopathol. 88:76-80.

Brodny, U., and M. Rivadeneira. 1996. Physiologic specialization of Puccinia hordei in Israel and Ecuador. Can. J. Plant Pathol. 18:375-378.

Brown, A.M. 1931. Physiologic specialization in the dwarf leaf rust of barley. Rep. Dom. Bot. 1929:58-60.

Browning, B.L., and S.R. Browning. 2016. Genotype imputation with millions of reference samples. Am. J. Hum. Genet. 98:116-126.

Brunner, S., B. Keller, and C. Feuillet. 2000. Molecular mapping of the Rph7.g leaf rust resistance gene in barley (Hordeum vulgare L.). Theor. Appl. Genet. 101:783-788.

Buchannon, K.W., and H.A.H. Wallace. 1962. Note on the effect of leaf diseases on yield bushel weight and thousand-kernal weight of Parkland barley. Can. J. Plant Sci. 42:534-536.

Caffarel, J.C. 2005. Leaf rust studies in barley using Bowman backcross-derived lines. M.S. thesis. North Dakota State University, Fargo. 
Cao, J. 2012. The pectin lyases in Arabidopsis thaliana: Evolution, selection and expression profiles. PLoS One 7(10).

Chen, X., C.A. Hackett, R.E. Niks, P.E. Hedley, C. Booth, A. Druka, T.C. Marcel, A. Vels, M. Bayer, I. Milne, J. Morris, L. Ramsay, D. Marshall, L. Cardle, and R. Waugh. 2010. An eQTL analysis of partial resistane to Puccinia hordei in barley. PLoS One 5(1): e8598.

Chicaiza, O. 1996. Genetic control of leaf rust. Ph.D. thesis. North Dakota State University, Fargo.

Christopher, M., E. Mace, D. Jordan, D. Rodgers, P. McGowan, I. Delacy, P. Banks, J. Sheppard, D. Butler, and D. Poulsen. 2007. Applications of pedigree-based genome mapping in wheat and barley breeding programs. Euphytica 154:307-316.

Clifford, B.C. 1977. Monitoring virulence in Puccinia hordei: a proposal for the choice of host genotypes and survey procedures. Cereal Rusts and Powdery Mildews Bull. 5:34-38.

Clifford, B.C. 1985. Chapter 6: Barley leaf rust. In: Roelfs, A.P. and W.R. Bushnell, The Cereal Rusts. Academic Press, Inc. Orlando, FL. p. 180-210.

Clifford, B.C., and A.C.C. Udeogalanya. 1976. Hypersensitive resistance of barley to brown rust (Puccinia hordei Otth.). 4th Eur. Mediterr. Cereal Rusts Conf. Interlaken:27-29.

Cotterill, P.J., R.F. Park, and R.G. Rees. 1995. Pathogenic Specialization of Puccinia hordei Otth. in Australia, 1966-1990. Aust. J. Agric. Res. 46:127134.

Cotterill, P.J., R.G. Rees, G.J. Platz, and R. Dill-Macky. 1992a. Effects of leaf rust on selected Australian barleys. Aust. J. Exp. Agric. 32:747-751.

Cotterill, P.J., R.G. Rees, and W.A. Vertigan. 1992b. Detection of Puccinia hordei virulent on the Pa9 and Triumph resistance genes in barley in Australia. Australas. Plant Pathol. 21:32-34.

Czembor, J.H., H.J. Czembor, G. Attene, R. Papa, V. Agraria, V.D. Nicola, and M. Dago. 2007. Leaf rust resistance in selections from barley landraces collected in Sardinia. Plant Breed. Seed Sci. 56:73-84.

D'Oliveira, B. 1939. Studies on Puccinia anomala Rost. I. physiologic races on cultivated barleys. Ann. Appl. Biol. 26:56-82.

D'Oliveira, B. 1949. Aecidia of barley dwarf rust. Nature 164:880-881.

D'Oliveira, B. 1961. Ideas concerning the evolution and distribution of cereal rusts. Recent Adv. Bot. 1:564-567.

Das, M.K., C.A. Griffey, R.E. Baldwin, C.M. Waldenmaier, M.E. Vaughn, A.M. Price, and W.S. Brooks. 2007. Host resistance and fungicide control of leaf rust (Puccinia hordel) in barley (Hordeum vulgare) and effects on grain yield and yield components. Crop Prot. 26:1422-1430. 
Dean, R., J.A.L. Van Kan, Z.A. Pretorius, K.E. Hammond-Kosack, A.D. Pietro, P.D. Spanu, J.J. Rudd, M. Dickman, R. Kahmann, J. Ellis, and G.D. Foster. 2012. The Top 10 fungal pathogens in molecular plant pathology. Mol. Plant Pathol. 13:414-430.

Derevnina, L., D. Singh, and R.F. Park. 2013. Identification and characterization of seedling and adult plant resistance to Puccinia hordei in Chinese barley germplasm. Plant Breed. 132:571-579.

Dillard, M.W., and A.R. Brown. 1969. Inheritance of reaction to race 8 of Puccinia hordei Otth. in two barley crosses. Crop Sci. 9:677-678.

Dmochowska-Boguta, M., S. Alaba, Y. Yanushevska, U. Piechota, E. Lasota, A. Nadolska-Orczyk, W.M. Karlowski, and W. Orczyk. 2015. Pathogenregulated genes in wheat isogenic lines differing in resistance to brown rust Puccinia triticina. BMC Genomics 16:1-17.

Dodds, P. and J. Rathjen. 2010. Plant immunity: Towards an integrated view of plant-pathogen interactions. Nat. Rev. Genet. 1:539-548.

Dracatos, P.M., M.S. Khatkar, D. Singh, and R.F. Park. 2014. Genetic mapping of a new race specific resistance allele effective to Puccinia hordei at the Rph9/Rph12 locus on chromosome 5HL in barley. BMC Plant Biol. 14:382.

Dreiseitl, A., and B.J. Steffenson. 2000. Postulation of leaf-rust resistance genes in Czech and Slovak barley cultivars and breeding lines. Plant Breed. 119:211-214.

Druka, A., J.D. Franckowiak, U. Lundqvist, N. Bonar, J. Alexander, K. Houston, S. Radovic, F. Shahinnia, V. Vendramin, M. Morgante, N. Stein, and R. Waugh. 2011. Genetic dissection of barley morphology and development. Plant Physiol. 155:617-627.

Dyck, P. 1977. Genetics of leaf rust reaction in three introductions of common wheat. Can. J. Genet. Cytol. 19:711-716.

Ellis, J., E. Lagudah, W. Spielmeyer, and P. Dodds. 2014. The past, present and future of breeding rust resistant wheat. Front. Plant Sci. 5:641.

Fetch, T., B.J. Steffenson, and Y. Jin. 1998. Worldwide virulence of Puccinia hordei on barley. Phytopathology 88:S28.

Feuerstein, U., A.H.D. Brown, and J.J. Burdon. 1990. Linkage of rust resistance genes from wild barley (Hordeum spontaneum) with isozyme markers. Plant Breed. 104:318-324.

Flor, H.H. 1942. Inheritance of pathogenicity in Melampsora lini. Phytopathology 32:653-669.

Franckowiak, J.D., A.E. Foster, B.D. Pederson, and R.E. Pyler. 1985. Registration of 'Bowman' barley. Crop Sci. 25:883.

Franckowiak, J.D., Y. Jin, and B.J. Steffenson. 1997. Recommended allele symbols for leaf rust resistance genes in barley. Barley Genet. Newsl. 27:36-44.

Frecha, J.H. 1970. Inheritance of the resistance to Puccinia hordei Otth. in barley. Bol. Genet. 7:1-8. 
Gale, M.D., and K.M. Devos. 1998. Comparative genetics in the grasses. Proc. Natl. Acad. Sci. 95:1971-1974.

Germán, S., and S. Pereyra. 2007. Winter Crops Day. INIA LA Estanzuela:8-24. (In Spanish)

Gilmour, J. 1973. Octal notation for designating physiologic races of plant pathogens. Nature 242:620.

Golan, T., Y. Anikster, J.G. Moseman, and I. Wahl. 1978. A new virulent strain of Puccinia hordei. Euphytica 27:185-189.

Golegaonkar, P.G., H. Karaoglu, and R.F. Park. 2009. Molecular mapping of leaf rust resistance gene Rph14 in Hordeum vulgare. Theor. Appl. Genet. 119:1281-1288.

González, M.G., M.Z. Díaz, R. Huerta, and S. Solano. 2013. Efficiency of three fungicides to control the leaf rust in malting barley. J. Mexican Agric. Sci. 4:1237-1250. (In Spanish)

Graner, A., S. Streng, and A. Drescher. 2000. Molecular mapping of the leaf rust resistance gene Rph7 in barley. Plant Breeding 119:389-392.

Griffey, C.A., M.K. Das, R.E. Baldwin, and C.M. Waldenmaier. 1994. Yield losses in winter barley resulting from a new race of Puccinia hordei in North America. Plant Dis. 78:256-260.

Grunewaldt-Stöcker, G. 1983. Development of a differential set for the race analysis of Puccinia hordei Otth. J. Phytopathology 107: 309-317.

Heath, M.C. 1991. The role of gene-for-gene interactions in the determination of host species specificity. Phytopathology 81: 127-130.

Henderson, M.T. 1945. Studies of sources of resistance and inheritance of reaction to leaf rust, Puccinia anomala Rostr., in barley. Ph.D. Thesis. University of Minnesota, Saint Paul.

Hey, A. 1931. Contribution to the specialization of the barley rust, Puccinia simplex Erikss. and Henn. Work from the Biological Imperial Institute for land and forestry 19(3): 227-261. (In German)

Hickey, L.T., W. Lawson, G.J. Platz, M. Dieters, V.N. Arief, S. Germán, S. Fletcher, R.F. Park, D. Singh, S. Pereyra, and J.D. Franckowiak. 2011. Mapping Rph20: A gene conferring adult plant resistance to Puccinia hordei in barley. Theor. Appl. Genet. 123:55-68.

Hirschhorn, J. 1933. Two rusts of barley, new for Argentina. J. Fac. Agron. 19:390-397. (In Spanish)

Hubbard, A., S. Wilderspin, S. Holdgate, and H. Road. October 2017. United Kingdom Cereal Pathogen Virulence Survey 2017 Annual Report.

Ivandic, V., U. Walther, and A. Graner. 1998. Molecular mapping of a new gene in wild barley conferring complete resistance to leaf rust (Puccinia hordei Otth). Theor. Appl. Genet. 97:1235-1239. 
Jafary, H., L.J. Szabo, and R.E. Niks. 2006. Innate nonhost immunity in barley to different heterologous rust fungi is controlled by sets of resistance genes with different and overlapping specificities. Mol. Plant. Microbe. Interact. 19:1270-9.

Jin, Y., G.H. Cui, B.J. Steffenson, and J.D. Franckowiak. 1996. New leaf rust resistance genes in barley and their allelic and linkage relationships with other Rph genes. Phytopathology 86:887-890.

Jin, Y., G.D. Statler, J.D. Franckowiak, and B.J. Steffenson. 1993. Linkage between leaf rust resistance genes and morphological markers in barley. Phytopathology 83:230-233.

Jin, Y., and B.J. Steffenson. 1994. Inheritance of resistance to Puccinia hordei in cultivated and wild barley. J. Hered. 85:451-454.

Jin, Y., and B.J. Steffenson. 1996. A multi-allelic series at the Rph2 locus for leaf rust resistance in barley. Cereal Rusts Powdery Mildews Bull. 24:74-75.

Johnson, R. 1968. The genetics of resistance of some barley varieties to Puccinia hordei. Eur. Mediterr. Cereal Rust Conf. Oeiras, Portugal:160-162. Johnson, D.A., and R.D. Wilcoxson. 1979. Yield losses of fast and slow rusting barleys infected with Puccinia hordei. Plant Dis. Report. 63:764-768.

Johnston, P.A., R.E. Niks, V. Meiyalaghan, E. Blanchet, and R.A. Pickering. 2013. Rph22: mapping of a novel leaf rust resistance gene introgressed from the non-host Hordeum bulbosum L. into cultivated barley (Hordeum vulgare L.). Theor. Appl. Genet. 126:1613-25.

Jones, E.R.L. 2005. Brown rust of barley. UK Cereal Pathogen Virulence Survey. Jones, E.R.L., and B.C. Clifford. 1980. Brown rust of barley. UK Cereal Pathogen Virulence Survey:61-65.

Jones, J.D.G., and J.L. Dangl. 2006. The plant immune system. Nature 444:323329.

Kavanagh, P.J., D. Singh, U.K. Bansal, and R.F. Park. 2017. Inheritance and characterization of the new and rare gene Rph25 conferring seedling resistance in Hordeum vulgare against Puccinia hordei. Plant Breed. 136:908-912.

Khokhlova, A.P. 1982. Genes for resistance against leaf rust of barley. Works on applied botany genetics and selection. 71:63-67. (In Russian)

King, J.E. 1972. Surveys of foliar diseases of spring barley in England and Wales 1967-70. Plant Pathol. 21:23-35.

King, J.E., and R.W. Polley. 1976. Observations on the epidemiology and effect on grain yield of brown rust in spring barley. Plant Pathol. 25:63-73.

Kølster, P., L. Munk, O. Stølen, and J. Løhde. 1986. Near-isogenic barley lines with genes for resistance to powdery mildew. Crop Sci. 26:903-907.

Kopahnke, D., M. Nachtigall, F. Ordon, and B.J. Steffenson. 2004. Evaluation and mapping of a leaf rust resistance gene derived from Hordeum vulgare subsp. spontaneum. Czech J. Genet. Plant Breed. 40:86-90. 
Krings, M., N. Dotzler, J. Galtier, and T.N. Taylor. 2011. Oldest fossil basidiomycete clamp connections. Mycoscience 52:18-23.

Lee, H.Y., C.H. Bowen, G. V. Popescu, H.-G. Kang, N. Kato, S. Ma, S. DineshKumar, M. Snyder, and S.C. Popescu. 2011. Arabidopsis RTNLB1 and RTNLB2 reticulon-like proteins regulate intracellular trafficking and activity of the FLS2 immune receptor. Plant Cell Online 23:3374-3391.

Levine, M.N., and W.J. Cherewick. 1952. Studies on dwarf leaf rust of barley. USDA Tech. Bull. 1046:1-17.

$\mathrm{Li}, \mathrm{H}$. 2011. A statistical framework for SNP calling, mutation discovery, association mapping and population genetical parameter estimation from sequencing data. Bioinformatics 27 (21):2987-93. "http://samtools.sourceforge.net/mpileup.shtml".

$\mathrm{Li}, \mathrm{H}$. and R. Durbin. 2009. Fast and accurate short read alignment with BurrowsWheeler Transform. Bioinformatics 25:1754-60. " http://biobwa.sourceforge.net/".

Lim, L.G., and R.E. Gaunt. 1986. The effect of powdery mildew (Erysiphe graminis f. sp. hordel) and leaf rust (Puccinia hordel) on spring barley in New Zealand. I. Epidemic development, green leaf area and yield. Plant Pathol. 35:44-53.

Limpert, E., and K, Müller. 1994. Designation of pathotypes of plant pathogens. J. Phytopathol. 140:346-358.

Mains, E.B. 1930. Host specialization of barley leaf rust, Puccinia anomala. Phytopathology 20:873-882.

Mains, E.B., and H.S. Jackson. 1924. Aecial stages of the leaf rusts of rye, Puccinia dispersa Erikss. and Henn., and of barley, P. anomala Rostr., in the United States. J. Agric. Res. 28:1119-1126.

Mains, E.B., and M.L. Martini. 1932. Susceptibility of barley to leaf rust (Puccinia anomala) and to powdery mildew (Erysiphe graminis hordei). USDA Tech. Bull. 295:1-33.

Marcel, T.C., R. Aghnoum, J. Durand, R.K. Varshney, and R.E. Niks. 2007. Dissection of the barley $2 \mathrm{~L} 1.0$ region carrying the "Laevigatum" quantitative resistance gene to leaf rust using near-isogenic lines (NIL) and subNIL. Mol. Plant. Microbe. Interact. 20:1604-15.

Marcel, T.C., B. Gorguet, M.T. Ta, Z. Kohutova, A. Vels, and R.E. Niks. 2008. Isolate specificity of quantitative trait loci for partial resistance of barley to Puccinia hordei confirmed in mapping populations and near-isogenic lines. New Phytol. 177:743-755.

Martínez, F., R.E. Niks, and D. Rubiales. 2001. Partial Resistance to leaf rust in a collection of ancient Spanish barleys. Hereditas 135:199-203.

Mascher, M., H. Gundlach, A. Himmelbach, S. Beier, S.O. Twardziok, T. Wicker, V. Radchuk, C. Dockter, P.E. Hedley, J. Russell, M. Bayer, L. Ramsay, H. Liu, G. Haberer, X.Q. Zhang, Q. Zhang, R.A. Barrero, L. Li, S. Taudien, M. Groth, M. Felder, A. Hastie, H. Šimková, H. Stanková, J. Vrána, S. Chan, M. 
Munõz-Amatriaín, R. Ounit, S. Wanamaker, D. Bolser, C. Colmsee, T. Schmutzer, L. Aliyeva-Schnorr, S. Grasso, J. Tanskanen, A. Chailyan, D. Sampath, D. Heavens, L. Clissold, S. Cao, B. Chapman, F. Dai, Y. Han, H. Li, X. Li, C. Lin, J.K. McCooke, C. Tan, P. Wang, S. Wang, S. Yin, G. Zhou, J.A. Poland, M.I. Bellgard, L. Borisjuk, A. Houben, J. Doleael, S. Ayling, S. Lonardi, P. Kersey, P. Langridge, G.J. Muehlbauer, M.D. Clark, M. Caccamo, A.H. Schulman, K.F.X. Mayer, M. Platzer, T.J. Close, U. Scholz, M. Hansson, G. Zhang, I. Braumann, M. Spannagl, C. Li, R. Waugh, and N. Stein. 2017. A chromosome conformation capture ordered sequence of the barley genome. Nature 544:427-433.

Mayer, K.F.X., R. Waugh, P. Langridge, T.J. Close, R.P. Wise, A. Graner, T. Matsumoto, K. Sato, A. Schulman, R. Ariyadasa, D. Schulte, N. Poursarebani, R. Zhou, B. Steuernagel, M. Mascher, U. Scholz, B. Shi, K. Madishetty, J.T. Svensson, P. Bhat, M. Moscou, J. Resnik, G.J. Muehlbauer, P. Hedley, H. Liu, J. Morris, Z. Frenkel, A. Korol, H. Bergès, S. Taudien, M. Felder, M. Groth, M. Platzer, A. Himmelbach, S. Lonardi, D. Duma, M. Alpert, F. Cordero, M. Beccuti, G. Ciardo, Y. Ma, S. Wanamaker, F. Cattonaro, V. Vendramin, S. Scalabrin, S. Radovic, R. Wing, M. Morgante, T. Nussbaumer, H. Gundlach, M. Martis, J. Poland, M. Pfeifer, C. Moisy, J. Tanskanen, A. Zuccolo, M. Spannagl, J. Russell, A. Druka, D. Marshall, M. Bayer, D. Swarbreck, D. Sampath, S. Ayling, M. Febrer, M. Caccamo, T. Tanaka, S. Wannamaker, T. Schmutzer, J.W.S. Brown, G.B. Fincher, and N. Stein. 2012. A physical, genetic and functional sequence assembly of the barley genome. Nature 491:711-716.

Melville, S.C., and G.W. Griffin. 1976. Effects of fungicide spraying on brown rust and yield in spring barley. Plant Pathol. 25:99-107.

Middleton, C.P., N. Senerchia, N. Stein, E.D. Akhunov, B. Keller, T. Wicker, and B. Kilian. 2014. Sequencing of chloroplast genomes from wheat, barley, rye and their relatives provides a detailed insight into the evolution of the Triticeae tribe. PLoS One 9:1-12.

Misas-Villamil, J.C., R.A.L. van der Hoorn, and G. Doehlemann. 2016. Papainlike cysteine proteases as hubs in plant immunity. New Phytol. 212:902-907. Murray, G.M., and J.P. Brennan. 2010. Estimating disease losses to the Australian barley industry. Australas. Plant Pathol. 39:85-96.

Neervoort, W.J., and J.E. Parlevliet. 1978. Partial resistance of barley to leaf rust Puccinia hordei. Analysis of the components of partial resistance in eight barley cultivars. Euphytica 27:33-39.

Newton, M., B. Peterson, and W.O.S. Meredith. 1945. The effect of leaf rust of barley on the yield and quality of barley varieties. Can. J. Res. 23:212-218.

van Niekerk, B.D., Z.A. Pretorius, and W.H.P. Boshoff. 2001. Occurrence and pathogenicity of Puccinia hordei on barley in South Africa. Plant Dis. 85:713717. 
Niks, R.E. 1983. Comparative histology of partial resistance and the nonhost reaction to leaf rust pathogens in barley and wheat seedlings. Phytopathology :60-64.

Niks, R.E., J.E. Parlevliet, P. Lindhout, and Y. Bai. 2011. Breeding crops with resistance to diseases and pests. Wageningen Academic, Wageningen.

Nover, V.I., and C.O. Lehmann. 1974. Resistance in the barley and wheat collection Gatersleben. 18. Screening spring barleys for their reaction to leaf rust (Puccinia hordei Otth.). Crop 22: 25-43. (In German)

Patil, V., A. Bjornstad, H. Magnus, and J.M. Key. 2002. Resistance to scald (Rhynchosporium secalis) in barley (Hordeum vulgare) studied by nearisogenic lines: II. Diallel analysis of near-isogenic lines. Hereditas 137:186197.

Park, R.F. 2003. Pathogenic specialization and pathotype distribution of Puccinia hordei in Australia, 1992 to 2001. Plant Dis. 87:1311-1316.

Park, R.F. 2013. Barley leaf rust pathotype compromises WA. Farming Ahead 262:56-58.

Park, R.F., P.G. Golegaonkar, L. Derevnina, K.S. Sandhu, H. Karaoglu, H.M. Elmansour, P.M. Dracatos, and D. Singh. 2015. Leaf rust of cultivated barley: Pathology and control. Annu. Rev. Phytopathol. 53:565-589.

Park, R.F., and A. Karakousis. 2002. Characterization and mapping of gene Rph19 conferring resistance to Puccinia hordei in the cultivar 'Reka 1' and several Australian barleys. Plant Breed. 121:232-236.

Parlevliet, J.E. 1976. The genetis of seedling resistance to leaf rust, Puccinia hordei Otth. in some spring barley cultivars. Euphytica 25:249-254.

Person, C. 1959. Gene-for-gene relationships in host : parasite systems. Can. J. Bot. 37:1101-1130.

Pereyra, S., and M.D. d Ackermann. 2007. Use of fungicides to control leaf rust of barley and wheat. INIA LA Estanzuela. (In Spanish)

Pickering, R.A., A.M. Hill, M. Michel, and G.M. Timmerman-Vaughan. 1995. The transfer of a powdery mildew resistance gene from Hordeum bulbosum $\mathrm{L}$. to barley (H. vulgare L.) chromosome 2 (21). Theor. Appl. Genet. 91:12881292.

Pickering, R.A., S. Malyshev, A. Johnston, V. Korzun, M. Menke, and I. Schubert. 2000. Locating introgressions of Hordeum bulbosum chromatin within the $H$. vulgare genome. Theor. Appl. Genet. 100:27-31.

Pickering, R.A., B.J. Steffenson, A.M. Hill, and I.G. Borovkova. 1998. Association of leaf rust and powdery mildew resistance in a recombinant derived from a Hordeum vulgare x Hordeum bulbosum hybrid. Plant Breed. 117:83-84.

Poulsen, D.M.E., R.J. Henry, R.P. Johnston, J.A.G. Irwin, and R.G. Rees. 1995. The use of bulk segregant analysis to identify a RAPD marker linked to leaf rust resistance in barley. Theor. Appl. Genet. 91:270-273. 
Qi, X., R.E. Niks, P. Stam, and P. Lindhout. 1998. Identification of QTLs for partial resistance to leaf rust (Puccinia hordei) in barley. Theor. Appl. Genet. 96:1205-1215.

Rintelen, J. 1976. Physiological specialization of Puccinia hordei Otth. and reactions of barley varieties and cultivars to physiological races. Proc. 3rd Int. Barley Genet. Symp. p. 464-467.

Roane, C.W. 1962. Inheritance of reaction to Puccinia hordei in barley. 1. Genes for resistance among North American race differentiating varieties. Phytopathology 52:1288-1295.

Roane, C.W., and T.M. Starling. 1967. Inheritance of reaction to Puccinia hordei in barley. II. Gene symbols for loci in differential cultivars. Phytopathology 57:66-68.

Roelfs, A.P., and J.W. Martens. 1988. An international system of nomenclature for Puccinia graminis f. sp. tritici. Phytopathology 78:526-533.

Ronsdorf, L. 1935. Further studies on the detection of biological breeds of the barley rust, Puccinia simplex Erikss. and Henn. Phytopathology Magazine 8:237-243. (In German)

Rouse, M., C.A. Griffey, and W.S. Brooks. 2013. First detection of Puccinia hordei virulence to barley leaf rust resistance gene Rph3 and combination with virulence to Rph7 in North America. Plant Dis. 97:838.

Rubiales, D., and R.E. Niks. 1992. Histological responses in Hordeum chilense to brown and yellow rust fungi. Plant Pathol. 41:611-617.

Sadravi, M., Y. Ono, M. Pei, and K. Rahnama. 2007. Fourteen rusts from northeast Iran. J. Plant Pathol. 89:191-202.

Sandhu, K.S., K.L. Forrest, S. Kong, U.K. Bansal, D. Singh, M.J. Hayden, and R.F. Park. 2012. Inheritance and molecular mapping of a gene conferring seedling resistance against Puccinia hordei in the barley cultivar Ricardo. Theor. Appl. Genet. 125:1403-1411.

Sandhu, K.S., D. Singh, and R.F. Park. 2016. Characterization of leaf rust resistance in international barley nurseries. J. Plant Breed. Crop Sci. 8:117125.

Schnaithmann, F., D. Kopahnke, and K. Pillen. 2014. A first step toward the development of a barley NAM population and its utilization to detect QTLS conferring leaf rust seedling resistance. Theor. Appl. Genet. 127:1513-25.

Schweizer, P., and N. Stein. 2011. Large-scale data integration reveals colocalization of gene functional groups with meta-QTL for multiple disease resistance in barley. Mol. Plant-Microbe Interact. 24:1492-1501.

Shelko, L.G. 1974. Race differentiation of the causative agent and immunity sources of barley to dwarf rust. Bull. of Appl. Bot. Genet. Plant Breed. 53:105-112. (In Russian)

Shtaya, M.J.Y., J.C. Sillero, and D. Rubiales. 2006. Screening for Resistance to Leaf Rust (Puccinia hordel) in a Collection of Spanish Barleys. Breed. Sci. 56:173-177. 
Singh, D., P.M. Dracatos, L. Derevnina, M. Zhou, and R.F. Park. 2015. Rph23: A new designated additive adult plant resistance gene to leaf rust in barley on chromosome 7H. Plant Breed. 134:62-69.

Spaner, D., L.P. Shugar, T.M. Choo, I. Falak, K.G. Briggs, W.G. Legge, D.E. Falk, S.E. Ullrich, N.A. Tinker, B.J. Steffenson, and D.E. Mather. 1998. Mapping of disease resistance loci in barley on the basis of visual assessment of naturally occurring symptoms. Crop Sci. 38:843-850.

Stakman, E.C., D.M. Stewart, and W.Q. Loegering. 1962. Identification of physiologic races of Puccinia graminis var. tritici. USDA Agric. Res. Serv. E617:5-53.

Stakman, E.C., M.N. Levine, C.J. T, and K. Isenbeck. 1933. Determination of physiological breeds of phytopathogenic fungi. November 8 Leopoldina treatises of Kais. Lopoldinisch-Carolinisch Duetschland Academy. The Naturalist 3:281-336. (In German)

Stein, N., G. Herren, and B. Keller. 2001. A new DNA extraction method for highthroughput marker analysis in a large-genome species such as Triticum aestivum. Plant Breed. 120:354-356.

Steffenson, B.J., Y. Jin, and C.A. Griffey. 1993. Pathotypes of Puccinia hordei with virulence for the barley Leaf rust resistance gene Rph7 in the United States. Plant Dis. 77:867-869.

Stevenson, J.A., and A.G. Johnson. 1946. The nomenclature of the barley leaf rust. Plant Dis. Report. 30:372.

Straib, W. 1937. On the question of the rust species occurring on Hordeum murinum L. and the independence of Puccinia hordei. Rep. German Bot. Soc. 55:120-126. (In German)

Subedi, S. 2017. Identification of the gene underlying the Rphq2 resistance of barley (Hordeum vulgare) to barley leaf rust (Puccinia hordeI). M.S. thesis. Wageningen University and Research, Wageningen.

Tan, B.H. 1977a. A new gene for resistance to Puccinia hordei in certain Ethiopian barleys. Cereal Rusts Bull. 5:39-43.

Tan, B.H. 1977b. Evaluating host differentials of Puccinia hordei. Cereal Rusts Bull. 5:17-23.

Tan, B.H. 1978. Verifying the genetic relationships between three leaf rust resistance genes in barley. Euphytica 27:317-323.

Tiffney, B.H., and E.S. Barghoorn. 1974. The fossil record of the fungi. Occassional Pap. Farlow Herb. Cryptogam. Bot. 7:1-42.

Tosa, Y. 1992. A model for the evolution of formae speciales and races. Phytopathology:728-730.

Tuleen, N.A., and M.E. McDaniel. 1971. Location of genes Pa and Pa5. Barley Newsl. 15:106-107.

Ullrich, S.E. 2011. Barley: Production, Improvement, and Uses. Wiley-Blackwell, Ames, IA, USA. 
USDA. 2017. World Agricultural Production. Circ. Ser. August 2016 (WAP 816):1-29.

Valjavec-Gratian, M., and B.J. Steffenson. 1997. Pathotypes of Cochliobolus sativus on Barley in North Dakota. Plant Dis. 81:1275-1278.

Voorrips, R.E. 2002. MapChart: Software for the graphical presentation of linkage maps and QTLs. J. Hered. 93:77-78.

Walther, U. 1987. Inheritance of resistance to Puccinia hordei Otth in the spring barley variety Trumpf. Cereal Rusts Bull. 15:20-26.

Wan, A., and X. Chen. 2014. Virulence characterization of Puccinia striiformis $\mathrm{f}$. $\mathrm{sp}$. tritici using a new set of $\mathrm{Yr}$ single-gene line differentials in the United States in 2010. Phytopathology 98:1534-1542.

Waterhouse, W.L. 1927. Studies in the inheritance of resistance to leaf rust, Puccinia anomala Rostr., in crosses of barley. I. J. Proc. R. Soc. New South Wales 61:218-247.

Watson, I.A., and F.C. Butler. 1947. Resistance to barley leaf rust (Puccinia anomala Rost.). Proc. Linn. Soc. New South Wales 72:379-386.

Weerasena, J.S., B.J. Steffenson, and A.B. Falk. 2004. Conversion of an amplified fragment length polymorphism marker into a co-dominant marker in the mapping of the Rph15 gene conferring resistance to barley leaf rust, Puccinia hordei Otth. Theor. Appl. Genet. 108:712-9.

Wendler, N., M. Mascher, C. Nöh, A. Himmelbach, U. Scholz, B. Ruge-Wehling, and N. Stein. 2014. Unlocking the secondary gene-pool of barley with nextgeneration sequencing. Plant Biotechnol. J. 12:1122-1131.

Whelan, H.G., R.E. Gaunt, and W.R. Scott. 1997. The effect of leaf rust (Puccinia hordei) on yield response in barley (Hordeum vulgare L.) crops with different yield potentials. Plant Pathol. 46:397-406.

Williamson, B., B. Tudzynski, P. Tudzynski, and J.A.L. Van Kan. 2007. Botrytis cinerea: The cause of grey mould disease. Mol. Plant Pathol. 8:561-580.

Wilten, W. 1953. Fighting dwarf rust (Puccinia simplex) in summer barley. Notebook of the Natl. Committee for Brewers 17:72-79. (In Dutch)

Woldeab, G., C. Fininsa, H. Singh, and J. Yuen. 2006. Virulence spectrum of Puccinia hordei in barley production systems in Ethiopia. Plant Pathol. 55:351-357.

Woldeab, G., J. Yuen, C. Fininsa, and H. Singh. 2007. Barley leaf rust (Puccinia hordei Otth) in three production systems and practices in Ethiopia. Crop Prot. 26:1193-1202.

Yahyaoui, A.H. 1986. Epidemiology of Puccinia hordei and new sources of resistance in barley. Ph.D. Thesis. Montana State University, Bozeman.

Yahyaoui, A.H., E.L. Sharp, and M. Reinhold. 1988. New sources of resistance to Puccinia hordei in barley land race cultivars. Phytopathology 78:905-908. 
Yu, X., H.Y. Kong, V. Meiyalaghan, S. Casonato, S. Chng, E.E. Jones, R.C. Butler, R. Pickering, and P.A. Johnston. 2018. Genetic mapping of a barley leaf rust resistance gene Rph26 introgressed from Hordeum bulbosum. Theor. Appl. Genet. In press.

Zhong, S., R.J. Effertz, Y. Jin, J.D. Franckowiak, and B.J. Steffenson. 2003. Molecular mapping of the leaf rust resistance gene Rph6 in barley and its linkage relationships with Rph5 and Rph7. Phytopathology 93:604-609.

Zhou, B., R. V. Mural, X. Chen, M.E. Oates, R.A. Connor, G.B. Martin, J. Gough, and L. Zeng. 2017. A subset of ubiquitin-conjugating enzymes Is essential for plant immunity. Plant Physiol. 173:1371-1390.

Ziems, L.A., L.T. Hickey, G.J. Platz, J.D. Franckowiak, P.M. Dracatos, D. Singh, and R.F. Park. 2017. Characterisation of Rph24: A gene conferring adult plant resistance to Puccinia hordei in barley. Phytopathology 107: 834-841. Zimmer, D.E., J.F. Schafer, and F.L. Patterson. 1963. Mutations for virulence in Puccinia coronata. Phytopathology 53:171-176.

Zloten, R.R. 1952. The inheritance of reaction to leaf rust in barley. M.S. thesis. University of Manitoba, Winnipeg. 
Appendix Table 1. Accession details for the 24 barley leaf rust differential lines used in this study.

\begin{tabular}{|c|c|c|c|c|c|}
\hline Line Name ${ }^{1}$ & Accession Number ${ }^{2}$ & Gene & Country & Improvement Status $^{3}$ & Donor ${ }^{4}$ \\
\hline Sudan & Clho 6489 & Rph1 & Portugal & Cultivar & Brian Steffenson \\
\hline Peruvian & Clho 2441 & Rph2 & Peru & Landrace & Brian Steffenson \\
\hline Estate & $\mathrm{Cl} 3410$ & Rph3 & Egypt & Landrace & Brian Steffenson \\
\hline Gold & Clho 1145 & Rph4 & Sweden & Cultivar & Brian Steffenson \\
\hline Magnif 102 & PI 337140 & Rph5 & Argentina & Cultivar & Brian Steffenson \\
\hline Bolivia New & $\mathrm{Cl} 1257$ & Rph6 & Bolivia & Landrace & Brian Steffenson \\
\hline Cebada Capa & $\mathrm{Cl} 6193$ & Rph7 & Argentina & Cultivar & Brian Steffenson \\
\hline Egypt 4 & $\mathrm{Cl} 6481$ & Rph8 & Egypt & Unknown & Brian Steffenson \\
\hline Hor 2596 & $\mathrm{Cl} 1243$ & Rph9 & Ethiopia & Landrace & Brian Steffenson \\
\hline Clipper BC 8 & GSHO 1588 & Rph10 & Israel & H.v.s. introgression & Brian Steffenson \\
\hline Clipper BC 67 & GSHO 1589 & Rph11 & Israel & H.v.s. introgression & Brian Steffenson \\
\hline Triumph & PI 290195 & Rph12 & Germany & Cultivar & Brian Steffenson \\
\hline PI 531849 & PI 531849 & Rph13 & Unknown & H.v.s. introgression & Brian Steffenson \\
\hline PI 584760 & PI 584760 & Rph14 & Egypt & Breeding line & Brian Steffenson \\
\hline $195-282-2$ & PI355447/5*Bowman & Rph15 & Israel & H.v.s. introgression & Brian Steffenson \\
\hline HOR15560 & $\mathrm{HSO78}+\mathrm{HSO84}$ & Rph16 & Israel & H.v.s. introgression & Robert Park \\
\hline 81882/BS1 & - & Rph17 & Unknown & H.b. introgression & Robert Park \\
\hline $38 \mathrm{P} 18 / 8 / 1 / 10$ & - & Rph18 & Unknown & H.b. introgression & Robert Park \\
\hline Prior & Cl 5051 & Rph2+19 & Australia & Cultivar & Robert Park \\
\hline Flagship & - & Rph20 & Australia & Cultivar & Robert Park \\
\hline Ricardo & PI 328933 & $R p h 2+21$ & Denmark & Cultivar & Robert Park \\
\hline 182Q20/1/M1 & - & Rph22 & Unknown & H.b. introgression & NorGen \\
\hline Yerong & PI 573730 & Rph23 & Australia & Cultivar & Robert Park \\
\hline ND24260 & - & Rph24 & United States & Breeding line & Jerry Franckowial \\
\hline
\end{tabular}

${ }^{1 .}$ The original names given for each of the differential lines for Rph1-24.

2. The accession numbers for each differential line used to search in genebank databases.

- ${ }^{3}$ Improvement status indicates the level of domestication for each of the differential lines. Hordeum vulgare subsp. spontaneum and Hordeum bulbosum are

$\vec{\circ}$ respectively abbreviated as H.v.s. and H.b.

4. The research scientist who provided stocks for each of the differential lines. 
Appendix Table 2. Accession details for the barley cultivar Bowman and the 95 donors of leaf rust resistance used in this study.

\begin{tabular}{|c|c|c|c|c|c|}
\hline BW Line ${ }^{1}$ & Parental Accession $^{2}$ & Other ID & Origin & Status $^{3}$ & Pedigree $^{4}$ \\
\hline- & Bowman & PI 483237 & North Dakota, USA & Cultivar & $\begin{array}{l}\text { Klages//Fergus/Nordic/3/ND115 } \\
6 / 4 / \text { Hector }\end{array}$ \\
\hline BW667 & PI 405338 & HS 733 & Israel & Wild & - \\
\hline BW668 & PI 405169 & HS 534 & Israel & Wild & - \\
\hline BW669 & PI 405298 & HS 689 & Israel & Wild & - \\
\hline BW670 & PI 391007 & HS 520 & Israel & Wild & - \\
\hline BW671 & PI 466470 & 6 & Northern Israel & Wild & - \\
\hline BW672 & PI 466373 & 40 & Southern Israel & Wild & - \\
\hline BW673 & PI 405305 & HS 697 & Israel & Wild & - \\
\hline BW674 & PI 466245 & 3157 & Israel & Wild & - \\
\hline BW675 & Gija/Tanekase & - & - & - & - \\
\hline BW676 & PI 531990 & 2712 & Egypt & Wild & - \\
\hline BW677 & PI 531853 & 2280 & Northern Israel & Wild & - \\
\hline BW678 & PI 354926 & HS 527 & Israel & Wild & - \\
\hline BW679 & PI 282610 & 11001 & Israel & Wild & - \\
\hline BW680 & PI 391049 & HS 705 & Israel & Wild & - \\
\hline BW681 & PI 391044 & HS 665 & Israel & Wild & - \\
\hline BW682 & CIho 6489 & Sudan & Lisbon, Portugal & Unknown & - \\
\hline BW683 & Clipper BC8 & GSHO 1588 & Australia & Introgreesion line & - \\
\hline BW684 & Clipper BC67 & GSHO 1589 & Australia & Introgreesion line & - \\
\hline BW685 & PI 531849 & BS 99-2-1 & England & Introgreesion line & Berac*3/HS 2986 \\
\hline BW686 & PI 531901-1 & PI 584760 & Egypt & Wild & Selection from PI 531901 \\
\hline BW687 & PI 531901-2 & PI 584761 & Egypt & Wild & Selection from PI 531901 \\
\hline
\end{tabular}


Appendix Table 2 continued. Accession details for the barley cultivar Bowman and the 95 donors of leaf rust resistance used in this study.

\begin{tabular}{|c|c|c|c|c|c|}
\hline BW Line ${ }^{1}$ & Parental Accession $^{2}$ & Other ID & Origin & Status $^{3}$ & Pedigree $^{4}$ \\
\hline BW688 & PI 354940 & HS 708 & Israel & Wild & - \\
\hline BW689 & PI 405277 & HS 661 & Israel & Wild & - \\
\hline BW690 & PI 354923 & HS 498 & Israel & Wild & - \\
\hline BW691 & PI 391045 & HS 697 & Israel & Wild & - \\
\hline BW692 & PI 296841 & Dinoor No. 445 & Southern Israel & Wild & - \\
\hline BW693 & PI 354932 & HS 610 & Israel & Wild & - \\
\hline BW694 & PI 391002 & HS 506 & Israel & Wild & - \\
\hline BW695 & PI 391072 & - & Northern Israel & Wild & - \\
\hline BW696 & PI 391087 & - & Northern Israel & Wild & - \\
\hline BW697 & PI 391121 & - & Jerusalem, Israel & Wild & - \\
\hline BW698 & PI 405154 & HS 515 & Israel & Wild & - \\
\hline BW699 & PI 405194 & HS 564 & Israel & Wild & - \\
\hline BW700 & PI 405201 & HS 572 & Israel & Wild & - \\
\hline BW701 & PI 405215 & HS 587 & Israel & Wild & - \\
\hline BW702 & PI 405219 & HS 591 & Israel & Wild & - \\
\hline BW703 & PI 405233 & HS 607 & Israel & Wild & - \\
\hline BW704 & PI 405289 & HS 676 & Israel & Wild & - \\
\hline BW705 & PI 405308 & HS 701 & Israel & Wild & - \\
\hline BW706 & PI 405332 & HS 727 & Israel & Wild & - \\
\hline BW707 & PI 405335 & HS 730 & Israel & Wild & - \\
\hline BW708 & PI 405364 & HS 774 & Israel & Wild & - \\
\hline BW709 & PI 405399 & HS 819 & Israel & Wild & - \\
\hline BW710 & PI 405235 & HS 609 & Israel & Wild & - \\
\hline
\end{tabular}

$\overrightarrow{\mathrm{N}}$ 
Appendix Table 2 continued. Accession details for the barley cultivar Bowman and the 95 donors of leaf rust resistance used in this study.

\begin{tabular}{|c|c|c|c|c|c|}
\hline BW Line ${ }^{1}$ & Parental Accession $^{2}$ & Other ID & Origin & Status $^{3}$ & Pedigree $^{4}$ \\
\hline BW711 & PI 405311 & HS 704 & Israel & Wild & - \\
\hline BW712 & PI 354928 & HS 595 & Israel & Wild & - \\
\hline BW713 & PI 391000 & HS 503 & Israel & Wild & - \\
\hline BW714 & PI 391024 & HS 585 & Israel & Wild & - \\
\hline BW715 & PI 355444 & 665 & Israel & Wild & - \\
\hline BW716 & PI 405227 & HS 599 & Israel & Wild & - \\
\hline BW717 & PI 405236 & HS 610 & Israel & Wild & - \\
\hline BW718 & PI 405354 & HS 760 & Israel & Wild & - \\
\hline BW719 & PI 355447 & 703 & Israel & Wild & - \\
\hline BW720 & PI 391089 & - & Northern Israel & Wild & - \\
\hline BW721 & PI 354937 & HS 687 & Israel & Wild & - \\
\hline BW722 & PI 391069 & - & Northern Israel & Wild & - \\
\hline BW723 & PI 405179 & HS 544 & Israel & Wild & - \\
\hline BW724 & PI 405341 & HS 740 & Israel & Wild & - \\
\hline BW725 & PI 391004 & HS 511 & Israel & Wild & - \\
\hline BW726 & PI 405212 & HS 584 & Israel & Wild & - \\
\hline BW727 & PI 405209 & HS 580 & Israel & Wild & - \\
\hline BW728 & PI 355445 & 697 & Israel & Wild & - \\
\hline BW729 & PI 355434 & 504 & Israel & Wild & - \\
\hline BW730 & PI 405210 & HS 581 & Israel & Wild & - \\
\hline BW731 & PI 466247 & $3161-2$ & Israel & Wild & - \\
\hline BW732 & MSI 3351 & - & - & - & Selection from Aim/MSI3351 \\
\hline BW733 & PI 405220 & HS 592 & Israel & Wild & - \\
\hline BW734 & PI 466483 & 19 & Northern Israel & Wild & - \\
\hline
\end{tabular}


Appendix Table 2 continued. Accession details for the barley cultivar Bowman and the 95 donors of leaf rust resistance used in this study.

\begin{tabular}{|c|c|c|c|c|c|}
\hline BW Line ${ }^{1}$ & Parental Accession $^{2}$ & Other ID & Origin & Status $^{3}$ & Pedigree $^{4}$ \\
\hline BW735 & Vada/H. bulbosum & 81882 & New Zealand & $\begin{array}{l}\text { Introgression } \\
\text { Line }\end{array}$ & $\begin{array}{l}\text { H. bulbosum introgression } \\
\text { line }\end{array}$ \\
\hline BW736 & Emir/H. bulbosum & $38 \mathrm{P} 18 / 9 / 4$ & New Zealand & $\begin{array}{l}\text { Introgression } \\
\text { Line }\end{array}$ & $\begin{array}{l}\text { H. bulbosum introgression } \\
\text { line }\end{array}$ \\
\hline BW737 & Peruvian & CIho 2441 & Cuzco, Peru & Landrace & Selection from PI 39150 \\
\hline BW738 & Batna & CIho 3391 & Algeria & Unknown & - \\
\hline BW739 & Juliaca & PI 39151 & Puno, Peru & Landrace & - \\
\hline BW740 & Q21861 & PI 584766 & $\begin{array}{l}\text { Western } \\
\text { Australia }\end{array}$ & Unknown & CIMMYT line \\
\hline BW741 & Quinn & PI 39401 & $\begin{array}{l}\text { New South } \\
\text { Wales, Australia }\end{array}$ & Landrace & - \\
\hline BW742 & Bolivia & PI 36360 & Oruro, Bolivia & Landrace & - \\
\hline BW743 & Reka I & CIho 5051 & $\begin{array}{l}\text { New South } \\
\text { Wales, Australia }\end{array}$ & Cultivar & $\begin{array}{l}\text { Selection from Cape or } \\
\text { Californian brewing type }\end{array}$ \\
\hline BW744 & PI 531841 & BS 78-3-4 & England & Introgreesion line & HJ $198 * 3 /$ HS 2310 \\
\hline BW745 & PC 249 & PI 584765 & $\begin{array}{l}\text { Federal District } \\
\text { Mexico }\end{array}$ & Unknown & $\begin{array}{l}\text { CI12823/CI585//CI9805.16D/ } \\
\text { 3/Cita } \\
\text { 'S'/4/Ga1//K1/2*CI2376/3/Glo } \\
\text { ria 'S' }\end{array}$ \\
\hline BW746 & Estate & PI 57700 & Sharqiya, Egypt & Landrace & - \\
\hline BW747 & PI 466324 & 10 & Haifa, Israel & Wild & - \\
\hline BW748 & Tunisia 25 & - & - & - & - \\
\hline BW749 & Tunisia 33 & - & - & - & - \\
\hline BW750 & Tunisia 29 & - & - & - & - \\
\hline BW751 & Columbia & PI 494520 & Montana, USA & Cultivar & Gus/Kombar \\
\hline
\end{tabular}


Appendix Table 2 continued. Accession details for the barley cultivar Bowman and the 95 donors of leaf rust resistance used in this study.

\begin{tabular}{llllll} 
BW Line $^{1}$ & Parental Accession $^{2}$ & Other ID & Origin & Status $^{\mathbf{3}}$ & Pedigree $^{\mathbf{4}}$ \\
\hline BW752 & Gold & CIho 1145 & Malmohus, Sweden & Cultivar & $\begin{array}{l}\text { Selection from landrace in } \\
\text { Gotlan region }\end{array}$ \\
\hline BW753 & Lechtaler & CIho 6488 & Portugal & Unknown & - \\
\hline BW754 & Quinn & PI 39401 & New South Wales, Australia & Landrace & - \\
\hline BW755 & Magnif 102 & PI 337140 & Buenos Aires, Argentina & Cultivar & Malteria Heda*4/Quinn \\
\hline BW756 & Bolivia & PI 36360 & Oruro, Bolivia & Landrace & - \\
\hline BW757 & Tunisia 17 & - & - & - & - \\
\hline BW758 & Cebada Capa & PI 539113 & Argentina & Cultivar & - \\
\hline BW759 & Egypt 4 & CIho 6481 & Germany & Unknown & - \\
\hline BW760 & Hor 2596 & CIho 1243 & Ethiopia & Landrace & - \\
\hline BW761 & Triumph & PI 290195 & Germany & Cultivar & $\begin{array}{l}\text { Selection from Scotch } \\
\text { Common }\end{array}$ \\
\hline
\end{tabular}

\footnotetext{
${ }^{1 .}$ Bowman leaf rust resistance introgression lines are abbreviated as "BW" followed by a numeric value.
}

2. Accession numbers are a combination of an abbreviation and a numerical identifier. PI stands for Plant Introduction, CIho stands

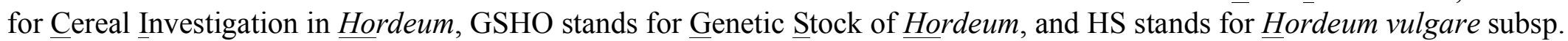
spontaneum.

3. Status indicates the level of domestication for each of the differential lines. Hordeum vulgare subsp. spontaneum and Hordeum bulbosum are respectively abbreviated as H.v.s. and H.b.

4. The known pedigrees used to develop each of the leaf rust resistant donor parents are listed. 
Appendix Table 3. Pedigrees and recognized $R p h$ genes in the 95 Bowman introgression lines used in this study.

\begin{tabular}{|c|c|c|c|c|}
\hline BW Line ${ }^{1}$ & Donor Parent $^{2}$ & Generation $^{3}$ & Pedigree $^{4}$ & Gene Identity $^{5}$ \\
\hline BW667 & PI 405338 & $\mathrm{BC}_{2} \mathrm{~F}_{3}$ & PI405338/3*Bowman & Rph15 \\
\hline BW668 & PI 405169 & $\mathrm{BC}_{3} \mathrm{~F}_{3}$ & Bowman*4/PI405169A & $?$ \\
\hline BW669 & PI 405298 & $\mathrm{BC}_{3} \mathrm{~F}_{3}$ & PI405298/4*Bowman & Rph15 \\
\hline BW670 & PI 391007 & $\mathrm{BC}_{3} \mathrm{~F}_{3}$ & PI391007/4*Bowman & Rph15 \\
\hline BW671 & PI 466470 & $\mathrm{BC}_{4} \mathrm{~F}_{3}$ & PI466470/5*Bowman & Rph15 \\
\hline BW672 & PI 466373 & $\mathrm{BC}_{4} \mathrm{~F}_{3}$ & Bowman*5//Moore/PI466373 & $?$ \\
\hline BW673 & PI 405303 & $\mathrm{BC}_{5} \mathrm{~F}_{3}$ & Bowman*6//Aim/PI405303 & Rph15 \\
\hline BW674 & PI 466245 & $\mathrm{BC}_{6} \mathrm{~F}_{3}$ & Bowman*7/PI466245 & Rph15 \\
\hline BW675 & Gija/Tanekase & $\mathrm{BC}_{6} \mathrm{~F}_{3}$ & Bowman*7//Gija 119/Tanekase & Rph3 \\
\hline BW676 & PI 531990 & $\mathrm{BC}_{7} \mathrm{~F}_{3}$ & Bowman*8/PI531990 & Rph5 \\
\hline BW677 & PI 531853 & $\mathrm{BC}_{5} \mathrm{~F}_{3}$ & Bowman*6/PI531853 & Rph9 \\
\hline BW678 & PI 354926 & $\mathrm{BC}_{3} \mathrm{~F}_{3}$ & Bowman*4/PI354926 & Rph15 \\
\hline BW679 & PI 282610 & $\mathrm{BC}_{5} \mathrm{~F}_{3}$ & Bowman*6/PI282610 & Rph15 \\
\hline BW680 & PI 391049 & $\mathrm{BC}_{5} \mathrm{~F}_{3}$ & PI391049/4*Bowman & Rph15 \\
\hline BW681 & PI 391044 & $\mathrm{BC}_{4} \mathrm{~F}_{3}$ & PI391044/ND13944//4*Bowman & Rph15 \\
\hline BW682 & Sudan & $\mathrm{BC}_{5} \mathrm{~F}_{3}$ & Bowman*6/Sudan & Rph1.a \\
\hline BW683 & Clipper BC8 & $\mathrm{BC}_{5} \mathrm{~F}_{3}$ & Clipper BC8/6*Bowman & Rph10.o \\
\hline BW684 & Clipper BC67 & $\mathrm{BC}_{5} \mathrm{~F}_{3}$ & Bowman*6/Clipper BC67 & Rph11.p \\
\hline BW685 & PI 531849 & $\mathrm{BC}_{6} \mathrm{~F}_{3}$ & Bowman*7/PI 531849 & Rph13.x \\
\hline BW686 & PI 584760 & $\mathrm{BC}_{4} \mathrm{~F}_{3}$ & Bowman*5/PI 584760 & Rph14.ab \\
\hline BW687 & PI 584761 & $\mathrm{BC}_{4} \mathrm{~F}_{3}$ & PI584761/5*Bowman & Rph3 \\
\hline BW688 & PI 354940 & $\mathrm{BC}_{4} \mathrm{~F}_{3}$ & PI354940/5*Bowman & Rph15 \\
\hline
\end{tabular}


Appendix Table 3 continued. Pedigrees and recognized $R p h$ genes in the 95 Bowman introgression lines used in this study.

\begin{tabular}{|c|c|c|c|c|}
\hline BW Line ${ }^{1}$ & Donor Parent $^{2}$ & Generation $^{3}$ & Pedigree $^{4}$ & Gene Identity $^{5}$ \\
\hline BW689 & PI 405277 & $\mathrm{BC}_{4} \mathrm{~F}_{3}$ & Bowman*5/PI405277 & Rph15 \\
\hline BW690 & PI 354923 & $\mathrm{BC}_{4} \mathrm{~F}_{3}$ & PI354923/5*Bowman & Rph15 \\
\hline BW691 & PI 391045 & $\mathrm{BC}_{4} \mathrm{~F}_{3}$ & Bowman*5/PI391045A het Eam1 & Rph15+? \\
\hline BW692 & PI 296841 & $\mathrm{BC}_{5} \mathrm{~F}_{3}$ & PI296841/6*Bowman & Rph15 \\
\hline BW693 & PI 354932 & $\mathrm{BC}_{5} \mathrm{~F}_{3}$ & PI354932/6*Bowman & Rph15 \\
\hline BW694 & Pi 391002 & $\mathrm{BC}_{5} \mathrm{~F}_{3}$ & PI391002/6*Bowman & Rph15 \\
\hline BW695 & PI 391072 & $\mathrm{BC}_{5} \mathrm{~F}_{3}$ & PI391072/6*Bowman & Rph15 \\
\hline BW696 & PI 391087 & $\mathrm{BC}_{5} \mathrm{~F}_{3}$ & PI391087/6*Bowman & Rph15 \\
\hline BW697 & PI 391121 & $\mathrm{BC}_{5} \mathrm{~F}_{3}$ & Bowman*6/PI391121 & Rph15+? \\
\hline BW698 & PI 405154 & $\mathrm{BC}_{5} \mathrm{~F}_{3}$ & Bowman*6/PI405154 & $?$ \\
\hline BW699 & PI 405194 & $\mathrm{BC}_{5} \mathrm{~F}_{3}$ & PI405194/6*Bowman & Rph15 \\
\hline BW700 & PI 405201 & $\mathrm{BC}_{5} \mathrm{~F}_{3}$ & Bowman*6/PI405201 & Rph15 \\
\hline BW701 & PI 405215 & $\mathrm{BC} 5 \mathrm{~F} 3$ & PI405215/ND13944//5*Bowman & $?$ \\
\hline BW702 & PI 405219 & $\mathrm{BC} 5 \mathrm{~F} 3$ & Bowman*6/PI405219 & Rph15 \\
\hline BW703 & PI 405233 & $\mathrm{BC} 5 \mathrm{~F} 3$ & PI405233/6*Bowman & Rph15 \\
\hline BW704 & PI 405289 & $\mathrm{BC} 5 \mathrm{~F} 3$ & PI405289/6*Bowman & Rph15 \\
\hline BW705 & PI 405308 & $\mathrm{BC} 5 \mathrm{~F} 3$ & PI405308/6*Bowman & Rph15 \\
\hline BW706 & PI 405332 & $\mathrm{BC} 5 \mathrm{~F} 3$ & Bowman*6/PI405332 & Rph15 \\
\hline BW707 & PI 405335 & $\mathrm{BC} 5 \mathrm{~F} 3$ & Bowman*6/PI405335 & Rph15 \\
\hline BW708 & PI 405364 & $\mathrm{BC} 5 \mathrm{~F} 3$ & Bowman*6/PI405364 & Rph15 \\
\hline BW709 & PI 405399 & $\mathrm{BC} 5 \mathrm{~F} 3$ & Bowman*6/PI405399 & Rph15+? \\
\hline BW710 & PI 405235 & $\mathrm{BC} 6 \mathrm{~F} 3$ & Bowman*7/PI405235 & Rph15 \\
\hline
\end{tabular}


Appendix Table 3 continued. Pedigrees and recognized $R p h$ genes in the 95 Bowman introgression lines used in this study.

\begin{tabular}{|c|c|c|c|c|}
\hline BW Line ${ }^{1}$ & Donor Parent $^{2}$ & Generation $^{3}$ & Pedigree $^{4}$ & Gene Identity $^{5}$ \\
\hline BW711 & PI 405311 & $\mathrm{BC}_{6} \mathrm{~F}_{3}$ & Bowman*7/PI405311 & Rph15 \\
\hline BW712 & PI 354928 & $\mathrm{BC}_{3} \mathrm{~F}_{3}$ & PI354928/4*Bowman & Rph15 \\
\hline BW713 & PI 391000 & $\mathrm{BC}_{5} \mathrm{~F}_{3}$ & PI391000/6*Bowman & Rph15 \\
\hline BW714 & PI 391024 & $\mathrm{BC}_{5} \mathrm{~F}_{3}$ & PI391024/6*Bowman & Rph15 \\
\hline BW715 & PI 355444 & $\mathrm{BC}_{5} \mathrm{~F}_{3}$ & Bowman*6/PI355444 & Rph15 \\
\hline BW716 & PI 405227 & $\mathrm{BC}_{5} \mathrm{~F}_{3}$ & Bowman*6/PI405227 & Rph15 \\
\hline BW717 & PI 405236 & $\mathrm{BC}_{5} \mathrm{~F}_{3}$ & PI405236/6*Bowman & Rph15 \\
\hline BW718 & PI 405354 & $\mathrm{BC}_{5} \mathrm{~F}_{3}$ & Bowman*6/PI405354A & Rph15 \\
\hline BW719 & PI 355447 & $\mathrm{BC}_{7} \mathrm{~F}_{3}$ & PI $355447 / 8 *$ Bowman & Rph15 \\
\hline BW720 & PI 391089 & $\mathrm{BC}_{7} \mathrm{~F}_{3}$ & PI391089/8*Bowman & Rph15 \\
\hline BW721 & PI 354937 & $\mathrm{BC}_{7} \mathrm{~F}_{3}$ & Bowman*8/PI354937 & Rph15 \\
\hline BW722 & PI 391069 & $\mathrm{BC}_{7} \mathrm{~F}_{3}$ & Bowman*8/PI391069 & Rph15 \\
\hline BW723 & PI 405179 & $\mathrm{BC}_{3} \mathrm{~F}_{3}$ & PI405179/4*Bowman 0:cn & Rph15 \\
\hline BW724 & PI 405341 & $\mathrm{BC}_{5} \mathrm{~F}_{3}$ & Bowman*6/PI405341 & Rph15 \\
\hline BW725 & PI 391004 & $\mathrm{BC}_{6} \mathrm{~F}_{3}$ & PI391004/7*Bowman Translocation & Rph15 \\
\hline BW726 & PI 405212 & $\mathrm{~F}_{3}$ & HS 584/Bowman & $?$ \\
\hline BW727 & PI 405209 & $\mathrm{~F}_{4}$ & HS 580/Bowman & $?$ \\
\hline BW728 & PI 355445 & $\mathrm{BC}_{3} \mathrm{~F}_{3}$ & Bowman*4/PI355445 & $?$ \\
\hline BW729 & PI 355434 & $\mathrm{BC}_{4} \mathrm{~F}_{3}$ & Bowman*5/PI355434 & Rph15 \\
\hline BW730 & PI 405210 & $\mathrm{BC}_{4} \mathrm{~F}_{3}$ & PI405210/5*Bowman & Rph15 \\
\hline BW731 & PI 466247 & $\mathrm{BC}_{4} \mathrm{~F}_{3}$ & PI466247/5*Bowman & Rph9 \\
\hline BW732 & MSI 3351 & $\mathrm{BC}_{5} \mathrm{~F}_{3}$ & Bowman*6//AIM/MSI 3351 & Rph2 \\
\hline
\end{tabular}


Appendix Table 3 continued. Pedigrees and recognized $R p h$ genes in the 95 Bowman introgression lines used in this study.

\begin{tabular}{|c|c|c|c|c|}
\hline BW Line ${ }^{1}$ & Donor Parent $^{2}$ & Generation $^{3}$ & Pedigree $^{4}$ & Gene Identity $^{5}$ \\
\hline BW733 & PI 405220 & $\mathrm{BC}_{5} \mathrm{~F}_{3}$ & PI405220/6*Bowman & Rph15 \\
\hline BW734 & PI 466483 & $\mathrm{BC}_{5} \mathrm{~F}_{3}$ & PI466483/6*Bowman & Rph15 \\
\hline BW735 & 81882 (Vada/H. bulbosum) & $\mathrm{F}_{4}$ & 81882 Rph17.af/Bowman & Rph17 \\
\hline BW736 & 38P18/9/4 (Emir/H. bulbosum) & $\mathrm{BC}_{1} \mathrm{~F}_{3}$ & Bowman*2/38P18-9-4 & Rph18 \\
\hline BW737 & Peruvian & $\mathrm{BC}_{2} \mathrm{~F}_{3}$ & Bowman*3/PERUVIAN & Rph2.b \\
\hline BW738 & Batna & $\mathrm{BC}_{5} \mathrm{~F}_{3}$ & BATNA/6*Bowman & Rph4 \\
\hline BW739 & Juliaca & $\mathrm{BC}_{3} \mathrm{~F}_{3}$ & Bowman*4/JULIACA $0 ; 1$ & Rph2.l \\
\hline BW740 & Q21861 & $\mathrm{BC}_{1} \mathrm{~F}_{3}$ & Bowman*2/Q21861 Rph2.Q & Rph3 \\
\hline BW741 & Quinn & $\mathrm{BC}_{4} \mathrm{~F}_{3}$ & QUINN/5*Bowman & Rph9 \\
\hline BW742 & Bolivia & $\mathrm{BC}_{4} \mathrm{~F}_{3}$ & Bowman*5/BOLIVIA & Rph2.r \\
\hline BW743 & Reka I & $\mathrm{BC}_{7} \mathrm{~F}_{3}$ & B0WMAN*8/REKA 1 & Rph2.t \\
\hline BW744 & PI 531841 & $\mathrm{BC}_{4} \mathrm{~F}_{3}$ & PI $531841 \mathrm{~A} / 5 *$ Bowman & Rph2.y \\
\hline BW745 & PC249 & $\mathrm{BC}_{5} \mathrm{~F}_{3}$ & PC249A/6*Bowman PI584765 & Rph3.aa \\
\hline BW746 & Estate & $\mathrm{BC}_{10} \mathrm{~F}_{3}$ & Bowman*11//CI3410/3.2 uz als MM & Rph3.c \\
\hline BW747 & PI 466324 & $\mathrm{BC}_{6} \mathrm{~F}_{3}$ & Bowman*7/PI466324 & Rph3.w \\
\hline BW748 & Tunisia 25 & $\mathrm{BC}_{4} \mathrm{~F}_{3}$ & Bowman*5/TUNISIA 25 & Rph5 \\
\hline BW749 & Tunisia 33 & $\mathrm{BC}_{5} \mathrm{~F}_{3}$ & Bowman*6/TUNISIA 33 & Rph19? \\
\hline BW750 & Tunisia 29 & $\mathrm{BC}_{5} \mathrm{~F}_{3}$ & Bowman*6/TUNISIA 29 & Rph5 \\
\hline BW751 & Columbia & $\mathrm{BC}_{5} \mathrm{~F}_{3}$ & $\begin{array}{l}\text { 12022/3/CMB822/BOW//Columbia/4/ } \\
6 * \text { Bowman }\end{array}$ & $?$ \\
\hline BW752 & Gold & $\mathrm{BC}_{5} \mathrm{~F}_{3}$ & GULL/6*Bowman & Rph4.d \\
\hline BW753 & Lechtaler & $\mathrm{BC}_{6} \mathrm{~F}_{3}$ & LECHTALER/7*Bowman & Rph4.d \\
\hline
\end{tabular}


Appendix Table 3 continued. Pedigrees and recognized Rph genes in the 95 Bowman introgression lines used in this study.

\begin{tabular}{lllll} 
BW Line $^{\mathbf{1}}$ & Donor Parent & Generation & Pedigree $^{\mathbf{4}}$ & Gene Identity $^{\mathbf{3}}$ \\
\hline BW754 & Quinn & BC7F3 & Bowman*8/QUINN & $R p h 9$ \\
\hline BW755 & Magnif 102 & BC7F3 & MAGNIF/8*Bowman & $R p h 5 . e$ \\
\hline BW756 & Bolivia & BC7F3 & Bowman*8/BOLIVIA & $R p h 5 . f$ \\
\hline BW757 & Tunisia 17 & BC7F3 & Bowman*8/TUNISIA 17 & $R p h 5$ \\
\hline BW758 & Cebada Capa & BC7F3 & Bowman*8/4/ND7771//CI6193/MT81 & $R p h 7 . g$ \\
\hline BW759 & Egypt 4 & BC5F3 & Bowman*6/EGYPT 4 & $R p h 8 . h$ \\
\hline BW760 & Hor2596 & BC7F3 & Bowman*8/HOR 2596 & $R p h 9 . i$ \\
\hline BW761 & Triumph & BC8F3 & Bowman*9/TRIUMPH & $R p h 9 . z$ \\
\hline
\end{tabular}

${ }^{1}$ Bowman leaf rust resistance introgression lines are abbreviated as "BW" followed by a numeric value.

2. The leaf rust resistance donor parent for the corresponding Bowman introgression line.

3. The backcross generation achieved for each Bowman introgression line.

4. The pedigree used to develop each Bowman introgression line.

5. The $R p h$ allele derived from each leaf rust resistance donor. 
Appendix Table 4. Details for the 12 Puccinia hordei isolates used to characterize 95 leaf rust resistant introgression lines in Bowman.

\begin{tabular}{llllll} 
Isolate $^{1}$ & Collector $^{2}$ & City & State & Country & Rph Vir $^{4}$ \\
\hline BR (Octal 11) & B. Clifford / E. Jones & Aberystwyth & Wales & United Kingdom & 1 \\
\hline Arg 231* & E. Antonelli & Castelar & - & Argentina & 3 \\
\hline WGCC & C. Roane & - & Virginia & USA & 4 \\
\hline Ger 7 & U. Walther & Hadmersleben & Sachsen-Anhalt & Germany & 4 \\
\hline Race 4* & C. Roane & - & Virginia & USA & 4 \\
\hline Aus 220* & R. Rees & Toowoomba & Queensland & Australia & 5 \\
\hline $98-20$ & B. Steffenson & Blacksburg & Virginia & USA & 9 \\
\hline $94-8 *$ & J. Franckowiak & Aleppo (Tel Hadya) & - & Syria & 10 \\
\hline BRS 76-12 & B. Clifford / E. Jones & Aberystwyth & Wales & United Kingdom & 10 \\
\hline Neth 28 & J. Parlievliet & Wageningen & Gelderland & Netherlands & 15 \\
\hline $90-3$ & A. Roelfs & Sha & Jerusalem HaGai & Israel & 16 \\
\hline $92-7$ & A. Roelfs & - & - & Morocco & 17 \\
\hline
\end{tabular}

1. The original isolate name designated by the original collector.

2. The name of the research scientist who first collected the $P$. hordei isolate.

3. Avr/Vir displays the combinations of avirulence and virulence genes of each isolate, respectively.

4. $R p h$ Vir indicates the number of $R p h$ genes for which an isolate is virulent. Asterisks indicate the four isolates also used by Chicaiza (1996). 
Appendix Table 5. Raw infection types ${ }^{1}$ of Bowman introgression lines postulated to carry $R p h 2, R p h 3, R p h 4, R p h 5, R p h 9$, or unknown resistance gene(s).

\begin{tabular}{|c|c|c|c|c|c|c|c|c|c|c|c|c|c|c|c|c|c|c|c|}
\hline \multirow[b]{3}{*}{ BW Line ${ }^{2}$} & \multirow[b]{3}{*}{ Gene $^{3}$} & \multicolumn{18}{|c|}{ Isolates of Puccinia hordei } \\
\hline & & \multicolumn{3}{|c|}{ BR (Octal 11) } & \multicolumn{3}{|c|}{ ARG231 } & \multicolumn{3}{|c|}{ Aus 220} & \multicolumn{3}{|c|}{ Race 4} & \multicolumn{3}{|c|}{ Ger 7} & \multicolumn{3}{|c|}{ WGCC } \\
\hline & & Rep1 & Rep2 & Rep3 & Rep1 & Rep2 & Rep3 & Rep1 & Rep2 & Rep3 & Rep1 & Rep2 & Rep3 & Rep1 & Rep2 & Rep3 & Rep1 & Rep2 & Rep3 \\
\hline BW743* & Rph2.t & $12-\mathrm{c}$ & $0 ; 12 \mathrm{c}$ & $120 ; \mathrm{c}$ & 213- & $0 ; 1 \mathrm{c}$ & $120 ;$ & $23-\mathrm{c}$ & $213-c$ & $23-1$ & 213-c & $213-c$ & $0 ; 12 \mathrm{c}$ & 32 & 33- & $3-2$ & 120 & $23-1 c$ & $120 ; c$ \\
\hline BW732 & $R p h 2$ & 21 & $0 ; 12 \mathrm{c}$ & $0 ; 1$ & $3-2$ & $0 ; 1-\mathrm{c}$ & $0 ; 1$ & $3-2$ & $0 ; 1 \mathrm{c}$ & $0 ; 1-\mathrm{cn}$ & $33+$ & $0 ; 12 \mathrm{c}$ & $0 ; 1 \mathrm{cn}$ & $3+3$ & 33- & 3 & $0 ; 1-\mathrm{c}$ & 3 & $0 ; 12 \mathrm{c}$ \\
\hline BW737 & $R p h 2 . b$ & $21 \mathrm{c}$ & $23-\mathrm{c}$ & $21 \mathrm{c}$ & 21 & $0 ; 1 \mathrm{c}$ & 10 & $23-1 c$ & $3-2 \mathrm{c}$ & $3-2$ & $120 ;$ & 213-c & $0 ; 12 \mathrm{c}$ & 3 & 3- & $3-2 \mathrm{c}$ & $21 \mathrm{c}$ & $213-c$ & $0 ; 12$ \\
\hline BW739 & Rph $2 . l$ & $21 \mathrm{c}$ & $10 ; \mathrm{c}$ & $120 ; \mathrm{c}$ & $21 \mathrm{c}$ & $0 ; 1-\mathrm{c}$ & $0 ; 12$ & $21 \mathrm{c}$ & $0 ; 12 \mathrm{c}$ & $0 ; 12$ & $3-21$ & 213- & $120 ; \mathrm{c}$ & $33+$ & 33- & 3 & $210 ;$ & $0 ; 12 \mathrm{c}$ & $0 ; 12 \mathrm{c}$ \\
\hline BW742 & Rph2.r & 21 & $0 ; 12 \mathrm{c}$ & $10 ; \mathrm{c}$ & 12 & $0 ; 1 \mathrm{c}$ & $120 ;$ & $3-2$ & 213-c & 23-1 & $120 ;$ & $23-1 \mathrm{c}$ & $120 ; \mathrm{c}$ & 23- & 3 & 213-c & $120 ;$ & $3-2 \mathrm{c}$ & $120 ; c$ \\
\hline BW744 & Rph2.y & 21 & $0 ; 12 \mathrm{c}$ & $120 ; \mathrm{c}$ & 213- & $0 ; 12 \mathrm{c}$ & $120 ;$ & $23-1 c$ & 213-c & $23-1$ & $210 ; \mathrm{c}$ & $0 ; 12 \mathrm{c}$ & $0 ; 12 \mathrm{c}$ & $33+$ & 33- & 3 & $120 ;$ & $213-c$ & $0 ; 12 c$ \\
\hline BW746* & Rph3.c & $0 ; 1-$ & $0 ; 1 \mathrm{c}$ & $0 ; 1 \mathrm{c}$ & $0 ; 1-$ & $00 ; \mathrm{c}$ & $0 ; 1-\mathrm{c}$ & $0 ; 1-\mathrm{c}$ & $0 ; 1-\mathrm{c}$ & $0 ; 1$ & $0 ; 1-$ & $0 ; 1 \mathrm{c}$ & $0 ; 12 \mathrm{c}$ & $00 ; 1$ & $00 ; \mathrm{cn}$ & $00 ; 2$ & $0 ; 1 \mathrm{c}$ & $0 ; 1 \mathrm{c}$ & $0 ; 1 \mathrm{c}$ \\
\hline BW675 & $R p h 3$ & $0 ; 1-\mathrm{c}$ & $00 ;$ & $0 ; 1$ & $0 ; 1-$ & $00 ; 1$ & $0 ; 1-$ & $0 ; 1 \mathrm{c}$ & $00 ; 1 \mathrm{c}$ & $0 ; 1-$ & $00 ; 1-$ & $0 ; 1-$ & $0 ; n$ & $00 ; 1-$ & $00 ; n$ & $00 ; 2$ & $0 ; 1-\mathrm{c}$ & $0 ; 1 \mathrm{c}$ & $0 ; 12 \mathrm{c}$ \\
\hline BW687 & $R p h 3$ & $0 ; 1-$ & $00 ; 1-\mathrm{cn}$ & $00 ; 1$ & $0 ; 1-$ & $0 ; \mathrm{c}$ & $00 ;$ & $0 ; 1-\mathrm{c}$ & $0 ; 1-\mathrm{c}$ & $0 ; 1-$ & $0 ; 1-$ & $0 ; 1-\mathrm{c}$ & $00 ; 1$ & $00 ; n$ & $00 ; 1=$ & 00 & $0 ; 1-$ & $0 ; 12 \mathrm{c}$ & $0 ; 12$ \\
\hline BW740 & $R p h 3$ & $0 ; 1-$ & $00 ; 2$ & 00 & $0 ; 1-$ & $00 ; 1-\mathrm{c}$ & 00 & $0 ; 1-\mathrm{c}$ & $0 ; 1-\mathrm{c}$ & $00 ;$ & 00 & $0 ; 1 \mathrm{c}$ & $00 ; n$ & 00 & $00 ; 2$ & $00 ; 1$ & $00 ; 1=$ & $0 ; 12 \mathrm{c}$ & $00 ; n$ \\
\hline BW745 & Rph3.aa & $10 ; \mathrm{c}$ & $0 ; 1-\mathrm{c}$ & $0 ; 1-$ & $0 ; 1-$ & $0 ; 1 \mathrm{c}$ & $00 ; 1$ & $12 \mathrm{c}$ & $0 ; 12 \mathrm{c}$ & $00 ; 1$ & $0 ; 1-$ & $0 ; 12$ & $00 ; 1$ & $00 ; 1=$ & $00 ; 2$ & $00 ; 1$ & $0 ; 1 \mathrm{c}$ & $0 ; 12 \mathrm{c}$ & $0 ; 12$ \\
\hline BW747 & Rph3.w & $0 ; 1-$ & $00 ; 1-\mathrm{c}$ & $00 ; 1$ & $0 ; 1-\mathrm{c}$ & $00 ; 1-\mathrm{c}$ & 00 & $0 ; 1-\mathrm{c}$ & $0 ; 1-\mathrm{c}$ & $0 ; 1-$ & $0 ; 1-$ & $0 ; 1 \mathrm{c}$ & $00 ; n$ & $00 ; 1$ & $00 ; 2$ & $00 ; 2$ & $00 ; 1-n$ & $0 ; 12 \mathrm{c}$ & $0 ; 12 \mathrm{c}$ \\
\hline BW752* & Rph4.d & 213- & $3-2$ & $3-\mathrm{c}$ & 21 & $23-\mathrm{c}$ & $120 ; \mathrm{c}$ & $210 ; \mathrm{c}$ & $0 ; 1-\mathrm{c}$ & 120 & $210 ;$ & $120 ; \mathrm{c}$ & $0 ; 1 \mathrm{c}$ & $3-2$ & 3 & 3 & $23-1$ & $120 ; \mathrm{c}$ & $0 ; 1$ \\
\hline BW738 & $R p h 4$ & $21 \mathrm{c}$ & 23-c & $3-2$ & $21 \mathrm{c}$ & 23-c & $120 ; \mathrm{c}$ & $0 ; 1-\mathrm{c}$ & $0 ; 12 \mathrm{c}$ & $0 ; 1$ & $120 ;$ & 213-c & $0 ; 12 \mathrm{c}$ & 33- & 33- & 3 & 213-c & $0 ; 12 \mathrm{c}$ & $0 ; 12 \mathrm{c}$ \\
\hline BW753 & Rph4.d & $23-1$ & 3-2 & $3-2$ & $12 \mathrm{c}$ & $23-1$ & 213- & $10 ; \mathrm{c}$ & $0 ; 12 \mathrm{c}$ & $120 ;$ & $12 \mathrm{c}$ & 3 & 3- & 3 & 3 & 3 & 33- & 3 & $0 ; 1 \mathrm{c}$ \\
\hline
\end{tabular}


Appendix Table 5 continued. Raw infection types' of Bowman introgression lines postulated to carry $R p h 2, R p h 3, R p h 4, R p h 5$, Rph9, or unknown resistance gene(s).

$$
\text { BR (Octal 11) }
$$

ARG231 Isolates of Puccinia hordei

BW Line ${ }^{2}$ Gene $^{3} \quad$ Rep1 Rep2 Rep3 Rep1 Rep2 Rep3 Rep1 Rep2 Rep3 Rep1 Rep2 Rep3 Rep1 Rep2 Rep3 Rep1 Rep2 Rep3

\begin{tabular}{|c|c|c|c|c|c|c|c|c|c|c|c|c|c|c|c|c|c|c|c|}
\hline BW755* & Rph5.e & $1-1$ & $0 ; 1-\mathrm{c}$ & $0 ; 1$ & 12 & $3-2$ & $23-c$ & $3-2$ & 3 & 3 & $213-c$ & $3-2$ & $120 ; \mathrm{c}$ & $21 \mathrm{c}$ & $120 ; \mathrm{c}$ & $120 ; \mathrm{c}$ & $3-2$ & 3 & 3 \\
\hline BW756* & Rph5.f & $1=0$ & $0 ; 1 \mathrm{c}$ & $0 ; 1$ & $3-2$ & $3-2$ & 3- & 33- & 3 & 3 & $213-c$ & $3-2$ & 12 & $21 \mathrm{c}$ & $213-c$ & $21 \mathrm{c}$ & $3-2$ & 3 & 3 \\
\hline BW676 & Rph5 & $1-1$ & $0 ; 1 \mathrm{c}$ & $10 ; c$ & 23- & $3-2 c$ & $3-2$ & 3- & 3 & 3 & $33+$ & 3- & 23-c & 213- & $23-\mathrm{c}$ & $213-c$ & 213- & 3 & 3- \\
\hline BW748 & Rph5 & 11- & $0 ; 1 \mathrm{c}$ & $10 ;$ & 213- & $3-2$ & 213- & $3-2$ & 33- & 3 & 33- & $23-\mathrm{c}$ & 213- & $23-1 c$ & 23-c & $120 ; \mathrm{c}$ & $33=$ & 3- & $3-2$ \\
\hline BW750 & $R p h 5$ & $10 ; \mathrm{c}$ & $0 ; 1 \mathrm{c}$ & $10 ; c$ & $21 \mathrm{c}$ & 23-c & $3-2$ & $3-3$ & 33- & 3 & 23- & 33- & $3-2$ & $1 \mathrm{c}$ & 33- & $0 ; 12 \mathrm{c}$ & $21 \mathrm{c}$ & 3 & $3-2$ \\
\hline BW757 & Rph5 & $1-0$ & $10 ; \mathrm{c}$ & 10 & $21 \mathrm{c}$ & $120 ; \mathrm{c}$ & 3- & $3-2$ & $3-2$ & 3 & 23- & $23-\mathrm{c}$ & $3-2$ & $11-\mathrm{c}$ & 23-c & $210 ; \mathrm{c}$ & 213- & $33+$ & 3 \\
\hline BW760* & $R p h 9 . i$ & $11-\mathrm{c}$ & $0 ; 1 \mathrm{c}$ & 120 & $21 \mathrm{c}$ & $120 ; \mathrm{c}$ & $21 \mathrm{c}$ & $21 \mathrm{c}$ & $213-c$ & $3-2$ & 213- & $21 \mathrm{c}$ & $0 ; 1 \mathrm{c}$ & $0 ; 1-\mathrm{c}$ & $12 \mathrm{c}$ & $0 ; 1 \mathrm{c}$ & $213-c$ & $23-c$ & $0 ; 12 \mathrm{c}$ \\
\hline BW761* & $\operatorname{Rph} 9 . z$ & $11-\mathrm{c}$ & $0 ; 1 \mathrm{c}$ & $0 ; 1$ & $11-\mathrm{c}$ & $0 ; 1-\mathrm{c}$ & $0 ; 12 \mathrm{c}$ & $21 \mathrm{c}$ & $0 ; 12 \mathrm{c}$ & 120 & $10 ; \mathrm{c}$ & $0 ; 12 \mathrm{c}$ & $0 ; 1 \mathrm{c}$ & $0 ; 1-\mathrm{c}$ & $10 ; \mathrm{c}$ & $0 ; 1 \mathrm{c}$ & $11-\mathrm{c}$ & $10 ; \mathrm{cn}$ & $10 ; \mathrm{c}$ \\
\hline BW677 & $R p h 9$ & $21 \mathrm{c}$ & $0 ; 12 \mathrm{c}$ & $12 \mathrm{c}$ & $21 \mathrm{c}$ & $0 ; 1 \mathrm{c}$ & $21 \mathrm{c}$ & $213-c$ & $0 ; 1 \mathrm{c}$ & 12 & $0 ; 1 \mathrm{c}$ & $23-\mathrm{c}$ & $0 ; 12 \mathrm{c}$ & $10 ; \mathrm{c}$ & $10 ; \mathrm{c}$ & $0 ; 12 \mathrm{c}$ & $21 \mathrm{c}$ & $0 ; 1 \mathrm{c}$ & $0 ; 1 \mathrm{c}$ \\
\hline BW731 & Rph 9 & $1-0 ; \mathrm{c}$ & $0 ; 1 \mathrm{c}$ & $12 \mathrm{c}$ & $0 ; 1 \mathrm{c}$ & $0 ; 1 \mathrm{c}$ & $0 ; 1 \mathrm{c}$ & $0 ; 1-\mathrm{c}$ & $0 ; 1 \mathrm{c}$ & $0 ; 1 \mathrm{c}$ & $0 ; 1 \mathrm{c}$ & $10 ; \mathrm{c}$ & $0 ; 1 \mathrm{c}$ & $0 ; 1 \mathrm{c}$ & $0 ; 1 \mathrm{c}$ & $0 ; 1 \mathrm{c}$ & $10 ; \mathrm{c}$ & $0 ; 1 \mathrm{c}$ & $0 ; 1 \mathrm{c}$ \\
\hline BW741 & $R p h 9$ & $1-0 ; \mathrm{c}$ & $0 ; 1-\mathrm{c}$ & $0 ; 1 \mathrm{c}$ & $10 ; \mathrm{c}$ & $0 ; 1-\mathrm{c}$ & $120 ; \mathrm{c}$ & $21 \mathrm{c}$ & $0 ; 12 \mathrm{c}$ & $12 \mathrm{c}$ & $0 ; 12 \mathrm{c}$ & $0 ; 12 \mathrm{c}$ & $120 ; \mathrm{c}$ & $0 ; 1 \mathrm{c}$ & $10 ; \mathrm{cn}$ & $0 ; 12 \mathrm{c}$ & $11-\mathrm{c}$ & $12 \mathrm{cn}$ & $10 ; \mathrm{c}$ \\
\hline BW754 & $R p h 9$ & $1-0 ; \mathrm{c}$ & $0 ; 1 \mathrm{c}$ & $0 ; 1 \mathrm{c}$ & $12 \mathrm{c}$ & $0 ; \mathrm{cn}$ & $0 ; 1 \mathrm{c}$ & $12 \mathrm{c}$ & $0 ; 12 \mathrm{c}$ & $12 \mathrm{c}$ & $10 ; \mathrm{c}$ & $10 ; \mathrm{c}$ & $0 ; 12 \mathrm{c}$ & $0 ; 1 \mathrm{c}$ & $10 ; \mathrm{c}$ & $0 ; 1 \mathrm{c}$ & $10 ; \mathrm{c}$ & $120 ; \mathrm{c}$ & $10 ; \mathrm{c}$ \\
\hline BW735 & $?$ & $00 ; n$ & 00 & 00 & $00 ; n$ & $00 ; n$ & $00 ;$ & $00 ; n$ & $00 ; n$ & 00 & $00 ;$ & 00 & $00 ;$ & $00 ; n$ & 00 & 00 & $00 ;$ & 00 & 00 \\
\hline BW736 & $?$ & $00 ; \mathrm{n}$ & 00 & 00 & $00 ; n$ & $00 ; n$ & $00 ;$ & $00 ; n$ & $00 ; n$ & 00 & $00 ;$ & $00 ;$ & $00 ;$ & $00 ; 1=$ & 0 & 00 ; & $00 ;$ & $00 ;$ & 00 \\
\hline BW726 & $?$ & $0 ; 1-\mathrm{cn}$ & $0 ; \mathrm{cn}$ & $0 ;$ & $0 ; 1-\mathrm{cn}$ & & $120 ;$ & $00 ; 1-n$ & $00 ; \mathrm{n}$ & $0 ; n$ & $0 ; 1$-cn & $0 ; 1 \mathrm{c}$ & $0 ; 1-\mathrm{c}$ & $0 ; 1-\mathrm{cn}$ & & 0 & $0 ; 1-\mathrm{cn}$ & $0 ; 1 \mathrm{c}$ & 0 \\
\hline BW672 & $?$ & 213- & 23-c & $0 ; 1-\mathrm{cn}$ & 21 & $0 ; 1-\mathrm{cn}$ & $0 ; 1-\mathrm{cn}$ & $21 \mathrm{c}$ & $0 ; 1 \mathrm{c}$ & $0 ; 1-\mathrm{cn}$ & $0 ; 1-\mathrm{c}$ & $10 ; \mathrm{c}$ & $0 ; 1-\mathrm{c}$ & 33- & $21 \mathrm{c}$ & $0 ; 1 \mathrm{c}$ & $0 ; 1-\mathrm{c}$ & 23-c & $0 ; 1-\mathrm{c}$ \\
\hline BW727 & $?$ & 21 & $3-2 c$ & $23-1$ & 12 & 3-21 & 3 & $3-2$ & 33- & 3 & 3 & 3- & 213- & $33+$ & 33- & 3 & 33- & $33+$ & $3-2$ \\
\hline BW728 & $?$ & 21 & $3-2 c$ & $23-c$ & 213- & $120 ; \mathrm{c}$ & $3-2$ & $21 \mathrm{c}$ & $120 ; \mathrm{c}$ & $120 ; \mathrm{c}$ & $3+3$ & $3+$ & 3 & $3+3$ & 3 & 3 & $213-c$ & $21 \mathrm{c}$ & $10 ; \mathrm{c}$ \\
\hline BW749 & $?$ & 213-c & $120 ; \mathrm{c}$ & $210 ; \mathrm{c}$ & $21 \mathrm{c}$ & $0 ; 1 \mathrm{c}$ & 120 & $3-2 c$ & 213-c & $3-2$ & $3-3$ & 21 & 213- & 33- & 3 & 3 & $23-1$ & $213-c$ & $21 \mathrm{c}$ \\
\hline BW668 & $?$ & 33- & $3-2 c$ & 3- & 23- & 33- & $23-\mathrm{c}$ & $21-\mathrm{c}$ & $120 ; \mathrm{c}$ & $3-2$ & 33- & 3 & $23=$ & $3-2$ & 3 & $3-2$ & $213-c$ & 23-c & $21 \mathrm{c}$ \\
\hline BW698 & $?$ & 12- & $213-c$ & $120 ; \mathrm{c}$ & $3-2$ & 33- & 3- & & $23-\mathrm{c}$ & $21 \mathrm{c}$ & $3-3$ & 33- & 3- & 21 & 3 & $3-2$ & 21 & 3- & $21 \mathrm{c}$ \\
\hline BW701 & $?$ & 213- & 33- & $3-2$ & $3-3$ & 33- & 3- & $3-3$ & 3 & 3 & $3+3$ & 33- & 3 & 3 & 3 & 3 & $23-1$ & 3 & 3 \\
\hline BW751 & $?$ & 23- & 33- & 3- & 33- & 3 & 3 & $3-2$ & 33- & 3 & 33- & 3 & 3 & 23- & 3 & 3 & 3 & 3 & 3 \\
\hline
\end{tabular}

$\vec{\omega}$ 
Appendix Table 5 continued. Raw infection types' of Bowman introgression lines postulated to carry $R p h 2, R p h 3, R p h 4, R p h 5, R p h 9$, or unknown resistance gene(s).

\begin{tabular}{|c|c|c|c|c|c|c|c|c|c|c|c|c|c|c|c|c|c|c|c|}
\hline \multirow[b]{3}{*}{ BW Line ${ }^{2}$} & \multirow[b]{3}{*}{ Gene $^{3}$} & \multicolumn{18}{|c|}{ Isolates of Puccinia hordei } \\
\hline & & \multicolumn{3}{|c|}{ 98-20 } & \multicolumn{3}{|c|}{$94-8$} & \multicolumn{3}{|c|}{ BRS 76-12 } & \multicolumn{3}{|c|}{$90-3$} & \multicolumn{3}{|c|}{ Neth 28} & \multicolumn{3}{|c|}{$92-7$} \\
\hline & & Rep1 & Rep2 & Rep3 & Rep1 & Rep2 & Rep3 & Rep1 & Rep2 & Rep3 & Rep1 & Rep & Rep3 & Rep1 & Rep2 & Rep3 & Rep1 & Rep2 & Rep3 \\
\hline BW743* & Rph2.t & 23- & $3+$ & 3 & $3-2$ & 33- & $210 ; \mathrm{c}$ & $213-c$ & 33- & $213-c$ & 33- & 33- & 3- & $3-2 \mathrm{c}$ & $3-$ & 3- & $3-2 \mathrm{c}$ & 33- & 3- \\
\hline BW732 & $\operatorname{Rph} 2$ & $3-2$ & 33- & $3-2$ & $3-2 \mathrm{c}$ & $33-$ & 213- & $213-c$ & $3-2$ & $213-\mathrm{c}$ & $33-$ & $33-$ & $3-2$ & $3-2$ & $3-2$ & 3- & 3 & 33- & 3- \\
\hline BW737 & $R p h 2 . b$ & $3-2$ & 3 & 3 & $3-$ & 33- & 23- & $3-2$ & 33- & 213- & 3 & 3- & 33- & $3-2$ & $3-2$ & 3- & $3+3$ & 3- & 3 \\
\hline BW739 & Rph2.l & $23-1$ & 3- & 3 & 33- & 3 & $210 ;$ & $3-2 c$ & $23-c$ & $3-2 c$ & 33- & 33- & 33- & 33- & 23- & $3-2$ & $33+c$ & 33- & 3- \\
\hline BW742 & $R p h 2 . r$ & 23- & $3+$ & 3 & 33- & 3 & $210 ; \mathrm{c}$ & $3-2$ & $23-\mathrm{c}$ & $23-1 c$ & 33- & 3 & 3- & $3-2$ & $3-$ & $3-$ & $3-2 c$ & 33- & 3- \\
\hline BW744 & Rph $2 . y$ & 23- & 33- & $3-2$ & 33- & 3 & 23- & $23-1 c$ & $3-2$ & $23-1 c$ & $3-2$ & 3- & 33- & $3-2$ & 2 & 3- & 33- & 3- & $3-$ \\
\hline BW746* & Rph3.c & $0 ; \mathrm{cn}$ & $0 ; 1 \mathrm{c}$ & $00 ;$ & $0 ; 1-\mathrm{c}$ & $00 ; 1-\mathrm{c}$ & 0 & $3-2 c$ & $33-\mathrm{c}$ & 23-c & $120 ; \mathrm{c}$ & $21 \mathrm{c}$ & 213-c & 23- & 23- & 3- & 3 & 3- & $3-2$ \\
\hline BW675 & $R p h 3$ & $0 ; 1-\mathrm{cn}$ & $1-0 ; \mathrm{cn}$ & $00 ; 1$ & $0 ; 1-\mathrm{c}$ & $00 ; 1$ & 00 ; & $3-2$ & 33- & $210 ; \mathrm{c}$ & $21 \mathrm{c}$ & $21 \mathrm{c}$ & 213-c & 33- & $23-$ & $3-2$ & 33- & 3 & 3 \\
\hline BW687 & Rph 3 & 0 & $10 ; \mathrm{c}$ & 00 & $0 ; 1 \mathrm{c}$ & $00 ; 1-\mathrm{c}$ & 00 & $23-1 c$ & 23- & 213- & $210 ; \mathrm{c}$ & $21 \mathrm{c}$ & $213-c$ & $213-c$ & 213- & 3- & 23- & 3- & \\
\hline BW740 & $R p h 3$ & $0 ; 1-\mathrm{c}$ & $00 ; 1 \mathrm{n}$ & $00 ; 1$ & $0 ; 1-\mathrm{c}$ & $00 ; 2 \mathrm{c}$ & 00 & $3-2$ & 33- & $210 ; \mathrm{c}$ & $210 ; \mathrm{c}$ & $12 \mathrm{c}$ & $0 ; 12 \mathrm{c}$ & 33- & 33- & $3-21$ & $33+$ & 33- & 3 \\
\hline BW745 & Rph3.aa & $0 ; 1-\mathrm{c}$ & $00 ; 1$ & 00 & $0 ; 1-\mathrm{c}$ & $00 ; 1 \mathrm{c}$ & 00 ; & $213-c$ & 23-c & $3-2$ & $10 ; \mathrm{c}$ & 3- & 213-c & 23- & 23- & $3-2$ & 33- & 33- & \\
\hline BW747 & Rph $3 . w$ & $00 ; 2 \mathrm{c}$ & 00 & $00 ;$ & $0 ; 1-\mathrm{c}$ & $00 ; 1-\mathrm{c}$ & 00 & $3-2 c$ & $3-2 \mathrm{c}$ & $3-2 c$ & $120 ; \mathrm{c}$ & $21 \mathrm{c}$ & $210 ; \mathrm{c}$ & 3- & $3-2$ & 3 & 3- & 3- & 3 \\
\hline BW752* & $R p h 4 . d$ & 3 & 3 & $23-1$ & $3-2$ & $33+$ & $21 \mathrm{c}$ & $3-2$ & 33- & $23-c$ & 33- & 3 & $3-2$ & $210 ; \mathrm{c}$ & $120 ; \mathrm{c}$ & $0 ; 12 \mathrm{c}$ & 3 & 3 & 3 \\
\hline BW738 & $R p h 4$ & $23-1$ & 3 & 3 & 23- & 33- & $210 ; \mathrm{c}$ & $3-2 c$ & $23-\mathrm{c}$ & $3-2$ & $3-2$ & 3 & 33- & $210 ; \mathrm{c}$ & 21 & $120 ; \mathrm{c}$ & 33- & 33- & 3 \\
\hline BW753 & Rph4.d & 33- & 3 & 23- & $3-2$ & $33+$ & 23- & $3-2 c$ & 23- & 23-1c & $3-2$ & 33- & 3 & 213- & $10 ; \mathrm{c}$ & $120 ; \mathrm{c}$ & $23-c$ & 33- & 3- \\
\hline
\end{tabular}

$\overrightarrow{\vec{A}}$ 
Appendix Table 5 continued. Raw infection types ${ }^{1}$ of Bowman introgression lines postulated to carry $R p h 2, R p h 3, R p h 4, R p h 5, R p h 9$, or unknown resistance gene(s).

\begin{tabular}{|c|c|c|c|c|c|c|c|c|c|c|c|c|c|c|c|c|c|c|c|}
\hline \multirow[b]{3}{*}{ BW Line ${ }^{2}$} & \multirow[b]{3}{*}{ Gene $^{3}$} & \multicolumn{18}{|c|}{ Isolates of Puccinia hordei } \\
\hline & & \multicolumn{3}{|c|}{$98-20$} & \multicolumn{3}{|c|}{$94-8$} & \multicolumn{3}{|c|}{ BRS 76-12 } & \multicolumn{3}{|c|}{$90-3$} & \multicolumn{3}{|c|}{ Neth 28} & \multicolumn{3}{|c|}{$92-7$} \\
\hline & & Rep1 & Rep2 & Rep3 & Rep1 & Rep2 & Rep3 & Rep1 & Rep2 & Rep3 & Rep1 & $\begin{array}{c}\text { Rep } \\
2\end{array}$ & Rep3 & Rep1 & Rep2 & Rep3 & Rep1 & Rep2 & Rep3 \\
\hline BW755* & Rph5.e & $120 ; \mathrm{c}$ & $10 ; \mathrm{c}$ & $0 ; 12$ & $10 ; \mathrm{c}$ & $10 ; \mathrm{c}$ & $0 ; 1-$ & $3-2 \mathrm{c}$ & 33- & $210 ; \mathrm{c}$ & 3- & 33- & 3 & 3- & 3- & $3-2$ & 33- & 33- & 3- \\
\hline BW676 & Rph5 & $21 \mathrm{c}$ & $00 ; 1$ & 120 & $10 ; \mathrm{c}$ & $0 ; 1 \mathrm{c}$ & $0 ; 12 \mathrm{c}$ & $3-2 \mathrm{c}$ & 33- & $23-1 \mathrm{c}$ & $33-\mathrm{c}$ & $33+$ & 33- & $3-2$ & 3- & $3-2$ & 33- & 3 & 3- \\
\hline BW748 & Rph5 & $12 \mathrm{c}$ & $10 ; \mathrm{c}$ & $0 ; 12$ & $10 ; \mathrm{c}$ & $0 ; 1 \mathrm{c}$ & $0 ; 1-$ & $3-2 c$ & 3-c & $213-\mathrm{c}$ & 3 & $3-2$ & $3-2$ & $3-2 \mathrm{c}$ & 33- & 3- & 3 & 33- & 3- \\
\hline BW750 & Rph5 & $10 ; \mathrm{c}$ & 10 & 120 & $10 ; \mathrm{c}$ & $0 ; 1 \mathrm{c}$ & $0 ; 1-$ & 33- & 33- & $210 ; \mathrm{c}$ & $3+$ & 33- & 3 & 3 & 3 & $3-2$ & $3+3$ & 33- & 3- \\
\hline BW757 & Rph5 & $120 ; \mathrm{c}$ & $120 ; \mathrm{c}$ & 120 & $120 ; \mathrm{c}$ & $10 ; \mathrm{c}$ & $0 ; 1$ & 23-c & $21 \mathrm{c}$ & $23-1$ & 33- & 33- & $3-2$ & $3-2$ & 3 & $3-2$ & $3-2$ & 33- & 3- \\
\hline BW760* & $R p h 9 . i$ & $23-\mathrm{c}$ & $23-\mathrm{c}$ & 213- & $3-2$ & 33- & $213-c$ & $12 \mathrm{c}$ & $10 ; \mathrm{c}$ & $21 \mathrm{c}$ & 3 & 3- & 3 & $23-c$ & 33- & $3-2$ & 3-3 & & 3 \\
\hline BW761* & $\operatorname{Rph} 9 . z$ & $120 ; \mathrm{c}$ & $10 ; \mathrm{c}$ & $0 ; 12 \mathrm{c}$ & $3-3$ & $33+$ & 213- & $10 ; \mathrm{c}$ & $10 ; \mathrm{c}$ & $120 ; \mathrm{c}$ & 3 & 3 & 33- & $3-2 \mathrm{c}$ & 33- & $3-2$ & $3-2 c$ & 33- & \\
\hline BW677 & $R p h 9$ & $21 \mathrm{c}$ & $3-2 c$ & $3-2$ & $23-1 c$ & 23-c & $3-2 c$ & $0 ; 1-\mathrm{cn}$ & $10 ; \mathrm{c}$ & $0 ; 1 \mathrm{c}$ & $33-\mathrm{c}$ & 3 & 3- & $3-2 c$ & $23-\mathrm{c}$ & $23-\mathrm{c}$ & $21 \mathrm{c}$ & $2 \mathrm{c}$ & 3- \\
\hline BW731 & Rph 9 & $12 \mathrm{c}$ & $10 ; \mathrm{c}$ & 213- & $23-1 c$ & $213-c$ & $21 \mathrm{c}$ & $10 ; \mathrm{cn}$ & $10 ; \mathrm{c}$ & $0 ; 12 \mathrm{c}$ & $3-2$ & 33- & 3- & $213-c$ & $21 \mathrm{c}$ & $213-c$ & $21 \mathrm{c}$ & $10 ; \mathrm{c}$ & $210 ;$ \\
\hline BW741 & Rph 9 & $12 \mathrm{c}$ & $12 \mathrm{c}$ & $21 \mathrm{c}$ & $3-2$ & 3 & 3-c & $10 ; \mathrm{cn}$ & $10 ; \mathrm{c}$ & $0 ; 12 \mathrm{c}$ & 3 & 33- & 3 & $23-\mathrm{c}$ & 3- & $3-2$ & $3-2 c$ & 3- & 3- \\
\hline BW754 & Rph 9 & $12 \mathrm{c}$ & $12 \mathrm{c}$ & $21 \mathrm{c}$ & 33- & 33- & $213-c$ & $10 ; \mathrm{c}$ & $10 ; \mathrm{c}$ & $10 ;$ & 3- & 33- & $3-$ & $3-2$ & 23- & 3- & 3 & 33- & $3=$ \\
\hline BW735 & $?$ & 00 & 00 & 00 & 00 & 00 & 00 & 00 & 00 & 00 ; & 00 ; & 00 & 00 & 00 ; & 00 & 0 & $00 ;$ & $00 ;$ & 00 ; \\
\hline BW736 & $?$ & $00 ;$ & 0 & $00 ;$ & $00 ;$ & $0 ;$ & $00 ;$ & $00 ;$ & 0 & 00 ; & 00 & 0 & $00 ; n$ & 00 & $00 ;$ & $00 ;$ & $00 ; n$ & $00 ;$ & 00 \\
\hline BW726 & $?$ & $1-0 ; \mathrm{cn}$ & $10 ; \mathrm{c}$ & $0 ; 1 \mathrm{c}$ & $1-0 ; \mathrm{cn}$ & $1-0 ; \mathrm{cn}$ & $0 ; 1-\mathrm{cn}$ & $0 ; \mathrm{cn}$ & $00 ; n$ & 0 & 210 & $1 \mathrm{c}$ & $0 ; 12 \mathrm{c}$ & $120 ; \mathrm{c}$ & $0 ; 1 \mathrm{c}$ & $0 ; 1-\mathrm{c}$ & $0 ; 1 \mathrm{c}$ & $0 ; 1 \mathrm{c}$ & $0 ; 1 \mathrm{c}$ \\
\hline BW727 & $?$ & $3-2 c$ & $12 \mathrm{c}$ & 210 & $213-c$ & 10 & 120 & $3-2$ & $213-c$ & $0 ; 12$ & 33- & 3 & $3-2$ & 3- & 23- & $3-2$ & 3 & 3- & $3-2$ \\
\hline BW728 & $?$ & $3-2 c$ & $21 \mathrm{c}$ & 21 & $213-c$ & $12 \mathrm{c}$ & 213- & $3-2$ & $23-c$ & $3-2 c$ & 3 & 33- & 3- & 3- & $3-2$ & $210 ; \mathrm{c}$ & 3 & 3 & 3 \\
\hline BW749 & $?$ & 3 & 3 & 3-2 & $3-2$ & $3+$ & $23-1$ & 3-c & 3 & $3-2 c$ & 33- & 33- & 3- & $3-2$ & 33- & $33-$ & $3+3$ & 33- & $3-$ \\
\hline BW668 & $?$ & $3-2 c$ & $12 \mathrm{c}$ & $23-1$ & $213-c$ & $21 \mathrm{c}$ & $210 ; \mathrm{c}$ & $3-2 \mathrm{c}$ & 33- & $23-1 \mathrm{c}$ & 33- & 3- & 3 & $23-1$ & $21 \mathrm{c}$ & $23-\mathrm{c}$ & $3-2 c$ & $3-$ & $3-2$ \\
\hline BW698 & $?$ & $23-1$ & & 21 & 33- & 3- & $21 \mathrm{c}$ & 33- & $2 \mathrm{c}$ & $210 ;$ & $3-2$ & 33- & 33- & $3-$ & 3- & 3- & $33+$ & 3 & 33- \\
\hline BW701 & $?$ & 33- & $33+$ & $3-2$ & $3-2$ & 3 & 23-c & 33- & 33- & $210 ; \mathrm{c}$ & $3-2$ & 3 & 3- & $3-2$ & 23- & $3-2$ & $3+3$ & 3 & $3-2$ \\
\hline BW751 & $?$ & 3 & $33+$ & 23- & 33- & $33+$ & 23-c & $3-2$ & 33- & $210 ; \mathrm{c}$ & $33+$ & 33- & 3 & 3 & 3 & $3-2$ & $3+3$ & 3 & $3-$ \\
\hline
\end{tabular}

"Infection types were scored using the original 0-4 rating scale developed by Mains (1930) with the additional notations of "+" and "_" to indicate larger or smaller size variations of classically described uredinia (Levine and Cherewick, 1952) and "c" and " $n$ " to indicate the presence of chlorotic or necrotic reactions (Moseman and Roane, 1959), respectively. Complex ITs were recorded when more than one IT was observed on the surface of a single leaf. For example, an IT of 213-indicates that all three pustule types exist on the same leaf and that the "2" type pustules were the most common, followed by the "1" type, with " $3-$ " type pustules being the leas common. Infection types from " 0 ;" to " $0 ; 12$ " are classified as highly resistant ("R", green cells), infections types from "12" to "23-c" are classified as moderately resistant ("M", yellow cells), and infection types from "23-" to "33+" are classified as susceptible ("S", red cells) (Steffenson et al., 1993).

${ }^{2}$ BW lines are the 95 Bowman leaf rust resistance introgression lines.

3. The $R p h$ gene retained in each leaf rust resistant introgression line. 
Appendix Table 6. Raw infection types ${ }^{1}$ of 50 Bowman introgression lines postulated to carry Rph15.

\section{Isolates of Puccinia hordei}

BR (Octal 11) $\quad$ ARG231 $\quad$ Aus 220 $\quad$ Race 4

Ger 7

WGCC

BW Line ${ }^{2}$ Gene $^{3} \quad$ Rep1 Rep2 Rep3 Rep1 Rep2 Rep3 Rep1 Rep2 Rep3 Rep1 Rep2 Rep3 Rep1 Rep2 Rep3 Rep1 Rep2 Rep3

\begin{tabular}{|c|c|c|c|c|c|c|c|c|c|c|c|c|c|c|c|c|c|c|c|}
\hline BW719* & Rph15 & 1-cn & $0 ; 1-\mathrm{cn}$ & $0 ; 1-\mathrm{cn}$ & $0 ; \mathrm{cn}$ & $0 ; \mathrm{cn}$ & $0 ; 1-\mathrm{cn}$ & $0 ; \mathrm{cn}$ & $0 ; \mathrm{cn}$ & $0 ; \mathrm{cn}$ & $1-0 ; \mathrm{cn}$ & 1-cn & $1-0 ; \mathrm{cn}$ & $1-0 ; \mathrm{cn}$ & $0 ; 1$-cn & $0 ; 1$-cn & $1-0 ; \mathrm{cn}$ & $0 ; \mathrm{cn}$ & $0 ; \mathrm{cn}$ \\
\hline BW667 & Rph15 & $0 ; 1$-cn & $1-\mathrm{cn}$ & $0 ; 1-\mathrm{cn}$ & $0 ; 1$-cn & $0 ; \mathrm{cn}$ & $0 ; \mathrm{cn}$ & $0 ; \mathrm{cn}$ & $0 ; \mathrm{cn}$ & $0 ; \mathrm{cn}$ & $1-0 ; \mathrm{cn}$ & $1-0 ; \mathrm{cn}$ & $120 ; \mathrm{c}$ & $1-0 ; \mathrm{cn}$ & $1-\mathrm{cn}$ & $0 ; 1$-cn & $1-0 ; \mathrm{cn}$ & $0 ; \mathrm{cn}$ & $0 ; \mathrm{cn}$ \\
\hline BW669 & Rph15 & $0 ; 1$-cn & 1-cn & $0 ; 1-\mathrm{cn}$ & $0 ; \mathrm{cn}$ & $0 ; \mathrm{cn}$ & $0 ; 1$-cn & $0 ; \mathrm{cn}$ & $0 ; \mathrm{cn}$ & $0 ; \mathrm{cn}$ & $1-0 ; \mathrm{cn}$ & $0 ; 1$-cn & $1-0 ; \mathrm{cn}$ & $0 ; 1$-cn & 1-cn & $0 ; 1$-cn & $1-0 ; \mathrm{cn}$ & $0 ; \mathrm{cn}$ & $0 ; \mathrm{cn}$ \\
\hline BW670 & Rph15 & $0 ; 1$-cn & $0 ; \mathrm{cn}$ & $0 ; \mathrm{cn}$ & $0 ; 1$-cn & $0 ; \mathrm{cn}$ & $0 ; 1$-cn & $0 ; \mathrm{cn}$ & $0 ; \mathrm{cn}$ & $0 ; \mathrm{cn}$ & $1-0 ; \mathrm{cn}$ & $1 \mathrm{cn}$ & $12 \mathrm{cn}$ & $0 ; 1$-cn & $0 ; \mathrm{cn}$ & $0 ; \mathrm{cn}$ & $1-0 ; \mathrm{c}$ & $0 ; \mathrm{cn}$ & $0 ; \mathrm{cn}$ \\
\hline BW671 & Rph15 & $0 ; \mathrm{cn}$ & $0 ; \mathrm{cn}$ & $0 ; \mathrm{cn}$ & $1-\mathrm{cn}$ & $0 ; 1$-cn & $0 ; 1$-cn & $0 ; \mathrm{cn}$ & $0 ; 1$-cn & $0 ; \mathrm{cn}$ & $1-\mathrm{cn}$ & $1 \mathrm{cn}$ & $21 \mathrm{cn}$ & $0 ; \mathrm{cn}$ & $0 ; \mathrm{cn}$ & $0 ; \mathrm{cn}$ & $1 \mathrm{cn}$ & $1 \mathrm{cn}$ & $0 ; \mathrm{cn}$ \\
\hline BW673 & Rph15 & 1-cn & $0 ; \mathrm{cn}$ & $0 ; 1$-cn & $0 ; \mathrm{cn}$ & $0 ; \mathrm{cn}$ & $0 ; 1$-cn & $0 ; \mathrm{cn}$ & $0 ; 1-\mathrm{cn}$ & $0 ; \mathrm{cn}$ & $1-0 ; \mathrm{cn}$ & $0 ; 1$-cn & $0 ; 1-\mathrm{cn}$ & $0 ; 1-\mathrm{c}$ & $10 ; \mathrm{cn}$ & $0 ; 1-\mathrm{cn}$ & $0 ; 1$-cn & $0 ; \mathrm{cn}$ & $0 ; \mathrm{cn}$ \\
\hline BW674 & Rph15 & 1-cn & $0 ; \mathrm{cn}$ & $0 ; 1$-cn & $0 ; 1$-cn & $0 ; \mathrm{cn}$ & $0 ; 1$-cn & $0 ; 1$-cn & $0 ; \mathrm{cn}$ & $0 ; \mathrm{cn}$ & $1-0 ; \mathrm{cn}$ & $0 ; 1$-cn & $0 ; 1$-cn & $1-0 ; \mathrm{cn}$ & $10 ; \mathrm{cn}$ & $0 ; 1$-cn & $0 ; 1$-cn & $0 ; \mathrm{cn}$ & $1-0 ; \mathrm{cn}$ \\
\hline BW678 & Rph15 & $1-\mathrm{cn}$ & $0 ; 1-\mathrm{cn}$ & $0 ; 1-\mathrm{cn}$ & $0 ; 1-\mathrm{cn}$ & $0 ; \mathrm{cn}$ & $0 ; 1-\mathrm{cn}$ & $0 ; \mathrm{cn}$ & $0 ; \mathrm{cn}$ & $0 ; \mathrm{cn}$ & $0 ; 1-\mathrm{cn}$ & $1-0 ; \mathrm{cn}$ & $1-0 ; \mathrm{cn}$ & $0 ; 1-\mathrm{cn}$ & $0 ; 1-\mathrm{cn}$ & $0 ; 1-\mathrm{cn}$ & $1-0 ; \mathrm{cn}$ & $0 ; \mathrm{cn}$ & $0 ; \mathrm{cn}$ \\
\hline BW & Rph15 & $0 ; 1-\mathrm{cn}$ & $0 ; \mathrm{cn}$ & $0 ; 1$-cn & $11-\mathrm{c}$ & $0 ; 1$-cn & $0 ; 1$-cn & $0 ; 1$-cn & $0 ; 1$-cn & $0 ; \mathrm{cn}$ & $0 ; 1-\mathrm{c}$ & $1 \mathrm{cn}$ & 23-cn & $1-0 ; \mathrm{cn}$ & $0 ; \mathrm{cn}$ & $0 ; \mathrm{cn}$ & $0 ; 1$-cn & $0 ; 1 \mathrm{cn}$ & $1-0 ; \mathrm{cn}$ \\
\hline BW680 & Rph15 & $0 ; 1-\mathrm{cn}$ & $0 ; \mathrm{cn}$ & $0 ; \mathrm{cn}$ & $0 ; 1-\mathrm{cn}$ & $0 ; \mathrm{cn}$ & $0 ; 1-\mathrm{cn}$ & $0 ; \mathrm{cn}$ & $0 ; \mathrm{cn}$ & $0 ; \mathrm{cn}$ & $0 ; 1-\mathrm{cn}$ & $0 ; 1 \mathrm{cn}$ & $12 \mathrm{cn}$ & $0 ; \mathrm{cn}$ & $0 ; \mathrm{cn}$ & $0 ; \mathrm{cn}$ & $1-0 ; \mathrm{cn}$ & $0 ; \mathrm{cn}$ & $0 ; \mathrm{cn}$ \\
\hline BW681 & Rph15 & $11-\mathrm{c}$ & $0 ; 12 \mathrm{cn}$ & $0 ; 1-\mathrm{cn}$ & $0 ; 1$-cn & $0 ; \mathrm{cn}$ & $0 ; 1$-cn & $0 ; \mathrm{cn}$ & $0 ; \mathrm{cn}$ & $0 ; \mathrm{cn}$ & $1-0 ; \mathrm{cn}$ & $0 ; 1$-cn & $0 ; 12 \mathrm{c}$ & $1-0 ; \mathrm{cn}$ & $1 \mathrm{cn}$ & $1-\mathrm{cn}$ & $0 ; 1-\mathrm{c}$ & $0 ; \mathrm{cn}$ & $0 ; \mathrm{cn}$ \\
\hline BW & Rph15 & 1-cn & $0 ; 1-\mathrm{cn}$ & $0 ; 1-\mathrm{cn}$ & $0 ; \mathrm{cn}$ & $0 ; \mathrm{cn}$ & $0 ; 1-\mathrm{cn}$ & $0 ; \mathrm{cn}$ & $0 ; \mathrm{cn}$ & $0 ; \mathrm{cn}$ & $0 ; 1$-cn & $0 ; \mathrm{cn}$ & $0 ; 1-\mathrm{cn}$ & $1-0 ; \mathrm{cn}$ & $1 \mathrm{cn}$ & $0 ; 1-\mathrm{cn}$ & $0 ; \mathrm{cn}$ & $0 ; \mathrm{cn}$ & $0 ; \mathrm{cn}$ \\
\hline BW689 & Rph15 & 1-cn & $1-0 ; \mathrm{cn}$ & $0 ; 1-\mathrm{cn}$ & $1-\mathrm{cn}$ & $0 ; \mathrm{cn}$ & $0 ; 1$-cn & $0 ; \mathrm{cn}$ & $0 ; \mathrm{cn}$ & $0 ; \mathrm{cn}$ & $1-0 ; \mathrm{cn}$ & $0 ; 1$-cn & $0 ; 1$-cn & $1-0 ; \mathrm{cn}$ & $1 \mathrm{cn}$ & $0 ; 1$-cn & $1-0 ; \mathrm{cn}$ & $0 ; \mathrm{cn}$ & $0 ; \mathrm{cn}$ \\
\hline BW & Rph15 & 1-cn & $0 ; 1-\mathrm{cn}$ & $0 ; 1-\mathrm{cn}$ & 1 -cn & $0 ; \mathrm{cn}$ & $0 ; 1-\mathrm{cn}$ & $0 ; \mathrm{cn}$ & $0 ; \mathrm{cn}$ & $0 ; \mathrm{cn}$ & $1-0 ; \mathrm{cn}$ & $0 ; 1$-cn & 1 -cn & $1-0 ; \mathrm{cn}$ & $10 ; \mathrm{cn}$ & $0 ; 1$-cn & $1-0 ; \mathrm{cn}$ & $0 ; \mathrm{cn}$ & $0 ; \mathrm{cn}$ \\
\hline 692 & Rph15 & 1-cn & $0 ; 1$-cn & $0 ; 1-\mathrm{cn}$ & $0 ; 1-\mathrm{cn}$ & $0 ; \mathrm{cn}$ & $0 ; \mathrm{cn}$ & $0 ; \mathrm{cn}$ & $0 ; \mathrm{cn}$ & $0 ; \mathrm{cn}$ & $1-0 ; \mathrm{cn}$ & $0 ; \mathrm{cn}$ & $0 ; 12 \mathrm{c}$ & $0 ; 1-\mathrm{cn}$ & $10 ; \mathrm{cn}$ & $0 ; 1$-cn & $1-0 ; \mathrm{cn}$ & $0 ; \mathrm{cn}$ & $0 ; \mathrm{cn}$ \\
\hline 693 & Rph15 & $1-\mathrm{cn}$ & $1-\mathrm{cn}$ & $0 ; 1-\mathrm{cn}$ & $0 ; 1-\mathrm{cn}$ & $0 ; \mathrm{cn}$ & $0 ; 1$-cn & $0 ; \mathrm{cn}$ & $0 ; 1-\mathrm{cn}$ & $0 ; \mathrm{cn}$ & $1-0 ; \mathrm{cn}$ & $0 ; 1 \mathrm{cn}$ & $12 \mathrm{cn}$ & $1-0 ; \mathrm{cn}$ & $10 ; \mathrm{cn}$ & $1-\mathrm{cn}$ & $0 ; 1-\mathrm{cn}$ & $0 ; \mathrm{cn}$ & $0 ; \mathrm{cn}$ \\
\hline BW & Rph15 & 1-cn & 1-cn & $0 ; 1-\mathrm{cn}$ & $0 ; 1-\mathrm{cn}$ & $0 ; 1$-cn & $0 ; 1-\mathrm{cn}$ & $0 ; \mathrm{cn}$ & $0 ; \mathrm{cn}$ & $0 ; \mathrm{cn}$ & $0 ; 1$-cn & $1-\mathrm{cn}$ & $0 ; 1-$ & $1-0 ; \mathrm{cn}$ & $10 ; \mathrm{cn}$ & $1-0 ; \mathrm{cn}$ & $1-0 ; \mathrm{cn}$ & $0 ; \mathrm{cn}$ & $0 ; \mathrm{cn}$ \\
\hline BV & Rph15 & $1-\mathrm{cn}$ & $1-\mathrm{cn}$ & $0 ; 1-\mathrm{cn}$ & $0 ; \mathrm{cn}$ & $0 ; \mathrm{cn}$ & $0 ; 1$-cn & $0 ; \mathrm{cn}$ & $0 ; \mathrm{cn}$ & $0 ; \mathrm{cn}$ & $1-\mathrm{cn}$ & $0 ; 1 \mathrm{cn}$ & $0 ; 1 \mathrm{cn}$ & $1-0 ; \mathrm{cn}$ & $1 \mathrm{cn}$ & $1-0 ; \mathrm{cn}$ & $1-0 ; \mathrm{cn}$ & $0 ; \mathrm{cn}$ & $0 ; \mathrm{cn}$ \\
\hline 596 & Rph15 & 1-cn & $0 ; 1$-cn & $0 ; 1$-cn & $1-\mathrm{cn}$ & $0 ; \mathrm{cn}$ & $0 ; 1-\mathrm{cn}$ & $0 ; \mathrm{cn}$ & $0 ; \mathrm{cn}$ & $0 ; \mathrm{cn}$ & $1-0 ; \mathrm{cn}$ & $0 ; \mathrm{cn}$ & $1 \mathrm{cn}$ & $1-0 ; \mathrm{cn}$ & $1 \mathrm{cn}$ & $0 ; 1-\mathrm{cn}$ & $1-0 ; \mathrm{cn}$ & $0 ; \mathrm{cn}$ & $0 ; \mathrm{cn}$ \\
\hline BW & Rph15 & 1-cn & $0 ; 1$-cn & $0 ; 1-\mathrm{cn}$ & $0 ; 1-\mathrm{cn}$ & $0 ; \mathrm{cn}$ & $0 ; \mathrm{cn}$ & $0 ; \mathrm{cn}$ & $0 ; \mathrm{cn}$ & $0 ; \mathrm{cn}$ & $1-0 ; \mathrm{cn}$ & $0 ; 1$-cn & $1 \mathrm{cn}$ & $0 ; 1$-cn & $1 \mathrm{cn}$ & $10 ; \mathrm{cn}$ & $1-0 ; \mathrm{cn}$ & $0 ; 1$-cn & $0 ; \mathrm{cn}$ \\
\hline BW700 & Rph15 & 21 & $1-0 ; \mathrm{cn}$ & $0 ; 1-\mathrm{cn}$ & $0 ; 1-\mathrm{cn}$ & $0 ; 1$-cn & $0 ; 1$-cn & $0 ; 1$-cn & $0 ; 1$-cn & $0 ; \mathrm{cn}$ & 210 & $0 ; \mathrm{cn}$ & $0 ; 1$-cn & $1-0 ; \mathrm{cn}$ & 3- & $0 ; 1-\mathrm{cn}$ & $0 ; \mathrm{cn}$ & $1 \mathrm{cn}$ & $0 ; \mathrm{cn}$ \\
\hline BW702 & Rph15 & $0 ; 1$-cn & $0 ; \mathrm{cn}$ & $0 ; \mathrm{cn}$ & $0 ; 1-\mathrm{cn}$ & $0 ; 1-c$ & $0 ; 1$-cn & $0 ; \mathrm{cn}$ & $0 ; \mathrm{cn}$ & $0 ; 1$-cn & $1-0 ; \mathrm{cn}$ & $0 ; 1$-cn & $0 ; 1 \mathrm{cn}$ & $0 ; \mathrm{cn}$ & $0 ; \mathrm{cn}$ & $0 ; \mathrm{cn}$ & 1 -cn & $0 ; 1-\mathrm{cn}$ & $0 ; 1-\mathrm{cn}$ \\
\hline BW703 & Rph15 & 1-cn & $1-0 ; \mathrm{cn}$ & $0 ; 1-\mathrm{cn}$ & $0 ; 1$-cn & $0 ; \mathrm{cn}$ & $0 ; 1$-cn & $0 ; \mathrm{cn}$ & $0 ; \mathrm{cn}$ & $0 ; \mathrm{cn}$ & $1-0 ; \mathrm{cn}$ & $0 ; 1-\mathrm{cn}$ & $0 ; 1 \mathrm{cn}$ & $0 ; 1-\mathrm{cn}$ & $1 \mathrm{cn}$ & $0 ; 1$-cn & $1-0 ; \mathrm{cn}$ & $0 ; \mathrm{cn}$ & $0 ; \mathrm{cn}$ \\
\hline BW704 & Rph15 & 1-cn & $1-\mathrm{cn}$ & $0 ; 1-\mathrm{cn}$ & $0 ; 1$-cn & $0 ; \mathrm{cn}$ & $0 ; 1$-cn & $0 ; \mathrm{cn}$ & $0 ; \mathrm{cn}$ & $0 ; \mathrm{cn}$ & $0 ; 1$-cn & $0 ; \mathrm{cn}$ & $0 ; 1 \mathrm{cn}$ & $1-0 ; \mathrm{cn}$ & $1 \mathrm{cn}$ & $0 ; 1$-cn & $1-0 ; \mathrm{cn}$ & $0 ; \mathrm{cn}$ & $0 ; \mathrm{cn}$ \\
\hline BW705 & Rph15 & $1-\mathrm{cn}$ & $1-0 ; \mathrm{cn}$ & $0 ; 1-\mathrm{cn}$ & $0 ; \mathrm{cn}$ & $0 ; \mathrm{cn}$ & $0 ; 1-\mathrm{cn}$ & $0 ; \mathrm{cn}$ & $0 ; \mathrm{cn}$ & $0 ; 1-\mathrm{cn}$ & $10 ; \mathrm{cn}$ & $0 ; \mathrm{cn}$ & $1-\mathrm{cn}$ & $1-0 ; \mathrm{cn}$ & $0 ; 1-\mathrm{cn}$ & $0 ; 1-\mathrm{cn}$ & $1-0 ; \mathrm{cn}$ & $0 ; \mathrm{cn}$ & $0 ; \mathrm{cn}$ \\
\hline
\end{tabular}

$\vec{\sigma}$ 
Appendix Table 6 continued. Raw infection types ${ }^{1}$ of 50 Bowman introgression lines postulated to carry Rph15.

\section{$\begin{array}{llll} & & \text { Isolates of Puccinia hordei } \\ \text { BR (Octal 11) } & \text { ARG231 } & \text { Race } 4\end{array}$}

Ger 7

WGCC

BW Line ${ }^{2}$ Gene $^{3} \quad$ Rep1 Rep2 Rep3 Rep1 Rep2 Rep3 Rep1 Rep2 Rep3 Rep1 Rep2 Rep3 Rep1 Rep2 Rep3 Rep1 Rep2 Rep3

\begin{tabular}{|c|c|c|c|c|c|c|c|c|c|c|c|c|c|c|c|c|c|c|c|}
\hline & $p h 15$ & $1-\mathrm{cn}$ & $0 ; 1-\mathrm{cn}$ & $0 ; 1-\mathrm{cn}$ & $0 ; \mathrm{cn}$ & $0 ; \mathrm{cn}$ & $0 ; 1-\mathrm{cn}$ & $0 ; \mathrm{cn}$ & $0 ; \mathrm{cn}$ & $0 ; \mathrm{cn}$ & $1-0 ; \mathrm{cn}$ & $0 ; \mathrm{cn}$ & $0 ; 1 \mathrm{cn}$ & $1-0 ; \mathrm{cn}$ & $1 \mathrm{cn}$ & $0 ; 1-\mathrm{cn}$ & $0 ; 1-\mathrm{cn}$ & $0 ; \mathrm{cn}$ & $0 ; \mathrm{cn}$ \\
\hline & Rph15 & 1-cn & $0 ; \mathrm{cn}$ & $0 ; 1-\mathrm{cn}$ & $0 ; \mathrm{cn}$ & $0 ; \mathrm{cn}$ & $0 ; 1-\mathrm{cn}$ & $0 ; \mathrm{cn}$ & $0 ; \mathrm{cn}$ & $0 ; \mathrm{cn}$ & $1-0 ; \mathrm{cn}$ & $1-0 ; \mathrm{cn}$ & $1-0 ; \mathrm{cn}$ & $0 ; 1$-cn & $1 \mathrm{cn}$ & $0 ; 1-\mathrm{cn}$ & $0 ; \mathrm{cn}$ & & $0 ; \mathrm{cn}$ \\
\hline & & & & & & & & & & & & & & & $1 \mathrm{cn}$ & & & & \\
\hline & $h 15$ & $\mathrm{cn}$ & $1-\mathrm{cn}$ & 1-cn & $1-\mathrm{cn}$ & $0 ; \mathrm{cn}$ & $1-\mathrm{cn}$ & & & & $-0 ; \mathrm{cn}$ & $0 ; 1 \mathrm{cn}$ & $0 ; 12 \mathrm{cn}$ & $-0 ; \mathrm{cn}$ & 1-cn & ;1-cn & ;1-cn & ;cn & cn \\
\hline & 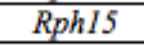 & 1-cn & $0 ; \mathrm{cn}$ & $1-\mathrm{cn}$ & 1-cn & $0 ; \mathrm{cn}$ & $1-\mathrm{cn}$ & $0 ; \mathrm{cn}$ & & & $-0 ; \mathrm{cn}$ & $0 ; \mathrm{cn}$ & $0 ; 1$-cn & $1-0 ; \mathrm{cn}$ & 1-cn & $0 ; 1$-cn & $1-0 ; \mathrm{cn}$ & $0 ; \mathrm{cn}$ & $0 ; \mathrm{cn}$ \\
\hline & & & & & & & & & & $0 ; \mathrm{cn}$ & & & $0 ; 1-\mathrm{cn}$ & & & & & & $0, \mathrm{cin}$ \\
\hline & & -cn & ;cn & $0 ; 1-\mathrm{cn}$ & $0 ; 1-\mathrm{cn}$ & $0 ; \mathrm{cn}$ & $0 ; 1-\mathrm{cn}$ & $0 ; \mathrm{cn}$ & $0 ; \mathrm{cn}$ & $0 ; \mathrm{cn}$ & $-0 ; \mathrm{cn}$ & $0 ; 1 \mathrm{cn}$ & $0 ; 1$-cn & $-0 ; \mathrm{cn}$ & $0 ; 1 \mathrm{cn}$ & $0 ; 1$-cn & $-0 ; \mathrm{cn}$ & $0 ; \mathrm{cn}$ & $0 ; \mathrm{cn}$ \\
\hline & RphIS & $0 ; 1-\mathrm{cn}$ & $0 ; \mathrm{cn}$ & $0 ; \mathrm{cn}$ & $1-\mathrm{cn}$ & $0 ; 1-\mathrm{cn}$ & ;1-cn & $0 ; \mathrm{cn}$ & $0 ; \mathrm{cn}$ & $0 ; 1-\mathrm{cn}$ & $-0 ; \mathrm{cn}$ & $1 \mathrm{cn}$ & $0 ; 1-\mathrm{cn}$ & $0 ; 1-\mathrm{cn}$ & $0 ; \mathrm{cn}$ & $0 ; \mathrm{cn}$ & $1-0 ; \mathrm{cn}$ & $0 ; \mathrm{cn}$ & $0 ; 1-\mathrm{cn}$ \\
\hline & Rph15 & 1-cn & $0 ; \mathrm{cn}$ & $0 ; 1-\mathrm{cn}$ & ;1-cn & $0 ; 1$-cn & ;1-cn & $0 ; \mathrm{cn}$ & $0 ; \mathrm{cn}$ & $0 ; \mathrm{cn}$ & $-0 ; \mathrm{cn}$ & $1 \mathrm{cn}$ & $0 ; 1$-cn & $0 ; \mathrm{cn}$ & $0 ; 1$-cn & $0 ; \mathrm{cn}$ & $1-0 ; \mathrm{cn}$ & $0 ; \mathrm{cn}$ & 0 ;cn \\
\hline & & $\mathrm{cn}$ & $1-\mathrm{cn}$ & 1-cn & $1-\mathrm{cn}$ & $0 ; \mathrm{cn}$ & & ;cn & $0 ; \mathrm{cn}$ & & $-0 ; \mathrm{cn}$ & $0 ; 1-\mathrm{cn}$ & & & $0 ; 1-\mathrm{cn}$ & $0 ; 1-\mathrm{cn}$ & $-0 ; \mathrm{cn}$ & 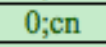 & ;cn \\
\hline & Rph15 & 1-cn & $1-\mathrm{cn}$ & $1-\mathrm{cn}$ & $0 ; \mathrm{cn}$ & $0 ; \mathrm{cn}$ & $1-\mathrm{cn}$ & $0 ; \mathrm{cn}$ & $0 ; \mathrm{cn}$ & $0 ; \mathrm{cn}$ & ;cn & $0 ; 1-\mathrm{cn}$ & $1-0 ; \mathrm{cn}$ & $0 ; 1-\mathrm{cn}$ & $10 ; \mathrm{cn}$ & $0 ; 1-\mathrm{cn}$ & $1-0 ; \mathrm{cn}$ & $0 ; \mathrm{cn}$ & $0 ; \mathrm{cn}$ \\
\hline & & $\mathrm{cn}$ & $1-\mathrm{cn}$ & 1-cn & $0 ; \mathrm{cn}$ & $0 ; \mathrm{cn}$ & len & $0 ; \mathrm{cn}$ & $0 ; \mathrm{cn}$ & & $0 ; \mathrm{cn}$ & $0 ; 1$-cn & $1-0 ; \mathrm{cn}$ & & $10 ; \mathrm{cn}$ & $0 ; 1$-cn & $1-0 ; \mathrm{cn}$ & $0 ;$ & $0 ; \mathrm{cn}$ \\
\hline & & $\mathrm{cn}$ & $1-\mathrm{cn}$ & $1-\mathrm{cn}$ & $1-\mathrm{cn}$ & $0 ; 1-\mathrm{cn}$ & $1=-11$ & $0 ; \mathrm{cn}$ & $0 ; 1-\mathrm{cn}$ & & $1-0 ; \mathrm{cn}$ & $0 ; 1 \mathrm{cn}$ & 10 & $0 ; 1-\mathrm{cn}$ & $0 ; 1-\mathrm{cn}$ & $0 ; 1-\mathrm{cn}$ & $1-0 ; \mathrm{cn}$ & $0 ; \mathrm{cn}$ & $0 ; \mathrm{cn}$ \\
\hline & Rph15 & $-\mathrm{cn}$ & $0 ; 1-\mathrm{cn}$ & $1-\mathrm{cn}$ & $1-\mathrm{cn}$ & $0 ; \mathrm{cn}$ & $0 ; 1-\mathrm{cn}$ & $0 ; \mathrm{cn}$ & $0 ; \mathrm{cn}$ & $0 ; \mathrm{cn}$ & $1-0 ; \mathrm{cn}$ & $0 ; 1-\mathrm{cn}$ & 10 & $1-0 ; \mathrm{cn}$ & $0 ; 1$-cn & $0 ; 1$-cn & $1-0 ; \mathrm{cn}$ & $0 ; \mathrm{cn}$ & $0 ; \mathrm{cn}$ \\
\hline & & $\mathrm{cn}$ & $0 ; \mathrm{cn}$ & $0 ; 1-\mathrm{cn}$ & 1-cn & $0 ; \mathrm{cn}$ & & $0 ; \mathrm{cn}$ & & & $-0 ; \mathrm{cn}$ & $1-0 ; \mathrm{cn}$ & & $1-0 ; \mathrm{cn}$ & $0 ; 1-\mathrm{cn}$ & & $1-0 ; \mathrm{cn}$ & $0 ;$ & $0 ; \mathrm{cn}$ \\
\hline & Rph15 & $\mathrm{cn}$ & $0 ; \mathrm{cn}$ & $0 ; \mathrm{cn}$ & $0 ; 1-\mathrm{cn}$ & $0 ; 1-\mathrm{cn}$ & $10 ; \mathrm{c}$ & $1-\mathrm{cn}$ & $0 ; \mathrm{cn}$ & & 10 ;cn & $21 \mathrm{cn}$ & 12 & $0 ; 1-\mathrm{cn}$ & $0 ; \mathrm{cn}$ & & 11-c & $0 ; 1-\mathrm{cn}$ & $0 ; 1-$ \\
\hline & RphIS & $\mathrm{cn}$ & $0 ; \mathrm{cn}$ & $1-\mathrm{cn}$ & 1-cn & $0 ; 1$-cn & $10 ; \mathrm{c}$ & 1-cn & $0 ; \mathrm{cn}$ & $1-\mathrm{cn}$ & $1-0 ; \mathrm{cn}$ & $12 \mathrm{cn}$ & $0 ; 1$ & ;1-cn & $0 ; \mathrm{cn}$ & $0 ; 1-\mathrm{cn}$ & $11-\mathrm{c}$ & $0 ; 1 \mathrm{cn}$ & $0 ; 1-$ \\
\hline & Rph15 & -cn & ;1-cn & $1-\mathrm{cn}$ & $\mathrm{cn}$ & ;1-cn & $10 ;$ & $0 ; 1-\mathrm{cn}$ & $0 ; \mathrm{cn}$ & $0 ; 1-\mathrm{cn}$ & $11-\mathrm{c}$ & $21 \mathrm{cn}$ & $10 ;$ & $1-0 ; \mathrm{cn}$ & $0 ; \mathrm{cn}$ & $0 ; \mathrm{cn}$ & 11- & $10 ; \mathrm{cn}$ & $0 ; 1=$ \\
\hline & Rph15 & $1-\mathrm{cn}$ & $0 ; 1-\mathrm{cn}$ & $0 ; 1-\mathrm{cn}$ & $1-\mathrm{cn}$ & $0 ; 1-\mathrm{cn}$ & $0 ; 1-\mathrm{cn}$ & $0 ; \mathrm{cn}$ & $0 ; 1-\mathrm{cn}$ & $0 ; \mathrm{cn}$ & $0 ; 1-\mathrm{cn}$ & $0 ; 1-\mathrm{cn}$ & & $1-0 ; \mathrm{cn}$ & $0 ; 1-\mathrm{cn}$ & $0 ; 1-\mathrm{cn}$ & $1-0 ; \mathrm{cn}$ & $0 ; \mathrm{cn}$ & $0 ; \mathrm{cn}$ \\
\hline & Rph15 & $0 ; 1-\mathrm{cn}$ & $0 ; \mathrm{cn}$ & $0 ; \mathrm{cn}$ & $1-\mathrm{cn}$ & $0 ; 1-\mathrm{cn}$ & $0 ; 1-\mathrm{cn}$ & $0 ; \mathrm{cn}$ & $0 ; \mathrm{cn}$ & $0 ; 1-\mathrm{cn}$ & $1-0 ; \mathrm{c}$ & $1 \mathrm{cn}$ & $10 ; \mathrm{cn}$ & $0 ; 1-\mathrm{cn}$ & $0 ; \mathrm{cn}$ & $0 ; \mathrm{cn}$ & $1-0 ; \mathrm{cn}$ & $0 ; 1$-cn & $0 ; \mathrm{cn}$ \\
\hline & Rph15 & 1-cn & $0 ; 1-\mathrm{cn}$ & $0 ; 1-\mathrm{cn}$ & $1-\mathrm{cn}$ & $0 ; \mathrm{cn}$ & $0 ; 1 \mathrm{cn}$ & cn & $0 ; \mathrm{cn}$ & & $1-0 ; \mathrm{cn}$ & $0 ; 1 \mathrm{c}$ & $0 ; 1-\mathrm{cn}$ & $1-0 ; \mathrm{cn}$ & $1-\mathrm{cn}$ & $0 ; 1-\mathrm{cn}$ & $1-\mathrm{cn}$ & $0 ; \mathrm{cn}$ & $0 ; \mathrm{cn}$ \\
\hline & Rph15 & $\mathrm{cn}$ & & & $0 ; 1-\mathrm{cn}$ & $0 ; 1-\mathrm{cn}$ & 1 & $1-\mathrm{cn}$ & $0 ; \mathrm{cn}$ & $0 ;$ & $1-0 ; \mathrm{cn}$ & $1 \mathrm{cn}$ & $0 ; 1-\mathrm{cn}$ & $1-0 ; \mathrm{cn}$ & $0 ; \mathrm{cn}$ & $0 ; \mathrm{cn}$ & $1-0 ; \mathrm{cn}$ & $0 ; \mathrm{cn}$ & $0 ; \mathrm{cn}$ \\
\hline & phIS+? & $1-0 ; \mathrm{c}$ & & & $1 \mathrm{c}$ & $0 ; 1 \mathrm{c}$ & $10 ; \mathrm{c}$ & $0 ; 1-\mathrm{c}$ & $0 ; 1-\mathrm{cn}$ & $0 ; 1$ & & $12 \mathrm{c}$ & $1-0 ; \mathrm{cn}$ & & $21 \mathrm{c}$ & 10 ;cn & $10 ; \mathrm{c}$ & $0 ; 1 \mathrm{c}$ & $0 ; 1-\mathrm{cn}$ \\
\hline & 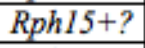 & $0 ; 1-$ & ;1c & & $10 ;$ & $10 ; \mathrm{c}$ & & $12 \mathrm{c}$ & $120 ; \mathrm{c}$ & $120 ; \mathrm{c}$ & $10 ; \mathrm{c}$ & $0 ; 12 \mathrm{c}$ & $0 ; 1-$ & 213- & $23-\mathrm{c}$ & $0 ; 12$ & $0 ; 1$ & $3-2$ & $0 ; 12$ \\
\hline BW709 & Rph15+? & $1-\mathrm{cn}$ & ;en & ;cn & $0 ; 1-\mathrm{cn}$ & ;en & $0 ; 1-\operatorname{cn}$ & $0 ; \mathrm{cn}$ & $0 ; \mathrm{cn}$ & $0 ; \mathrm{cn}$ & $1-0 ; \mathrm{cn}$ & $\mathrm{ICn}$ & $12 \mathrm{cn}$ & $1-0 ; \mathrm{cn}$ & $\mathrm{ICn}$ & $0 ; 1-\mathrm{cn}$ & $0 ; 1-\mathrm{cn}$ & $0 ; \mathrm{cn}$ & $\mathrm{U}, \mathrm{Cr}$ \\
\hline
\end{tabular}

言 
Appendix Table 6 continued. Raw infection types' of 50 Bowman introgression lines postulated to carry Rph15.

Isolates of Puccinia hordei

\begin{tabular}{|c|c|c|c|c|c|c|c|c|c|c|c|c|c|c|c|c|c|c|c|}
\hline \multirow[b]{3}{*}{ BW Line ${ }^{2}$} & \multirow[b]{3}{*}{ Gene $^{3}$} & \multirow{2}{*}{\multicolumn{15}{|c|}{$90-3$}} & \multirow{2}{*}{\multicolumn{3}{|c|}{$92-7$}} \\
\hline & & & & & & & & & & & & & & & & & & & \\
\hline & & Rep1 & Rep2 & Rep3 & Rep1 & Rep2 & Rep3 & Rep1 & Rep2 & Rep3 & Rep1 & $\begin{array}{c}\text { Rep } \\
2\end{array}$ & Rep3 & Rep1 & Rep2 & Rep3 & Rep1 & Rep2 & Rep3 \\
\hline BW719* & Rph15 & $0 ; 1-\mathrm{cn}$ & $10 ; \mathrm{cn}$ & $10 ; \mathrm{cn}$ & $1-0 ; \mathrm{cn}$ & $1-0 ; \mathrm{cn}$ & $1 \mathrm{cn}$ & $0 ; \mathrm{cn}$ & $0 ; \mathrm{cn}$ & $0 ; \mathrm{cn}$ & $3-3$ & 33- & 3- & 12-cn & $21 \mathrm{cn}$ & 213- & $0 ; 1-\mathrm{cn}$ & $0 ; 1-\mathrm{cn}$ & $10 ; \mathrm{cn}$ \\
\hline BW667 & Rph15 & $1-0 ; \mathrm{cn}$ & $1-0 ; \mathrm{cn}$ & $213-c$ & $1-0 ; \mathrm{cn}$ & $0 ; 1-\mathrm{cn}$ & $120 ; \mathrm{cn}$ & $0 ; 1-\mathrm{cn}$ & $0 ; \mathrm{cn}$ & $0 ; \mathrm{cn}$ & 3-c & 33- & 3 & $21 \mathrm{c}$ & $21 \mathrm{cn}$ & 3-2 & $1-0 ; \mathrm{cn}$ & $21 \mathrm{cn}$ & $10 ; \mathrm{cn}$ \\
\hline BW669 & Rph15 & $0 ; 1-\mathrm{cn}$ & $0 ; 1-\mathrm{cn}$ & $12 \mathrm{cn}$ & $1-0 ; \mathrm{cn}$ & $0 ; 1-\mathrm{cn}$ & $10 ; \mathrm{cn}$ & $0 ; 1-\mathrm{cn}$ & $0 ; \mathrm{cn}$ & $0 ; \mathrm{cn}$ & 33- & 33- & 3 & 23-1 & $12 \mathrm{cn}$ & $3-2 \mathrm{c}$ & $1-0 ; \mathrm{cn}$ & $1-0 ; \mathrm{cn}$ & $10 ; \mathrm{cn}$ \\
\hline BW670 & Rph15 & 11-cn & $1-0 ; \mathrm{cn}$ & $12 \mathrm{cn}$ & 11-cn & $12 \mathrm{cn}$ & $12 \mathrm{cn}$ & $0 ; 1$-cn & $0 ; \mathrm{cn}$ & $0 ; \mathrm{cn}$ & 33- & 33- & 3 & $3-2$ & $21 \mathrm{c}$ & $3-2$ & $1-0 ; \mathrm{cn}$ & $1-0 ; \mathrm{cn}$ & $10 ; \mathrm{cn}$ \\
\hline BW671 & Rph15 & $21 \mathrm{cn}$ & $11-\mathrm{cn}$ & $12 \mathrm{cn}$ & $21 \mathrm{cn}$ & $12 \mathrm{cn}$ & $21 \mathrm{cn}$ & $0 ; \mathrm{cn}$ & $0 ; \mathrm{cn}$ & $0 ; \mathrm{cn}$ & 3 & $33+$ & 3-2 & 33- & $22+$ & $3-2$ & $1-\mathrm{cn}$ & $1 \mathrm{cn}$ & $12 \mathrm{cn}$ \\
\hline BW673 & Rph15 & $1-\mathrm{cn}$ & $1-0 ; \mathrm{cn}$ & $10 ; \mathrm{cn}$ & $1-0 ; \mathrm{cn}$ & $0 ; 1-\mathrm{cn}$ & $0 ; 1-\mathrm{cn}$ & $0 ; \mathrm{cn}$ & $0 ; \mathrm{cn}$ & $0 ; \mathrm{cn}$ & $33-\mathrm{c}$ & 3 & 33- & $3-2 \mathrm{cn}$ & $12 \mathrm{cn}$ & $21 \mathrm{cn}$ & $1-0 ; \mathrm{cn}$ & $0 ; 1-\mathrm{cn}$ & $10 ; \mathrm{cn}$ \\
\hline BW674 & Rph15 & 1-cn & $1 \mathrm{cn}$ & $12 \mathrm{cn}$ & $10 ; \mathrm{cn}$ & $1-0 ; \mathrm{cn}$ & $1 \mathrm{cn}$ & $0 ; \mathrm{cn}$ & $0 ; \mathrm{cn}$ & $0 ; \mathrm{cn}$ & $33-\mathrm{c}$ & $33+$ & $3-2$ & $3-2 \mathrm{cn}$ & 213-c & 23-cn & $0 ; 1-\mathrm{cn}$ & $0 ; 1-\mathrm{cn}$ & $10 ; \mathrm{cn}$ \\
\hline BW678 & Rph15 & $1-0 ; \mathrm{cn}$ & $10 ; \mathrm{cn}$ & 12 & $1-0 ; \mathrm{cn}$ & $1-0 ; \mathrm{cn}$ & $21 \mathrm{cn}$ & $0 ; \mathrm{cn}$ & $0 ; \mathrm{cn}$ & $0 ; \mathrm{cn}$ & 33-c & 33- & 3 & $3-2 \mathrm{cn}$ & $21 \mathrm{c}$ & 3-2 & $1-0 ; \mathrm{cn}$ & $0 ; 1-\mathrm{cn}$ & $10 ; \mathrm{cn}$ \\
\hline BW679 & Rph15 & 1-cn & $12 \mathrm{cn}$ & 21 & $1-0 ; \mathrm{cn}$ & $10 ; \mathrm{cn}$ & $10 ; \mathrm{cn}$ & $0 ; 1-\mathrm{cn}$ & $0 ; \mathrm{cn}$ & $0 ; \mathrm{cn}$ & $33-\mathrm{c}$ & 33- & 3 & $3-2$ & 213- & $3-2$ & $1-0 ; \mathrm{cn}$ & $0 ; 1-\mathrm{cn}$ & $10 ; \mathrm{cn}$ \\
\hline BW680 & Rph15 & 11-cn & $1 \mathrm{cn}$ & $12 \mathrm{cn}$ & $120 ; \mathrm{cn}$ & $1-0 ; \mathrm{cn}$ & $10 ; \mathrm{cn}$ & $0 ; \mathrm{cn}$ & $0 ; \mathrm{cn}$ & $0 ; \mathrm{cn}$ & $33-\mathrm{c}$ & 3 & 3 & $3-2$ & $33+$ & $3-2$ & 12-cn & $1-0 ; \mathrm{cn}$ & $10 ; \mathrm{cn}$ \\
\hline BW681 & Rph15 & $11-\mathrm{c}$ & $10 ; \mathrm{cn}$ & $10 ; \mathrm{cn}$ & $1-0 ; \mathrm{cn}$ & $0 ; 1-\mathrm{cn}$ & $10 ; \mathrm{cn}$ & $0 ; \mathrm{cn}$ & $0 ; \mathrm{cn}$ & $0 ; \mathrm{cn}$ & 33- & $33+$ & 33- & 3-2 & $21 \mathrm{cn}$ & $3-2$ & $1-0 ; \mathrm{cn}$ & $1-0 ; \mathrm{cn}$ & $10 ; \mathrm{cn}$ \\
\hline BW688 & Rph15 & $1-0 ; \mathrm{cn}$ & $00 ;$ & $21 \mathrm{cn}$ & $1-0 ; \mathrm{cn}$ & $0 ; 1-\mathrm{cn}$ & $1 \mathrm{cn}$ & $0 ; \mathrm{cn}$ & $0 ; \mathrm{cn}$ & $0 ; \mathrm{cn}$ & 33-c & 33- & 33- & $23-\mathrm{cn}$ & $21 \mathrm{cn}$ & 213- & $1-0 ; \mathrm{cn}$ & $0 ; 1-\mathrm{cn}$ & $0 ; 1 \mathrm{cn}$ \\
\hline BW689 & Rph15 & $1-0 ; \mathrm{cn}$ & $0 ; 1-\mathrm{cn}$ & $10 ; \mathrm{cn}$ & $1-0 ; \mathrm{cn}$ & $1-0 ; \mathrm{cn}$ & $1 \mathrm{cn}$ & $0 ; \mathrm{cn}$ & $0 ; \mathrm{cn}$ & $0 ; \mathrm{cn}$ & $3 \mathrm{c}$ & $33+$ & 33- & $23-\mathrm{c}$ & $21 \mathrm{cn}$ & 213- & $0 ; 1-\mathrm{cn}$ & $1-0 ; \mathrm{cn}$ & $10 ; \mathrm{cn}$ \\
\hline BW690 & Rph15 & $1=0 ; \mathrm{cn}$ & $10 ; \mathrm{cn}$ & $12 \mathrm{cn}$ & $1-0 ; \mathrm{cn}$ & $1-0 ; \mathrm{cn}$ & $1 \mathrm{cn}$ & $0 ; \mathrm{cn}$ & $0 ; \mathrm{cn}$ & $0 ; \mathrm{cn}$ & $3-2$ & 3- & 33- & 23- & $21 \mathrm{cn}$ & 23-1 & $1-0 ; \mathrm{cn}$ & $0 ; 1-\mathrm{cn}$ & $10 ; \mathrm{cn}$ \\
\hline BW692 & Rph15 & $1-0 ; \mathrm{cn}$ & $10 ; \mathrm{c}$ & $10 ; \mathrm{cn}$ & $1-0 ; \mathrm{cn}$ & $0 ; 1-\mathrm{cn}$ & $10 ; \mathrm{cn}$ & $0 ; \mathrm{cn}$ & $0 ; \mathrm{cn}$ & $0 ; \mathrm{cn}$ & $3-2 c$ & 33- & 3- & 213-c & 213-c & 23-cn & $1-0 ; \mathrm{cn}$ & $1-0 ; \mathrm{cn}$ & $10 ; \mathrm{cn}$ \\
\hline BW693 & Rph15 & $1-0 ; \mathrm{cn}$ & $10 ; \mathrm{cn}$ & $0 ; 1-\mathrm{cn}$ & $1-0 ; \mathrm{cn}$ & $0 ; 1-\mathrm{cn}$ & $10 ; \mathrm{cn}$ & $0 ; \mathrm{cn}$ & $0 ; \mathrm{cn}$ & $0 ; \mathrm{cn}$ & $3-\mathrm{c}$ & 3- & 33- & 23- & $21 \mathrm{cn}$ & 23-cn & $1-0 ; \mathrm{cn}$ & $1-0 ; \mathrm{cn}$ & $1 \mathrm{cn}$ \\
\hline BW694 & Rph15 & $1-\mathrm{cn}$ & $10 ; \mathrm{cn}$ & $10 ; \mathrm{cn}$ & $1-\mathrm{cn}$ & $0 ; 1-\mathrm{cn}$ & $1 \mathrm{cn}$ & $0 ; 1-\mathrm{cn}$ & $0 ; \mathrm{cn}$ & $0 ; \mathrm{cn}$ & 33-c & 33- & $3-$ & 23-c & $21 \mathrm{cn}$ & $21 \mathrm{cn}$ & $1-0 ; \mathrm{cn}$ & $1-0 ; \mathrm{cn}$ & 10 ;cn \\
\hline BW695 & Rph15 & 1-cn & $1 \mathrm{cn}$ & $10 ; \mathrm{cn}$ & $10 ; \mathrm{cn}$ & 10 ;cn & $1 \mathrm{cn}$ & $0 ; 1-\mathrm{cn}$ & $0 ; \mathrm{cn}$ & $0 ; \mathrm{cn}$ & $33+\mathrm{c}$ & $33+$ & $3-2$ & 33- & $21 \mathrm{c}$ & $21 \mathrm{cn}$ & $1-0 ; \mathrm{cn}$ & $1-0 ; \mathrm{cn}$ & $12 \mathrm{cn}$ \\
\hline BW696 & Rph15 & $1-0 ; \mathrm{cn}$ & $1-0 ; \mathrm{cn}$ & $1 \mathrm{cn}$ & $1-0 ; \mathrm{cn}$ & $1-0 ; \mathrm{cn}$ & $10 ; \mathrm{cn}$ & $0 ; \mathrm{cn}$ & $0 ; \mathrm{cn}$ & $0 ; \mathrm{cn}$ & $33-\mathrm{c}$ & 3 & 33- & 23-c & $21 \mathrm{cn}$ & 3-2 & $1-0 ; \mathrm{cn}$ & $0 ; 1-\mathrm{cn}$ & $12 \mathrm{cn}$ \\
\hline BW699 & Rph15 & $1-0 ; \mathrm{cn}$ & 10 ;cn & $10 ; \mathrm{cn}$ & $1-0 ; \mathrm{cn}$ & $1-0 ; \mathrm{cn}$ & $0 ; 1 \mathrm{cn}$ & $0 ; \mathrm{cn}$ & $0 ; \mathrm{cn}$ & $0 ; \mathrm{cn}$ & 33-c & 3- & 3 & $23-\mathrm{c}$ & $21 \mathrm{cn}$ & 3-2 & $1-0 ; \mathrm{cn}$ & $1-0$ & $1-\mathrm{cn}$ \\
\hline BW700 & Rph15 & $1=0 ; \mathrm{cn}$ & $10 ; \mathrm{cn}$ & $10 ; \mathrm{cn}$ & $1-0 ; \mathrm{cn}$ & 23-1 & $10 ; \mathrm{cn}$ & $1-0 ; \mathrm{cn}$ & $0 ; \mathrm{cn}$ & $0 ; \mathrm{cn}$ & $3-2 c$ & 3 & 3 & 213-cn & $21 \mathrm{cn}$ & 213- & 12-cn & $0 ; 1-\mathrm{cn}$ & $10 ; \mathrm{cn}$ \\
\hline BW702 & Rph15 & $1-0 ; \mathrm{cn}$ & $10 ; \mathrm{cn}$ & $12 \mathrm{cn}$ & $1-0 ; \mathrm{cn}$ & $10 ; \mathrm{cn}$ & $1 \mathrm{cn}$ & $0 ; \mathrm{cn}$ & $0 ; \mathrm{cn}$ & $0 ; \mathrm{cn}$ & $3-2$ & 33- & 3 & 213- & $21 \mathrm{cn}$ & $21 \mathrm{cn}$ & 12-cn & $1-0 ; \mathrm{cn}$ & $10 ; \mathrm{cn}$ \\
\hline BW703 & Rph15 & $1-0 ; \mathrm{cn}$ & $10 ; \mathrm{cn}$ & $1 \mathrm{cn}$ & $1=0 ; \mathrm{cn}$ & $1-0 ; \mathrm{cn}$ & $1 \mathrm{cn}$ & $0 ; \mathrm{cn}$ & $0 ; \mathrm{cn}$ & $0 ; \mathrm{cn}$ & 33-c & 33- & 33- & 213-c & $21 \mathrm{cn}$ & $21 \mathrm{cn}$ & $1-0 ; \mathrm{cn}$ & $1-0 ; \mathrm{cn}$ & $10 ; \mathrm{cn}$ \\
\hline BW704 & Rph15 & $1=0 ; \mathrm{cn}$ & $10 ; \mathrm{cn}$ & $10 ; \mathrm{cn}$ & $1=0 ; \mathrm{cn}$ & $1-0 ; \mathrm{cn}$ & $1 \mathrm{cn}$ & $0 ; \mathrm{cn}$ & $0 ; \mathrm{cn}$ & $0 ; \mathrm{cn}$ & $3 \mathrm{c}$ & $33-\mathrm{c}$ & 3- & $213-c$ & $21 \mathrm{cn}$ & 213- & $1-0 ; \mathrm{cn}$ & $10 ; \mathrm{cn}$ & $0 ; 1 \mathrm{cn}$ \\
\hline BW705 & Rph15 & $1-0 ; \mathrm{cn}$ & $1-0 ; \mathrm{cn}$ & $10 ; \mathrm{cn}$ & $1-0 ; \mathrm{cn}$ & $1-0 ; \mathrm{cn}$ & $10 ; \mathrm{cn}$ & $0 ; \mathrm{cn}$ & $0 ; \mathrm{cn}$ & $0 ; \mathrm{cn}$ & 33- & 33- & 3 & 23- & $21 \mathrm{cn}$ & $21 \mathrm{cn}$ & $1-0 ; \mathrm{cn}$ & $1-0 ; \mathrm{cn}$ & $0 ; 1-\mathrm{cn}$ \\
\hline
\end{tabular}

$\vec{\infty}$ 
Appendix Table 6. Raw infection types ${ }^{1}$ of 50 Bowman introgression lines postulated to carry $R p h 15$.

\begin{tabular}{|c|c|c|c|c|c|c|c|c|c|c|c|c|c|c|c|c|c|c|c|}
\hline \multirow[b]{3}{*}{ BW Line ${ }^{2}$} & \multirow[b]{3}{*}{ Gene $^{3}$} & \multicolumn{18}{|c|}{ Isolates of Puccinia hordei } \\
\hline & & \multicolumn{3}{|c|}{ 98-20 } & \multicolumn{3}{|c|}{$94-8$} & \multicolumn{3}{|c|}{ BRS 76-12 } & \multicolumn{3}{|c|}{$90-3$} & \multicolumn{3}{|c|}{ Neth 28} & \multicolumn{3}{|c|}{$92-7$} \\
\hline & & Rep1 & Rep2 & Rep3 & Rep1 & Rep2 & Rep3 & Rep1 & Rep2 & Rep3 & Rep1 & Rep2 & Rep3 & Rep1 & Rep2 & Rep3 & Rep1 & Rep2 & Rep3 \\
\hline BW706 & Rph15 & $0 ; \mathrm{cn}$ & $0 ; 1-\mathrm{cn}$ & $1-0 ; \mathrm{cn}$ & $1-\mathrm{cn}$ & $0 ; 1-\mathrm{cn}$ & $0 ; 1-\mathrm{cn}$ & $0 ; 1-\mathrm{cn}$ & $0 ; \mathrm{cn}$ & $0 ; \mathrm{cn}$ & $33-$ & $3-$ & 33- & $12-\mathrm{cn}$ & $21 \mathrm{cn}$ & 23-cn & $1-0 ; \mathrm{cn}$ & $0 ; 1-\mathrm{cn}$ & $10 ; \mathrm{cn}$ \\
\hline BW707 & Rph15 & $0 ; \mathrm{cn}$ & $0 ; 1-\mathrm{cn}$ & $10 ; \mathrm{cn}$ & $1-\mathrm{cn}$ & $0 ; 1-\mathrm{cn}$ & $1 \mathrm{cn}$ & $0 ; \mathrm{cn}$ & $0 ; \mathrm{cn}$ & $0 ; \mathrm{cn}$ & $3-3$ & $23-$ & $3-2$ & $12-\mathrm{cn}$ & & & & $0 ; 1-\mathrm{cn}$ & \\
\hline BW710 & Rph15 & $0 ; \mathrm{cn}$ & $1-0 ; \mathrm{cn}$ & $10 ; \mathrm{cn}$ & $0 ; \mathrm{cn}$ & $0 ; 1-\mathrm{cn}$ & $0 ; 1 \mathrm{cn}$ & $\mathrm{cn}$ & $0 ; \mathrm{cn}$ & $0 ; \mathrm{cn}$ & -2 & 33- & 3- & $12-\mathrm{cn}$ & & 213- & $-0 ; \mathrm{cn}$ & $0 ; 1-\mathrm{cn}$ & $0 ; 1 \mathrm{cn}$ \\
\hline & Rph15 & $1-0 ; \mathrm{cn}$ & $10 ; \mathrm{cn}$ & $10 ; \mathrm{cn}$ & $1-0 ; \mathrm{cn}$ & $1-0 ; \mathrm{cn}$ & $10 ; \mathrm{cn}$ & $0 ; \mathrm{cn}$ & $0 ; \mathrm{cn}$ & $0 ; \mathrm{cn}$ & $3-2$ & 3- & $3-2$ & $12-\mathrm{cn}$ & $21 \mathrm{cn}$ & 213- & & $0 ; 1-\mathrm{cn}$ & $0 ; 1-\mathrm{cn}$ \\
\hline & Rph15 & & & $10 ; \mathrm{cn}$ & & & $1 \mathrm{cn}$ & & & $0 ; \mathrm{cn}$ & & & 3 & & & $21 \mathrm{cn}$ & & & $0 ; 1 \mathrm{cn}$ \\
\hline BW713 & Rph15 & $1-0 ; \mathrm{c}$ & $10 ; \mathrm{cn}$ & $10 ; \mathrm{cn}$ & $1-0 ; \mathrm{cn}$ & $10 ; \mathrm{cn}$ & $10 ; \mathrm{cn}$ & $0 ; \mathrm{cn}$ & $0 ; \mathrm{cn}$ & $0 ; \mathrm{cn}$ & $3-2$ & $3-2$ & 3- & $23-\mathrm{c}$ & & 213-cn & $1-0 ; \mathrm{cn}$ & $0 ; 1-\mathrm{CN}$ & $0 ; 1-\mathrm{cn}$ \\
\hline & & $1-0 ; \mathrm{cn}$ & $10 ; \mathrm{cn}$ & $1 \mathrm{cn}$ & 1-cn & $1-0 ; \mathrm{cn}$ & $1 \mathrm{cn}$ & $0 ; \mathrm{cn}$ & $0 ; \mathrm{cn}$ & & 33- & 33- & 3 & $12-\mathrm{cn}$ & & $\mathrm{cn}$ & $1-0 ; \mathrm{cn}$ & $0 ; 1-\mathrm{cn}$ & $10 ; \mathrm{cn}$ \\
\hline & Rph15 & $1-0 ; \mathrm{cn}$ & $10 ; \mathrm{cn}$ & $12 \mathrm{cn}$ & $1-0 ; \mathrm{cn}$ & $1-0 ; \mathrm{cn}$ & $10 ; \mathrm{cn}$ & $0 ; \mathrm{cn}$ & $0 ; \mathrm{cn}$ & $0 ; \mathrm{cn}$ & $3-2 c$ & $3-2$ & $3-2$ & $12-\mathrm{cn}$ & $21 \mathrm{cn}$ & 213- & $0 ; 1-\mathrm{cn}$ & $0 ; 1-\mathrm{cn}$ & $10 ; \mathrm{cn}$ \\
\hline & Rph15 & $1-0 ; \mathrm{cn}$ & $10 ; \mathrm{cn}$ & $10 ; \mathrm{cn}$ & $1-0 ; \mathrm{cn}$ & $1-0 ; \mathrm{cn}$ & $1-0 ; \mathrm{cn}$ & $0 ; \mathrm{cn}$ & $0 ; \mathrm{cn}$ & $0 ; \mathrm{cn}$ & $3-2 c$ & 3- & $3-2$ & $12-\mathrm{cn}$ & 21 & $21 \mathrm{cn}$ & $0 ; 1-\mathrm{cn}$ & $0 ; 1-\mathrm{cn}$ & $10 ; \mathrm{cn}$ \\
\hline & Rph15 & $1-0 ; \mathrm{cn}$ & $120 ; \mathrm{cn}$ & $10 ; \mathrm{cn}$ & $1-0 ; \mathrm{cn}$ & $1-0 ; \mathrm{cn}$ & $10 ; \mathrm{cn}$ & $0 ; \mathrm{cn}$ & $0 ; \mathrm{cn}$ & $0 ; \mathrm{cn}$ & 3- & 33- & 3- & $12-\mathrm{cn}$ & & & $0 ; 1-\mathrm{cn}$ & $0 ; 1-\mathrm{cn}$ & $10 ; \mathrm{cn}$ \\
\hline & 615 & $1-0 ; \mathrm{cn}$ & $10 ; \mathrm{cn}$ & $12 \mathrm{cn}$ & $1-0 ; \mathrm{cn}$ & $1-0 ; \mathrm{cn}$ & $10 ; \mathrm{cn}$ & $0 ; \mathrm{cn}$ & $0 ; \mathrm{cn}$ & $0 ;$ & $23-c$ & 3- & 3- & 12-cn & & & $0 ; 1$-cn & $0 ; 1-\mathrm{cn}$ & $10 ; \mathrm{cn}$ \\
\hline & & $0 ; \mathrm{cn}$ & $10 ; \mathrm{cn}$ & 10 ; & $-0 ; \mathrm{cn}$ & $1-0 ; \mathrm{cn}$ & $10 ; \mathrm{cn}$ & $0 ; \mathrm{cn}$ & $0 ; \mathrm{cn}$ & 0 & $3-3$ & $3-$ & $3-2$ & $12-\mathrm{cn}$ & & & $0 ; 1-\mathrm{cn}$ & $0 ; 1-\mathrm{cn}$ & $12 \mathrm{c}$ \\
\hline & & $1-0 ; \mathrm{cn}$ & $10 ; \mathrm{cn}$ & $10 ; \mathrm{cn}$ & $1-0 ; \mathrm{cn}$ & $0 ; 1$-cn & $1 \mathrm{cn}$ & $0 ; \mathrm{cn}$ & $0 ; \mathrm{cn}$ & 0 ; & $3-2$ & 3- & $3-2$ & 12-cn & & $3-2$ & $0 ; 1-\mathrm{cn}$ & $1-0 ; \mathrm{cn}$ & \\
\hline 723 & Rph15 & $1-0 ; \mathrm{cn}$ & $12 \mathrm{cn}$ & $21 \mathrm{cn}$ & $12 \mathrm{cn}$ & $10 ; \mathrm{cn}$ & $12 \mathrm{cn}$ & $0 ; \mathrm{cn}$ & $0 ; \mathrm{cn}$ & $0 ; \mathrm{cn}$ & $3-2$ & 3- & $3-2$ & $3-2$ & $213-c$ & 3- & $12-\mathrm{cn}$ & $1-0 ; \mathrm{cn}$ & $21 \mathrm{cn}$ \\
\hline & h15 & $1-0 ; \mathrm{cn}$ & $10 ; \mathrm{cn}$ & $10 ; \mathrm{cn}$ & $1-0 ; \mathrm{cn}$ & $1-0 ; \mathrm{cn}$ & $0 ; 1-\mathrm{cn}$ & $0 ; \mathrm{cn}$ & $0 ; \mathrm{cn}$ & $0 ; n$ & $23-\mathrm{c}$ & $21 \mathrm{c}$ & 3- & 23-cn & & 23-cn & $0 ; 1-\mathrm{cn}$ & $1-0 ; \mathrm{cn}$ & $10 ; \mathrm{cn}$ \\
\hline & Rph15 & $1-0 ; \mathrm{cn}$ & $10 ; \mathrm{cn}$ & $12 \mathrm{cn}$ & $1-0 ; \mathrm{cn}$ & $10 ; \mathrm{cn}$ & $10 ; \mathrm{cn}$ & $0 ; \mathrm{cn}$ & $0 ; \mathrm{cn}$ & $0 ;$ & $3-2$ & 3- & $3-2$ & $23-1 \mathrm{cn}$ & $21 \mathrm{cn}$ & 3. & $1-0 ; \mathrm{cn}$ & $0 ; 1-\mathrm{cn}$ & $1 \mathrm{cn}$ \\
\hline & Rph15 & $1-0 ; \mathrm{cn}$ & $10 ; \mathrm{cn}$ & $1 \mathrm{cn}$ & $1-0 ; \mathrm{cn}$ & $0 ; 1$-cn & $10 ; \mathrm{cn}$ & $0 ; \mathrm{cn}$ & $0 ; \mathrm{cn}$ & $0 ; \mathrm{cn}$ & $3-3$ & $3-2$ & 33- & $23-\mathrm{c}$ & $21 \mathrm{cn}$ & $3-2$ & $1-0 ; \mathrm{cn}$ & $0 ; 1-\mathrm{cn}$ & $1 \mathrm{cn}$ \\
\hline BW734 & Rph15 & $1-0 ; \mathrm{cn}$ & $10 ; \mathrm{cn}$ & $1 \mathrm{cn}$ & $1-0 ; \mathrm{cn}$ & $120 ; \mathrm{cn}$ & $1 \mathrm{cn}$ & $0 ; \mathrm{cn}$ & $0 ; \mathrm{cn}$ & $0 ; \mathrm{cn}$ & $3-2$ & $3-2 c$ & $3-2$ & $3-2$ & 213-cn & $23-1$ & $1-0 ; \mathrm{cn}$ & $0 ; 1-\mathrm{cn}$ & $1-\mathrm{cn}$ \\
\hline BW697 & Rph15+? & $120 ; c$ & $21 \mathrm{c}$ & $0 ; 12 \mathrm{c}$ & $0 ; 1-c$ & $10 ; \mathrm{cn}$ & $0 ; 1$-cn & $120 ; c$ & $120 ; \mathrm{c}$ & $0 ; 1 \mathrm{c}$ & $3-2 c$ & 3- & 33- & $0 ; 1 \mathrm{c}$ & $0 ; 1-$ & $0 ; 1-\mathrm{c}$ & $21 \mathrm{c}$ & 10 & $12 \mathrm{c}$ \\
\hline BW691 & & $21 \mathrm{c}$ & $10 ; \mathrm{cn}$ & $0 ; 1-$ & $10 ; \mathrm{c}$ & $0 ; 1-\mathrm{c}$ & $0 ; 1-$ & $12 \mathrm{c}$ & $10 ; \mathrm{c}$ & $0 ; 1-$ & $3-2 c$ & $23-\mathrm{c}$ & $23-1 \mathrm{c}$ & 213-c & $10 ; \mathrm{c}$ & $0 ; 12 \mathrm{c}$ & $10 ; \mathrm{c}$ & $120 ; \mathrm{c}$ & $0 ; 1-\mathrm{c}$ \\
\hline BW709 & Rph15+? & $1-0 ; \mathrm{cn}$ & $1-0 ; \mathrm{cn}$ & $1 \mathrm{cn}$ & $1-0 ; \mathrm{cn}$ & $1-0 ; \mathrm{cn}$ & $0 ; 1-\mathrm{cn}$ & $0 ; \mathrm{cn}$ & $0 ; \mathrm{cn}$ & $0 ; \mathrm{cn}$ & $23-c$ & $23-c$ & $23-1 \mathrm{c}$ & 12 -cn & $21 \mathrm{cn}$ & $21 \mathrm{cn}$ & $1-0 ; \mathrm{cn}$ & $0 ; 1-\mathrm{cn}$ & $10 ; \mathrm{cn}$ \\
\hline
\end{tabular}

${ }^{1}$ "Infection types were scored using the original 0-4 rating scale developed by Mains (1930) with the additional notations of "+" and "-" to indicate larger or smaller size variations of classically described uredinia (Levine and Cherewick, 1952) and " $c$ " and " $n$ " to indicate the presence of chlorotic or necrotic reactions (Moseman and

Roane, 1959), respectively. Complex ITs were recorded when more than one IT was observed on the surface of a single leaf. For example, an IT of 213- indicates that all three pustule types exist on the same leaf and that the " 2 " type pustules were the most common, followed by the " 1 " type, with " 3 -" type pustules being the least common. Infection types from "0;" to " $0 ; 12$ " are classified as highly resistant ("R", green cells), infections types from "12" to "23-c" are classified as moderately

resistant ("M", yellow cells), and infection types from "23-" to "33+" are classified as susceptible ("S", red cells) (Steffenson et al., 1993).

2. BW lines are the 95 Bowman leaf rust resistance introgression lines.

3. The $R p h$ gene retained in each leaf rust resistant introgression line.

\# Asterisks indicate the introgression line selected to represent that $R p h$ gene in the differential host set. 
Appendix Table 7. Raw infection types ${ }^{1}$ for barley cultivar Bowman and the 95 leaf rust resistance gene donors across three experiments.

solates of Puccinia hordei

$$
\begin{array}{llll} 
& & \text { Isolates of Puccinia hordei } \\
\hline \text { BR (Octal 11) } & \text { ARG231 } & \text { Aus 220 } & \text { Race } 4
\end{array}
$$

Race 4 Ger 7

WGCC

Line

Gene Identity

Rep1 Rep2 Rep3

Rep2 Rep3

\begin{tabular}{|c|c|c|c|c|c|c|c|c|c|c|c|c|c|c|c|c|c|c|c|}
\hline Bowman & NA & 3 & $33-$ & 3 & 3 & $33-$ & 3 & 3 & $33-$ & 3 & $33+$ & $3+$ & 3 & $33+$ & $33+$ & 3 & $33-$ & $33+$ & 3 \\
\hline Sudan & Rphl.a & $23-1$ & $3-2 c$ & $3-2$ & $23-1$ & $3-21$ & $3-0$ & $1-0$ & $0 ; \mathrm{cn}$. & $0 ; 1$ & $0 ; 1-$ & $01 \mathrm{c}$ & $0 ; 1-$ & $0 ; 1-$ & $0 ; 1-$ & $0 ; 1$ & $0 ; 12$ & $0 ; 12$ & $0 ; 2$ \\
\hline Bolivia & Rph2.r+Rph6.f & $0 ; 1-$ & $00 ; 1 \mathrm{c}$ & $0 ; 1$ & $0 ; 1-n$ & $00 ; \mathrm{cn}$ & $0 ; 1-$ & $0 ; 12$ & $0 ; 1 \mathrm{c}$ & $0 ; 1$ & $0 ; 1-$ & $00 ; 1-\mathrm{cn}$ & 0 & $0 ; 1$ & 120 & $0 ; 1 \mathrm{c}$ & 0 & $0 ; 1$ & $0 ; 1$ \\
\hline Juliaca & Rph2.l & $0 ; 1$ & & $0 ; 12$ & $10 ; \mathrm{c}$ & & $0 ; 1-$ & $23-1$ & & $0 ; 1$ & $0 ; 1-$ & & $0 ; 1$ & 120 & & $213-$ & $0 ; 1-\mathrm{c}$ & & $0 ; 12 \mathrm{c}$ \\
\hline Peruvian & Rph $2 . b$ & $213-$ & $0 ; 1 \mathrm{c}$ & $0 ; 1$ & 21 & $0 ; 12 \mathrm{c}$ & $0 ; 12$ & $23-1$ & $0 ; 12 \mathrm{c}$ & $0 ; 12$ & 210 & $0 ; 12 \mathrm{c}$ & 120 & $213-\mathrm{c}$ & 210 & $23-1$ & 10 & $210 ; \mathrm{c}$ & $0 ; 12 \mathrm{c}$ \\
\hline PI 531841 & Rph2.y & $0 ; 1$ & & $0 ; 1-$ & 10 & $0 ; 1-\mathrm{c}$ & $0 ; \mathrm{n}$ & $120 ; \mathrm{c}$ & $0 ; 1 \mathrm{cn}$ & $0 ; \mathrm{n}$ & $0 ; 1-1$ & & $0 ; 1-$ & $12 \mathrm{c}$ & & $120 ; \mathrm{c}$ & $0 ; 1-$ & & $0 ; 1-$ \\
\hline Reka I & Rph2.t+Rph19.ah & & & $0 ; n$ & $213-\mathrm{c}$ & 120 & $0 ; n$ & $23-c$ & $0 ; 1-n$ & $0 ; 1-$ & $0 ; 1-$ & $1-0 ; \mathrm{c}$ & $0 ; 1$ & $0 ; 1-$ & $0 ; 1-$ & $120 ; \mathrm{c}$ & $0 ; 13-$ & $0 ; 12 \mathrm{c}$ & $0 ; 12$ \\
\hline Estate & Rph3.c & $0 ; 1-\mathrm{c}$ & $0 ; 12 \mathrm{c}$ & 0 & $0 ; 1-$ & $00 ; 1$ & 00 & $0 ; 1-\mathrm{c}$ & $0 ; 1-\mathrm{c}$ & $0 ; 1$ & $00 ; 1-$ & $0 ; 1 \mathrm{c}$ & 00 & $00 ; 1-$ & $00 ; 2$ & $00 ; 2$ & $00 ; 1-$ & $0 ; 12 \mathrm{c}$ & $00 ; 2$ \\
\hline PC249 & Rph3.aa & 00 & & $00 ; 1$ & $00 ; n$ & & 00 & $0 ; \mathrm{cn}$ & & 00 & 00 & $00 ; n$ & 00 & 00 & 00 & 00 & $00 ; n$ & $0 ; 2 \mathrm{n}$ & $00 ; 2$ \\
\hline PI 466324 & Rph3+? & $0 ; 1-$ & 00 & $0 ; 1$ & $0 ; 1-$ & $0 ; \mathrm{cn}$ & 10 & $120 ; \mathrm{c}$ & $0 ; 1 \mathrm{c}$ & $0 ; 1$ & & $00 ; 2 \mathrm{cn}$ & 00 & 10 & $0 ; 1 \mathrm{c}$ & 0 & $0 ; 1-$ & $0 ; \mathrm{c}$ & $0 ; 1 \mathrm{c}$ \\
\hline Q21861 & Rph3 & $1-0$ & $00 ; 2$ & $0 ; 1$ & 10 & $00 ; 2 n$ & $0 ; 1-$ & 120 & $00 ; n$ & $0 ; 1-$ & & & $0 ; 1$ & & $00 ; n$ & $23-$ & $0 ; 1-$ & $0 ; 2 \mathrm{n}$ & $0 ; 1 \mathrm{c}$ \\
\hline Batna & Rph4 & 21 & & $3-2$ & $21 \mathrm{c}$ & & $213-$ & 10 & & $0 ; 1$ & 10 & & 120 & $3-2$ & & 3 & 210 & & $0 ; 1 \mathrm{c}$ \\
\hline Gold & Rph4.d & 12 & $23-c$ & $3-2 c$ & 21 & $23-c$ & $23-1$ & $0 ; 1-$ & $0 ; 12 \mathrm{c}$ & $0 ; 1$ & 10 & $0 ; 1 \mathrm{c}$ & 120 & $3-2$ & $3-2$ & $3-2$ & $10 ; 2$ & $0 ; 12$ & $0 ; 1$ \\
\hline Lechtaler & Rph4.d & 21 & $3-2$ & $23-$ & 21 & $210 ; \mathrm{c}$ & $23-1$ & $0 ; 1 \mathrm{c}$ & $0 ; 1-\mathrm{c}$ & $0 ; 1 \mathrm{c}$ & $0 ; 1 \mathrm{c}$ & $12 \mathrm{c}$ & $0 ; 12 \mathrm{c}$ & $33-$ & $33-$ & $3-2$ & $213-$ & $120 ; \mathrm{c}$ & $0 ; 1-\mathrm{c}$ \\
\hline Magnif 102 & Rph5.e & $0 ; 1-\mathrm{n}$ & $0 ; 1-\mathrm{cN}$ & $0 ; 1 \mathrm{n}$ & $11-\mathrm{cN}$ & $10 ; \mathrm{c}$ & $23-c$ & $23-$ & $3-2 c$ & 3 & $213-c$ & $23-c$ & $213-$ & $1 \mathrm{c}$ & $12 \mathrm{c}$ & $120 ; \mathrm{c}$ & $10 ; 2 \mathrm{c}$ & $3-2$ & 3 \\
\hline Bolivia & Rph2.r+Rph6.f & $0 ; 1-$ & $00 ; 1 \mathrm{c}$ & $0 ; 1$ & $0 ; 1-n$ & $00 ; \mathrm{cn}$ & $0 ; 1-$ & $0 ; 12$ & $0 ; 1 \mathrm{c}$ & $0 ; 1$ & $0 ; 1-$ & $00 ; 1-\mathrm{cn}$ & 0 & $0 ; 1$ & 120 & $0 ; 1 \mathrm{c}$ & 0 & $0 ; 1$ & $0 ; 1$ \\
\hline PI 531990 & Rph3 & $0 ; 1-$ & $00 ; 1-$ & 0 & $0 ; 1-$ & 3 & $00 ; 1$ & $00 ; 1-$ & $0 ; 1 \mathrm{c}$ & $0 ; \mathrm{c}$ & $00 ; 1-n$ & $00 ; 2 \mathrm{c}$ & $00 ; \mathrm{c}$ & $00 ; 1-$ & $00 ; 2$ & $00 ; 2$ & $00 ; 1-$ & $0 ; 12 \mathrm{c}$ & $0 ; 12 \mathrm{c}$ \\
\hline Tunisian 17 & Rph $5+R p h 7$ & $00 ; 1-$ & 00 & 00 & & 00 & 00 & $00 ; 1-$ & 00 & 00 & 00 & $00 ; 1$ & 00 & 00 & 00 & 00 & 00 & $00 ; 1-$ & 00 \\
\hline Tunisia 25 & Rph $5+R p h 7$ & $00 ; 1-$ & & $00 ; 1$ & $00 ; n$ & & 00 & $00 ; 1$ & & 00 & $00 ; 1-$ & & 00 & 00 & & 00 & 00 & & 00 \\
\hline Tunisia 29 & Rph $5+R p h 7$ & 00 & & 00 & & & 00 & 00 & & 00 & 00 & & 00 & $00 ; 1-$ & & 00 & $00 ; 1-$ & & 00 \\
\hline Cebada Capa & Rph7.g & $00 ; n$ & $00 ; \mathrm{cn}$ & $0 ; n$ & $0 ; 1-\mathrm{c}$ & $0 ; 1-\mathrm{cn}$ & $00 ; n$ & $00 ; 1-$ & 00 & 00 & $0 ; 1-$ & $0 ; 1-\mathrm{c}$ & 0 & $0 ; 1-$ & $0 ; 1-\mathrm{c}$ & $0 ; 1-\mathrm{c}$ & $00 ; 1-\mathrm{c}$ & $00 ; n$ & 00 \\
\hline Egypt 4 & Rph8.h & $210 ; n$ & $0 ; 1 \mathrm{cn}$ & $0 ; 1 \mathrm{n}$ & $3-2$ & $213-c$ & $3-$ & $23-c$ & $0 ; 12 \mathrm{c}$ & $3-$ & $3+3$ & 3 & 3 & $0 ; 1$-cn & $0 ; \ln$ & $0 ; 1-\mathrm{c}$ & $3-2 c$ & $23-\mathrm{c}$ & $23-\mathrm{c}$ \\
\hline Hor2596 & Rph9.i & $0 ; 1-\mathrm{cn}$ & $10 ; \mathrm{cn}$ & $0 ; 1 \mathrm{~N}$ & $0 ; \mathrm{cN}$ & $0 ; 1-\mathrm{cn}$ & $0 ; n$ & $0 ; \mathrm{cN}$ & $0 ; 1-\mathrm{cn}$ & $0 ; 1 \mathrm{c}$ & $0 ; 1-\mathrm{n}$ & $0 ; 1 \mathrm{c}$ & $0 ; 1-c$ & $1-0 ; \mathrm{cN}$ & $10 ; \mathrm{c}$ & $0 ; 1 \mathrm{c}$ & $00 ; 1-\mathrm{N}$ & $0 ; 1 \mathrm{c}$ & $0 ; 1-\mathrm{c}$ \\
\hline PI 466247 & Rph 9 & 21 & $0 ; 1 \mathrm{c}$ & $213-$ & 12 & $0 ; 1 \mathrm{c}$ & 213- & & $00 ; 2 n$ & $00 ; 1$ & & $00 ; n$ & $00 ; 1$ & 00 & 00 & $00 ; 2$ & $21 \mathrm{c}$ & $00 ; 2 n$ & $0 ; 12$ \\
\hline Quinn & Rph2.q+Rph5.e & $0 ; 1-\mathrm{n}$ & $00 ; 1$ & $0 ; 1$ & 10 & $0 ; 12 \mathrm{c}$ & $0 ; 1$ & $3-3$ & 210 & $0 ; 1$ & $0 ; 1-$ & & $0 ; 1$ & $0 ; 1-$ & $120 ; c$ & $0 ; 1$ & & $0 ; 12 \mathrm{c}$ & $0 ; 12 \mathrm{c}$ \\
\hline
\end{tabular}

$\overrightarrow{\widetilde{O}}$ 
Appendix Table 7 continued. Raw infection types ${ }^{1}$ for barley cultivar Bowman and the 95 leaf rust resistance gene donors across three experiments.

\begin{tabular}{|c|c|c|c|c|c|c|c|c|c|c|c|c|c|c|c|c|c|c|c|}
\hline \multirow[b]{3}{*}{ Line } & \multirow[b]{3}{*}{ Gene Identity } & \multicolumn{18}{|c|}{ Isolates of Puccinia hordei } \\
\hline & & \multicolumn{3}{|c|}{ BR (Octal 11) } & \multicolumn{3}{|c|}{ ARG231 } & \multicolumn{3}{|c|}{ Aus 220} & \multicolumn{3}{|c|}{ Race 4} & \multicolumn{3}{|c|}{ Ger 7} & \multicolumn{3}{|c|}{ WGCC } \\
\hline & & Rep1 & Rep2 & Rep3 & Rep1 & Rep2 & Rep3 & Rep1 & Rep2 & Rep3 & Rep1 & Rep2 & Rep3 & Rep1 & Rep2 & Rep3 & Rep1 & Rep2 & Rep3 \\
\hline Triumph & Rph $9 . z$ & $0 ; 1-$ & $0 ; 1-\mathrm{cn}$ & 10 & $1-0 ; \mathrm{c}$ & $0 ; 1-\mathrm{cn}$ & $0 ; 1$ & $0 ; 1-\mathrm{c}$ & $0 ; 1$-cn & $0 ; 1-\mathrm{c}$ & $10 ; \mathrm{c}$ & $10 ; \mathrm{c}$ & $0 ; 1-\mathrm{c}$ & $0 ; 1-\mathrm{c}$ & $0 ; \mathrm{cn}$ & $0 ; 1-$ & $11-\mathrm{c}$ & $0 ; 1-\mathrm{cn}$ & $0 ; 1-\mathrm{c}$ \\
\hline Quinn & Rph $2 . q+R p h 5 . e$ & $0 ; 1-\mathrm{n}$ & $00 ; 1$ & $0 ; 1$ & 10 & $0 ; 12 \mathrm{c}$ & $0 ; 1$ & $3-3$ & 210 & $0 ; 1$ & $0 ; 1-$ & & $0 ; 1$ & $0 ; 1-$ & $120 ; \mathrm{c}$ & $0 ; 1$ & & $0 ; 12 \mathrm{c}$ & $0 ; 12 \mathrm{c}$ \\
\hline Clipper BC 8 & Rph10.o & 120 & $10 ; c$ & $213-$ & $1-0 ; \mathrm{c}$ & $12 \mathrm{c}$ & $213-$ & $11-\mathrm{c}$ & $0 ; 12 \mathrm{c}$ & $10 ; \mathrm{c}$ & $213-\mathrm{c}$ & $23-$ & $3-2$ & $23-$ & $23-$ & $3-2$ & $12 \mathrm{c}$ & $23-\mathrm{c}$ & $0 ; 1 \mathrm{c}$ \\
\hline Clipper BC 67 & Rph11.p & 120 & $213-\mathrm{c}$ & 21 & $1-0 ; \mathrm{c}$ & $21 \mathrm{c}$ & $21 \mathrm{c}$ & $11-\mathrm{c}$ & $3-2 \mathrm{c}$ & $23-\mathrm{c}$ & $21 \mathrm{c}$ & $21 \mathrm{c}$ & $12 \mathrm{c}$ & $21 \mathrm{c}$ & $213-\mathrm{c}$ & $21 \mathrm{c}$ & $21 \mathrm{c}$ & $23-\mathrm{c}$ & $23-\mathrm{c}$ \\
\hline PI 531849 & Rph13x & $0 ; 1-$ & $0 ; 12$ & $00 ; 1$ & $0 ; 1-$ & $0 ; 1 \mathrm{c}$ & $0 ; 1$ & $00 ; 1-$ & $00 ; 1-n$ & $0 ; 1$ & $0 ; 1$ & $0 ; 1-\mathrm{c}$ & 120 & $0 ; 1-$ & $0 ; 1-$ & $0 ; 1-$ & $0 ; 1-$ & $0 ; 1-n$ & $0 ; 1$ \\
\hline PI 531901-1 & Rph14.ab & & & $0 ; \ln$ & & & $23-$ & $12 \mathrm{c}$ & & $21 \mathrm{c}$ & & & $213-$ & & & $0 ; \mathrm{cn}$ & & & $10 ; \mathrm{c}$ \\
\hline HS584 & Rph15+? & $1-1$ & $0 ; 1$-cn. & $0 ; 1-$ & $1-\mathrm{c}$ & $0 ; 1$-cn. & $0 ; 12$ & $0 ; 1$-cn & & $0 ; \mathrm{n}$ & $1-0 ; \mathrm{cn}$ & $0 ; 1-\mathrm{c}$ & $10 ; \mathrm{c}$ & $0 ; 1$-cn & $1-\mathrm{cn}$ & $0 ; 1-\mathrm{cn}$ & $1-0 ; \mathrm{cn}$ & $0 ; \mathrm{n}$ & 0 \\
\hline PI 282610 & Rph15? & $11-$ & $0 ; 1-\mathrm{cn}$ & $0 ; 1-$ & $0 ; \mathrm{cn}$ & $0 ; \mathrm{cn}$ & $0 ; n$ & $0 ; 1-2 \mathrm{cn}$ & $0 ; 1-\mathrm{cn}$ & 00 & $00 ; n$ & $00 ; 2 n$ & 00 & $0 ; 1-n$ & $0 ; 1-$ & $00 ; 1$ & $00 ; 1-n$ & $0 ; 1-\mathrm{cn}$ & 0 \\
\hline PI 296841 & Rph15 & $0 ; 1-$ & $0 ; \mathrm{cn}$. & $0 ; \mathrm{cn}$ & $0 ; \mathrm{cn}$ & $0 ; \mathrm{cn}$. & $0 ; \mathrm{n}$ & $0 ; \mathrm{cn}$ & $0 ; \mathrm{n}$ & $0 ; n$ & & $0 ; \mathrm{cn}$ & $0 ; \mathrm{cn}$ & $0 ; \mathrm{cn}$ & $0 ; \mathrm{cn}$ & $0 ; \mathrm{cn}$ & & $0 ; \mathrm{cn}$ & $0 ; n$ \\
\hline PI 354923 & Rph15 & $0 ; \mathrm{cn}$ & & $0 ; \mathrm{cn}$ & $0 ; \mathrm{cn}$ & & $0 ; 1-\mathrm{cn}$ & & & $0 ; \mathrm{cn}$ & $1-n$ & & $1-\mathrm{cn}$ & & & $0 ; \mathrm{cn}$ & & & $0 ; \mathrm{cn}$ \\
\hline PI 354923 & Rph15 & $0 ; \mathrm{cn}$ & $0 ; \mathrm{cn}$ & $0 ; \mathrm{cn}$ & $0 ; \mathrm{cn}$ & $0 ; \mathrm{cn}$ & $0 ; 1-\mathrm{cn}$ & & $0 ; \mathrm{cn}$ & $0 ; \mathrm{cn}$ & $21 \mathrm{c}$ & $0 ; 1-\mathrm{cn}$ & 1-cn & $0 ; \mathrm{cn}$ & $0 ; \mathrm{cn}$ & $0 ; \mathrm{cn}$ & $0 ; 1-\mathrm{cn}$ & $0 ; \mathrm{cn}$ & $0 ; \mathrm{cn}$ \\
\hline PI 354926 & Rph15 & $0 ; 1-n$ & $0 ; \mathrm{cn}$ & 0 & $0 ; \mathrm{n}$ & $0 ; \mathrm{cn}$ & 00 & $0 ; 1-\mathrm{cn}$ & $0 ; \mathrm{cn}$ & 00 & $00 ; 1-n$ & $00 ; n$ & 00 & $0 ; \mathrm{cn}$ & $0 ; \mathrm{cn}$ & $0 ; 1-\mathrm{c}$ & $00 ; 1-$ & $00 ; 1-n$ & 0 \\
\hline PI 354928 & Rph15 & & $0 ; \mathrm{cn}$ & 00 & & $00 ; 1-$ & $0 ; 1-\mathrm{n}$ & & $0 ; \mathrm{cn}$ & 0 & $0 ; \mathrm{cn}$ & $0 ; \mathrm{cn}$ & $0 ; \mathrm{cn}$ & $0 ; \mathrm{cn}$ & $0 ; \mathrm{cn}$ & $0 ; \mathrm{cn}$ & $0 ; \mathrm{cn}$ & $0 ; \mathrm{cn}$ & $0 ; n$ \\
\hline PI 354932 & Rph15 & $0 ; 1-\mathrm{cn}$ & $0 ; \mathrm{cn}$ & $0 ; \mathrm{cn}$ & $0 ; 1-\mathrm{cn}$ & $0 ; \mathrm{cn}$ & $0 ; \mathrm{cn}$ & $0 ; \mathrm{cn}$ & $0 ; \mathrm{cn}$ & $0 ; \mathrm{cn}$ & $1-0 ; \mathrm{cn}$ & $0 ; 1-\mathrm{cn}$ & $0 ; \mathrm{cn}$ & $0 ; \mathrm{cn}$ & & $0 ; \mathrm{cn}$ & $1-0 ; \mathrm{cn}$ & $0 ; \mathrm{cn}$ & $0 ; \mathrm{cn}$ \\
\hline PI 354937 & Rph15 & $0 ; 1-\mathrm{cn}$ & $0 ; \mathrm{cn}$ & $0 ; \mathrm{cn}$ & $1-\mathrm{cn}$ & $0 ; \mathrm{cn}$ & $0 ; \mathrm{cn}$ & $0 ; \mathrm{cn}$ & $0 ; \mathrm{cn}$ & $0 ; \mathrm{cn}$ & $0 ; 1-\mathrm{cn}$ & $0 ; \mathrm{cn}$ & $0 ; \mathrm{cn}$ & $0 ; \mathrm{cn}$ & $0 ; 1-\mathrm{cn}$ & $0 ; \mathrm{cn}$ & $1-0 ; \mathrm{cn}$ & $0 ; \mathrm{cn}$ & $0 ; \mathrm{cn}$ \\
\hline PI 354940 & Rph15 & $1-0 ; \mathrm{cn}$ & & $0 ; \mathrm{cn}$ & $0 ; \mathrm{cn}$ & $0 ; \mathrm{cn}$ & $0 ; \mathrm{cn}$ & $0 ; \mathrm{cn}$ & $0 ; \mathrm{cn}$ & $0 ; \mathrm{cn}$ & $1-0 ; \mathrm{cn}$ & $0 ; \mathrm{cn}$ & $0 ; \mathrm{cn}$ & $0 ; \mathrm{cn}$ & $0 ; \mathrm{cn}$ & $0 ; \mathrm{cn}$ & $0 ; \mathrm{cn}$ & $0 ; \mathrm{cn}$ & $0 ; \mathrm{cn}$ \\
\hline PI 355434 & Rph15 & $0 ; \mathrm{cn}$ & $0 ; \mathrm{cn}$ & $0 ; \mathrm{cn}$ & $0 ; 1-\mathrm{cn}$ & $0 ; \mathrm{cn}$ & $0 ; 1$-cn & $0 ; \mathrm{cn}$ & $0 ; \mathrm{cn}$ & $0 ; \mathrm{cn}$ & $1-0 ; \mathrm{cn}$ & $0 ; 1-\mathrm{cn}$ & $0 ; 1-\mathrm{cn}$ & $0 ; \mathrm{cn}$ & $0 ; \mathrm{cn}$ & $0 ; \mathrm{cn}$ & $0 ; \mathrm{cn}$ & $0 ; \mathrm{cn}$ & $0 ; \mathrm{cn}$ \\
\hline PI 355447 & Rph15 & $1-\mathrm{c}$ & $0 ; 1-\mathrm{cn}$ & $0 ; \mathrm{cn}$ & $1-\mathrm{cn}$ & $0 ; \mathrm{cn}$ & $0 ; 1-$ & $0 ; \mathrm{cn}$ & $0 ; \mathrm{cn}$ & $0 ; \mathrm{cn}$ & $0 ; 1-\mathrm{cn}$ & $0 ; 1-\mathrm{cn}$ & $0 ; 1-\mathrm{cn}$ & $0 ; \mathrm{cn}$ & 1-cn & $0 ; \mathrm{cn}$ & $1-0 ; \mathrm{cn}$ & $0 ; \mathrm{cn}$ & $0 ; \mathrm{cn}$ \\
\hline PI 391000 & Rph15 & & $0 ; \mathrm{cn}$ & $0 ; \mathrm{cn}$ & & $0 ; \mathrm{cn}$ & $0 ; \mathrm{cn}$ & $0 ; \mathrm{cn}$ & $0 ; \mathrm{cn}$ & $0 ; \mathrm{cn}$ & $1-\mathrm{cn}$ & $0 ; \mathrm{cn}$ & $0 ; 1-\mathrm{cn}$ & $0 ; \mathrm{cn}$ & $0 ; \mathrm{cn}$ & $0 ; \mathrm{cn}$ & $1-0 ; \mathrm{cn}$ & $0 ; \mathrm{cn}$ & $0 ; \mathrm{cn}$ \\
\hline Pi 391002 & Rph15 & $1-0$ & $0 ; 1$-cn. & $0 ; \mathrm{cn}$ & $0 ; 1-\mathrm{cn}$ & $0 ; 1-\mathrm{cn}$ & $0 ; \mathrm{cn}$ & $12 \mathrm{c}$ & $0 ; 1-\mathrm{c}$ & $0 ; 1 \mathrm{c}$ & $0 ; 1-\mathrm{n}$ & $0 ; 1 \mathrm{cn}$ & $0 ; \mathrm{cn}$ & $1-0$ & $21 \mathrm{c}$ & $1-\mathrm{cn}$ & & $120 ; \mathrm{c}$ & $0 ; \mathrm{c}$ \\
\hline Pi 391004 & Rph15+? & $0 ; 1-n$ & & $0 ; 1$ & $1-0 ; \mathrm{cn}$ & & $0 ; 1-$ & $210 ; \mathrm{c}$ & & $0 ; 1 \mathrm{c}$ & $0 ; 1-n$ & $0 ; 1 \mathrm{cn}$ & $0 ; \mathrm{cn}$ & $0 ; 1-\mathrm{c}$ & $120 ; \mathrm{c}$ & $0 ; 1 \mathrm{c}$ & $1-0 ; \mathrm{cn}$ & $210 ; \mathrm{c}$ & $0 ; \mathrm{c}$ \\
\hline PI 391007 & Rph15+? & $0 ; 1-$ & & 0 & $0 ; n$ & & 0 & $00 ; 1-n$ & $00 ; n$ & 0 & $00 ; 1-n$ & & 0 & $0 ; 1-n$ & & $0 ; \mathrm{c}$ & $00 ; \mathrm{n}$ & $0 ; 1-\mathrm{cn}$ & 0 \\
\hline PI 391024 & Rph15 & $00 ; 1-n$ & & 0 & $0 ; 1-n$ & & 0 & $0 ; 1-\mathrm{cn}$ & & 0 & $0 ; 1-n$ & $00 ; 2 \mathrm{cn}$ & 00 & $0 ; 1-\mathrm{cn}$ & $0 ; \mathrm{cn}$ & $0 ; 1-\mathrm{c}$ & $0 ; 1-n$ & $0 ; 1-\mathrm{n}$ & 0 \\
\hline PI 391044 & Rph15 & & $0 ; 1-\mathrm{cn}$ & $0 ; \mathrm{cn}$ & & $0 ; \mathrm{cn}$ & $0 ; 1$-cn & & $0 ; \mathrm{cn}$ & $0 ; \mathrm{cn}$ & $12 \mathrm{c}$ & $1 \mathrm{cn}$ & $10 ; \mathrm{cn}$ & $0 ; 1-\mathrm{cn}$ & $0 ; \mathrm{cn}$ & $0 ; 1-\mathrm{cn}$ & $1-0 ; \mathrm{cn}$ & $0 ; \mathrm{cn}$ & $0 ; \mathrm{cn}$ \\
\hline PI 391045 & Rph15 & $0 ; 1-\mathrm{cn}$ & $0 ; \mathrm{cn}$ & $0 ; \mathrm{cn}$ & $0 ; \mathrm{cn}$ & $0 ; \mathrm{cn}$ & $0 ; \mathrm{cn}$ & $0 ; \mathrm{cn}$ & $0 ; \mathrm{cn}$ & $0 ; \mathrm{cn}$ & & $0 ; \mathrm{cn}$ & $0 ; \mathrm{cn}$ & $0 ; \mathrm{cn}$ & $0, \mathrm{cn}$ & $0 ; \mathrm{cn}$ & & $0 ; \mathrm{cn}$ & $0 ; \mathrm{cn}$ \\
\hline
\end{tabular}


Appendix Table 7 continued. Raw infection types ${ }^{1}$ for barley cultivar Bowman and the 95 leaf rust resistance gene donors across three experiments.

\begin{tabular}{lrrr} 
& & Isolates of Puccinia hordei \\
\hline BR (Octal 11) & ARG231 & Aus 220
\end{tabular}

Race 4

WGCC

Line

Gene Identity

Rep1 Rep2 Rep3

$1 \quad$ Rep2 Rep3

PI 391049 PI 391069

PI 391072

PI 391087

Rph15 Rph15

PI 391089 Rph15

Rph15 PI 391121 Rph15+?

PI 405154

PI 405179

PI 405194

PI 405201

PI 405210

PI 405219

PI 405220

PI 405227

PI 405233

PI 405235

PI 405236

PI 405277

PI 405289

PI 405305

PI 405308

PI 405311

PI 405332

$|-| 1-c)$

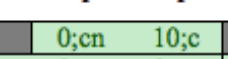

\begin{tabular}{|c|cc|ccc|ccc|ccc|ccc|} 
& $0 ; \mathrm{cn}$ & $23-$ & $21 \mathrm{c}$ & $0 ; 12 \mathrm{c}$ & $3-2$ & $21 \mathrm{c}$ & $10 ; \mathrm{cn}$ & 3 & $0 ; 1-\mathrm{cn}$ & $0 ; \mathrm{cn}$ & $10 ; \mathrm{cn}$ & $0 ; 1 \mathrm{cn}$ & $0 ; \mathrm{cn}$ & $21 \mathrm{c}$ \\
\hline $1-0 ; \mathrm{cn}$ & $0 ; \mathrm{cn}$ & $0 ; \mathrm{cn}$ & $0 ; \mathrm{cn}$ & $0 ; \mathrm{cn}$ & $0 ; \mathrm{cn}$ & $1-0 ; \mathrm{cn}$ & $10 ; \mathrm{cn}$ & $0 ; \mathrm{cn}$ & $0 ; 1-\mathrm{cn}$ & $0 ; \mathrm{cn}$ & $0 ; \mathrm{cn}$ & $11-\mathrm{cn}$ & $0 ; 1-\mathrm{cn}$ & $0 ; \mathrm{cn}$ \\
\hline
\end{tabular}

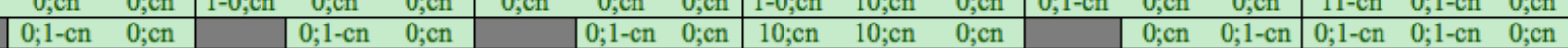

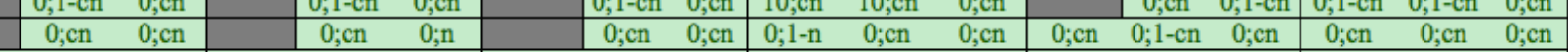

\begin{tabular}{|lll|lll|llllllllllll}
$0 ; 1-\mathrm{cn}$ & $0 ; \mathrm{cn}$ & $0 ; \mathrm{cn}$ & $0 ; 1-\mathrm{cn}$ & $0 ; \mathrm{cn}$ & $0 ; \mathrm{cn}$ & $0 ; \mathrm{cn}$ & $0 ; \mathrm{cn}$ & $0 ; \mathrm{cn}$ & $0 ; 1-\mathrm{cn}$ & $0 ; 1 \mathrm{cn}$ & $0 ; \mathrm{cn}$ & $0 ; \mathrm{cn}$ & $0 ; \mathrm{cn}$ & $0 ; \mathrm{cn}$ & $0 ; \mathrm{cn}$ & $0 ; \mathrm{cn}$ & $0 ; \mathrm{cn}$ \\
\hline
\end{tabular}

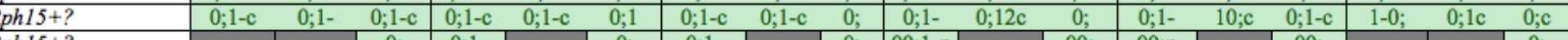

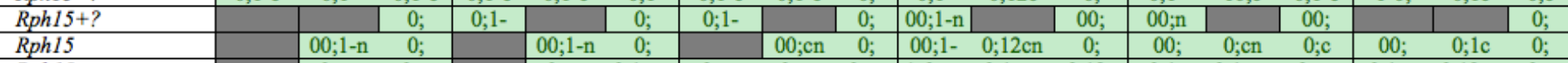
Rph15

Rph15

Rph15

Rph15

Rph15 Rph15

\begin{tabular}{|c|c|c|c|c|c|c|c|c|c|c|c|c|c|c|c|c|}
\hline & & & & & & & $0 ;$ & ;1-n & & $00 ;$ & $00 ; n$ & & 00 & & & 0 \\
\hline $00 ; 1-n$ & 0 & & $00 ; 1-n$ & 0 & & $00 ; \mathrm{cn}$ & 0 & $00 ; 1-$ & $0 ; 12 \mathrm{cn}$ & 0 & 00 & $0 ; \mathrm{cn}$ & $0 ; \mathrm{c}$ & 00 & $0 ; 1 \mathrm{c}$ & 0 \\
\hline $0 ; \mathrm{cn}$ & $0 ; n$ & & $0 ; \mathrm{cn}$ & $0 ; 1-\mathrm{cn}$ & $0 ; \mathrm{cn}$ & $0 ; \mathrm{cn}$ & $0 ; \mathrm{cn}$ & $1-0 ; \mathrm{cn}$ & $0 ; 1-\mathrm{cn}$ & $0 ; 12 \mathrm{c}$ & $0 ; 1-$ & $0 ; 1-\mathrm{cn}$ & $0 ; \mathrm{cn}$ & $0 ; 1 \mathrm{cn}$ & $0 ; 12 \mathrm{cn}$ & $0 ; n$ \\
\hline $0 ; \mathrm{cn}$ & 00 ; & $0 ; 1-\mathrm{cn}$ & $0 ; 1 \mathrm{cn}$ & 0 & $0 ; 1$-cn & $0 ; \mathrm{cn}$ & 0 & $00 ; 1-n$ & $00 ; 2 n$ & $00 ; n$ & $00 ; 1-1$ & $0 ; \mathrm{cn}$ & $0 ; 1-c$ & $00 ; 1-$ & $0 ; \mathrm{cn}$ & 0 \\
\hline
\end{tabular}

$0 ; \mathrm{cn} \quad 00 ; \quad 0 ; 1-\mathrm{cn} \quad 0 ; 1 \mathrm{cn}-$

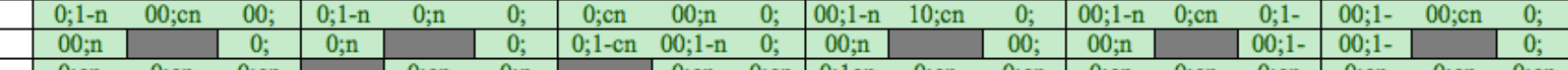

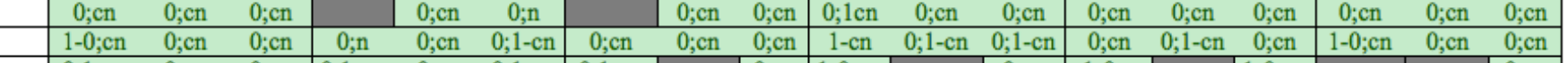
Rph15 Rph15

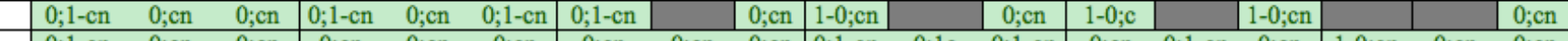

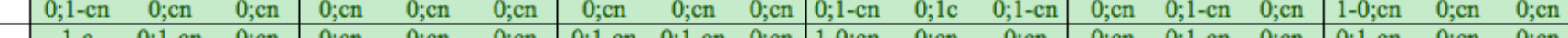

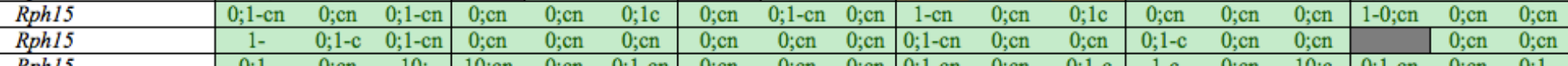

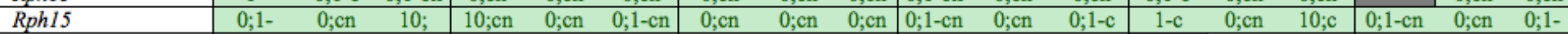

PI 405335 Rph15 Rph15 Rph15 $1-0 ; \mathrm{c}$

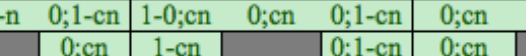

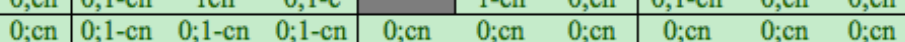
Rph15

$\begin{array}{ccc}0 ; \mathrm{cn} & 0 ; 1 \mathrm{cn} & 0 ; \mathrm{cn} \\ 00 ; 1-\mathrm{cn} & 0 ; 1-\mathrm{n} & 0 ; \mathrm{cn}\end{array}$

$0 ; 1 \mathrm{c} \quad 0 ; \mathrm{n}$

\begin{tabular}{|cc|ccc|ccccccc} 
& $0 ; 1-\mathrm{cn}$ & $0 ; \mathrm{cn}$ & $0 ; 13-\mathrm{c}$ & $0 ; \mathrm{cn}$ & $0 ; \mathrm{cn}$ & $0 ; 1-\mathrm{cn}$ & $120 ; \mathrm{c}$ & $0 ; \mathrm{cn}$ & $21 \mathrm{c}$ & $0 ; 1-\mathrm{cn}$ & $0 ; \mathrm{cn}$ \\
\hline
\end{tabular}

\begin{tabular}{lll|lll|l|ll|lllllllll}
\hline $00 ; 1-\mathrm{cn}$ & $0 ; 1-\mathrm{n}$ & $0 ; \mathrm{cn}$ & 12 & $0 ; \mathrm{cn}$ & $0 ; 1-\mathrm{cn}$ & & $0 ; \mathrm{cn}$ & $0 ; \mathrm{cn}$ & $10 ; \mathrm{c}$ & $0 ; \mathrm{cn}$ & $0 ; 1 \mathrm{cn}$ & $0 ; \mathrm{cn}$ & $0 ; \mathrm{cn}$ & $0 ; \mathrm{cn}$ & $1-0 ; \mathrm{cn}$ & $0 ; \mathrm{cn}$ & $0 ; \mathrm{cn}$ \\
\hline
\end{tabular} 
Appendix Table 7 continued. Raw infection types ${ }^{1}$ for barley cultivar Bowman and the 95 leaf rust resistance gene donors across three experiments.

\begin{tabular}{|c|c|c|c|c|c|c|c|c|c|c|c|c|c|c|c|c|c|c|c|}
\hline \multirow[b]{3}{*}{ Line } & \multirow[b]{3}{*}{ Gene Identity } & \multicolumn{18}{|c|}{ Isolates of Puccinia hordei } \\
\hline & & \multicolumn{3}{|c|}{ BR (Octal 11) } & \multicolumn{3}{|c|}{ ARG231 } & \multicolumn{3}{|c|}{ Aus 220} & \multicolumn{3}{|c|}{ Race 4} & \multicolumn{3}{|c|}{ Ger 7} & \multicolumn{3}{|c|}{ WGCC } \\
\hline & & Rep1 & Rep2 & Rep3 & Rep1 & Rep2 & Rep3 & Rep1 & Rep2 & Rep3 & Rep1 & Rep2 & Rep3 & Rep1 & Rep2 & Rep3 & Rep1 & Rep2 & Rep3 \\
\hline PI 405338 & Rph15 & $0 ; 1$ & $0 ; \mathrm{cn}$ & $0 ; 1 \mathrm{cn}$ & $0 ; \mathrm{cn}$ & $0 ; \mathrm{cn}$ & 00 & $0 ; \mathrm{cn}$ & $0 ; \mathrm{cn}$ & 00 & $0 ; \mathrm{cn}$ & $00 ; 2 \mathrm{n}$ & $0 ; \mathrm{n}$ & $0 ; \mathrm{cn}$ & $0 ; \mathrm{cn}$ & $0 ; 1$ & $0 ; \mathrm{cn}$ & $0 ; \mathrm{cn}$ & $0 ; 1$ \\
\hline PI 405341 & Rph15 & $0 ; 1-\mathrm{cn}$ & $00 ; 1-$ & 0 & & $00 ; \mathrm{n}$ & 0 & & $00 ; \mathrm{cn}$ & $00 ; n$ & $00 ; 1-\mathrm{n}$ & $0 ; \mathrm{cn}$ & 00 & $0 ; \mathrm{cn}$ & $0 ; \mathrm{cn}$ & 0 & $0 ; 1-n$ & $0 ; \mathrm{cn}$ & 0 \\
\hline PI 405354 & Rph15 & & $0 ; \mathrm{cn}$ & $0 ; \mathrm{cn}$ & $0 ; \mathrm{cn}$ & $0 ; \mathrm{cn}$ & $0 ; n$ & $0 ; 1-\mathrm{cn}$ & $0 ; \mathrm{cn}$ & $0 ; \mathrm{cn}$ & $0 ; \mathrm{cn}$ & $0 ; 1-\mathrm{cn}$ & $0 ; \mathrm{cn}$ & $0 ; \mathrm{cn}$ & $00 ; 1$ & $0 ; \mathrm{cn}$ & $0 ; 1-$ & $0 ; 12 \mathrm{c}$ & $0 ; \mathrm{cn}$ \\
\hline PI 405399 & Rph15 & $0 ; \mathrm{cn}$ & $0 ; \mathrm{cn}$ & $0 ; \mathrm{cn}$ & $1-0 ; \mathrm{cn}$ & $0 ; \mathrm{cn}$ & $0 ; 1-\mathrm{cn}$ & $0 ; \mathrm{cn}$ & $0 ; \mathrm{cn}$ & $0 ; \mathrm{cn}$ & $0 ; 1-n$ & $0 ; \mathrm{cn}$ & $10 ; \mathrm{cn}$ & $0 ; \mathrm{cn}$ & $0 ; \mathrm{cn}$ & $0 ; 1-\mathrm{cn}$ & $0 ; 1-\mathrm{cn}$ & $0 ; \mathrm{cn}$ & $0 ; \mathrm{cn}$ \\
\hline PI 466245 & Rph15 & $0 ; 1-\mathrm{cn}$ & $0 ; \mathrm{cn}$ & $0 ; \mathrm{cn}$ & $0 ; \mathrm{cn}$ & $0 ; \mathrm{cn}$ & $0 ; \mathrm{cn}$ & $0 ; \mathrm{cn}$ & $0 ; \mathrm{cn}$ & $0 ; \mathrm{cn}$ & $0 ; 1-\mathrm{cn}$ & $0 ; \mathrm{cn}$ & $0 ; 1-\mathrm{cn}$ & $0 ; \mathrm{cn}$ & $0 ; \mathrm{cn}$ & $0 ; \mathrm{cn}$ & $0 ; \mathrm{cn}$ & $0 ; \mathrm{cn}$ & $0 ; \mathrm{cn}$ \\
\hline PI 466470 & Rph15+? & $120 ; \mathrm{c}$ & $0 ; 12$ & $0 ; 12$ & & $0 ; 1 \mathrm{c}$ & $0 ; 1-$ & & $0 ; 1-$ & 0 & $0 ; 1$ & $0 ; 1 \mathrm{c}$ & $0 ; 1 \mathrm{c}$ & $0 ; 1-\mathrm{c}$ & $0 ; 1-\mathrm{c}$ & $0 ; 1 \mathrm{c}$ & $0 ; 1 \mathrm{c}$ & $0 ; 1 \mathrm{c}$ & $0 ; \mathrm{c}$ \\
\hline PI 466483 & Rph15+? & $0 ; 12$ & $0 ; 1$ & 00 & $120 ; \mathrm{c}$ & $0 ; 1-\mathrm{c}$ & $0 ; 1$ & $0 ; 1-\mathrm{c}$ & $0 ; 1-\mathrm{c}$ & 00 & $0 ; 1 \mathrm{c}$ & $0 ; 1 \mathrm{c}$ & $0 ; 1 \mathrm{c}$ & $0 ; 1-\mathrm{c}$ & $0 ; 1 \mathrm{c}$ & $0 ; 1 \mathrm{c}$ & $0 ; 1 \mathrm{c}$ & $0 ; \mathrm{c}$ & 0 \\
\hline Columbia & $?$ & $23-$ & $3-21$ & 3 & $3-2$ & $3-21$ & 3 & $33-$ & $33+$ & 3 & $33-$ & 3 & 3 & $3-2$ & $33+$ & 3 & $33-$ & $33+$ & 3 \\
\hline Emir/H. bulbosum & $?$ & $00 ; n$ & & $00 ;$ & $00 ; \mathrm{n}$ & & 00 & $0 ; \mathrm{n}$ & & 00 & 00 & & 0 & 00 & & 00 & 00 & & 00 \\
\hline HS580 & Rph15 & & $00 ; 1-n$ & $0 ; 1-\mathrm{cn}$ & $0 ; 1-\mathrm{cn}$ & $00 ; n$ & $0 ; 1-\mathrm{cn}$ & $0 ; \mathrm{cn}$ & $00 ; n$ & $0 ; \mathrm{cn}$ & $0 ; 1$-cn & $00 ; 2$ & $10 ; \mathrm{cn}$ & $1-0 ; \mathrm{cn}$ & $0 ; \mathrm{cn}$ & $0 ; 1-\mathrm{cn}$ & $1-\mathrm{cn}$ & $00 ; 1-n$ & $0 ; \mathrm{cn}$ \\
\hline PI 355445 & Rph15 & & $0 ; \mathrm{cn}$ & $0 ; 1-$ & & $0 ; 1-\mathrm{cn}$ & $0 ; \mathrm{cn}$ & $0 ; \mathrm{cn}$ & $0 ; \mathrm{cn}$ & $0 ; \mathrm{cn}$ & $0 ; 1-\mathrm{cn}$ & $0 ; \mathrm{cn}$ & $0 ; \mathrm{cn}$ & $0 ; 1-\mathrm{cn}$ & $0 ; \mathrm{cn}$ & $0 ; 1-\mathrm{cn}$ & $1-0 ; \mathrm{cn}$ & $0 ; \mathrm{cn}$ & $0 ; \mathrm{n}$ \\
\hline PI 405154 & Rph15+? & & $00 ; 1-$ & & & $00 ; \mathrm{n}$ & & & $00 ; \mathrm{cn}$ & & $00 ; \mathrm{n}$ & $00 ; 1-$ & & 00 & $0 ; 1-\mathrm{cn}$ & & $00 ; n$ & $0 ; 1 \mathrm{n}$ & \\
\hline PI 405169 & $\operatorname{Rph} 9$ & 21 & & 10 & 12 & $0 ; 1$ & $0 ; 1$ & $0 ; 1 \mathrm{c}$ & $10 ; \mathrm{c}$ & $0 ; \mathrm{cn}$ & $0 ; 1-$ & $0 ; 1$ & $0 ; \mathrm{c}$ & $0 ; 1-\mathrm{c}$ & $0 ; 1 \mathrm{c}$ & $0 ; 1$-cn & $0 ; 1-\mathrm{c}$ & $0 ; 1 \mathrm{c}$ & $0 ; 1-$ \\
\hline PI 405215 & Rph15+? & & $0 ; \mathrm{cn}$ & $0 ; \mathrm{cn}$ & & $0 ; 1-\mathrm{cn}$ & $0 ; \mathrm{cn}$ & & $0 ; \mathrm{cn}$ & $0 ; \mathrm{cn}$ & $0 ; 1-\mathrm{cn}$ & $0 ; \mathrm{cn}$ & $0 ; \mathrm{cn}$ & $0 ; \mathrm{cn}$ & $0 ; 1 \mathrm{cn}$ & $0 ; \mathrm{cn}$ & $0 ; \mathrm{cn}$ & $0 ; \mathrm{cn}$ & $0 ; \mathrm{cn}$ \\
\hline PI 466373 & Rph15+? & $0 ; 1-$ & $0 ; \mathrm{cn}$ & 0 & $0 ; 1-$ & $0 ; \mathrm{cn}$ & $0 ; \mathrm{n}$ & $0 ; 1 \mathrm{c}$ & $0 ; 1-\mathrm{c}$ & $0 ; 1$ & $00 ; \ln$ & $00 ; \mathrm{cn}$ & $00 ; n$ & $0 ; 1-\mathrm{c}$ & $0 ; 1 \mathrm{c}$ & $0 ; \mathrm{cn}$ & $00 ; 1-n$ & $0 ; 12 \mathrm{c}$ & $0 ; 1-$ \\
\hline PI 531901-2 & $?$ & & & 0 & & & 00 & & & $0 ; \mathrm{c}$ & $0 ; 1-$ & & 0 & & & $00 ; 1$ & & & $0 ; 1 \mathrm{c}$ \\
\hline Tunisia 33 & Rph $7+?$ & $00 ; 1-$ & & $00 ; 1$ & 00 & & $00 ; 1$ & & & 00 & 00 & & $00 ; 2$ & & & $210 ; \mathrm{c}$ & & & 0 \\
\hline Vada/H. bulbosum & $?$ & & & $10 ; \mathrm{c}$ & $120 ; \mathrm{c}$ & & 10 & & & 10 & & & $0 ; 1$ & & & $0 ; 1 \mathrm{c}$ & & & $0 ; 1-\mathrm{c}$ \\
\hline
\end{tabular}


Appendix Table 7 continued. Raw infection types ${ }^{1}$ for barley cultivar Bowman and the 95 leaf rust resistance gene donors across three experiments.

Isolates of Puccinia hordei
$98-20$
94-8
BRS 76-12
90-3

Neth 28

92-7

Line

Gene Identity

Rep1 Rep2 Rep3 Rep1 Rep2

Rep1 Rep2 Rep3 Rep1 Rep2 Rep3 Rep

Rep2 Rep3 Rep1 Rep2 Rep3

Bowman

Sudan NA

Bolivia Rphl.a

Juliaca

Peruvian

Reka I

Estate

PC249

PI 466324

Q21861

Batna

Gold

Lechtaler

Magnif 102

Bolivia

PI 531990

Tunisian 17

Tunisia 25

Tunisia 29

Rph2.r+Rph6.f

Rph $2 . l$

Rph $2 . b$

Rph2.y

Rph2.t+Rph19.ah

$\begin{array}{ll}3+3 & 33+ \\ 33- & 33-\end{array}$

\begin{tabular}{cc|cc}
+ & 3 & $33-$ & 33 \\
\hline $3-$ & $3-2$ & $3-$ & $33-$ \\
\hline
\end{tabular}

\begin{tabular}{r|rrr|rcc|c}
3 & 3 & 3 & $3-$ & $3+3$ & $33+$ & 3 & $33+$ \\
3 & $33-$ & $33-$ & $3-$ & $33+$ & 3 & 3 & $33-$
\end{tabular}

\begin{tabular}{ll|lllllllllll}
$3-2$ & $33-2$ \\
\hline
\end{tabular}

\begin{tabular}{|l|l|l|l|l|l|l|l|l|l|l|l|}
\hline $213-$ & & $23-1$ & $213-$ & & $210 ;$ & $210 ;$ & & $0 ; 12$ & $3-3$ & & 3 \\
\hline
\end{tabular}

\begin{tabular}{|c|c|c|c|c|c|c|c|c|c|c|c|c|c|c|c|c|c|}
$213-$ & & $23-1$ & $213-$ & & $210 ;$ & $210 ;$ & & $0 ; 12$ & $3-3$ & & 3 & $3-2$ & & 3 & 3 & & 3 \\
\hline $3-21 \mathrm{c}$ & $21 \mathrm{c}$ & $23-1$ & $3-2 \mathrm{c}$ & $210 ; \mathrm{c}$ & $210 ;$ & $213-\mathrm{c}$ & $120 ; \mathrm{c}$ & $120 ; \mathrm{c}$ & $320 ;$ & $33+$ & 3 & $33-$ & $3-2$ & $33-$ & $33-$ & $33-$ & $3-$ \\
\hline
\end{tabular} \begin{tabular}{|ccc|ccc|cccccc|c}
$3-21 \mathrm{c}$ & $21 \mathrm{c}$ & $23-1$ & $3-2 \mathrm{c}$ & $210, \mathrm{c}$ & $210 ;$ & $213-\mathrm{c}$ & $120, \mathrm{c}$ & $120 ; \mathrm{c}$ & $320 ;$ & $33+$ & 3 & $33-$ \\
\hline $213-$ & $23-\mathrm{c}$ & $213-$ & 21 & $33-$ & $213-$ & $10 ;$ & $210 ;$ & $0 ; 1$ & 3 & $3-$ & $23-1$ & 10 \\
\hline
\end{tabular} Rph3.c

Egypt 4 Rph3.0a

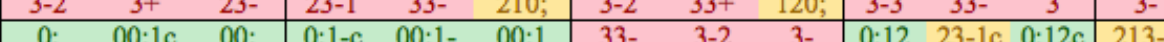

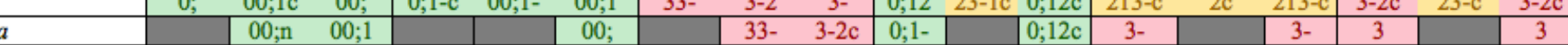
\begin{tabular}{l|c|cc|c|c|c|c|cc|c|c|c|c|} 
Rph3.aa & & $00 ; \mathrm{n}$ & $00 ; 1$ & & & $00 ;$ & & $33-$ & $3-2 \mathrm{c}$ & $0 ; 1-$ & & $0 ; 12 \mathrm{c}$ & $3-$ \\
\hline Rph3+? & $0 ; 1$ & $00 ; 1-$ & $0 ; 12$ & $00 ; 1-\mathrm{c}$ & $0 ; 1-$ & $0 ; 1-$ & $0 ; 1-\mathrm{c}$ & $00 ; 1-\mathrm{n}$ & $0 ; 1$ & $213-$ & $23-\mathrm{c}$ & $3-2 \mathrm{c}$ & $0 ; 1-$ \\
\hline
\end{tabular} \begin{tabular}{l|l|ll|lll|lll|l|l|l|l|l|} 
Rph3 & 21 & $00 ; 2$ & 21 & $213-$ & $00 ; 2 \mathrm{n}$ & 12 & $33-$ & $33-$ & $120 ;$ & $23-1$ & $0 ; 1 \mathrm{c}$ & $3-2$ & 21 \\
\hline
\end{tabular}

Rph4.

Rph4.d

Rph5.e Rph2.r+Rph6.f

\begin{tabular}{|c|c|c|c|c|c|c|c|ccc|c|}
\hline $33-$ & 3 & $3-2$ & & $3-$ & $3-2$ & & 3 & $3-2$ & $33-$ & 3 & $10 ; c$ \\
\hline
\end{tabular}

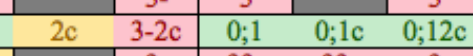

Hor 2596

PI 466247 Rph3 \begin{tabular}{|rrr|rrr|rrr|rrr|r}
$23-1$ & $3-$ & $3-2$ & $3-2 \mathrm{c}$ & $23-\mathrm{c}$ & 3 & $3-2$ & $33-$ & $3-2$ & $33-$ & 3 & $3-$ & $0 ; 12 \mathrm{c}$ \\
\hline
\end{tabular}

\begin{tabular}{rrrrrr}
$10 ; \mathrm{c}$ & 21 & $210 ;$ & $3+3$ & $33-$ & 3 \\
\hline $0 ; 12 c$ & $120 ; c$ & $0 ; 12$ & $3-2$ & $33-$ & $3-$
\end{tabular}

Rph $5+\operatorname{Rph} 7$ \begin{tabular}{llll|lll|lll|llll}
$12 \mathrm{c}$ & $10 ; \mathrm{c}$ & $120 ;$ & $10 ; \mathrm{c}$ & $0 ; 1 \mathrm{c}$ & $0 ; 1$ & $23-\mathrm{c}$ & $12 \mathrm{c}$ & $23-\mathrm{c}$ & $23-1 \mathrm{c}$ & $3-2 \mathrm{c}$ & $33-$ & $33-$
\end{tabular} \begin{tabular}{cc|ccc}
$10 ;$ & $0 ; 12 \mathrm{c}$ & $33-$ & $33-$ & 3 \\
$33-$ & 3 & $33-$ & $33-$ & 3
\end{tabular}

(2)

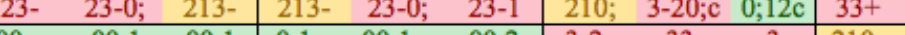
Rph $5+R p h 7$ Rph $5+R p h 7$ Rph $7 . g$ \begin{tabular}{|ccc|ccc|cccc}
$0 ; 1-$ & $0 ; 1$ & $00 ; 1$ & $00 ;$ & $00 ; 1$ & $00 ;$ & $0 ; 1 \mathrm{c}$ & $00 ;$ & $00 ; 1$
\end{tabular} \begin{tabular}{lll|lll|llll|lll}
$0 ; 1-\mathrm{cn}$ & $00 ; 1 \mathrm{n}$ & $00 ; 1$ & $0 ; 1-\mathrm{c}$ & $21 \mathrm{c}$ & $0 ; 1-$ & $10 ; \mathrm{c}$ & $210 ;$ & $00 ;$ & $23-1 \mathrm{c}$ & $33-$ & $3-0 ;$
\end{tabular} \begin{tabular}{ccc|cc}
$33-3$ & $33-$ & 3 & $33-$ & $33-$ \\
$33-$ & $33-$ & 3 & $33-$
\end{tabular}

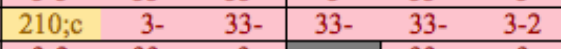

(100,

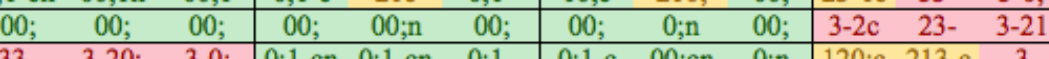
\begin{tabular}{l|cccccc|ccccc|ccc|c} 
Rph7.g & $33-$ & $3-20 ;$ & $3-0 ;$ & $0 ; 1-\mathrm{cn}$ & $0,1-\mathrm{cn}$ & $0 ; 1-$ & $0,1-\mathrm{c}$ & $00 ; \mathrm{cn}$ & $0 ; \mathrm{n}$ & $120 ; \mathrm{c}$ & $213-\mathrm{c}$ & 3 & $33-$ \\
\hline Rph8.h & $3-\mathrm{c}$ & $3-2 \mathrm{c}$ & 3 & $3-2 \mathrm{c}$ & $21 \mathrm{c}$ & $3-2$ & $33-$ & $23-\mathrm{c}$ & $3-2$ & $33+$ & 3 & $33-$ & $33-\mathrm{c}$
\end{tabular} Rphy

Quinn Rph2.q+Rph5.e

\begin{tabular}{lll|lll|lll|l}
$120 ; \mathrm{c}$ & $12 \mathrm{c}$ & $120 ; \mathrm{c}$ & $120 ; \mathrm{c}$ & $210 ;$ & $23-1 \mathrm{c}$ & $120 ; \mathrm{c}$ & $210 ; \mathrm{c}$ & $23-1 \mathrm{c}$ & $3-2$ \\
\hline
\end{tabular}

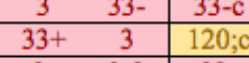

\begin{tabular}{|cc|c|cc|}
$33-$ & $3-$ & 3 & $33-$ & $3-$ \\
\hline $3-$ & $3-$ & & 3 & $3-$
\end{tabular}

3- 3-

\begin{tabular}{cc|c}
$33-\mathrm{c}$ & 3 & $33-$ \\
$33+$ & $33-$ & 3
\end{tabular}

\begin{tabular}{ll|cc}
$10 ; \mathrm{c}$ & $210 ; \mathrm{c}$ & $23-10$ & $33+$ \\
& $23-$
\end{tabular}

\begin{tabular}{ccc|ccc}
$120 ;$ & $00 ; 1-$ & $0 ; 12$ & $210 ; \mathrm{c}$ & $0 ; 1-\mathrm{c}$ & $0 ; 1$ \\
\hline
\end{tabular} 
Appendix Table 7 continued. Raw infection types ${ }^{1}$ for barley cultivar Bowman and the 95 leaf rust resistance gene donors across three experiments. Isolates of Puccinia hordei

$$
\begin{array}{rrr} 
& \text { Isolates of Puccinia hordei } \\
\hline 98-20 & \text { BRS 76-12 } & 90-3
\end{array}
$$

BRS 76-12

90-3 Neth 28

92-7

Line

Gene Identity

Triumph

Quinn

$\operatorname{Rph} 9 . z$

Clipper BC 8

Clipper BC 67

PI 531849

PI 531901-

HS584

Rep1 Rep2 Rep3 Rep1 Rep

\begin{tabular}{|c|c|c|c|c|c|c|c|c|c|c|c|c|c|c|c|c|c|}
\hline $10 ; \mathrm{c}$ & $120 ; \mathrm{c}$ & $0 ; 12$ & $3-2$ & 33- & 3- & $0 ; 1-\mathrm{c}$ & $0 ; 1-c$ & $0 ; 1$ & 33- & 3 & 3 & $23-c$ & $33+$ & 3 & $3-2 c$ & 3 & 3 \\
\hline 120 ; & $00 ; 1-$ & $0 ; 12$ & $210 ; \mathrm{c}$ & $0 ; 1-\mathrm{c}$ & $0 ; 1$ & $3-2$ & $3-2$ & $0 ; 12$ & $23-1$ & 33- & $3-21$ & $3-2$ & 33- & 33- & $33+$ & 3 & 3- \\
\hline $12 \mathrm{c}$ & 10 & $120 ; \mathrm{c}$ & $12 \mathrm{c}$ & $10 ; \mathrm{c}$ & $10 ;$ & $23-1 \mathrm{c}$ & $120 ; \mathrm{c}$ & $23-1$ & $23-c$ & $23-c$ & $3-2 c$ & $33+$ & 3 & 3 & 33- & $33+$ & 3 \\
\hline $21 \mathrm{c}$ & $23-\mathrm{c}$ & $23-1$ & $3-2 c$ & $23-\mathrm{c}$ & $213-$ & $21 \mathrm{c}$ & $21 \mathrm{c}$ & $23-1$ & $23-1 c$ & $23-\mathrm{c}$ & $3-2 c$ & 3-c & $3-2 c$ & $3-2 c$ & $23-\mathrm{c}$ & $23-\mathrm{c}$ & $3-$ \\
\hline $3-2$ & 213- & $23-1$ & $23-c$ & 213- & $3-2$ & $10 ; \mathrm{c}$ & $0 ; 1$ & $0 ; 1$ & $0 ; 1 \mathrm{c}$ & $0 ; 1 \mathrm{c}$ & $210 ;$ & $0 ; 1 \mathrm{c}$ & $0 ; 1 \mathrm{c}$ & $120 ;$ & $0 ; 1$ & $0 ; 1 \mathrm{c}$ & 12 \\
\hline $10 ;$ & & $210 ; \mathrm{c}$ & 21 & & $210 ; \mathrm{c}$ & $21 \mathrm{c}$ & & $10 ; \mathrm{c}$ & & & 3- & & & $23-c$ & & & $3-2$ \\
\hline $10 ; \mathrm{cn}$ & $10 ; \mathrm{cn}$ & $0 ; 1$ & $1-0 ; \mathrm{cn}$ & $1-0 ; \mathrm{cr}$ & $10 ; \mathrm{cn}$ & $0 ; \mathrm{cn}$ & $0 ; \mathrm{cn}$ & $0 ; \mathrm{cn}$ & $2 c$ & $2 c$ & $3-2 c$ & $10 ; \mathrm{c}$ & $1 \mathrm{c}$ & $210 ; \mathrm{c}$ & $10 ; \mathrm{c}$ & $2 c$ & $0 ; 1 \mathrm{c}$ \\
\hline $21 \mathrm{c}$ & $10 ; \mathrm{cn}$ & $0 ; 1$ & $10 ; \mathrm{c}$ & $10 ; \mathrm{cn}$ & $0 ; 1-n$ & $11-\mathrm{c}$ & $0 ; 1$-cn & $0 ; 1-$ & $33+$ & 3- & 3 & $3-2$ & 33- & $21 \mathrm{cn}$ & $3-2$ & 33- & $3-2$ \\
\hline $0 ; 1-\mathrm{cn}$ & $0 ; \mathrm{cn}$ & $0 ; \mathrm{cn}$ & $0 ; 1-\mathrm{cn}$ & $0 ; \mathrm{cn}$ & $0 ; \mathrm{cn}$ & $0 ; \mathrm{cn}$ & $0 ; \mathrm{cn}$ & $0 ; \mathrm{n}$ & $3-2$ & 33- & 33- & 12 -cn & $21 \mathrm{cn}$ & $21 \mathrm{cn}$ & $1-0 ; \mathrm{cn}$ & $10 ; \mathrm{cn}$ & $0 ; 1 \mathrm{c}$ \\
\hline & & $0 ; 1$-cn & & $0 ; 1-n$ & $10 ; \mathrm{cn}$ & & $0 ; \mathrm{cn}$ & $0 ; \mathrm{cn}$ & & & $3-c$ & & $21 \mathrm{cn}$ & $3-2 n$ & & & $0 ; 1-\mathrm{cn}$ \\
\hline $0 ; 1$-cn & $0 ; 1$-cn & $0 ; 1$-cn & $0 ; \mathrm{cn}$ & $0 ; 1-\mathrm{cr}$ & $10 ; \mathrm{cn}$ & $0 ; \mathrm{cn}$ & $0 ; \mathrm{cn}$ & $0 ; \mathrm{cn}$ & $3-2 c$ & 33- & 3-c & 23-cn & $21 \mathrm{cn}$ & $3-2 n$ & $1-0 ; \mathrm{cn}$ & $1-0 ; \mathrm{cn}$ & $0 ; 1-\mathrm{cn}$ \\
\hline $0 ; 1-\mathrm{cn}$ & $0 ; 1-\mathrm{cn}$ & $0 ; 1$ & $0 ; 1-\mathrm{c}$ & $0 ; 1-\mathrm{c}$ & $0 ; 1-$ & $0 ; 1-\mathrm{cn}$ & $00 ; \mathrm{cn}$ & 0 & $213-c$ & $12 \mathrm{c}$ & $3-2$ & $213-c$ & $21 \mathrm{c}$ & $213-c$ & $10 ; \mathrm{c}$ & $0 ; 1$-cn & $0 ; 1$ \\
\hline $0 ; 1$-cn & $0 ; 1$-cn & $0 ; \mathrm{cn}$ & $0 ; 1-\mathrm{c}$ & $0 ; 1-\mathrm{c}$ & $0 ; \mathrm{cn}$ & $0 ; \mathrm{cn}$ & $0 ; \mathrm{cn}$ & 0 & $213-\mathrm{c}$ & $23-\mathrm{c}$ & $3-2$ & 12 -cn & $21 \mathrm{c}$ & $210 ; c$ & $0 ; 1-\mathrm{cn}$ & $10 ; \mathrm{c}$ & $0 ; 1$ \\
\hline $1-0 ; \mathrm{cn}$ & $10 ; \mathrm{cn}$ & $0 ; 1$-cn & $1-0 ; \mathrm{cn}$ & $0 ; 1-\mathrm{cr}$ & $10 ; \mathrm{cn}$ & $0 ; \mathrm{cn}$ & $0 ; \mathrm{cn}$ & $0 ; \mathrm{cn}$ & $33+$ & $33-$ & $3-2 c$ & $21 \mathrm{cn}$ & $21 \mathrm{cn}$ & $21 \mathrm{cn}$ & $1-0 ; \mathrm{cn}$ & $0 ; 1$-cn & $0 ; 1$-cn \\
\hline $1-0 ; \mathrm{cn}$ & $10 ; \mathrm{cn}$ & $0 ; 1 \mathrm{cn}$ & $1-0 ; \mathrm{c}$ & $1-0 ; \mathrm{cr}$ & $0 ; 1$-cn & $0 ; \mathrm{cn}$ & $0 ; \mathrm{cn}$ & 0 & 3- & $23-c$ & 3- & $23-1 \mathrm{cn}$ & $21 \mathrm{cn}$ & $21 \mathrm{cn}$ & $1-0 ; \mathrm{cn}$ & $10 ; \mathrm{cn}$ & $0 ; 1 \mathrm{cn}$ \\
\hline $1-0 ; \mathrm{c}$ & & $0 ; 1-\mathrm{cn}$ & $1-0 ; \mathrm{c}$ & $0 ; 1-\mathrm{cr}$ & $0 ; \mathrm{cn}$ & $0 ; \mathrm{cn}$ & $0 ; \mathrm{cn}$ & $0 ; \mathrm{cn}$ & 3 & $3-2 c$ & 3- & 12 -cn & $21 \mathrm{cn}$ & $12 \mathrm{cn}$ & $1-0 ; \mathrm{cn}$ & 1 & $0 ; 1-\mathrm{cn}$ \\
\hline $0 ; 1-\mathrm{cn}$ & $10 ; \mathrm{cn}$ & $0 ; 1 \mathrm{cn}$ & $1-0 ; c$ & $0 ; 1-\mathrm{cr}$ & $0 ; 1-\mathrm{cn}$ & $0 ; \mathrm{cn}$ & $0 ; \mathrm{cn}$ & $0 ; \mathrm{cn}$ & $23-\mathrm{c}$ & 33- & $3-c$ & 12 -cn & $21 \mathrm{cn}$ & $21 \mathrm{cn}$ & $1-0 ; \mathrm{cn}$ & $1 \mathrm{cn}$ & $10 ; \mathrm{cn}$ \\
\hline $1-0 ; \mathrm{c}$ & $0 ; 1$-cn & $0 ; 1$-cn & $1-0$ & $0 ; 1-\mathrm{cr}$ & $0 ; 1$-cn & $0 ; \mathrm{cn}$ & $0 ; \mathrm{cn}$ & $0 ; \mathrm{cn}$ & $3-3$ & $3-$ & $3-2$ & 23-cn & $21 \mathrm{cn}$ & 23-cn & $1-0 ; \mathrm{cn}$ & $0 ; 1$-cn & $0 ; 1 \mathrm{cn}$ \\
\hline $0 ; 1-\mathrm{cn}$ & $0 ; \mathrm{cn}$ & $0 ; 1$-cn & $1-0 ; \mathrm{c}$ & $0 ; 1-\mathrm{cr}$ & $0 ; 1$-cn & $0 ; \mathrm{cn}$ & $0 ; \mathrm{cn}$ & $0 ; \mathrm{cn}$ & $3-2 c$ & 3 & 3 & 12-cn & $23-c$ & $3-2 n$ & $1-0 ; \mathrm{cn}$ & $1-0 ; \mathrm{cn}$ & $0 ; 1-\mathrm{cn}$ \\
\hline 120 & $0 ; 1$-cn & $0 ; 1 \mathrm{c}$ & $0 ; 1$ & 10 & $0 ; 1-$ & $10 ; \mathrm{c}$ & $0 ; 1-c$ & $0 ; \mathrm{c}$ & $213-\mathrm{c}$ & 213- & $3-2$ & $120 ; c$ & $2 c$ & $210 ; c$ & $0 ; 1-\mathrm{c}$ & 10 & $0 ; 1 \mathrm{c}$ \\
\hline $10 ; \mathrm{c}$ & $0 ; 1-\mathrm{cn}$ & $0 ; 1 \mathrm{c}$ & 10 & $0 ; 1-\mathrm{cr}$ & $0 ; 1$ & $0 ; 1-\mathrm{c}$ & $10 ; \mathrm{c}$ & $0 ; 1-$ & $23-1 c$ & $3-2$ & 213- & $10 ; \mathrm{c}$ & $10 ; \mathrm{c}$ & $210 ; \mathrm{c}$ & $0 ; 1-$ & $0 ; 1$ & \\
\hline $0 ; 1 \mathrm{c}$ & $0 ; 1-$ & $0 ; 1$-cn & $0 ; 1 \mathrm{c}$ & $0 ; 1-$ & $0 ; 1-$ & $0 ; \mathrm{cn}$ & $0 ; 1$-cn & $0 ;$ & $213-\mathrm{c}$ & $21 \mathrm{c}$ & $23-c$ & 213- & 21 & 210 & & $10 ; \mathrm{n}$ & $0 ; 1-$ \\
\hline $0 ; 1-\mathrm{c}$ & $0 ; 1$-cn & $0 ; 1$ & $0 ; 1-\mathrm{c}$ & $0 ; 1-\mathrm{c}$ & $0 ; 1$ & $0 ; 1-\mathrm{cn}$ & $00 ; \mathrm{cn}$ & $0 ; 1-$ & $23-1 \mathrm{c}$ & $23-\mathrm{c}$ & $3-2$ & $23-\mathrm{c}$ & $21 \mathrm{cn}$ & 210 & $1-0 ; \mathrm{cn}$ & $0 ; 1 \mathrm{cn}$ & $10 ; \mathrm{c}$ \\
\hline $1-0 ; \mathrm{cn}$ & $10 ; \mathrm{cn}$ & $10 ; \mathrm{cn}$ & $1-\mathrm{c}$ & $1-0 ; \mathrm{cr}$ & $10 ; \mathrm{cn}$ & $0 ; \mathrm{cn}$ & $0 ; \mathrm{cn}$ & $0 ; \mathrm{cn}$ & $3-2$ & 3 & 3- & $3-2 \mathrm{cn}$ & 23-cn & $3-2$ & $1-0 ; \mathrm{cn}$ & $1 \mathrm{cn}$ & $10 ; \mathrm{cn}$ \\
\hline $1-0 ; n$ & $10 ; \mathrm{cn}$ & $0 ; \mathrm{cn}$ & $1-0 ; \mathrm{cn}$ & $0 ; 1-\mathrm{cr}$ & & $0 ; \mathrm{cn}$ & $0 ; \mathrm{cn}$ & $0 ; \mathrm{cn}$ & 3 & 3- & 33- & $21 \mathrm{cn}$ & $21 \mathrm{cn}$ & $21 \mathrm{cn}$ & $1-0 ; \mathrm{cn}$ & $10 ; \mathrm{c}$ & $0 ; 1-$ \\
\hline
\end{tabular}

$\overrightarrow{\widetilde{N}}$ $2 . q+R p h 5$ Rph10.0 Rph11.p Rph13.x

Rph15+?

\begin{tabular}{ll} 
P 1354923 & Rph15 \\
\hline PI 354926 & Rph15
\end{tabular}

PI 354928 Rph15

PI 354932 Rph15

PI 354937 Rph15

\begin{tabular}{ll} 
PI 354940 & Rph15 \\
\hline PI 355434 & Rph15
\end{tabular}

I 355447

PI $391000-R p h 15$

Pi 391002 Rph15

Pi $391004 \quad$ Rph15+?

PI 391007 Rph15+?

PI391024 Rph15

PI 391044 Rph15

PI 391045 Rph15 
Appendix Table 7 continued. Raw infection types ${ }^{1}$ for barley cultivar Bowman and the 95 leaf rust resistance gene donors across three experiments.

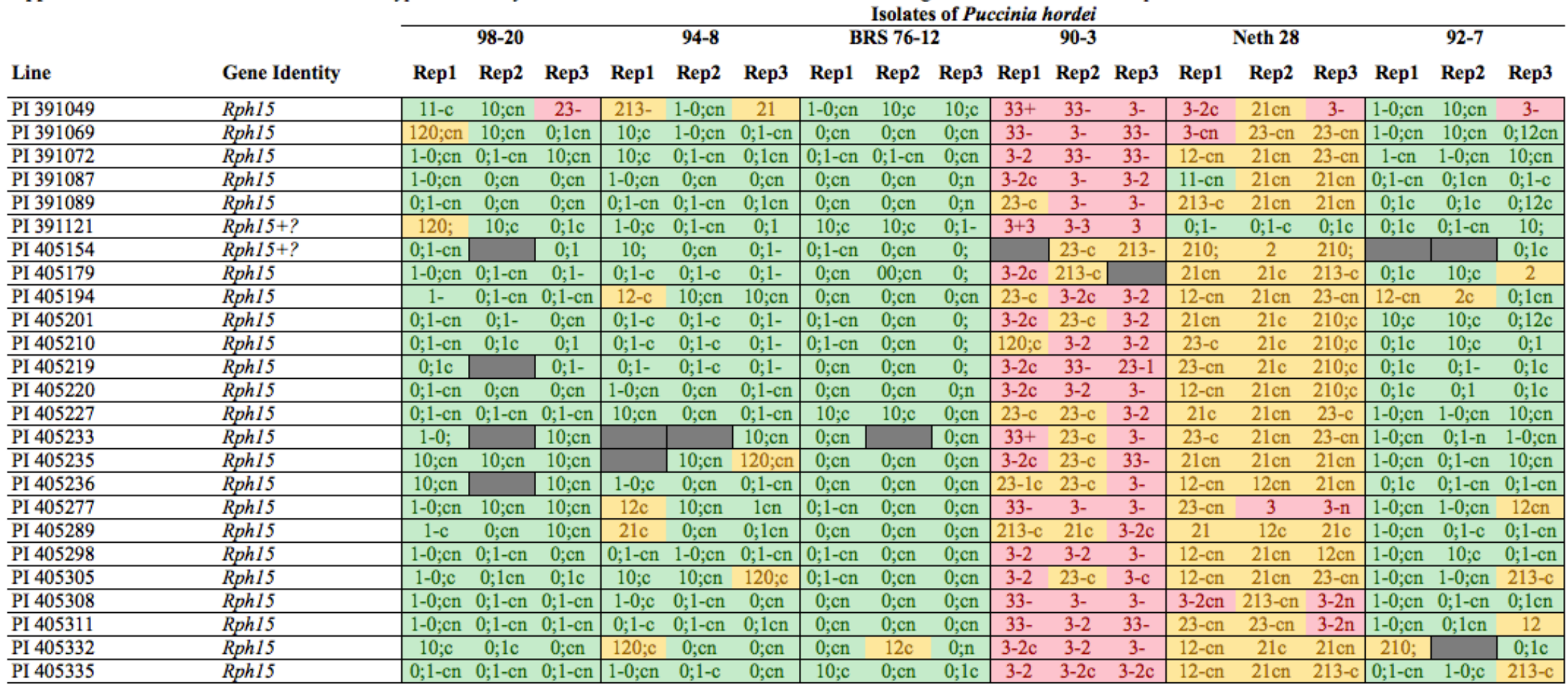

$\vec{N}$ 
Appendix Table 7 continued. Raw infection types ${ }^{1}$ for barley cultivar Bowman and the 95 leaf rust resistance gene donors across three experiments.

\begin{tabular}{|c|c|c|c|c|c|c|c|c|c|c|c|c|c|c|c|c|c|c|c|}
\hline \multirow[b]{3}{*}{ Line } & \multirow[b]{3}{*}{ Gene Identity } & \multicolumn{18}{|c|}{ Isolates of Puccinia hordei } \\
\hline & & \multicolumn{3}{|c|}{$98-20$} & \multicolumn{3}{|c|}{$94-8$} & \multicolumn{3}{|c|}{ BRS 76-12 } & \multicolumn{3}{|c|}{$90-3$} & \multicolumn{3}{|c|}{ Neth 28} & \multicolumn{3}{|c|}{ 92-7 } \\
\hline & & Rep1 & Rep2 & Rep3 & Rep1 & Rep2 & Rep3 & Rep1 & Rep2 & Rep3 & Rep1 & Rep2 & Rep3 & Rep1 & Rep2 & Rep3 & Rep1 & Rep2 & Rep3 \\
\hline PI 405338 & Rph15 & $120 ; \mathrm{c}$ & $0 ; \mathrm{cn}$ & $0 ; 1$ & $0 ; 1-\mathrm{cn}$ & $0 ; \mathrm{cn}$ & $0 ; 1 \mathrm{c}$ & $0 ; \mathrm{cn}$ & $0 ; \mathrm{cn}$ & $0 ; 1 \mathrm{c}$ & $33+$ & $33-$ & 3 & $210 ; \mathrm{cn}$ & $21 \mathrm{cn}$ & $3-2 c$ & $1-0 ; \mathrm{cn}$ & 10 & $23-1 \mathrm{c}$ \\
\hline PI 405341 & Rph15 & $0 ; 1-\mathrm{cn}$ & $0 ; 1-$ & $0 ; 1-$ & $0 ; 1-\mathrm{c}$ & $0 ; 1-\mathrm{c}$ & $0 ; 1-$ & $0 ; \mathrm{cn}$ & $00 ; \mathrm{cn}$ & 0 & $213-c$ & $3-2$ & $3-21$ & $210 ; \mathrm{c}$ & $21 \mathrm{c}$ & 210 & $0 ; 1-\mathrm{c}$ & $0 ; 1 \mathrm{c}$ & 120 \\
\hline PI 405354 & Rph15 & $0 ; 1$-cn & $0 ; 1$-cn & $0 ; \mathrm{cn}$ & $10 ; \mathrm{c}$ & $1-0 ; \mathrm{cn}$ & $0 ; \mathrm{cn}$ & $120 ; c$ & $0 ; \mathrm{cn}$ & $0 ; n$ & 3- & $3-2$ & $33-$ & $12-\mathrm{cn}$ & $21 \mathrm{cn}$ & $21 \mathrm{cn}$ & $1-0 ; \mathrm{cn}$ & $1-0 ; \mathrm{cn}$ & $0 ; 1 \mathrm{c}$ \\
\hline PI 405399 & Rph15 & $0 ; 1-\mathrm{cn}$ & $0 ; \mathrm{cn}$ & $0 ; 1-\mathrm{cn}$ & $2-1 c$ & $0 ; \mathrm{cn}$ & $0 ; 1 \mathrm{cn}$ & $0 ; \mathrm{cn}$ & $0 ; \mathrm{cn}$ & $0 ; \mathrm{cn}$ & $3+3$ & $3-$ & $33-$ & 23-cn & $21 \mathrm{cn}$ & $23-\mathrm{cn}$ & $1-0 ; \mathrm{cn}$ & $0 ; 1 \mathrm{cn}$ & $0 ; 1 \mathrm{cn}$ \\
\hline PI 466245 & Rph15 & $10 ; \mathrm{cn}$ & $0 ; 1 \mathrm{cn}$ & $0 ; 1 \mathrm{cn}$ & $1-0 ; \mathrm{c}$ & $0 ; 1-\mathrm{cn}$ & $10 ; \mathrm{cn}$ & $0 ; \mathrm{cn}$ & $0 ; \mathrm{cn}$ & $0 ; \mathrm{cn}$ & $33+$ & $3-3$ & $3-$ & $23-\mathrm{cn}$ & $21 \mathrm{cn}$ & $3-$ & $12-\mathrm{cn}$ & $1-0 ; \mathrm{cn}$ & $0 ; 1 \mathrm{cn}$ \\
\hline PI 466470 & Rph15+? & $213-\mathrm{c}$ & $120 ; c$ & $3-2$ & 210 & $120 ; \mathrm{c}$ & $0 ; 12$ & $0 ; 1-\mathrm{c}$ & $10 ; \mathrm{c}$ & $0 ; \mathrm{c}$ & $120 ; c$ & $120 ; c$ & $0 ; 12 \mathrm{c}$ & $0 ; 1 \mathrm{c}$ & $0 ; 1-\mathrm{c}$ & $0 ; 12 \mathrm{c}$ & $0 ; 1 \mathrm{c}$ & 10 & $0 ; 1-$ \\
\hline PI 466483 & Rph15+? & $11-\mathrm{c}$ & $23-1 \mathrm{c}$ & $23-1$ & $213-$ & 2 & $210 ; \mathrm{c}$ & $0 ; 1 \mathrm{c}$ & $0 ; 1-\mathrm{c}$ & $0 ; 1-$ & $210 ; \mathrm{c}$ & $120 ; \mathrm{c}$ & $120 ; \mathrm{c}$ & $0 ; 1 \mathrm{c}$ & $0 ; 1-\mathrm{c}$ & $0 ; 12 \mathrm{c}$ & $0 ; 1$ & $0 ; 1 \mathrm{c}$ & $0 ; 1 \mathrm{c}$ \\
\hline Columbia & $?$ & $33-$ & 3 & $3+$ & $33-$ & 3 & 3 & $213-$ & $33+$ & 3 & $33+$ & $33-$ & $33-$ & $21 \mathrm{c}$ & $213-$ & $3-2$ & $3-2$ & $33-$ & 3 \\
\hline Emir/H. bulbosum & $?$ & $00 ; n$ & 00 & 00 & $00 ; n$ & & 00 & 00 & & 00 & $00 ; n$ & $00 ; n$ & 00 & 00 & $00 ; n$ & 00 & 00 & $00 ; \mathrm{n}$ & $00 ; n$ \\
\hline HS580 & Rph15 & $1 \mathrm{c}$ & $0 ; 1-$ & $0 ; 1 \mathrm{cn}$ & $11-$ & $0 ; 1-\mathrm{c}$ & $10 ; \mathrm{cn}$ & $1-0 ; \mathrm{cn}$ & $00 ; \mathrm{cn}$ & $0 ; \mathrm{cn}$ & 3 & $23-c$ & $3-$ & 23 -cn & $21 \mathrm{cn}$ & $23-\mathrm{cn}$ & $0 ; 1-\mathrm{cn}$ & $0 ; 1$-cn & $0 ; 1-\mathrm{cn}$ \\
\hline PI 355445 & Rph15 & $1-0 ; \mathrm{cn}$ & $1-0 ; \mathrm{cn}$ & $0 ; 1 \mathrm{cn}$ & $1-0 ; \mathrm{c}$ & $10 ; \mathrm{cn}$ & $0 ; 1-\mathrm{cn}$ & $0 ; 1-\mathrm{cn}$ & $12 \mathrm{c}$ & 0 & $33-$ & $33-\mathrm{c}$ & $3-$ & $12-\mathrm{cn}$ & $21 \mathrm{c}$ & $210 ; n$ & $1-0 ; \mathrm{cn}$ & $10 ; \mathrm{c}$ & $0 ; 1-\mathrm{cn}$ \\
\hline PI 405154 & Rph15+? & $1-0 ; \mathrm{cn}$ & $0 ; 1-$ & & $0 ; 1-\mathrm{c}$ & $0 ; 1-\mathrm{cn}$ & & $0 ; \mathrm{cn}$ & $00 ; \mathrm{c}$ & & $23-1 \mathrm{c}$ & $23-1 \mathrm{c}$ & & $213-c$ & $21 \mathrm{c}$ & & $1-0 ; \mathrm{cn}$ & $10 ; \mathrm{c}$ & \\
\hline PI 405169 & $R p h 9$ & & $10 ; \mathrm{c}$ & 213- & $213-\mathrm{c}$ & $21 \mathrm{c}$ & $120 ; c$ & 12 & $33-$ & $213-c$ & & & $3-$ & $33-$ & $33-$ & $3-$ & & 3 & $3-$ \\
\hline PI 405215 & Rph15+? & $0 ; 1-\mathrm{cn}$ & $0 ; \mathrm{cn}$ & $0 ; \mathrm{cn}$ & $1-0 ; \mathrm{cn}$ & $0 ; \mathrm{cn}$ & $0 ; \mathrm{cn}$ & $0 ; \mathrm{cn}$ & $0 ; \mathrm{cn}$ & $0 ; \mathrm{cn}$ & $3-2 c$ & $23-c$ & $23-\mathrm{c}$ & 12 -cn & $21 \mathrm{cn}$ & $12 \mathrm{cn}$ & $0 ; 1-\mathrm{c}$ & $0 ; 1-\mathrm{cn}$ & $10 ; \mathrm{cn}$ \\
\hline PI 466373 & Rph15+? & $0 ; 1-\mathrm{cn}$ & $00 ; 1-$ & $0 ; \mathrm{cn}$ & $10 ; \mathrm{c}$ & $00 ; 1-\mathrm{c}$ & $0 ; \mathrm{cn}$ & $0 ; 1-\mathrm{cn}$ & $00 ; 1-$ & 0 & $23-\mathrm{c}$ & $21 \mathrm{c}$ & $3-$ & $210 ; \mathrm{c}$ & $21 \mathrm{c}$ & $213-\mathrm{c}$ & $00 ; 1$ & $0 ; 1$ & $0 ; 1-$ \\
\hline PI 531901-2 & $?$ & & & 00 & & & $0 ; 1$ & & & $0 ; 12$ & & & $0 ; 12 \mathrm{c}$ & & & $213-\mathrm{c}$ & & & $3-2$ \\
\hline Tunisia 33 & Rph7+? & 00 & $00 ; 1 \mathrm{n}$ & $0 ; 1$ & $00 ; n$ & & $0 ; 1$ & & & 00 & & & $0 ; 3-$ & & $33-$ & $3-$ & & & 3- \\
\hline Vada/H. bulbosum & $?$ & & & $213-$ & & & 10 & & & 10 & & & $3-$ & & & $3-$ & & $00 ; 2$ & $3-2$ \\
\hline
\end{tabular}

${ }^{1}$ Infection types were scored using the original 0-4 rating scale developed by Mains (1930) with the additional notations of "+" and "-" to indicate larger or smaller size variations of

classically described uredinia (Levine and Cherewick, 1952) and " $\mathrm{c}$ " and " $\mathrm{n}$ " to indicate the presence of chlorotic or necrotic reactions (Moseman and Roane, 1959), respectively. Complex ITs were recorded when more than one IT was observed on the surface of a single leaf. For example, an IT of 213- indicates that all three pustule types exist on the same leaf and that the " 2 " type pustules were the most common, followed by the "1" type, with "3-" type pustules being the least common. Infection types from "0;" to "0;12" are classified as highly resistant ("R", green cells), infections types from "12" to "23-c" are classified as moderately resistant ("M", yellow cells), and infection types from "23-" to "33+" are classified as susceptible ("S", red cells) (Steffenson et al., 1993). 
Appendix Table 8. Raw infection types ${ }^{1}$ of barley differential lines carrynig the leaf rust resistance genes Rph1-24 in this and a previous study.

Isolate $^{2} \quad$ Replication $^{3}$ BR (Octal 11) Fetch et al. (1998) Exp1 2003 GH INC Exp1 $2015 \mathrm{GH}$ INC Exp1 NSGC

Exp1 2014 Field INC Exp3 GH + Field INC Exp3 NSGC

Exp10 GH + Field INC Exp10 NSGC

Exp $11 \mathrm{GH}+$ Field INC ARG231 Fetch et al. (1998) Exp1 2003 GH INC Exp1 2015 GH INC Exp1 NSGC

Exp1 2014 Field INC Exp3 GH + Field INC Exp3 NSGC

Exp10 GH + Field INC

Exp10 NSGC

Exp $11 \mathrm{GH}+$ Field INC
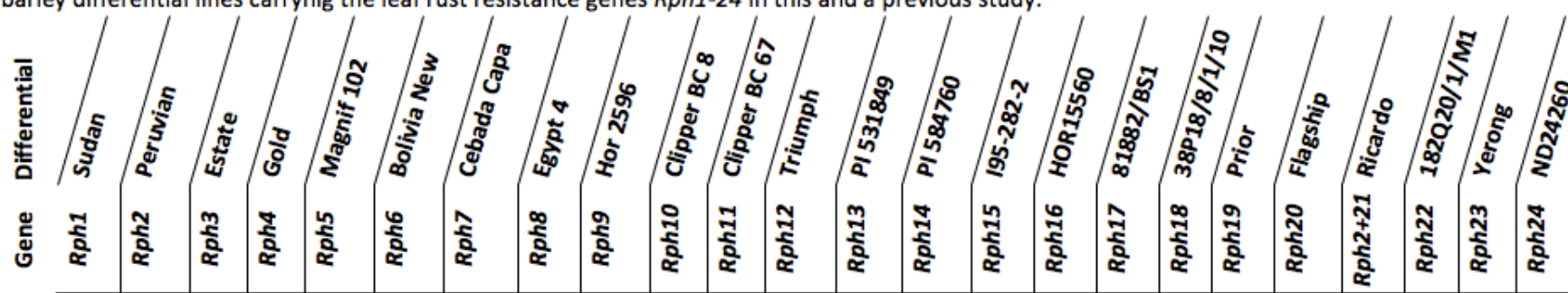

\begin{tabular}{|c|c|c|c|c|c|c|c|c|c|c|c|c|c|c|c|c|c|c|c|c|c|c|c|}
\hline $10 ; c$ & 210 & 0 & 3 & $0 ; n$ & $0 ; n$ & $0 ; n$ & $12 \mathrm{c}$ & $0 ; 1 \mathrm{c}$ & $231 c$ & $23 c$ & $0 ; \mathrm{nc}$ & 32 & $0 ; 1$ & $0 ; \mathrm{N}$ & & & & & & & & & \\
\hline 21 & 21 & $0 ; 1$ & 23 & $0 ; 1 \mathrm{~N}$ & 1C & $0 ; \mathrm{cN}$ & $0 ; 1 \mathrm{cn}$ & $0 ; 1 \mathrm{cN}$ & 20; & $12 \mathrm{C}$ & $0 ; 1 \mathrm{Cn}$ & $120 ; n$ & & $0 ; \mathrm{N}$ & & & & & & & & & \\
\hline $23 \mathrm{C}$ & $0 ; 1 C$ & $0 ; 12$ & $23 \mathrm{C}$ & & $21 \mathrm{C}$ & $0 ; \mathrm{cn}$ & & $0 ; \mathrm{Cn}$ & $0 ; 1 \mathrm{C}$ & $0 ; 1 \mathrm{~N}$ & & $10 ; \mathrm{cN}$ & $0 ; 1 n$ & $0 ; \mathrm{CN}$ & & & & & & & & & \\
\hline \multirow[t]{2}{*}{$0 ; 1 \mathrm{~N}$} & $0 ; 1 C$ & $0 ; \mathrm{CN}$ & $213 \mathrm{C}$ & $0 ; \mathrm{N}$ & & $0 ; \mathrm{cN}$ & $0 ; 2 \mathrm{C}$ & & & & 3 & & & & & & & & & & & & \\
\hline & & & & & & & & & & & & & & & 12 & $0 ; 1 \mathrm{c}$ & $00 ; n$ & $0 ; 1 \mathrm{Cn}$ & $0 ; 1 C$ & $0 ; 1 n$ & & $0 ; 12 c$ & \\
\hline 23-1 & 213- & $0 ; 1-c$ & 12 & $0 ; 1-n$ & $11-c$ & $00 ; n$ & 210;n & $0 ; 1-c n$ & 120; & 120; & $0 ; 1-$ & 0;1- & $00 ; 1-$ & $0 ; 1-c n$ & 12 & $1-0 ; \mathrm{c}$ & $00 ; n$ & 0;1- & $10 ; c$ & $1 c$ & 12 & 213- & 213. \\
\hline 0;1-n & $0 ; 1$ & $00 ; 1-$ & 12 & 0;1- & 0;1- & $00 ; 1-n$ & $210 ; n$ & $0 ; 1-\mathrm{cN}$ & 12 & $0 ; 1-c$ & 1-0; & 10; & $0 ; 1$ & $0 ; 1-\mathrm{cn}$ & & & & 0;1-n & & $0 ; 1$ & & 21 & \\
\hline $3-2 c$ & 0;1c & $0 ; 12 \mathrm{c}$ & 23-c & $0 ; 1-\mathrm{CN}$ & $0 ; 1 \mathrm{c}$ & $00 ; \mathrm{cn}$ & $0 ; 1 \mathrm{cn}$ & $10 ; \mathrm{cn}$ & $10 ; c$ & $213-c$ & $0 ; 1-c n$ & $0 ; 12$ & o;cn. & $0 ; 1-\mathrm{cn}$ & $23-c$ & $0 ; 12 c$ & $00 ;$ & $0 ; 1-\mathrm{cn}$ & $0 ; 1 \mathrm{c}$ & $0 ; 1 \mathrm{c}$ & & 23-1 & \\
\hline 0;1cn & $0 ; 1 \mathrm{c}$ & $0 ; 12$ & 23-c & $10 ; \mathrm{cn}$ & $0 ; 12 \mathrm{cn}$ & 00;cn & $0 ; 1 \mathrm{cn}$ & 0;1cn & & & $0 ; 12 \mathrm{cN}$ & $00 ; 1$ & $00 ; 1 \mathrm{cn}$ & & & & & $0 ; 1-\mathrm{cn}$ & & $00 ; 1 \mathrm{c}$ & & $0 ; 12$ & \\
\hline $3-2$ & $0 ; 1$ & 0 & $3-2 c$ & $0 ; 1 \mathrm{n}$ & $0 ; 1$ & $0 ; n$ & $0 ; 1 \mathrm{n}$ & $0 ; 1 \mathrm{~N}$ & 213- & 21 & 10; & $00 ; 1$ & 10; & $0 ; 1-\mathrm{cn}$ & 2 & $10 ; c$ & 00 ; & $0 ; 1 \mathrm{n}$ & $0 ; 1 \mathrm{c}$ & $10 ; c$ & 10; & $0 ; 12$ & 33. \\
\hline 3 & 3 & 0; & 3 & 3 & 3 & $0 ; n$ & 3 & $213 \mathrm{C}$ & 3 & 3 & $0 ; 1 n c$ & $0 ; c n$ & $12 c$ & $0 ; n$ & & & & & & & & & \\
\hline $210 ; c$ & $0 ; 1 \mathrm{c}$ & $00 ; 1$ & $21 \mathrm{C}$ & 21c & $12 \mathrm{C}$ & $0 ; \mathrm{cN}$ & & $0 ; \mathrm{N}$ & 21c & $2 c$ & & 120; & 2 & $0 ; \mathrm{N}$ & & & & & & & & & \\
\hline $213 c$ & $0 ; 1 c$ & $00 ; 1$ & 21c & & 21c & & & $0 ; \mathrm{N}$ & 21c & $1 c$ & $10 ; n$ & $0 ; 1$ & 21 & $0 ; \mathrm{CN}$ & & & & & & & & & \\
\hline \multirow[t]{2}{*}{$0 ; 2 \mathrm{~N}$} & $0 ; c n$ & $00 ; n$ & 2 & $12 c$ & & $00 ; \mathrm{cN}$ & 23. & & & & 21 & & & & & & & & & & & & \\
\hline & & & & & & & & & & & & & & & $213 c$ & $0 ; c n$ & $00 ; n$ & $0 ; 1 \mathrm{cn}$ & $0 ; 1 \mathrm{c}$ & $0 ; 1 \mathrm{~N}$ & & $0 ; 1$ & \\
\hline 23-1 & 21 & $0 ; 1-$ & 21 & $11-\mathrm{cN}$ & 11. & $0 ; 1-c$ & 3-2 & $0 ; \mathrm{cN}$ & $1-0 ; c$ & $1-0 ; \mathrm{c}$ & $1-0 ; c$ & 0;1- & 12 & $0 ; 1-\mathrm{cn}$ & 120; & $1-0 ; c$ & $00 ; n$ & 10; & $0 ; 1-c$ & $0 ; 1-$ & 23-1 & 1-0; & 23-1 \\
\hline 12 & $0 ; 1$ & $00 ; 1-$ & 12 & $213-\mathrm{N}$ & 0;1- & $00 ; n$ & 3-2 & $0 ; \mathrm{cN}$ & 11- & $0 ; 1-$ & $1-0 ; \mathrm{cN}$ & 0;1- & 12 & $0 ; 1-\mathrm{cn}$ & & & & 10; & & $0 ; 1-$ & & 1-0; & \\
\hline 3-21 & $0 ; 12 \mathrm{c}$ & $00 ; 1$ & 23-c & $10 ; c$ & $120 ; \mathrm{c}$ & $0 ; 1-\mathrm{cn}$ & $213-c$ & $0 ; 1-\mathrm{cn}$ & $12 \mathrm{c}$ & 21c & $0 ; 1-c n$ & $0 ; 1 \mathrm{c}$ & $0 ; 12 c$ & $0 ; c n$ & $0 ; 12$ & $0 ; 1-c$ & $00 ; n$ & $0 ; 1 \mathrm{c}$ & $0 ; 1 \mathrm{c}$ & $0 ; 1-\mathrm{c}$ & & $0 ; 1 \mathrm{cn}$ & \\
\hline 0;1-cn & $0 ; 1 \mathrm{c}$ & 00 ; & $120 ; c$ & $120 ; \mathrm{c}$ & $0 ; 1$ & $0 ; c n$ & 3-c & $0 ; \mathrm{cN}$ & & & $0 ; 1-c n$ & $0 ; 1-c$ & $0 ; 1-c n$ & & & & & $0 ; 1 \mathrm{cn}$ & & $0 ; c n$ & & $0 ; 12 c$ & \\
\hline 3-0; & $0 ; 12$ & 00 ; & 23-1 & $23-\mathrm{c}$ & 213- & $00 ; n$ & 3. & $0 ; n$ & 213- & $21 \mathrm{c}$ & $0 ; 1$ & $0 ; 1$ & 213- & $0 ; 1-\mathrm{cn}$ & 210 & $0 ; 1-$ & $00 ;$ & 120; & $0 ; 1$ & $0 ; 1$ & $120 ;$ & $0 ; 1$ & $3-2$ \\
\hline
\end{tabular}


Appendix Table 8 continued. Raw infection types ${ }^{1}$ of barley differential lines carrynig the leaf rust resistance genes Rph1-24 in this and a previous study.

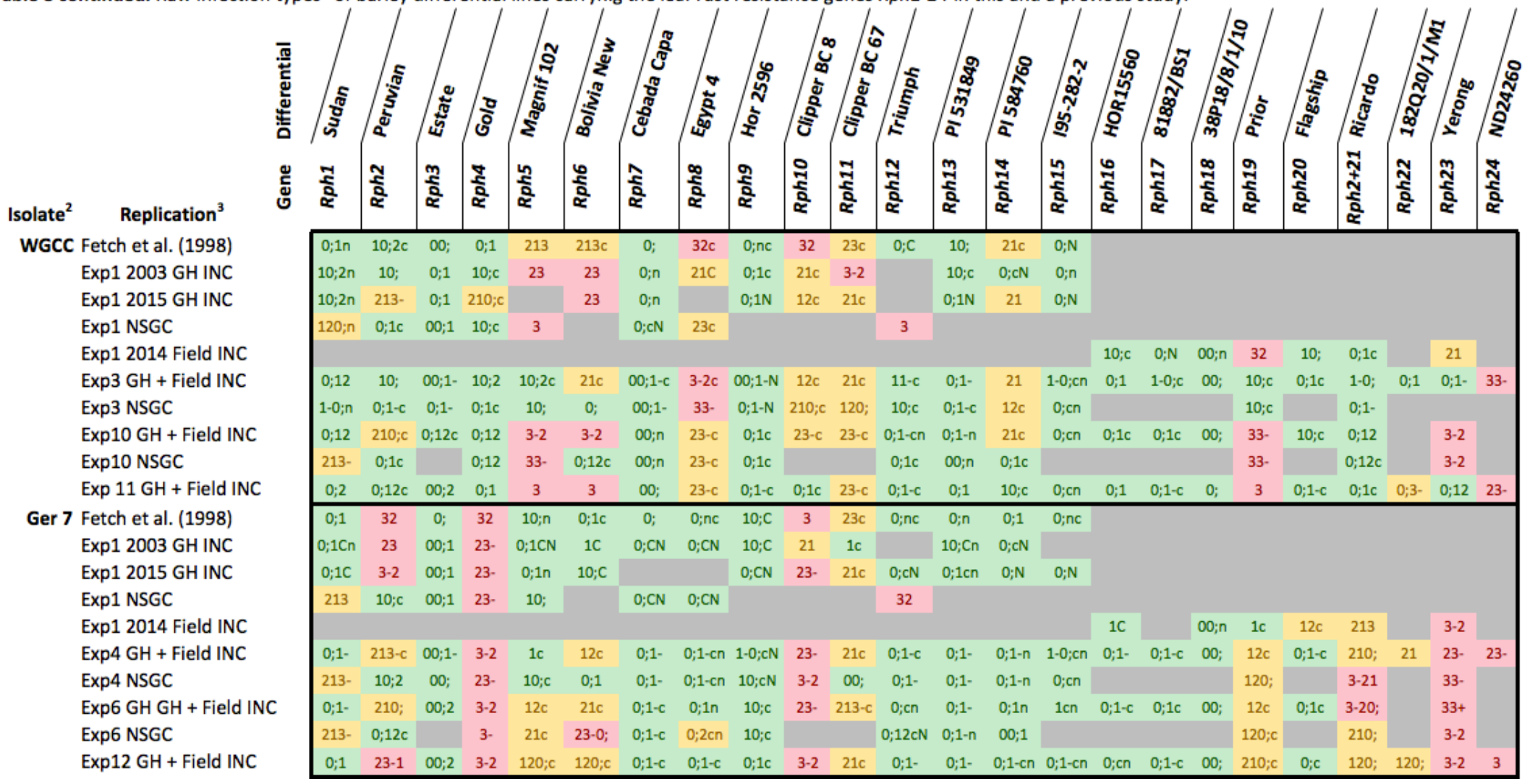


Appendix Table 8 continued. Raw infection types ${ }^{1}$ of barley differential lines carrynig the leaf rust resistance genes Rph1-24 in this and a previous study.

\section{Isolate $^{2} \quad$ Replication $^{3}$ \\ Race 4 Fetch et al. (1998) Exp1 $2003 \mathrm{GH}$ INC Exp1 2015 GH INC Exp1 NSGC \\ Exp1 2014 Field INC Exp4 GH + Field INC Exp4 NSGC \\ Exp9 GH + Field INC Exp9 NSGC \\ Exp12 GH + Field INC Aus 220 Fetch et al. (1998)} Exp1 2003 GH INC Exp1 2015 GH INC Exp1 NSGC

Exp1 2014 Field INC Exp3 GH + Field INC Exp3 NSGC

Exp10 GH + Field INC Exp10 NSGC

Exp $11 \mathrm{GH}+$ Field INC
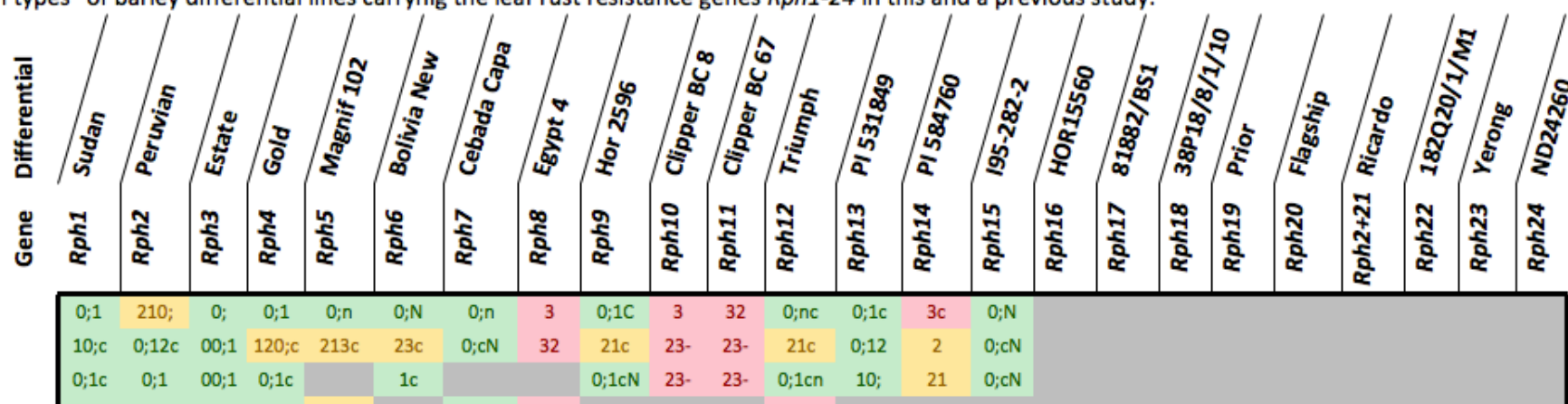

$0 ; 1 \mathrm{c} \quad 0 ; 1 \quad 00 ; 1 \quad 0 ; 1 \mathrm{c}$

$1 \mathrm{c}$

$0 ; 1 \mathrm{cN} \quad 23$

$0 ; 1 c$
32

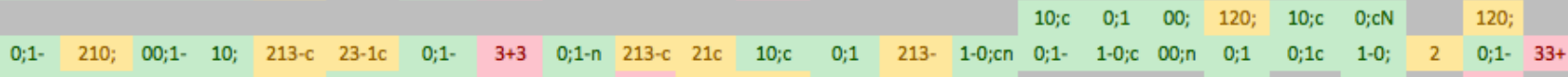

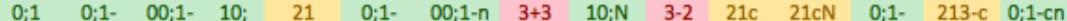

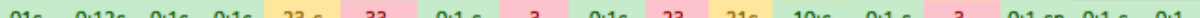

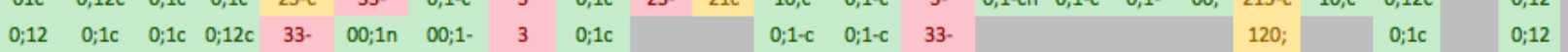

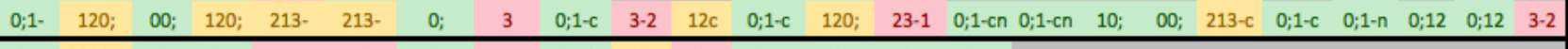

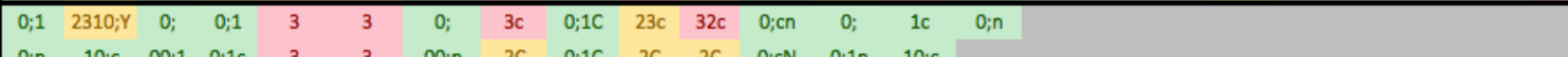

$\begin{array}{llllllllllllll}0 ; \mathrm{n} & 10 ; \mathrm{c} & 00 ; 1 & 0 ; 1 \mathrm{C} & 3 & 3 & 00 ; \mathrm{n} & 2 \mathrm{C} & 0 ; 1 \mathrm{C} & 2 \mathrm{C} & 2 \mathrm{C} & 0 ; \mathrm{cN} & 0 ; 1 \mathrm{n} & 10 ; \mathrm{c}\end{array}$

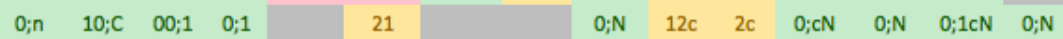$$
32
$$

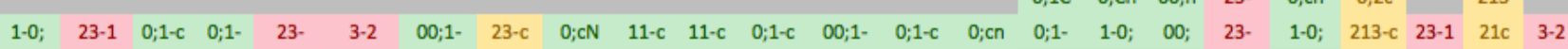

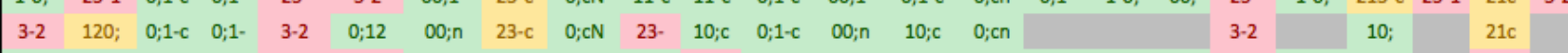

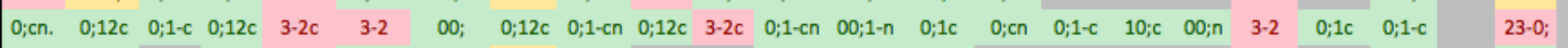

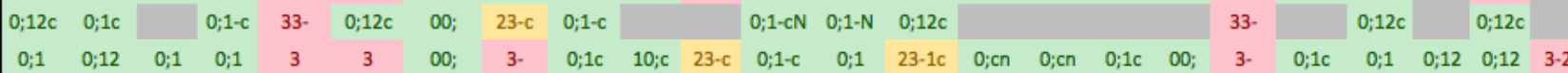


Appendix Table 8 continued. Raw infection types ${ }^{1}$ of barley differential lines carrynig the leaf rust resistance genes Rph1-24 in this and a previous study.

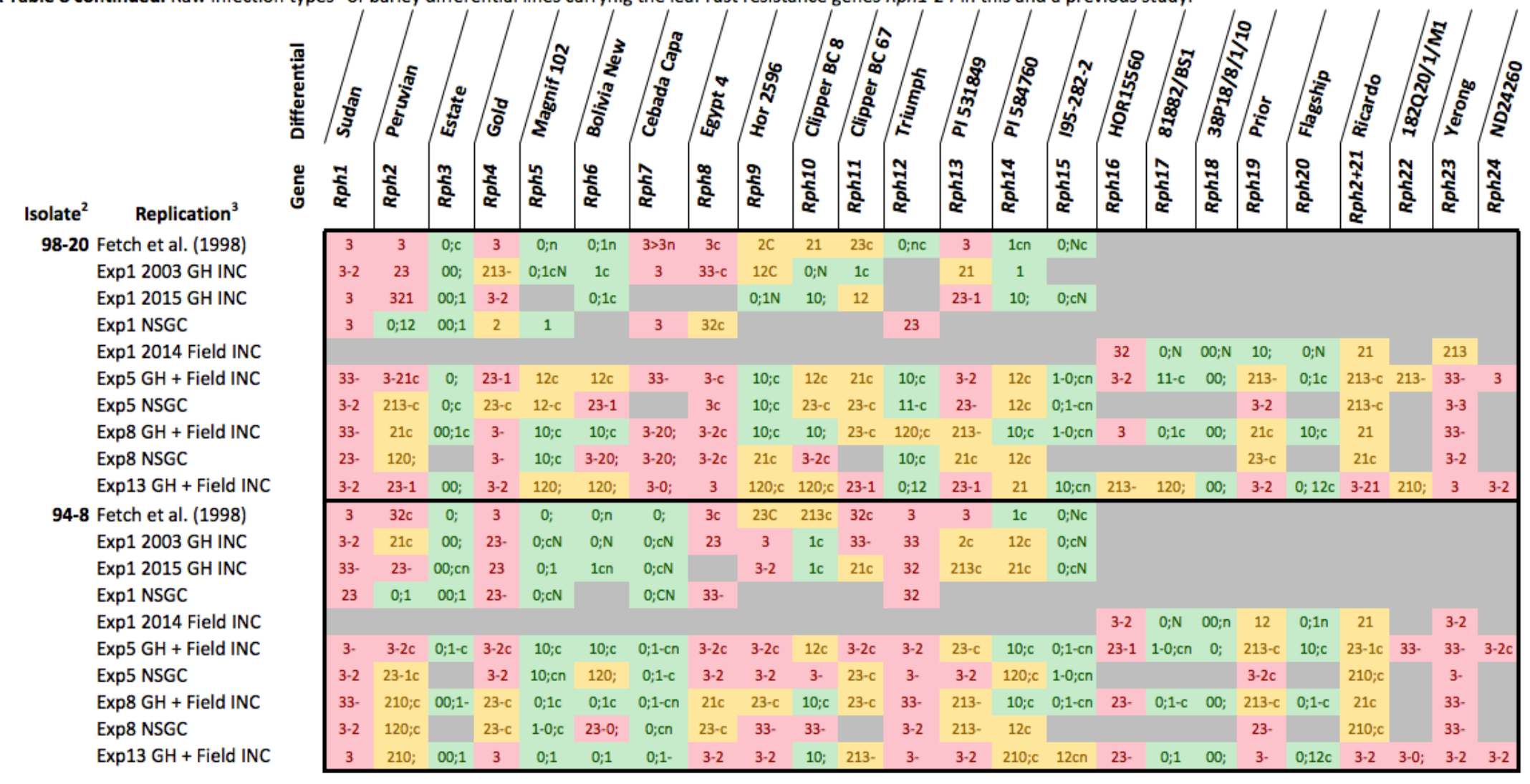


Appendix Table 8 continued. Raw infection types ${ }^{1}$ of barley differential lines carrynig the leaf rust resistance genes Rph1-24 in this and a previous study.

Isolate $^{2} \quad$ Replication $^{3}$

BRS 76-12 Fetch et al. (1998) Exp1 $2003 \mathrm{GH}$ INC Exp1 2015 GH INC Exp1 NSGC

Exp1 2014 Field INC Exp5 GH + Field INC Exp5 NSGC

Exp8 GH + Field INC Exp8 NSGC

Exp13 GH + Field INC

Neth 28 Fetch et al. (1998)

Exp1 2003 GH INC

Exp1 2015 GH INC

Exp1 NSGC

Exp1 2014 Field INC Exp6 GH + Field INC Exp6 NSGC

Exp7 GH + Field INC Exp7 NSGC

Exp14 GH + Field INC
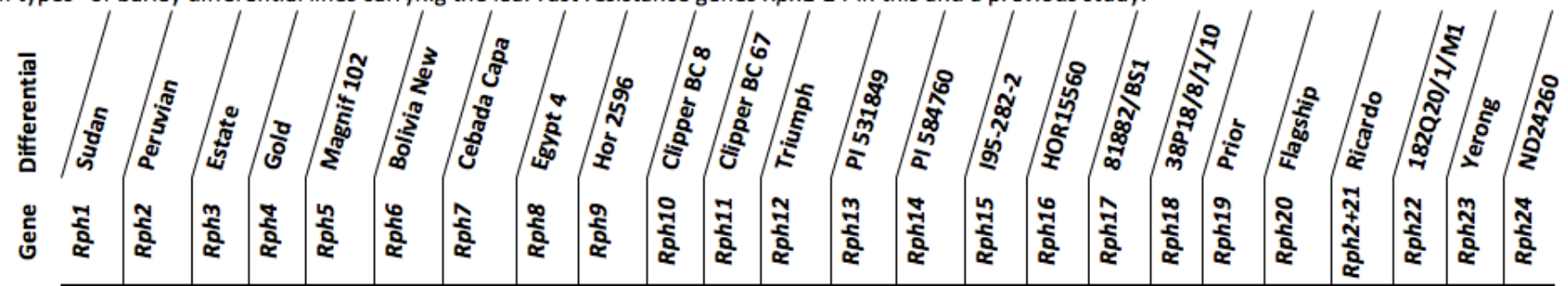

\begin{tabular}{|c|c|c|c|c|c|c|c|c|c|c|c|c|c|c|c|c|c|c|c|c|c|c|c|}
\hline 3 & 3 & 3 & 3 & 3 & 3 & $0 ; n$ & 3 & $2 C$ & 3 & $32 \mathrm{c}$ & $0 ; c n$ & $0 ; 1$ & $213 c$ & 0 ; & & & & & & & & & \\
\hline 21 & 23- & 3 & 23 & 32 & $21 \mathrm{c}$ & $0 ; \mathrm{cN}$ & & & 12 & $0 ; 1 c$ & $0 ; \mathrm{cN}$ & $0 ; 1 \mathrm{c}$ & $2 c$ & $0 ; \mathrm{N}$ & & & & & & & & & \\
\hline 23 & 23. & 23 & $10 ; c$ & & $12 \mathrm{c}$ & $0 ; \mathrm{cN}$ & 3 & $0 ; \mathrm{CN}$ & 21 & $21 \mathrm{c}$ & $0 ; c n$ & $21 \mathrm{cN}$ & $10 ; c$ & $0 ; \mathrm{c} \mathrm{N}$ & & & & & & & & & \\
\hline \multirow[t]{2}{*}{213} & 23. & $23-c$ & 23. & 2 & $0 ; \mathrm{cN}$ & 3 & 3 & & & & 3 & & & & & & & & & & & & \\
\hline & & & & & & & & & & & & & & & 3. & $10 ; n$ & $00 ; n$ & 23 & $1 c$ & $3-2$ & & 3 & \\
\hline 33- & $213-c$ & 33. & $3-2$ & $23-c$ & $23-c$ & $0 ; 1-c$ & 33- & $10 ; c$ & 23-1c & $21 \mathrm{c}$ & $0 ; 1-c$ & $10 ; c$ & $213-c$ & $0 ; 1-c n$ & 23. & $10 ; c$ & 00 ; & $12 c$ & $0 ; 1-c$ & $10 ; c$ & 23-1 & 33. & 33- \\
\hline $3-2$ & $120 ; \mathrm{c}$ & 23. & 3-2 & 213- & 120; & $0 ; 1-c$ & 3 & $10 ; c$ & $3-2$ & $21 c$ & $0 ; 1-c$ & $0 ; 1 \mathrm{c}$ & $210 ; c$ & & & & & $3 \cdot 2 \mathrm{c}$ & & $210 ; c$ & & 33. & \\
\hline 33. & $120 ; c$ & 3-2 & 33. & $12 \mathrm{c}$ & $213-c$ & $00 ; c n$ & $23-\mathrm{c}$ & $0 ; 1 \mathrm{c}$ & 120 ;c & $21 \mathrm{c}$ & $0 ; 1-c$ & $0 ; 1$ & $120 ; c$ & $0 ; c n$ & 3.2 & $10 ; c$ & 00 & 23-1c & $10 ; c$ & $210 ; c$ & & 33. & \\
\hline $23-1 c$ & $120 ; c$ & 23-1c & 23-c & 33. & $3-20 ; c$ & $0 ; n$ & 33. & $10 ; c$ & $3-2$ & & $0 ; 1-\mathrm{cN}$ & $0 ; 1-\mathrm{c}$ & $10 ; c$ & & & & & 23-1c & & $120 ; c$ & & $3-2$ & \\
\hline 3. & $120 ; c$ & 3. & 3-2 & $23-c$ & $23-c$ & $0 ; n$ & 3-2 & $10 ; c$ & 23-1 & 23-1 & $0 ; 1$ & $0 ; 1$ & $210 ; c$ & $0 ; c n$ & $3-2$ & $0 ; 1-c$ & $00 ;$ & 23-1 & $0 ; 1 c$ & 210; & 3-20; & 3-2 & 3-2 \\
\hline 3 & 3 & $23 \mathrm{c}$ & 210; & 3 & 3 & 3 & $3 C$ & $1 \mathrm{C}$ & 3 & 3 & 3 & 0 & 3 & $1 \mathrm{~N}$ & & & & & & & & & \\
\hline 32 & 32 & $3-2 c$ & 10; & 32 & 21 & 23 & 3 & $1 \mathrm{c}$ & $3-2$ & 23-c & 21c & $10 ; c$ & 21 & & & & & & & & & & \\
\hline 3-2 & 3-2 & $213 c$ & $0 ; 1$ & & 21 & $3-2$ & & $10 ; \mathrm{c}$ & 23 & $12 \mathrm{c}$ & & $10 ; c$ & 21c & $21 \mathrm{c}$ & & & & & & & & & \\
\hline \multirow[t]{2}{*}{32} & $3-2$ & $12 c$ & $0 ; 1$ & 3 & & 32 & 3 & & & 3 & & & & & & & & & & & & & \\
\hline & & & & & & & & & & & & & & & 2 & 32 & 00 ;n & 23 & 21c & 23 & & 3-2 & \\
\hline 33. & 33. & $213-c$ & $0 ; 12 c$ & 33. & 23-c & 33. & 33-c & $120 ; c$ & $33+$ & $3-c$ & $23-c$ & $0 ; 1 \mathrm{c}$ & $120 ; c$ & 12-cn & $3-2$ & $21 \mathrm{c}$ & $00 ; n$ & 33. & $23-c$ & $33-2 c$ & & 33. & 3 \\
\hline $3-c$ & & $0 ; 12 \mathrm{c}$ & 3. & 3-3 & $33+$ & $33+$ & $3+3$ & $120 ; c$ & $3+3 c$ & $3+3$ & $3-2 c$ & $0 ; 1 \mathrm{c}$ & $210 ; c$ & & & & & 3-3 & & $33-\mathrm{c}$ & & $33+$ & \\
\hline 3. & $3-2$ & $2 c$ & 120 ; & 33. & 23. & $33-c$ & $33+$ & $10 ; c$ & 3 & $3-2 c$ & $33+$ & $0 ; 1 \mathrm{c}$ & $12 \mathrm{c}$ & $12 \mathrm{cn}$ & 3.2 & 21c & 00; & $3-2$ & $23-c$ & 33. & & 3. & \\
\hline 3-3 & 33- & & $0 ; 1 c$ & 3. & 33- & 33. & 33+ & $10 ; c$ & 3. & $23-c$ & 33. & $0 ; 1 \mathrm{c}$ & 21c & & & & & 33. & & 33. & & 33. & \\
\hline 3 & 33- & $213-c$ & $0 ; 12$ & 3 & 3-2 & 3 & 33- & $210 ; c$ & 3 & $3-2 c$ & 3 & $120 ;$ & $3-2 c$ & 23-1c & $23-1 \mathrm{c}$ & 23-1c & $00 ;$ & 3 & $213-c$ & 33.- & 3-0; & 3 & 3 \\
\hline
\end{tabular}


Appendix Table 8 continued. Raw infection types ${ }^{1}$ of barley differential lines carrynig the leaf rust resistance genes Rph1-24 in this and a previous study.

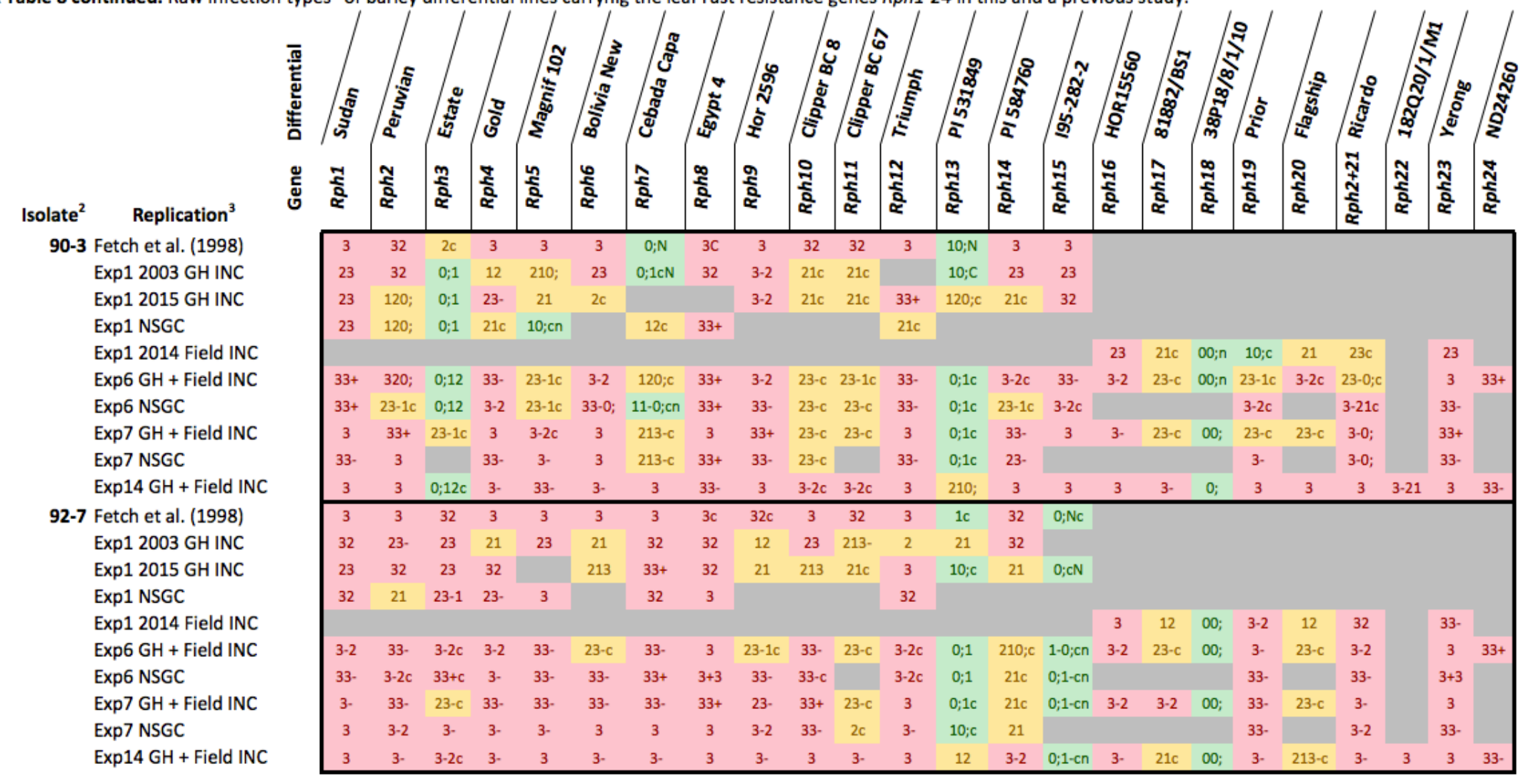




\section{Appendix Table 8 Footnotes.}

1. Infection types were scored using the original 0-4 rating scale developed by Mains (1930) with the additional notations of "+ "and "- "to indicate larger or smaller size variations of classically described uredinia (Levine and Cherewick, 1952) and " $c$ " and " $n$ " to indicate the presence of chlorotic or necrotic reactions (Moseman and Roane, 1959), respectively. Complex ITs were recorded when more than one IT was observed on the surface of a single leaf. For example, an IT of 213-indicates that all three pustule types exist on the same leaf and that the " 2 " type pustules were the most common, followed by the "1" type, with " 3 -" type pustules being the least common. Infection types from "0;" to "0;12" are classified as highly resistant ("R", green cells), infections types from "12" to "23-c" are classified as moderately resistant ("M", yellow cells), and infection types from "23-" to "33+" are classified as susceptible ("S", red cells) (Steffenson et al., 1993).

2. Twelve isolates of Puccinia hordei were characterized for their infection types (ITs) against the barley leaf rust differentials for Rph1-24.

3. The different experimental replications of these plant-plant pathogen interactions are listed. The previous study by Fetch et al. (1998) described the infection types of these 12 isolates against the barley leaf rust differentials for Rph1-15. The different experimental replicates in this study range from Experiment 1 (Exp1) to Experiment 14 (Exp14). Some replications are also identified as different seed sources grown from either greenhouse (GH) or field increased (INC) genetic stocks or from seed stocks provided by the National $\underline{\underline{S}}$ mall $\underline{\mathrm{G}}$ rains $\underline{\mathrm{C}}$ ollection (NSGC) genebank. 
Appendix Table 9. Annotated genes in the same contig as SNP markers residing in $R p h$-carrying introgressions.

\begin{tabular}{|c|c|c|c|c|}
\hline BW Line ${ }^{1}$ & Allele $^{2}$ & BOPA_SNP ${ }^{3}$ & Gene on same contig ${ }^{4}$ & Annotation $^{5}$ \\
\hline BW682 & Rph1.a & 1_0326 & AK364110 & Pyruvate dehydrogenase E1 component alpha subunit \\
\hline BW682 & Rph1.a & 1_0326 & MLOC_62638.1 & Polyketide cyclase/dehydrase and lipid transport-like protein \\
\hline BW682 & Rph1.a & 1_1059 & AK368531 & 12-oxophytodienoate reductase 1 \\
\hline BW682 & Rph1.a & 2_1377 & AK361947 & Zinc finger (Ran-binding) family protein \\
\hline BW682 & Rph1.a & 2_1377 & MLOC_10639.1 & NA \\
\hline BW682 & Rph1.a & 2_1377 & MLOC_10640.1 & NA \\
\hline BW682 & Rph1.a & 2_0563 & MLOC_67779.1 & Cullin-associated NEDD8-dissociated protein \\
\hline BW743 & Rph2.t & 2_0845 & MLOC_10278.1 & Single myb histone 6 \\
\hline BW743 & Rph2.t & 2_0845 & AK249399.1 & Pentatricopeptide repeat (PPR) superfamily protein \\
\hline BW743 & Rph2.t & 2_0980 & MLOC_10278.1 & Single myb histone 6 \\
\hline BW743 & Rph2.t & 2_0980 & AK249399.1 & Pentatricopeptide repeat (PPR) superfamily protein \\
\hline BW743 & Rph2.t & 2_1391 & MLOC_5116.4 & Vacuolar fusion protein CCZ1 homolog \\
\hline BW743 & Rph2.t & 2_1253 & MLOC_54218.3 & Protein kinase superfamily protein LENGTH=390 \\
\hline BW743 & Rph2.t & 2_1253 & MLOC_54219.1 & Tuftelin interacting protein \\
\hline BW743 & Rph2.t & 2_0571 & MLOC_3932.1 & Ubiquitin-conjugating enzyme family protein-like \\
\hline BW743 & Rph2.t & 2_0571 & MLOC_3933.1 & NA \\
\hline BW743 & Rph2.t & 1_0955 & MLOC_38116.1 & NA \\
\hline BW743 & Rph2.t & 1_0955 & AK356629 & L-galactose dehydrogenase \\
\hline BW743 & Rph2.t & 1_1432 & AK370125 & Auxin responsive protein \\
\hline BW743 & Rph2.t & 1_1432 & MLOC_73035.1 & Uridine kinase-like 5 \\
\hline BW743 & Rph2.t & 1_1432 & MLOC_73034.1 & NA \\
\hline BW743 & Rph2.t & 1_1432 & MLOC_73036.2 & Leucine Rich Repeat family protein \\
\hline BW743 & Rph2.t & 2_0841 & MLOC_38191.2 & NA \\
\hline BW743 & Rph2.t & 2_0841 & AK367062 & UNC93-like protein MFSD11 \\
\hline
\end{tabular}

$\vec{\omega}$ 
Appendix Table 9 continued. Annotated genes in the same contig as SNP markers residing in Rph-carrying introgressions.

\begin{tabular}{lllll} 
BW Line $^{1}$ & Allele $^{2}$ & BOPA_SNP & Gene on same contig & Annotation \\
\hline BW743 & Rph2.t & 2_0697 & MLOC_64255.1 & Transmembrane protein \\
\hline BW743 & Rph2.t & 1_0058 & MLOC_63593.1 & 40S ribosomal protein S9 \\
\hline BW743 & Rph2.t & 1_0058 & MLOC_63594.1 & NA \\
\hline BW743 & Rph2.t & 2_0179 & MLOC_59475.1 & V-type proton ATPase 16 kDa proteolipid subunit c1/c3/c5 \\
\hline BW743 & Rph2.t & 1_0157 & AK251398.1 & Eukaryotic translation initiation factor 5a-2, putative \\
\hline BW743 & Rph2.t & 1_0177 & NA & NA \\
\hline BW743 & Rph2.t & 1_0240 & MLOC_54831.1 & Thioredoxin m \\
\hline BW743 & Rph2.t & 1_0252 & AK368598 & Chaperone protein ClpB 1 \\
\hline BW743 & Rph2.t & 2_0332 & AK248962.1 & Ubiquitin activating enzyme 2 \\
\hline BW743 & Rph2.t & 1_0318 & AK371168 & Ubiquitin carboxyl-terminal hydrolase, putative \\
\hline BW743 & Rph2.t & 2_0461 & MLOC_19387.1 & Aldehyde dehydrogenase \\
\hline BW743 & Rph2.t & 2_0461 & AK251412.1 & Peroxidase superfamily protein \\
\hline BW743 & Rph2.t & 2_0461 & MLOC_19388.1 & NA \\
\hline BW743 & Rph2.t & 2_0524 & MLOC_57983.5 & Fe/S biogenesis protein nfuA \\
\hline BW743 & Rph2.t & 2_0524 & MLOC_57984.1 & NA \\
\hline BW743 & Rph2.t & 2_0524 & MLOC_57982.1 & NA \\
\hline BW743 & Rph2.t & 2_0524 & AK356301 & Transmembrane 9 superfamily protein member 3 \\
\hline BW743 & Rph2.t & 2_0700 & AK365226 & RNA polymerase-associated protein RTF1, putative \\
\hline BW743 & Rph2.t & 2_0700 & AK366262 & 2,3-bisphosphoglycerate-independent phosphoglycerate mutase \\
\hline BW743 & Rph2.t & 2_0708 & MLOC_38118.1 & NA \\
\hline BW743 & Rph2.t & 2_0708 & MLOC_38119.1 & NA \\
\hline BW743 & Rph2.t & 2_0737 & MLOC_5324.1 & Chalcone--flavonone isomerase \\
\hline BW743 & Rph2.t & 2_1011 & MLOC_40010.1 & NA \\
\hline BW743 & Rph2.t & 2_1040 & AK370183 & AP-2 complex subunit sigma-1 \\
\hline
\end{tabular}


Appendix Table 9 continued. Annotated genes in the same contig as SNP markers residing in Rph-carrying introgressions.

\begin{tabular}{lllll} 
BW Line $^{1}$ & Allele $^{2}$ & BOPA_SNP & Gene on same contig $^{4}$ & Annotation $^{5}$ \\
\hline BW743 & Rph2.t & 1_0856 & MLOC_57598.1 & NA \\
\hline BW743 & Rph2.t & 2_1215 & MLOC_33142.1 & NA \\
\hline BW743 & Rph2.t & 2_1215 & MLOC_33143.1 & NA \\
\hline BW743 & Rph2.t & 1_0913 & AK373225 & NA \\
\hline BW743 & Rph2.t & 2_1260 & AK251163.1 & Sorting and assembly machinery component-like protein \\
\hline BW743 & Rph2.t & 2_1260 & MLOC_72013.1 & Myb family transcription factor \\
\hline BW743 & Rph2.t & 2_1350 & MLOC_62403.4 & NA \\
\hline BW743 & Rph2.t & 2_1350 & MLOC_62404.1 & NA \\
\hline BW743 & Rph2.t & 1_0995 & MLOC_38005.1 & Syntaxin, putative \\
\hline BW743 & Rph2.t & 1_1469 & AK358200 & 4-alpha-L-fucosyltransferase \\
\hline BW743 & Rph2.t & 1_1506 & MLOC_73610.1 & NA \\
\hline BW743 & Rph2.t & 1_1506 & MLOC_73609.2 & Saposin B domain-containing protein \\
\hline BW743 & Rph2.t & 1_1260 & MLOC_4554.1 & ABSCISIC ACID-INSENSITIVE 5-like protein \\
\hline BW743 & Rph2.t & 2_1318 & MLOC_12555.1 & Vacuolar sorting receptor protein \\
\hline BW743 & Rph2.t & 2_1536 & MLOC_69295.2 & Ferritin \\
\hline BW743 & Rph2.t & 2_0306 & AK365203 & Polyadenylate-binding protein, putative \\
\hline BW743 & Rph2.t & 2_0283 & AK251150.1 & Protein phosphatase 2A regulatory subunit A \\
\hline BW743 & Rph2.t & 2_0372 & MLOC_6055.1 & Ubiquitin-conjugating enzyme variant \\
\hline BW743 & Rph2.t & 1_0671 & AK374108 & NA \\
\hline BW743 & Rph2.t & 1_0671 & MLOC_59580.1 & Ferrochelatase \\
\hline BW743 & Rph2.t & 2_0961 & AK252957.1 & ABC-1 domain protein \\
\hline BW743 & Rph2.t & 1_0840 & NA & NA \\
\hline BW743 & Rph2.t & 1_1240 & NA & NA \\
\hline BW743 & Rph2.t & 2_1200 & MLOC_52503.1 & Cytochrome b5-like \\
\hline & & & &
\end{tabular}


Appendix Table 9 continued. Annotated genes in the same contig as SNP markers residing in Rph-carrying introgressions.

\begin{tabular}{lllll} 
BW Line $^{1}$ & Allele $^{2}$ & BOPA_SNP & Gene on same contig & Annotation \\
\hline BW743 & Rph2.t & 1_1159 & MLOC_38219.1 & Protein arginine N-methyltransferase 1 \\
\hline BW743 & Rph2.t & 1_1221 & AK369379 & Fatty acid desaturase, putative \\
\hline BW743 & Rph2.t & 2_0265 & AK365065 & Trehalose-6-phosphate phosphatase \\
\hline BW743 & Rph2.t & 2_0441 & AK250045.1 & Jasmonate ZIM-domain protein 2 \\
\hline BW743 & Rph2.t & 2_0441 & AK365854 & Thioredoxin-like protein \\
\hline BW743 & Rph2.t & 2_1344 & NA & NA \\
\hline BW743 & Rph2.t & 1_1281 & MLOC_11773.1 & Trehalose-6-phosphate synthase \\
\hline BW743 & Rph2.t & 2_0713 & MLOC_68788.2 & TBP-associated factor 2 LENGTH=1390 \\
\hline BW743 & Rph2.t & 2_0713 & MLOC_68790.1 & NA \\
\hline BW743 & Rph2.t & 2_0713 & MLOC_68789.5 & NA \\
\hline BW743 & Rph2.t & 2_1275 & AK362143 & TATA-binding related factor (TRF) \\
\hline BW743 & Rph2.t & 2_1121 & MLOC_34809.1 & Cathepsin L-like cysteine proteinase \\
\hline BW743 & Rph2.t & 2_1001 & MLOC_59805.1 & Golgi SNAP receptor complex member 1-1 \\
\hline BW743 & Rph2.t & 1_0127 & MLOC_44755.2 & Chlorophyll a-b binding protein 4 \\
\hline BW743 & Rph2.t & 1_0127 & MLOC_44757.2 & O-fucosyltransferase family protein \\
\hline BW743 & Rph2.t & 1_0127 & MLOC_44756.1 & NA \\
\hline BW743 & Rph2.t & 2_0236 & MLOC_12614.1 & Formate-tetrahydrofolate ligase \\
\hline BW743 & Rph2.t & 2_1133 & MLOC_5225.1 & NA \\
\hline BW746 & Rph3.c & 1_0182 & MLOC_59546.1 & V-type ATP synthase alpha chain \\
\hline BW746 & Rph3.c & 2_1104 & MLOC_12098.1 & NA \\
\hline BW746 & Rph3.c & 2_1104 & AK364357 & Mitochondrial substrate carrier family protein \\
\hline BW746 & Rph3.c & 1_0078 & MLOC_13526.1 & NA \\
\hline BW746 & Rph3.c & 1_0078 & MLOC_13527.1 & NA \\
\hline BW746 & Rph3.c & 1_0797 & MLOC_50091.1 & Senescence-associated protein DH \\
\hline
\end{tabular}


Appendix Table 9 continued. Annotated genes in the same contig as SNP markers residing in Rph-carrying introgressions.

\begin{tabular}{lllll} 
BW Line $^{1}$ & Allele $^{2}$ & BOPA_SNP & Gene on same contig & Annotation \\
\hline BW746 & Rph3.c & 2_1160 & MLOC_60883.1 & NA \\
\hline BW746 & Rph3.c & 2__160 & MLOC_60884.1 & NA \\
\hline BW746 & Rph3.c & 2_1160 & MLOC_60880.1 & NA \\
\hline BW746 & Rph3.c & 2_1160 & MLOC_60881.1 & WD-repeat protein 57 \\
\hline BW746 & Rph3.c & 2_1160 & MLOC_60885.1 & NA \\
\hline BW746 & Rph3.c & 2__160 & MLOC_60886.1 & NA \\
\hline BW746 & Rph3.c & 2_1160 & MLOC_60882.1 & NA \\
\hline BW753 & Rph4.d & 2_0479 & NA & NA \\
\hline BW753 & Rph4.d & 1_0654 & NA & NA \\
\hline BW755 & Rph5.e & 2_0858 & AK374872 & RING-box protein 1a \\
\hline BW755 & Rph5.e & 2_0858 & MLOC_21379.2 & 1-deoxy-D-xylulose 5-phosphate reductoisomerase \\
\hline BW756 & Rph5.f & 2_0858 & AK374872 & RING-box protein 1a \\
\hline BW756 & Rph5.f & 2_0858 & MLOC_21379.2 & 1-deoxy-D-xylulose 5-phosphate reductoisomerase \\
\hline BW756 & Rph5.f & 2_0252 & AK367001 & NA \\
\hline BW756 & Rph5.f & 1_1453 & AK252051.1 & Dephospho-CoA kinase \\
\hline BW756 & Rph5.f & 1_1453 & MLOC_61361.2 & TPX2 (targeting protein for Xklp2) protein family \\
\hline BW756 & Rph5.f & 2_0529 & AK367229 & Fructose-bisphosphate aldolase \\
\hline BW756 & Rph5.f & 2_1398 & AK248209.1 & Glutamate decarboxylase \\
\hline BW758 & Rph7.g & 2_0858 & AK374872 & RING-box protein 1a \\
\hline BW758 & Rph7.g & 2_0858 & MLOC_21379.2 & 1-deoxy-D-xylulose 5-phosphate reductoisomerase \\
\hline BW758 & Rph7.g & 2_0159 & MLOC_61066.1 & NA \\
\hline BW758 & Rph7.g & 2_0159 & AK374643 & NA \\
\hline BW758 & Rph7.g & 2_0252 & AK367001 & NA \\
\hline BW758 & Rph7.g & 1_1453 & AK252051.1 & Dephospho-CoA kinase, putative, expressed \\
\hline
\end{tabular}


Appendix Table 9 continued. Annotated genes in the same contig as SNP markers residing in Rph-carrying introgressions.

\begin{tabular}{lllll} 
BW Line $^{1}$ & Allele $^{2}$ & BOPA_SNP & Gene on same contig & Annotation $^{5}$ \\
\hline BW758 & Rph7.g & 2_0529 & AK367229 & Fructose-bisphosphate aldolase \\
\hline BW758 & Rph7.g & 2_1398 & AK248209.1 & Glutamate decarboxylase \\
\hline BW758 & Rph7.g & 2_1027 & MLOC_69438.1 & Ethylene-responsive transcription factor \\
\hline BW758 & Rph7.g & 2_0976 & AK370400 & NA \\
\hline BW758 & Rph7.g & 1_0112 & MLOC_64595.1 & NA \\
\hline BW758 & Rph7.g & 1_0112 & AK249901.1 & Bowman-Birk type trypsin inhibitor \\
\hline BW758 & Rph7.g & 1_0886 & AK366387 & Mannose-6-phosphate isomerase \\
\hline BW758 & Rph7.g & 2_0595 & MLOC_36532.1 & Ubiquitin-conjugating enzyme 22 \\
\hline BW759 & Rph8.h & 1_0216 & AK372085 & 26S protease regulatory subunit 4 \\
\hline BW759 & Rph8.h & 2_1187 & MLOC_7090.1 & NA \\
\hline BW759 & Rph8.h & 2_1187 & AK369130 & NA \\
\hline BW759 & Rph8.h & 1_0787 & MLOC_56743.1 & Guanine nucleotide-binding protein-like 3 \\
\hline BW759 & Rph8.h & 1_0787 & MLOC_56745.1 & NA \\
\hline BW759 & Rph8.h & 1_0891 & MLOC_44215.2 & Poly(A) polymerase-like protein \\
\hline BW759 & Rph8.h & 1_0987 & AK357120 & Ovarian cancer-associated gene 2 protein-like \\
\hline BW759 & Rph8.h & 1_0987 & MLOC_34486.1 & NA \\
\hline BW760 & Rph9.i & 1_1507 & MLOC_4808.1 & NA \\
\hline BW760 & Rph9.i & 1_1507 & MLOC_4807.1 & NA \\
\hline BW760 & Rph9.i & 1_1507 & MLOC_4809.1 & NA \\
\hline BW760 & Rph9.i & 1_1456 & MLOC_4744.1 & Aspartyl/glutamyl-tRNA(Asn/Gln) amidotransferase subunit C \\
\hline BW760 & Rph9.i & 2_0003 & MLOC_55532.1 & GTP binding protein \\
\hline BW760 & Rph9.i & 2_0003 & MLOC_55533.1 & NA \\
\hline BW760 & Rph9.i & 1_0360 & MLOC_37451.1 & NA \\
\hline BW760 & Rph9.i & 1_0360 & AK250598.1 & Chaperone protein dnaJ \\
\hline
\end{tabular}


Appendix Table 9 continued. Annotated genes in the same contig as SNP markers residing in Rph-carrying introgressions.

\begin{tabular}{lllll} 
BW Line $^{1}$ & Allele $^{2}$ & BOPA_SNP & Gene on same contig & Annotation \\
\hline BW760 & Rph9.i & 2_0653 & MLOC_53946.1 & NA \\
\hline BW760 & Rph9.i & 2_0653 & MLOC_53947.1 & Pyruvate dehydrogenase E1 component beta subunit \\
\hline BW760 & Rph9.i & 2_0653 & MLOC_53948.1 & expansin B4 \\
\hline BW760 & Rph9.i & 2_0653 & MLOC_53949.2 & Leucine-rich repeat receptor-like protein kinase \\
\hline BW760 & Rph9.i & 2_1203 & AK356347 & Translation initiation factor elF-2B delta subunit \\
\hline BW760 & Rph9.i & 2_1325 & MLOC_76072.2 & Solute carrier family 22 member 1 \\
\hline BW760 & Rph9.i & 1_1375 & MLOC_81731.1 & Pentatricopeptide repeat-containing protein \\
\hline BW760 & Rph9.i & 1_1375 & MLOC_81732.1 & NA \\
\hline BW760 & Rph9.i & 1_0146 & AK364599 & Protein transport protein SEC23 \\
\hline BW760 & Rph9.i & 1_0146 & MLOC_54787.1 & Auxin responsive protein \\
\hline BW760 & Rph9.i & 2_0259 & MLOC_19607.1 & NA \\
\hline BW760 & Rph9.i & 2_1177 & AK366333 & Transmembrane emp24 domain-containing protein \\
\hline BW760 & Rph9.i & 2_1247 & MLOC_4610.1 & NA \\
\hline BW760 & Rph9.i & 2_1247 & MLOC_4611.1 & Protein kinase \\
\hline BW760 & Rph9.i & 1_1090 & AK373628 & Transcription factor \\
\hline BW760 & Rph9.i & 1_1090 & MLOC_51340.2 & Aluminum-induced protein-like protein \\
\hline BW760 & Rph9.i & 1_0783 & MLOC_66584.1 & NA \\
\hline BW760 & Rph9.i & 1_1080 & AK364080 & Cysteine proteinase \\
\hline BW760 & Rph9.i & 1_0755 & MLOC_16232.1 & NA \\
\hline BW760 & Rph9.i & 1_0755 & MLOC_16233.2 & Proteasome assembly chaperone \\
\hline BW760 & Rph9.i & 1_0845 & MLOC_56549.1 & NA \\
\hline BW760 & Rph9.i & 1_0845 & MLOC_56550.1 & Maternal effect embryo arrest 14 \\
\hline BW760 & Rph9.i & 2_1289 & AK363763 & Signal peptidase I \\
\hline BW760 & Rph9.i & 2_1289 & MLOC_63880.1 & NA \\
\hline
\end{tabular}


Appendix Table 9 continued. Annotated genes in the same contig as SNP markers residing in Rph-carrying introgressions.

\begin{tabular}{lllll} 
BW Line $^{1}$ & Allele $^{2}$ & BOPA_SNP & Gene on same contig & Annotation $^{5}$ \\
\hline BW760 & Rph9.i & 1_1532 & AK367148 & Molybdenum cofactor sulfurase \\
\hline BW760 & Rph9.i & 2_0375 & MLOC_65920.1 & NADH-quinone oxidoreductase subunit I \\
\hline BW760 & Rph9.i & 1_0292 & AK371585 & Succinate dehydrogenase subunit A \\
\hline BW760 & Rph9.i & 1_1092 & MLOC_10622.1 & Citrate synthase \\
\hline BW760 & Rph9.i & 1_1092 & MLOC_10623.1 & NA \\
\hline BW760 & Rph9.i & 1_1092 & MLOC_10625.1 & NA \\
\hline BW760 & Rph9.i & 1_1092 & MLOC_10624.1 & NA \\
\hline BW760 & Rph9.i & 1_0104 & MLOC_1273.1 & 60S ribosomal protein L44 \\
\hline BW760 & Rph9.i & 1_0104 & MLOC_1275.1 & NA \\
\hline BW760 & Rph9.i & 1_0104 & MLOC_1274.1 & NA \\
\hline BW760 & Rph9.i & 2_0676 & MLOC_43074.1 & NA \\
\hline BW760 & Rph9.i & 2_0731 & MLOC_6875.2 & Reticulon-like protein B8 \\
\hline BW760 & Rph9.i & 2_0731 & AK365628 & NA \\
\hline BW683 & Rph10.o & 1_0728 & AK358661 & Chitinase \\
\hline BW683 & Rph10.0 & 1_0281 & MLOC_52444.1 & Protein plastid transcriptionally active 16 \\
\hline BW683 & Rph10.o & 1_1191 & MLOC_4753.2 & Late embryogenesis abundant protein \\
\hline BW683 & Rph10.o & 1_0335 & MLOC_11772.1 & RING finger and CHY zinc finger domain-containing protein 1 \\
\hline BW683 & Rph10.o & 1_1391 & MLOC_56148.2 & Putative inositol-1,4,5-trisphosphate phosphatase \\
\hline BW683 & Rph10.o & 2_1305 & MLOC_50950.1 & NBS-LRR-like protein \\
\hline BW683 & Rph10.o & 2_1305 & MLOC_50949.1 & NA \\
\hline BW683 & Rph10.o & 2_0931 & MLOC_63920.1 & WD-40 repeat family protein \\
\hline BW683 & Rph10.0 & 1_1394 & AK366039 & ABC transporter ATP-binding protein \\
\hline BW683 & Rph10.o & 1_1394 & MLOC_5109.1 & B3 domain-containing protein \\
\hline BW683 & Rph10.o & 2_0115 & AK376197 & Maternal effect embryo arrest 22 \\
\hline
\end{tabular}


Appendix Table 9 continued. Annotated genes in the same contig as SNP markers residing in Rph-carrying introgressions.

\begin{tabular}{lllll} 
BW Line $^{1}$ & Allele $^{2}$ & BOPA_SNP & Gene on same contig & Annotation \\
\hline BW683 & Rph10.o & 2_1358 & MLOC_69131.1 & NA \\
\hline BW683 & Rph10.o & 2_1358 & MLOC_69130.3 & Zinc knuckle (CCHC-type) family protein \\
\hline BW683 & Rph10.o & 2_1358 & MLOC_69132.1 & NA \\
\hline BW684 & Rph11.p & 1_0107 & MLOC_67524.1 & Bidirectional sugar transporter N3 \\
\hline BW761 & Rph9.z & 1_1456 & MLOC_4744.1 & Aspartyl/glutamyl-tRNA(Asn/GIn) amidotransferase subunit C \\
\hline BW761 & Rph9.z & 2_0003 & MLOC_55532.1 & GTP binding protein \\
\hline BW761 & Rph9.z & 2_0003 & MLOC_55533.1 & NA \\
\hline BW761 & Rph9.z & 2_0347 & MLOC_5598.2 & Methyl-CpG binding domain containing protein \\
\hline BW761 & Rph9.z & 1_0360 & MLOC_37451.1 & NA \\
\hline BW761 & Rph9.z & 1_0360 & AK250598.1 & Chaperone protein dnaJ \\
\hline BW761 & Rph9.z & 1_0360 & MLOC_37450.1 & NA \\
\hline BW761 & Rph9.z & 2_0653 & MLOC_53946.1 & NA \\
\hline BW761 & Rph9.z & 2_0653 & MLOC_53947.1 & Pyruvate dehydrogenase E1 component beta subunit \\
\hline BW761 & Rph9.z & 2_0653 & MLOC_53948.1 & Expansin B4 \\
\hline BW761 & Rph9.z & 2_0653 & MLOC_53949.2 & Leucine-rich repeat receptor-like protein kinase \\
\hline BW761 & Rph9.z & 2_1203 & AK356347 & Translation initiation factor elF-2B delta subunit \\
\hline BW761 & Rph9.z & 2_0300 & MLOC_35821.1 & Ornithine aminotransferase \\
\hline BW761 & Rph9.z & 1_0805 & AK354421 & NA \\
\hline BW761 & Rph9.z & 1_0146 & AK364599 & Protein transport protein SEC23 \\
\hline BW761 & Rph9.z & 1_0146 & MLOC_54787.1 & Auxin responsive protein \\
\hline BW761 & Rph9.z & 2_0259 & MLOC_19607.1 & NA \\
\hline BW761 & Rph9.z & 2_0298 & MLOC_60235.1 & Histone H2A \\
\hline BW761 & Rph9.z & 1_0705 & MLOC_59423.4 & NA \\
\hline BW761 & Rph9.z & 1_0705 & MLOC_59424.2 & Tetratricopeptide repeat (TPR)-like superfamily protein \\
\hline
\end{tabular}


Appendix Table 9 continued. Annotated genes in the same contig as SNP markers residing in Rph-carrying introgressions.

\begin{tabular}{lllll} 
BW Line $^{1}$ & Allele $^{2}$ & BOPA_SNP & Gene on same contig & Annotation $^{5}$ \\
\hline BW761 & Rph9.z & 2_1177 & AK366333 & Transmembrane emp24 domain-containing protein \\
\hline BW761 & Rph9.z & 2_1247 & MLOC_4610.1 & NA \\
\hline BW761 & Rph9.z & 2_1247 & MLOC_4611.1 & Protein kinase \\
\hline BW761 & Rph9.z & 1_1090 & AK373628 & Transcription factor \\
\hline BW761 & Rph9.z & 1_1090 & MLOC_51340.2 & Aluminum-induced protein-like protein \\
\hline BW761 & Rph9.z & 1_0783 & MLOC_66584.1 & NA \\
\hline BW761 & Rph9.z & 1_0095 & MLOC_5287.1 & UDP-glucose 6-dehydrogenase \\
\hline BW761 & Rph9.z & 2_1241 & MLOC_57253.1 & receptor-like protein kinase 2 \\
\hline BW761 & Rph9.z & 1_1080 & AK364080 & Cysteine proteinase \\
\hline BW761 & Rph9.z & 1_0755 & MLOC_16232.1 & NA \\
\hline BW761 & Rph9.z & 1_0755 & MLOC_16233.2 & Proteasome assembly chaperone \\
\hline BW761 & Rph9.z & 1_0845 & MLOC_56549.1 & NA \\
\hline BW761 & Rph9.z & 1_0845 & MLOC_56550.1 & Maternal effect embryo arrest 14 \\
\hline BW761 & Rph9.z & 2_1289 & AK363763 & Signal peptidase I \\
\hline BW761 & Rph9.z & 2_1289 & MLOC_63880.1 & NA \\
\hline BW761 & Rph9.z & 1_1532 & AK367148 & Molybdenum cofactor sulfurase \\
\hline BW761 & Rph9.z & 2_0375 & MLOC_65920.1 & NADH-quinone oxidoreductase subunit I \\
\hline BW761 & Rph9.z & 1_0819 & MLOC_39144.1 & NA \\
\hline BW761 & Rph9.z & 1_0819 & MLOC_39140.1 & NA \\
\hline BW761 & Rph9.z & 1_0819 & MLOC_39141.1 & NA \\
\hline BW761 & Rph9.z & 1_0819 & MLOC_39143.3 & Cytosolic purine 5-nucleotidase \\
\hline BW761 & Rph9.z & 1_0819 & MLOC_39142.1 & NA \\
\hline BW761 & Rph9.z & 1_0292 & AK371585 & Succinate dehydrogenase subunit A \\
\hline BW761 & Rph9.z & 1_1092 & MLOC_10622.1 & Citrate synthase \\
\hline
\end{tabular}


Appendix Table 9 continued. Annotated genes in the same contig as SNP markers residing in Rph-carrying introgressions.

\begin{tabular}{lllll} 
BW Line $^{1}$ & Allele $^{2}$ & BOPA_SNP & Gene on same contig & Annotation \\
\hline BW761 & Rph9.z & 1_1092 & MLOC_10625.1 & NA \\
\hline BW761 & Rph9.z & 1_1092 & MLOC_10624.1 & NA \\
\hline BW761 & Rph9.z & 1_0104 & MLOC_1273.1 & 60S ribosomal protein L44 \\
\hline BW761 & Rph9.z & 1_0104 & MLOC_1275.1 & NA \\
\hline BW761 & Rph9.z & 1_0104 & MLOC_1274.1 & NA \\
\hline BW761 & Rph9.z & 2_0568 & AK370882 & Aldehyde oxidase 1 \\
\hline BW761 & Rph9.z & 2_0676 & MLOC_43074.1 & NA \\
\hline BW761 & Rph9.z & 2_0731 & MLOC_6875.2 & Reticulon-like protein B8 \\
\hline BW761 & Rph9.z & 2_0731 & AK365628 & NA \\
\hline BW761 & Rph9.z & 2_0388 & AK376464 & YTH domain family protein \\
\hline BW761 & Rph9.z & 2_0388 & MLOC_68497.2 & NA \\
\hline BW761 & Rph9.z & 1_0363 & AK368805 & ABI3-interacting protein 2 \\
\hline BW761 & Rph9.z & 2_0104 & MLOC_24232.1 & NA \\
\hline BW761 & Rph9.z & 2_0104 & MLOC_24233.1 & NA \\
\hline BW761 & Rph9.z & 1_0217 & MLOC_56767.1 & NA \\
\hline BW761 & Rph9.z & 1_0217 & MLOC_56768.1 & Eukaryotic translation initiation factor 3 subunit 9 \\
\hline BW761 & Rph9.z & 1_0589 & MLOC_19781.1 & NA \\
\hline BW761 & Rph9.z & 1_0589 & AK251250.1 & NA \\
\hline BW761 & Rph9.z & 1_0589 & AK364297 & DNA helicase family protein \\
\hline BW761 & Rph9.z & 2_1355 & AK359961 & rRNA-processing protein EFG1 \\
\hline BW761 & Rph9.z & 1_1497 & AK358288 & P-loop containing nucleoside triphosphate hydrolases superfamily protein \\
\hline BW761 & Rph9.z & 1_0901 & MLOC_56328.1 & NA \\
\hline BW761 & Rph9.z & 1_0901 & MLOC_56327.1 & Non-specific lipid-transfer protein \\
\hline BW761 & Rph9.z & 2_1041 & AK252089.1 & NA \\
\hline
\end{tabular}


Appendix Table 9 continued. Annotated genes in the same contig as SNP markers residing in Rph-carrying introgressions.

\begin{tabular}{lllll} 
BW Line $^{1}$ & Allele $^{2}$ & BOPA_SNP & Gene on same contig & Annotation \\
\hline BW761 & Rph9.z & 2_0078 & MLOC_44136.1 & NA \\
\hline BW761 & Rph9.z & 2_0078 & AK376547 & NA \\
\hline BW761 & Rph9.z & 1_0741 & MLOC_61930.2 & Cellulose synthase-5 \\
\hline BW761 & Rph9.z & 2_1024 & AK358394 & Phosphate transporter \\
\hline BW761 & Rph9.z & 1_0902 & AK358452 & NA \\
\hline BW761 & Rph9.z & 2_1452 & AK363434 & Early nodulin-like protein \\
\hline BW761 & Rph9.z & 2_0876 & MLOC_61508.1 & NA \\
\hline BW761 & Rph9.z & 2_0876 & MLOC_61507.1 & Mitochondrial Rho GTPase \\
\hline BW761 & Rph9.z & 2_0876 & AK367513 & Remorin \\
\hline BW761 & Rph9.z & 1_0336 & AK366329 & Development and Cell Death domain protein \\
\hline BW761 & Rph9.z & 2_0988 & MLOC_51705.1 & NA \\
\hline BW761 & Rph9.z & 2_0988 & MLOC_51707.1 & NA \\
\hline BW761 & Rph9.z & 2_0988 & MLOC_51706.2 & CRAL/TRIO domain containing protein \\
\hline BW761 & Rph9.z & 1_1464 & MLOC_71880.1 & Alkylated DNA repair protein AlkB \\
\hline BW761 & Rph9.z & 1_1216 & MLOC_55692.1 & NA \\
\hline BW761 & Rph9.z & 1_1216 & AK249737.1 & NA \\
\hline BW761 & Rph9.z & 2_0546 & AK252179.1 & Phosphoesterase family protein \\
\hline BW761 & Rph9.z & 2_0686 & AK364134 & Kinase family protein \\
\hline BW761 & Rph9.z & 2_0686 & MLOC_20051.2 & Mitochondrial import inner membrane translocase subunit Tim10 \\
\hline BW761 & Rph9.z & 2_1012 & MLOC_1045.1 & NA \\
\hline BW761 & Rph9.z & 2_0536 & AK367079 & Guanine deaminase \\
\hline BW761 & Rph9.z & 2_0536 & MLOC_13213.1 & Pectin lyase-like superfamily protein \\
\hline BW685 & Rph13.x & 1_1196 & MLOC_52456.1 & NA \\
\hline BW685 & Rph13.x & 1_1196 & MLOC_52455.4 & NA \\
\hline
\end{tabular}


Appendix Table 9 continued. Annotated genes in the same contig as SNP markers residing in Rph-carrying introgressions.

\begin{tabular}{|c|c|c|c|c|}
\hline BW Line ${ }^{1}$ & Allele $^{2}$ & BOPA_SNP ${ }^{3}$ & Gene on same contig ${ }^{4}$ & Annotation $^{5}$ \\
\hline BW685 & Rph13.x & 1_1196 & MLOC_52458.1 & NA \\
\hline BW685 & Rph13.x & 2_0612 & MLOC_37644.1 & NA \\
\hline BW685 & Rph13.x & 2_0612 & MLOC_37645.1 & Zinc finger $\mathrm{CCCH}$ domain-containing protein \\
\hline BW685 & Rph13.x & 1_0842 & MLOC_17018.1 & Peptidyl-prolyl cis-trans isomerase \\
\hline BW685 & Rph13.x & 2_0527 & MLOC_60122.1 & Hydroxyproline-rich glycoprotein-like \\
\hline BW685 & Rph13.x & 2_0527 & MLOC_60123.1 & NA \\
\hline BW685 & Rph13.x & $2 \_1428$ & MLOC_9078.1 & RING/U-box superfamily protein \\
\hline BW685 & Rph13.x & 2_1427 & AK248786.1 & Beta-glucosidase \\
\hline BW685 & Rph13.x & 2_1427 & MLOC_64032.1 & NA \\
\hline BW685 & Rph13.x & 2_1427 & AK369539 & NBS-LRR disease resistance protein homologue \\
\hline BW685 & Rph13.x & 2_1272 & MLOC_66627.2 & Glycerol-3-phosphate dehydrogenase \\
\hline BW685 & Rph13.x & 1_0681 & MLOC_10046.2 & Progesterone 5-beta-reductase \\
\hline BW685 & Rph13.x & 1_0893 & AK354147 & Alkaline phytoceramidase \\
\hline BW685 & Rph13.x & $1 \_0767$ & MLOC_114.1 & NA \\
\hline BW685 & Rph13.x & 1_0767 & AK367356 & Pentatricopeptide repeat-containing protein \\
\hline BW685 & Rph13.x & 1_0767 & MLOC_113.1 & NA \\
\hline BW685 & Rph13.x & 1_0343 & MLOC_81141.1 & NA \\
\hline BW685 & Rph13.x & 1_0343 & MLOC_81140.1 & NA \\
\hline BW686 & Rph14.ab & 2_0173 & NA & NA \\
\hline BW686 & Rph14.ab & 1_0342 & MLOC_44617.2 & Nucleolar protein 5 \\
\hline BW719 & Rph15.ad & 1_0399 & MLOC_38808.1 & GTPase, IMAP family member 4 \\
\hline BW719 & Rph15.ad & 1_0919 & AK368803 & Photosystem I reaction center subunit $\mathrm{N}$ \\
\hline BW719 & Rph15.ad & 1_0919 & MLOC_6378.3 & $60 \mathrm{~S}$ ribosome subunit biogenesis protein NIP7 \\
\hline BW719 & Rph15.ad & 2_1153 & MLOC_44144.1 & CW-type Zinc Finger family protein \\
\hline BW719 & Rph15.ad & 2_1153 & MLOC_44146.1 & Pentatricopeptide repeat-containing protein \\
\hline BW719 & Rph15.ad & 2_1153 & MLOC_44145.1 & NA \\
\hline
\end{tabular}




\section{Appendix Table 9 Footnotes.}

1. BW lines are the Bowman leaf rust resistance introgression lines whose introgressions carry annotated genes for defense.

2. $R p h$ introgressions carrying leaf rust resistance alleles and annotated defense genes.

3. BOPA SNP markers residing on the same genetic contig as annotated defense genes.

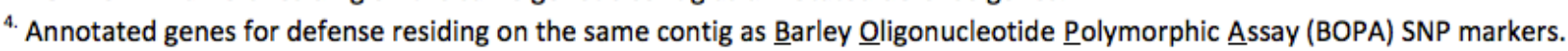

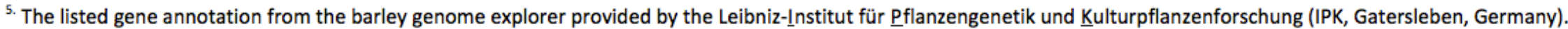

